\title{
THERMAL SYSTEM-SPECIFIC AND NET-ZERO CARBON LEAST-COST DESIGN OF NEW HOUSES IN CANADIAN COLD CLIMATES
}

\author{
By \\ Brandon Wilbur \\ B.Sc.E., Civil Engineering \\ University of New Brunswick \\ Fredericton, New Brunswick, 2010 \\ A thesis \\ presented to Ryerson University \\ in partial fulfillment of the \\ requirements for the degree of \\ Master of Applied Science \\ in the program of \\ Mechanical Engineering
}

Toronto, Ontario, Canada, 2018

(C) Brandon Wilbur, 2018 


\section{Author's Declaration}

I hereby declare that I am the sole author of this thesis. This is a true copy of the thesis, including any required final revisions, as accepted by my examiners.

I authorize Ryerson University to lend this thesis to other institutions or individuals for the purpose of scholarly research.

I further authorize Ryerson University to reproduce this thesis by photocopying or by other means, in total or in part, at the request of other institutions or individuals for the purpose of scholarly research.

I understand that my thesis may be made electronically available to the public. 


\begin{abstract}
Whole-building model optimizations have been performed for a single-detached house in 5 locations with varying climates, electricity emissions factors, and energy costs. The multiobjective optimizations determine the life-cycle cost vs. operational greenhouse gas emissions Pareto front to discover the 30-year life-cycle least-cost building design heated 1) with natural gas, and 2) electrically using a) central air-source heat pump, b) ductless mini-split heat pump c) ground-source heat pump, and d) electric baseboard, accounting for both initial and operational energy-related costs. A net-zero carbon design with grid-tied photovoltaics is also optimized. Results indicate that heating system type influences the optimal enclosure design, and that neither building total energy use, nor space heating demand correspond to GHG emissions across heating system types. In each location, at least one type of all-electric design has a lower life-cycle cost than the optimized gas-heated model, and such designs can mitigate the majority of operational GHG emissions from new housing in locations with a low carbon intensity electricity supply.
\end{abstract}




\section{Acknowledgments}

This work has been made possible through partial funding from several sources. I would like to thank the Ryerson Yeates School of Graduate Studies, the Mechanical and Industrial Engineering department, and the Mitacs Accelerate program-and the Canadian taxpayers who fund it - for their financial support. I would also like to thank the Energy group in the Toronto and Region Conservation Authority's Sustainable Technologies Evaluation Program for their indirect but beneficial financial support and sharing of expertise.

For his technical and academic support, patience, guidance, and trust in my ability to identify and address important problems facing the Canadian housing sector, I would like to thank my supervisor, Dr. Alan S. Fung. Guidance and expertise from professors in Ryerson's MIE department, and Building Science department has also been very helpful.

This research was only possible due to the existing foundation of knowledge and techniques developed by previous academics in the field of multi-objective building design optimization. For modelling and software-related issues, I would like to thank the online community of building energy modellers who freely and generously share their knowledge through the online forum, Unmet Hours. In particular, the developers of BEopt software at the U.S. National Renewable Energy Laboratory, especially Scott Horowitz, have been very helpful and timely in clarifying program functionality and providing solutions to simulation-related problems.

Finally, I am very grateful to my fellow graduate students in our research group, the Centre for Sustainable Energy Systems, as well as to others from the MIE and Building Science departments, for their knowledge, honest opinions, and constructive criticism. There is no substitute for an engaged community of peers with whom to share and develop one's ideas. 


\section{Table of Contents}

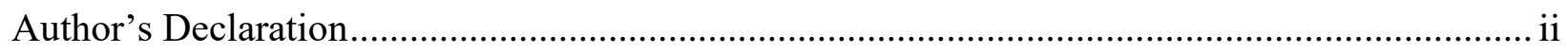

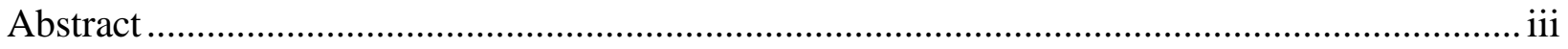

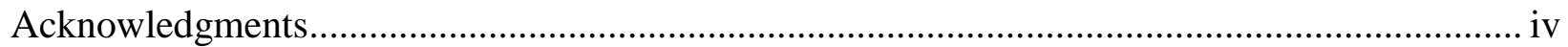

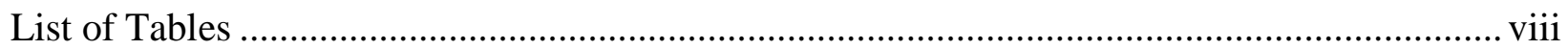

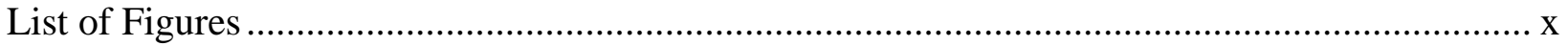

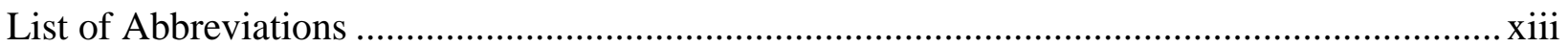

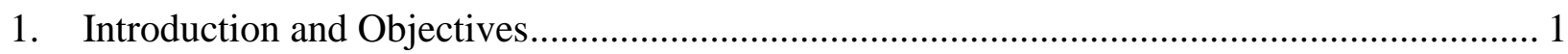

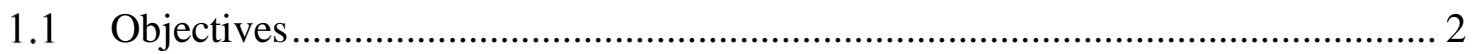

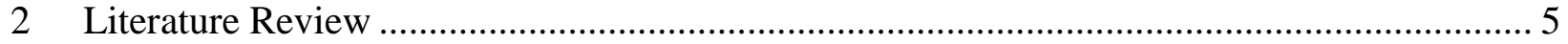

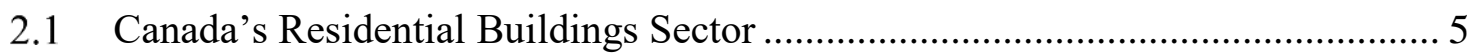

2.2 Energy and GHG Emissions from Canada's Housing ......................................... 7

2.2.1 Heating Energy Use ......................................................................... 9

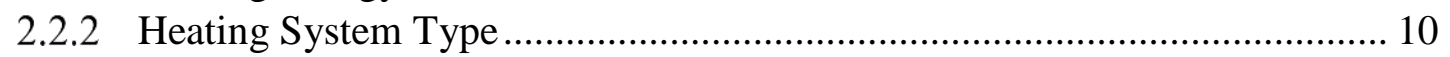

2.2.3 Electricity Emissions Factor (EF) ............................................................. 11

2.3 Housing Energy and Emissions Standards..................................................... 15

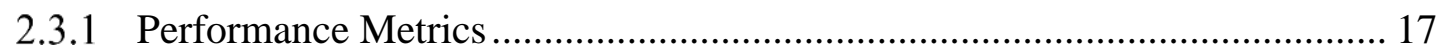

2.3.2 Net Zero Energy ................................................................................... 20

2.3.3 Passive House ...................................................................................... 22

2.3.4 National Building Code .......................................................................... 24

2.3.5 Ontario Building Code............................................................................ 26

2.3.6 Natural Resources Canada's R-2000 Standard ............................................... 27

2.3.7 Net Zero Carbon .................................................................................. 28

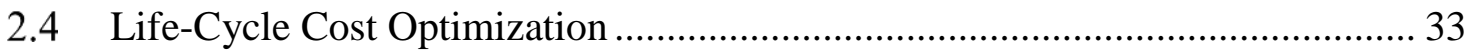

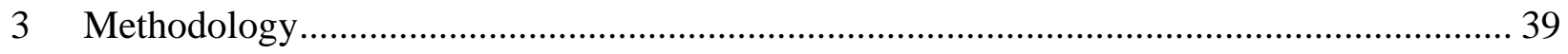

3.1 Whole-Building Optimization ...................................................................... 40

3.1.1 Thermal System-Specific Optimization........................................................ 41

3.1.2 Building Enclosure Thermal Performance.................................................... 43

3.1.3 Electrification of Heating ............................................................................ 44

3.1.4 Onsite Renewable Energy Generation ........................................................... 44

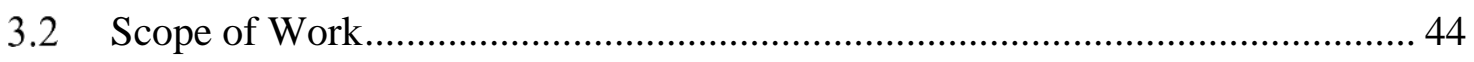

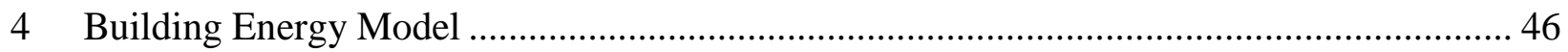

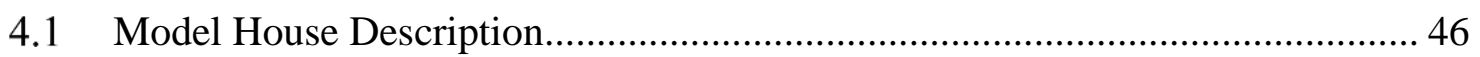


4.2 NBC 9.36 Reference Energy Model ............................................................. 48

4.2.1 Opaque Constructions ............................................................................... 50

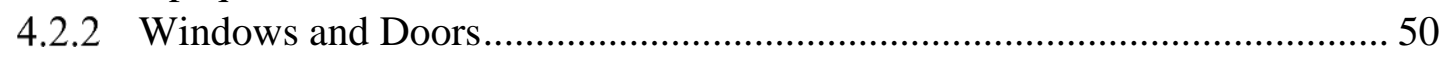

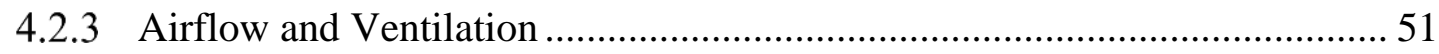

4.2.4 Space Conditioning .................................................................................. 54

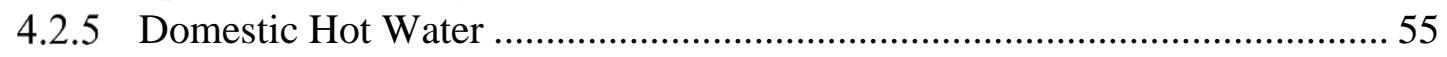

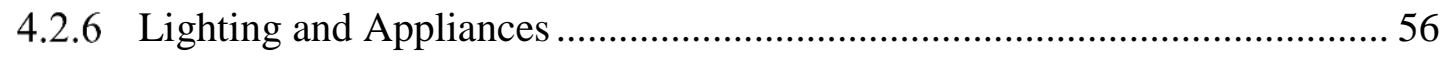

4.2.7 Internal Heat Gain and Mass........................................................................ 57

4.2.8 Reference Model Summary ………………………………………….... 58

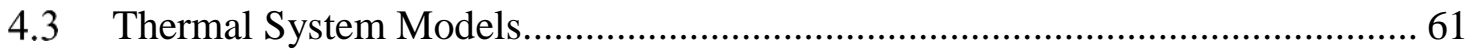

4.3.1 Air-Source Heat Pump (ASHP) ................................................................... 62

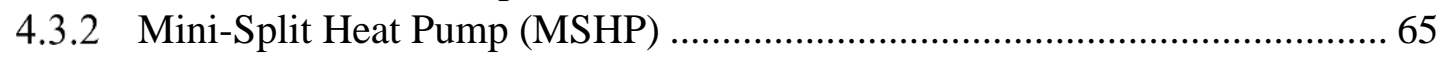

4.3.3 Ground-Source Heat Pump (GSHP) …………………………………….... 68

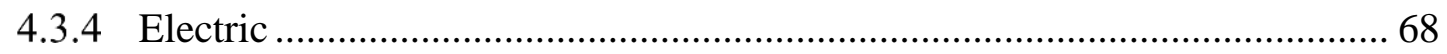

4.3.5 Thermal Systems Summary ……………………………………………. 69

4.4 Baseline Models Performance......................................................................... 69

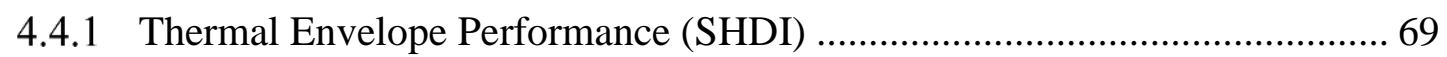

4.4.2 Purchased Energy Consumption (EUI) ........................................................... 70

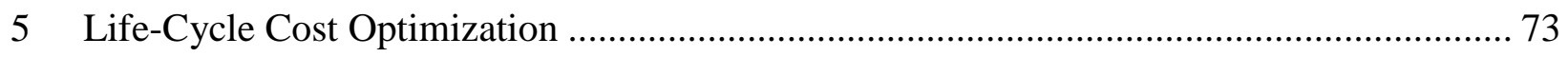

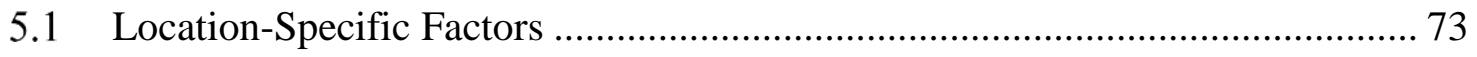

5.1.1 Climate and Latitude .............................................................................. 73

5.1.2 Electricity Emissions Factor (EF) ............................................................... 74

5.1.3 City Cost Index (CCI) ......................................................................... 74

5.1.4 Purchased Energy Prices ............................................................................... 75

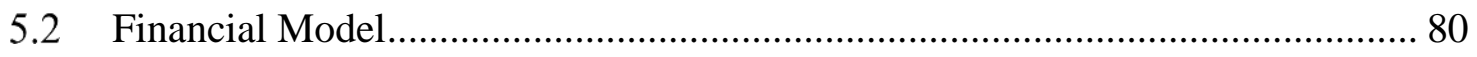

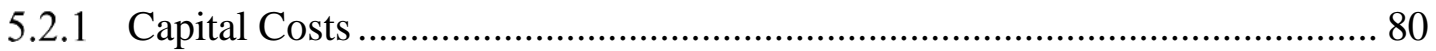

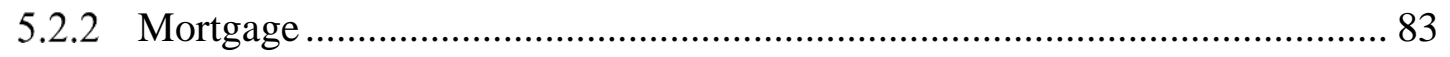

5.2.3 Economic Parameters............................................................................ 84

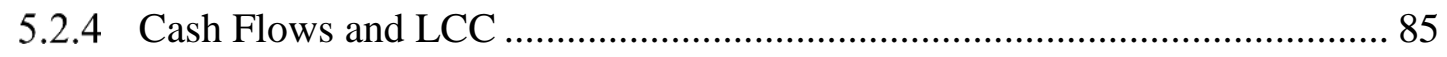

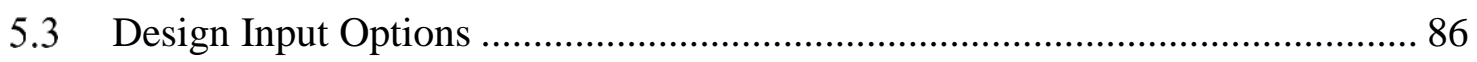

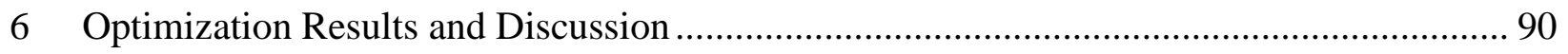

6.1 "Gas" Model Optimization............................................................................... 90

6.2 LCC versus GHG Optimization Results …………………………………...... 94

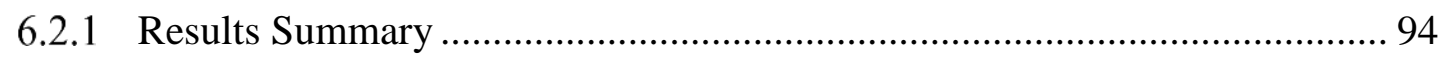

6.2.2 Net Zero Carbon Models ............................................................................ 97

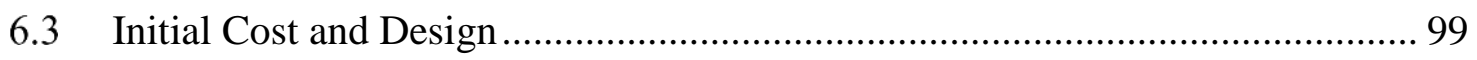


6.4 Operational Energy, Cost, and Emissions ............................................ 102

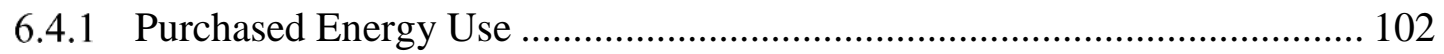

6.4.2 Enclosure Thermal Performance............................................................ 104

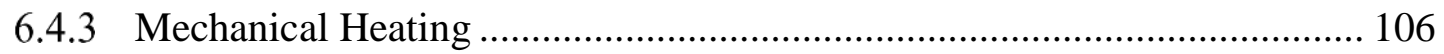

6.4.4 EUI versus GHGI Relationship .................................................... 109

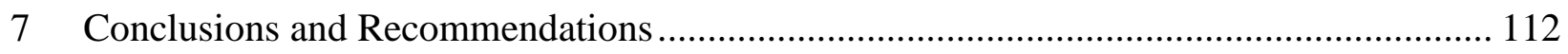

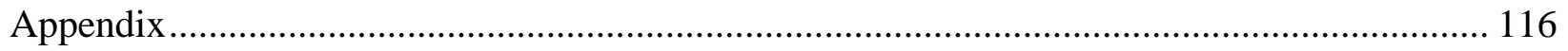

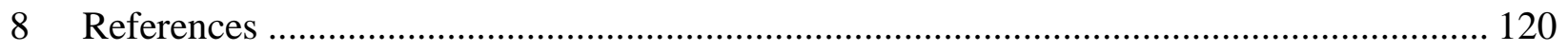




\section{List of Tables}

Table 2-1 Energy and GHG intensities of existing housing stock (NRCan, 2017) .................... 9

Table 2-2 National Building Code adoption by Province (NRC, 2018) .................................... 16

Table 2-3 House energy standards compliance options and performance metrics .................... 19

Table 2-4 PH and PHIUS+ Requirements (PHIUS+ thermal targets for Toronto, ON) ............ 24

Table 2-5 NBC 2015 - Table 9.63.2.6.B. Effective Thermal Resistance of Above-ground Opaque Assemblies in Buildings with a Heat-Recovery Ventilator (NRC, 2015) ............................... 25

Table 2-6 Qualitative Differences and Airtightness Prescriptions ........................................ 28

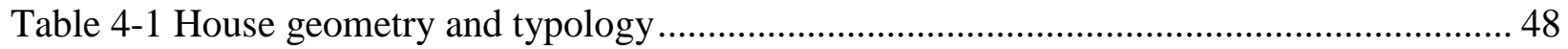

Table 4-2 NBC 9.36 R-Value requirements for house with HRV (table 9.36.2.6.B)................ 49

Table 4-3 Reference model R-effective (R-nominal) values ................................................. 50

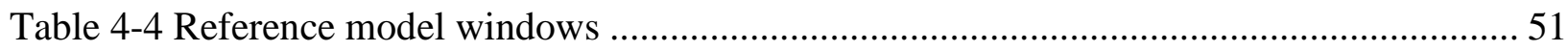

Table 4-5 WWR distribution and FDWR verification..................................................... 51

Table 4-6 Mechanical Ventilation Operational Control ( $V=$ air volume, HR=heat recovery) ...... 54

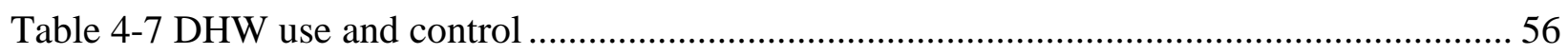

Table 4-8 Lighting and appliance sources and consumption ............................................ 57

Table 4-9 Reference model input parameters (Toronto).................................................... 58

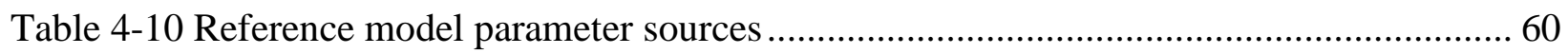

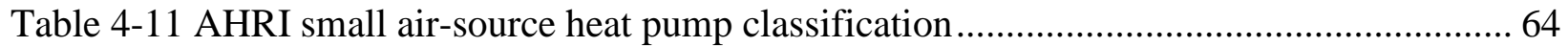

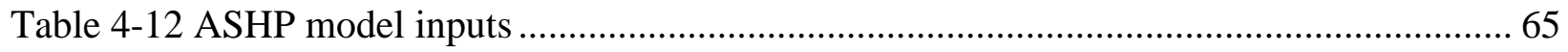

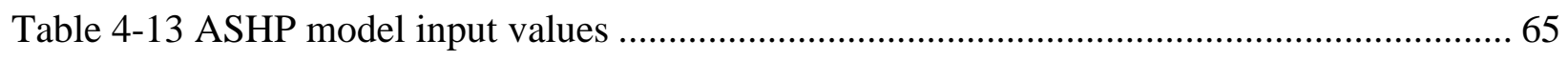

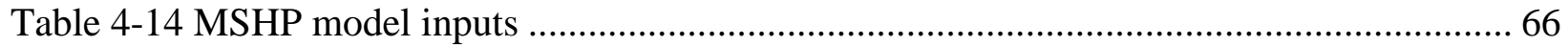

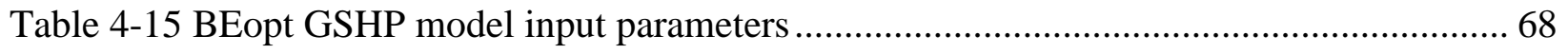

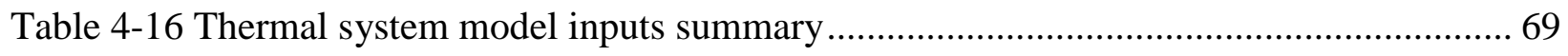

Table 4-17 Total simulated COP and heating delivery for Toronto baselines ......................... 72

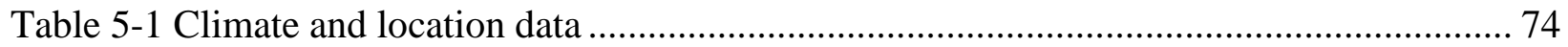

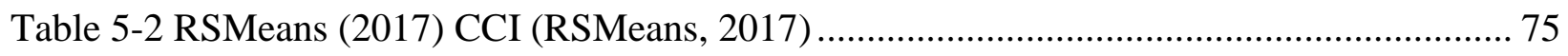

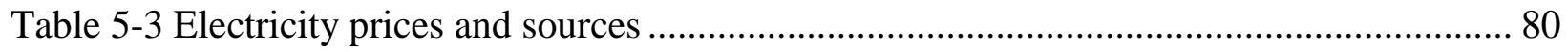

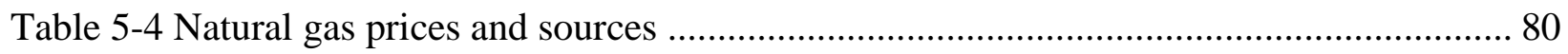

Table 5-5 Space conditioning system input capital costs ................................................ 82

Table 5-6 Mortgage and financial project inputs ............................................................. 85 
Table 5-7 Optimization design input options - "Gas" model only .......................................... 87

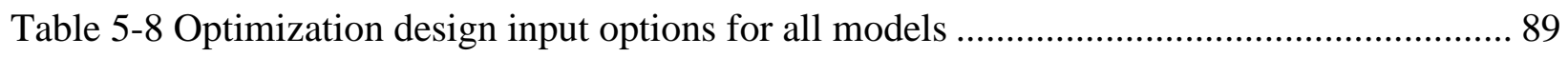

Table 6-1 Resultant least LCC Gas designs by location...................................................... 92

Table 6-2 Resultant least LCC designs for all thermal system types - Toronto ....................... 101

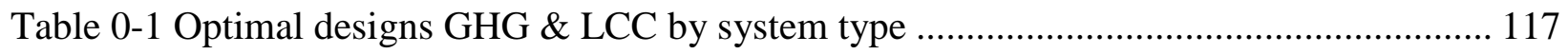

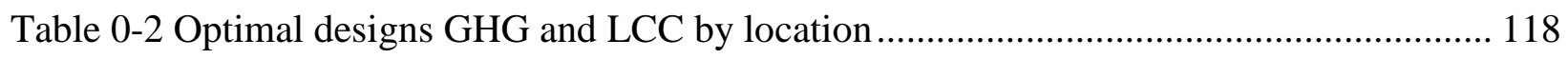

Table 0-3 Toronto optimal designs energy use by end-use ................................................ 119 


\section{List of Figures}

Figure 2-1 Canada's Housing Stock Breakdown (2016 Census) (Statistics Canada, 2017) .......... 5

Figure 2-2 2017 Canada Housing starts by Type [data from (CMHC, 2018)] .......................... 6

Figure 2-3 2017 Housing Price Quintiles - Single-Detached Starts [data from (CMHC, 2018)]... 6

Figure 2-4 Building emissions with residential breakdown, 2015 (blue=direct emissions,

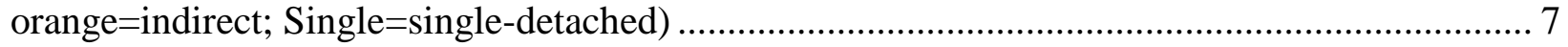

Figure 2-5 GHG emissions and energy use breakdown by fuel type for single detached housing stock

Figure 2-6 GHG emissions and energy use breakdown by end-use for single detached housing stock 8

Figure 2-7 Purchased energy use breakdown for heating - existing residential stock ............... 10

Figure 2-8 Residential space heating system stock by system type..................................... 11

Figure 2-9 Electricity annual average emissions factors (EF) by province, 2015 [Bubble area indicates population. Electricity data from: (NIR, 2018)] ...................................................... 12

Figure 2-10 Site Boundary of Energy Transfer for Zero Energy Accounting (EERE, 2015) ...... 20 Figure 2-11 Summary of NZE and NZC building types (Pembina, 2018) .............................. 29

Figure 2-12 Provincial electric grid annual emission factors [marginal: (Energy Star, 2017),

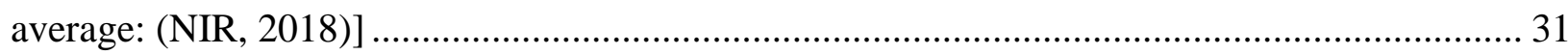

Figure 2-13 Conceptual optimization of NZE building (where $\mathrm{x}$-axis is \% energy savings) (Dembo \& Fung, 2012)

Figure 2-14 Multi-objective complete redesign of EcoTerra home (Bucking, Athienitis, \& Zmeureanu, 2014) 36

Figure 2-15 Optimization results of improvements showing energy savings versus change in life cycle costs and least cost improvement (Tokarik \& Richman, 2016) .................................... 37

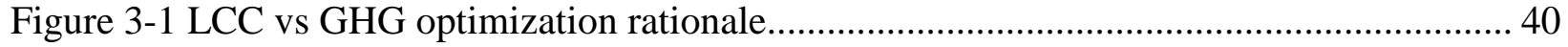

Figure 3-2 Active thermal system capital and operational interactions ................................. 42 Figure 3-3 Optimization schedule by location and thermal system type (NZC is the overall least

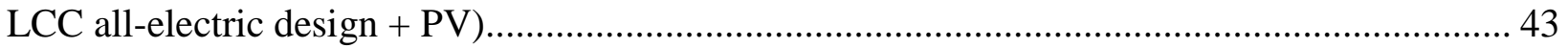

Figure 4-1 Model geometry - clockwise from top left: North, South, West, East (green = conditioned volume) 47

Figure 4-2 Orientation, shading, and wind sheltering 48 
Figure 4-3 Effect of natural ventilation and "economizer" control on cooling demand and thermal

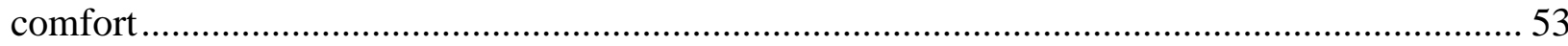

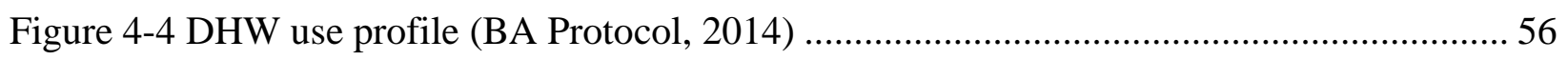

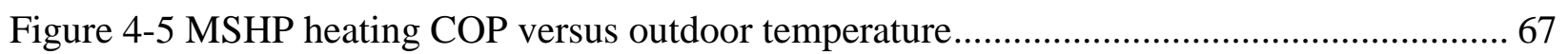

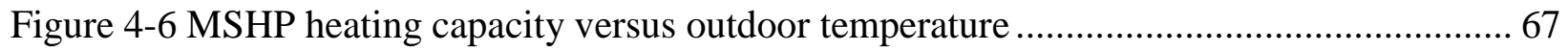

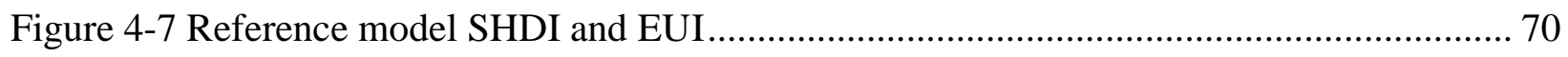

Figure 4-8 EUI Breakdown by end-use for thermal system-specific Toronto baseline models

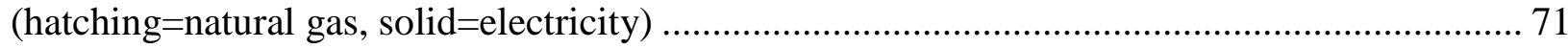

Figure 5-1 Electricity and natural gas price comparison (includes all marginal and fixed charges, expressed as a total price based on a set annual usage) ..................................................... 77

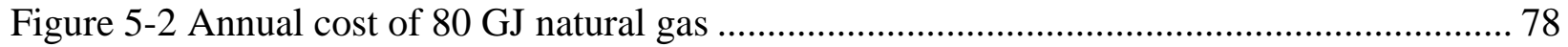

Figure 5-3 Electricity to gas price ratios (annual electricity use=12 MWh, gas use=80 GJ) ...... 79

Figure 5-4 Cost of air sealing for single-detached home (U.S. national average) .................... 81

Figure 5-5 Space conditioning system initial cost (heating main, supplementary electric, cooling, and delivery) 83

Figure 5-6 Toronto MSHP design cash flows (chart excludes residual value: $\$ 79,938$ in year 30,

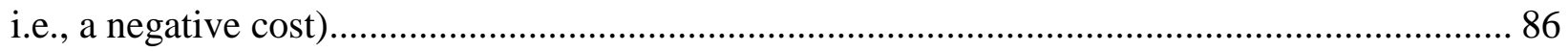

Figure 6-1 Gas-TO optimization plot with exterior wall insulation sensitivity frontiers ............ 91

Figure 6-2 Gas-TO design breakdown by cumulative improvement.................................... 93

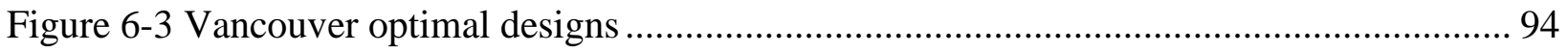

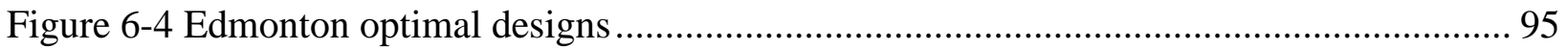

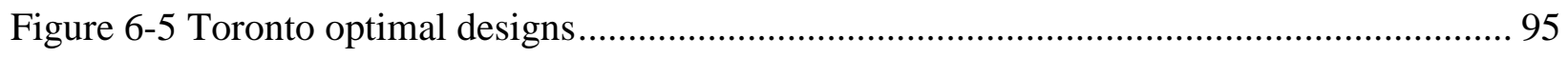

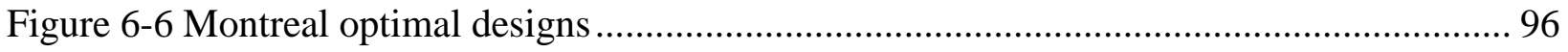

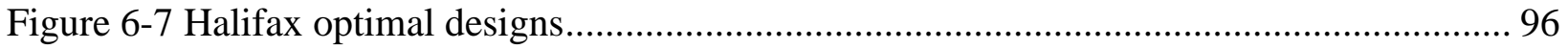

Figure 6-8 Edmonton NZE optimization results and selected design................................... 99

Figure 6-9 Initial cost optimal designs - Toronto ("fixed" includes lighting, appliances, ceiling

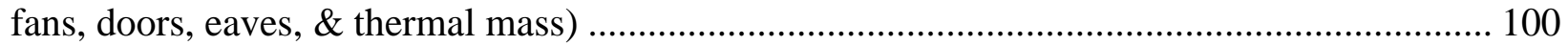

Figure 6-10: Annual energy use by end-use - Toronto (hatched=natural gas, solid=electricity) 103

Figure 6-11 Annual energy costs of optimal models - Toronto (E=electricity, G=natural gas) 103 Figure 6-12 Annual GHG emissions by fuel type - Toronto........................................... 104 
Figure 6-13 SHDI of optimal Toronto design enclosures................................................. 105

Figure 6-14 Hourly heating delivered by the MSHP - Toronto ........................................ 107

Figure 6-15 Electric load profile of heat pump and whole building for MSHP-TO design ....... 108

Figure 6-16 January day electric load profile - Toronto ................................................. 109

Figure 6-17 Energy use versus GHG emissions - Toronto (blue=MSHP design variants, grey=Gas

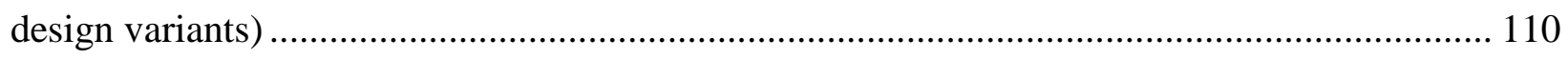

Figure 6-18 Energy use versus GHG emissions - Edmonton ............................................ 111 


\section{List of Abbreviations}

ACH50 Air Changes per Hour at 50 Pascals depressurization

$\mathrm{ACH}_{\mathrm{n}} \quad$ Air Changes per Hour at natural ambient pressure

AFUE Annual Fuel Utilization Efficiency

AHRI American Heating and Refrigeration Institute

ASHP Air-Source Heat Pump (air-to-air, centralized)

BEopt Building Energy Optimization simulation software

CaGBC Canada Green Building Council

CCHT Canadian Centre for Housing Technology

CCI RSMeans City Cost Index

CMHC Canada Mortgage and Housing Corporation

COP Coefficient of Performance (heating)

ECCC Environment and Climate Change Canada

EER Energy Efficiency Ratio (cooling)

EERE Office of Energy Efficiency and Renewable Energy (U.S. Department of Energy)

$\mathrm{EF} \quad$ Electricity grid Emissions Factor, or carbon intensity $\left(\mathrm{g} \mathrm{CO}_{2} \mathrm{e} / \mathrm{kWh}\right)$

ERV Energy Recovery Ventilator

EUI Total site Energy Use Intensity $\left(\mathrm{kWh} / \mathrm{m}^{2}\right.$ of finished floor area, annual basis)

FFA Finished Floor Area

DOAS Dedicated Outdoor Air System (ventilation)

DHW Domestic Hot Water

DOE U.S. Department of Energy

DWHR Drain-Water Heat Recovery

$\mathrm{CO}_{2} \mathrm{e} \quad$ Carbon Dioxide Equivalence based on 100 year global warming potential

COP Coefficient of Performance

GHG Greenhouse Gas

GHGI Greenhouse Gas Intensity $\left(\mathrm{g} \mathrm{CO}_{2} \mathrm{e} / \mathrm{m}^{2}\right.$ of finished floor area, annual basis)

GSHP Ground-Source Heat Pump

HPWH Heat Pump Water Heater

HRV Heat Recovery Ventilator

HSPF Heating Seasonal Performance Factor (AHRI rating for heating, BTU/hr-kWh) 


\begin{tabular}{|c|c|}
\hline HVAC & Heating, Ventilating, and Air-Conditioning \\
\hline LCC & Life-Cycle Cost \\
\hline MSHP & Mini-Split Heat Pump (air-to-air, ductless) \\
\hline $\mathrm{NBC}$ & National Building Code of Canada (set by NRC) \\
\hline NECB & National Energy Code for Buildings (set by NRC) \\
\hline NEEP & Northeast Energy Efficiency Partnership \\
\hline NIR & National Inventory Report \\
\hline NRC & National Research Council (Canada) \\
\hline NRCan & Natural Resources Canada \\
\hline NREL & National Renewable Energy Laboratory (U.S. Department of Energy) \\
\hline NREMDB & National Residential Efficiency Measures Database (NREL) \\
\hline $\mathrm{NZC}$ & Net Zero Carbon \\
\hline NZE & Net Zero Energy \\
\hline OBC & Ontario Building Code \\
\hline PHIUS & Passive House Institute of the U.S. \\
\hline PHIUS+ & Climate-specific North American Passive House Standard (set by PHIUS, 2015) \\
\hline $\mathrm{PH}$ & Passive House as defined by the German Passive House Institute \\
\hline PV & Photovoltaic \\
\hline $\mathrm{R}-2000$ & Voluntary housing energy standard developed by NRCan \\
\hline SEER & Seasonal Energy Efficiency Ratio (AHRI rating for cooling, BTU/hr-kWh) \\
\hline SHDI & $\begin{array}{l}\text { Space Heating Demand Intensity }\left(\mathrm{kWh} / \mathrm{m}^{2} \text { of finished floor area, thermal energy, }\right. \\
\text { annual basis) }\end{array}$ \\
\hline SRE & Sensible Recovery Efficiency \\
\hline TGS & Toronto Green Standard (v3 = version 3) \\
\hline TRE & Total Recovery Efficiency (sensible + latent) \\
\hline XPS & Extruded Polystyrene \\
\hline
\end{tabular}




\section{Introduction and Objectives}

Single-detached, single-family housing accounts for 53.6\% (Statistics Canada, 2017) of dwellings in Canada and 35\% of residential new construction (CMHC, 2018). Energy consumption by residential buildings accounts for approximately 17\% of Canada's secondary energy use and $14 \%$ of annual greenhouse gas (GHG) emissions from secondary energy (NRCan, 2016). These emissions are generated both during the off-site generation of electricity using fossils fuels, as well as through direct on-site combustion of fossil fuels for space and domestic hot water (DHW) heating. As of 2013, of the annual energy consumption from the national housing stock, approximately $63 \%$ was used for space heating, and 19\% for DHW, resulting in $83 \%$ of energy being used for the provision of heat. Furthermore, most of that heat is currently being provided through the combustion of fossil fuels including propane, heating oil, and primarily natural gas (NRCan, 2016). This, plus the fact that $80 \%$ of Canadians live in dwellings connected to a relatively clean electric grid (an annual average emissions factor of $50 \mathrm{~g} \mathrm{CO}_{2} \mathrm{e} / \mathrm{kWh}$ or less), indicates that the majority of GHG emissions from the residential sector are due to the on-site combustion of fossil fuels for heat (ECCC, 2018).

To reduce GHG emissions from the residential sector, building energy standards have tended to become more stringent over time. In addition to reducing environmental impact, standards are also designed with consideration toward reducing energy utility bills for the homeowner, without excessively increasing the initial cost of the home. As such, the National Building Code of Canada (NBC), Section 9.36, prescribes minimum levels of performance for specific building enclosure components, to control annual space heating demand (affecting utility bills), and peak heating load (affecting mechanical system size, and peak electrical load if electric). For the same reasons, it also specifies minimum efficiencies for: heating systems by type, heat recovery ventilators (HRV), DHW heaters and storage tanks, and air-conditioners.

Other housing standards, both mandatory and voluntary (OBC SB-12, R-2000, PH, PHIUS+), have important variations in approach, including: performance-based caps on space heating demand intensity (SHDI), total energy use intensity (EUI), peak heating/cooling loads, and heating system-specific building enclosure specifications. However, all standards share the commonality of not directly specifying heating system type, or GHG intensity. That is, there is no direct acknowledgement of the emissions (and life-cycle cost) relationship between electricity EF,

electrified heating costs and performance, and building enclosure thermal performance. 
Exceptions to this include some recent aspirational "step" codes designed to impose a GHGI limit that will be reduced to 0 by 2030 (Architecture 2030 Zero-Net Carbon, CaGBC Zero Carbon Buildings, Toronto Green Standard v3, etc.).

Traditionally common low-emitting alternatives to natural gas/oil furnaces, boilers, and water heaters include: wood-fired stoves furnaces, and electric resistance baseboard heaters and water heaters (where electricity is clean). However, the relatively high cost of electricity per unit energy usually renders electric resistance heating economically punitive, and the inconvenience and air pollution associated with wood stoves and furnaces renders this option undesirable and impractical in suburban and urban environments.

Other, as-yet less popular, alternatives include district heating systems derived from biomass, solar thermal hot water heaters, and electrically-driven heat pumps, either air-source or ground-source. In the case of ground source heat pumps, the operational cost of heat can be less than that for natural gas boilers and furnaces (due to their high coefficient of performance), but the initial capital investment is greater due to the necessity of drilling boreholes and installing groundloop heat exchangers. Air-source heat pumps, on the other hand, require a lower capital investment but have historically had a higher annual operational cost, especially in cold climates where the coefficient of performance is reduced.

The replacement of natural gas-derived heat with electric heat pumps represents a potential solution for the transition toward affordable, sustainable heat provision, and more generally, the sustainable consumption of energy. This approach is predicated on the fact that electricity must be generated from low and non-emitting sources (sustainable energy production). However, for zero emissions buildings standards to gain public and industry acceptance and become mandatory, it is necessary that practical design approaches be proposed that do not represent a substantial increase in initial or operational cost over the existing norm, and that they are practicably scalable.

\subsection{Objectives}

This study investigates the emissions and cost implications of the electrification of heating relative to a code-compliant, natural gas heated reference, in five Canadian cities, with a range of natural gas and electricity prices, electricity emissions factors (EF), climates, and local construction costs. Several all-electric space heating and DHW system configurations are investigated to determine the ideal system for each location. 
Rather than simply compare the operational cost of heat from different technologies and energy sources, or life-cycle costs of each system (initial + operational), this study approaches the issue as a whole-building optimization problem. The multi-objective optimization is intended to determine the relationship between life-cycle cost and operational GHG emissions for each heating system type in each location.

1. Primary Objective: Determine the life cycle least-cost electric and zero-carbon building designs (and associated costs and GHG emissions) based on fundamental economics (without subsidies or a carbon price), building physics, and the best available heating technologies.

\section{Secondary Objectives:}

a. Determine the relationship between heating system type/efficiency, and the optimal enclosure design (i.e., SHDI), and

b. Determine the relationships (if any) between the common performance metrics in energy standards (SHDI and EUI), and the metrics of primary concern to the homebuyer/ratepayer, and society (GHGI and LCC).

\subsection{Units of Measurement}

The North American construction and HVAC industries are dominated by professional associations, rating agencies, and manufacturers based in the U.S. Additionally, the legacy of British IP units (similar to US units) continues to survive informally in Canada. As such, US units are commonly used in Canada for some units of measurement, yet not others. Canada officially uses SI units, which are therefore used in this study. US units have also been included where they are the common unit of measurement in the industry. Furthermore, the primary software used, BEopt, operates only in US units. US units may therefore appear not strictly as values, but as labels

for building parameter input/output options, such as an "R-21 wall assembly." In a few cases, results are only presented in US units, like where it is necessary to represent both the nominal value, and the effective value, but where there is insufficient space in a table to represent both values in both US and SI units (1 RSI = 5.678 R-value).

In addition to measurement systems, there are conventions for units of energy depending on energy type. This study deals with three forms of energy: electrical, thermal, and chemical. Within the SI system, electricity is typically represented in kilowatt-hours (kWh), heat in Joules 
(J), and natural gas in either Joules or cubic meters of natural gas ( $1 \mathrm{GJ}=26.31 \mathrm{~m}^{3}$ nat.gas). Despite such convention, it is sometimes necessary to make comparisons between all three energy forms, and in such cases $\mathrm{kWh}$ is used, as it is especially convenient in the case of all-electric buildings. 


\section{Literature Review}

\subsection{Canada's Residential Buildings Sector}

This study is limited to Canada's single-family, single-detached, new construction housing subsector. The rationale for this decision is discussed further in Chapter 3. As shown in, with $53.6 \%$ of Canada's total existing housing stock, single-detached houses represent largest segment of Canada's 14.1 million dwellings (Statistics Canada, 2017). Additionally, 70.8\% of dwellings are in a building typically described as a "house," including, semi-detached, row houses, and apartments in a duplex (i.e., stacked units in a house), but not including low-rise apartment buildings. Unlike apartment buildings, such dwellings typically have decentralized, unitary mechanical systems, similar to single-detached houses. It should be recognized that substantial regional and urban/suburban/rural differences exist.

\section{In Canada, most dwellings are single-detached houses}

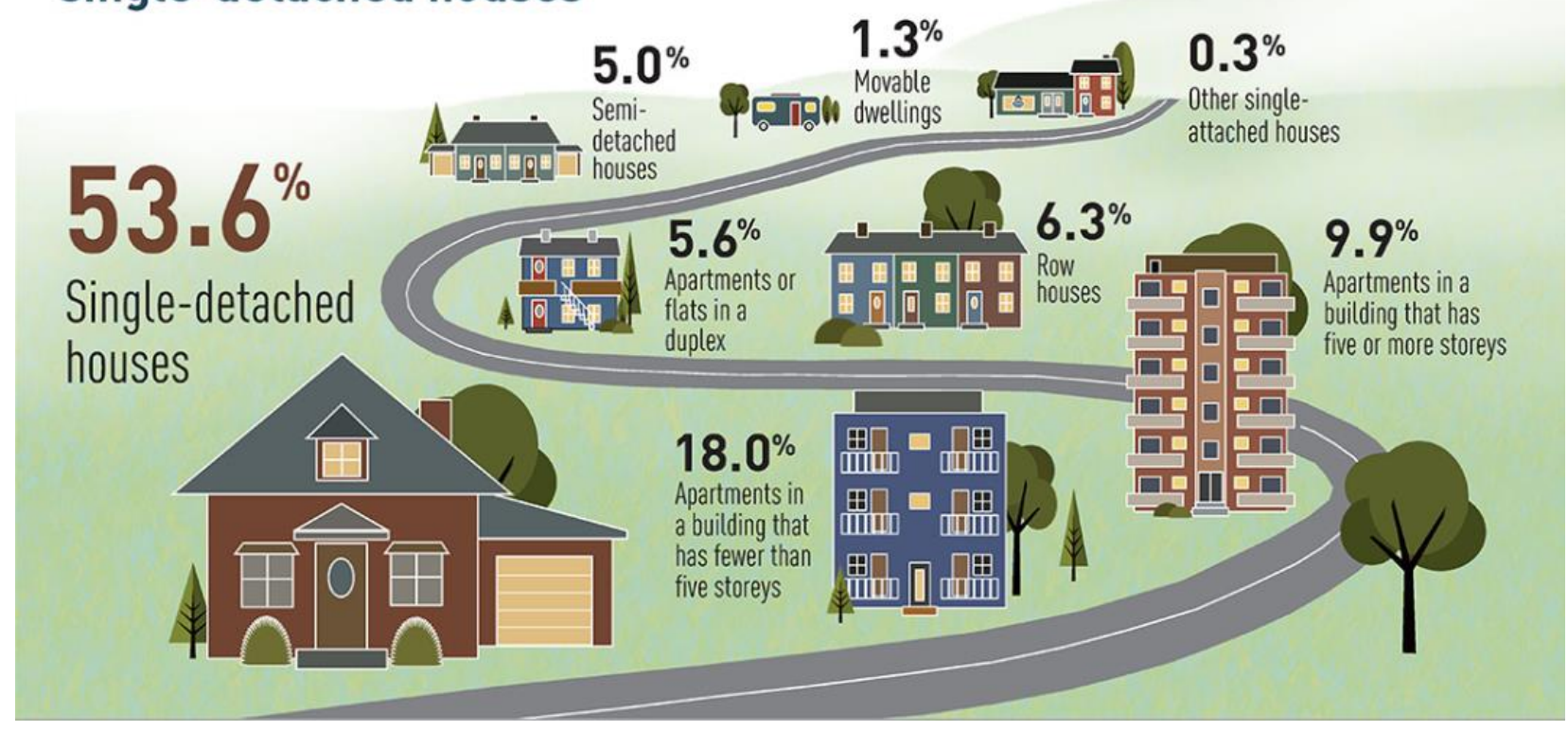

Figure 2-1 Canada's Housing Stock Breakdown (2016 Census) (Statistics Canada, 2017)

The breakdown of dwelling type for new housing starts is somewhat different, with singledetached dwellings showing a recent downward trend, representing $35 \%$ of the market. This nevertheless represented 76,843 new single-detached construction starts in 2017 (Figure 2-2). The median single-detached house price was $\$ 575,000$, although there is substantial variation within and between provinces (Figure 2-3). 


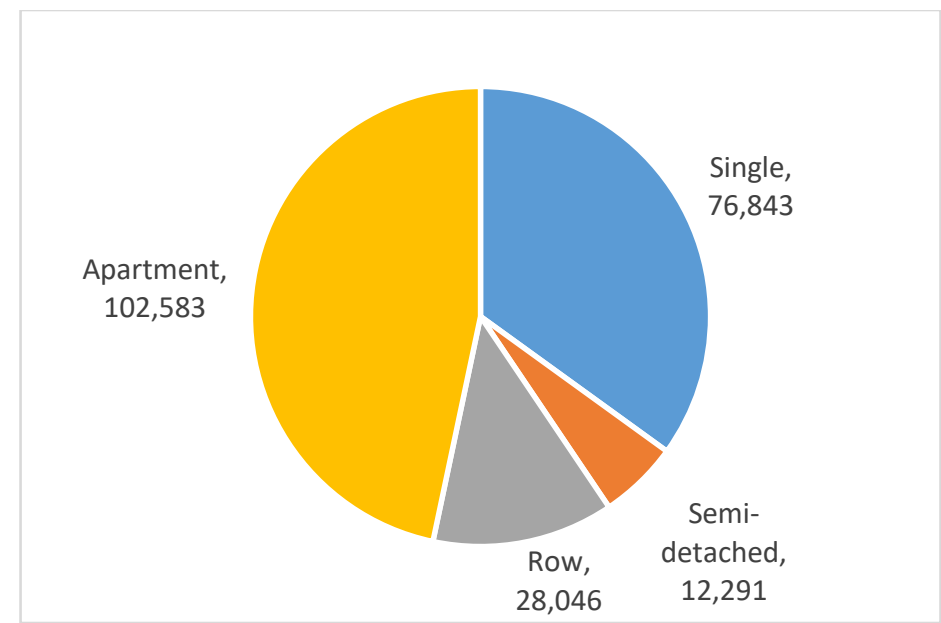

Figure 2-2 2017 Canada Housing starts by Type [data from (CMHC, 2018)]

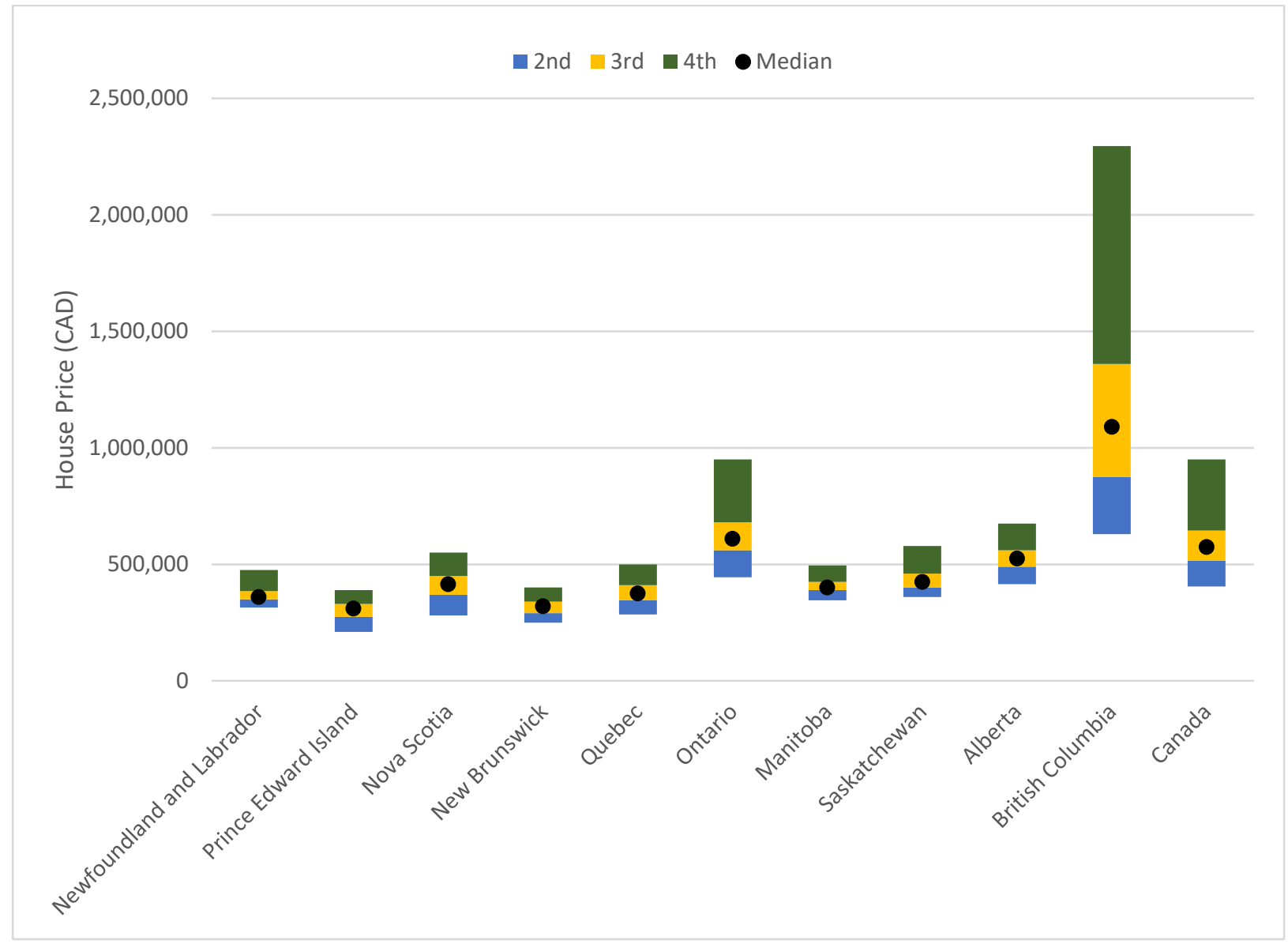

Figure 2-3 2017 Housing Price Quintiles - Single-Detached Starts [data from (CMHC, 2018)] 


\subsection{Energy and GHG Emissions from Canada’s Housing}

This study addresses only operational GHG emissions associated with energy consumption, and not embodied energy/carbon in the building materials and equipment. Operational energy includes direct emissions - onsite combustion of fuels for heat - and indirect emission - offsite combustion of fuels for electricity generation.

All data in this section, unless otherwise noted, is for the year 2015 from Natural Resources Canada's Office of Energy Efficiency energy use data handbook tables (NRCan, 2017), and from Environment and Climate Change Canada's National Inventory Report, Part 3 (NIR, 2018).

GHG Emissions from the building sector (commercial, institutional, residential, but not industrial), accounted for $15.5 \%$ of Canada's total of $714 \mathrm{Mt}$, and the residential subsector accounted for $9.16 \%$. Emissions for single-detached housing energy use in turn accounts for $70 \%$ of that, representing $6.39 \%$ of the total (Figure 2-4). The buildings share of emissions can vary greatly by region, especially depending on the level of activity in heavy industry, mining, and oil and gas. For example, The City of Toronto has calculated that buildings account for 53\% of the city's total emissions (Toronto, 2017).

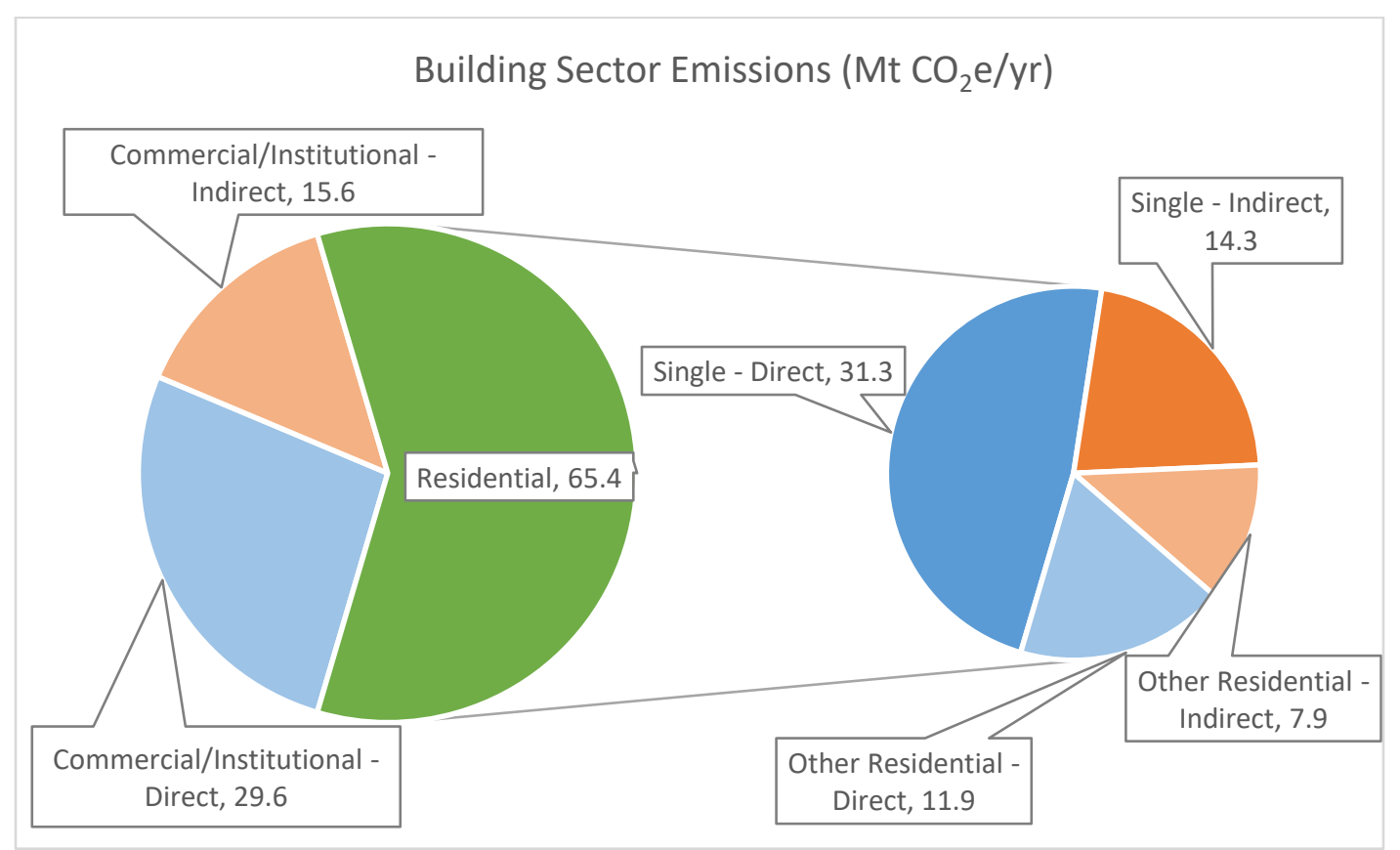

Figure 2-4 Building emissions with residential breakdown, 2015 (blue=direct emissions, orange $=$ indirect $;$ Single $=$ single-detached $)$ 
Nationally, non-electricity (direct) emissions represent $68.6 \%$ of emissions from singledetached houses (31.3 Mt, or $4.38 \%$ of Canada's total emissions). These emissions are almost entirely from the combustion of natural gas, heating oil, and wood for the provision of space and DHW heating. Figure 2-5 and Figure 2-6 provide a breakdown of energy use and emissions by fuel type and end use, respectively, for the single-detached housing stock.

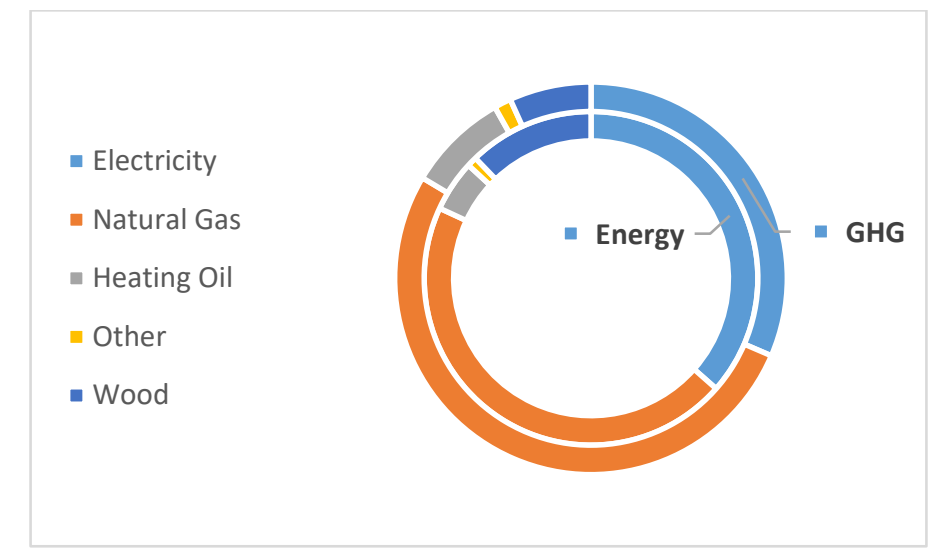

Figure 2-5 GHG emissions and energy use breakdown by fuel type for single detached housing stock

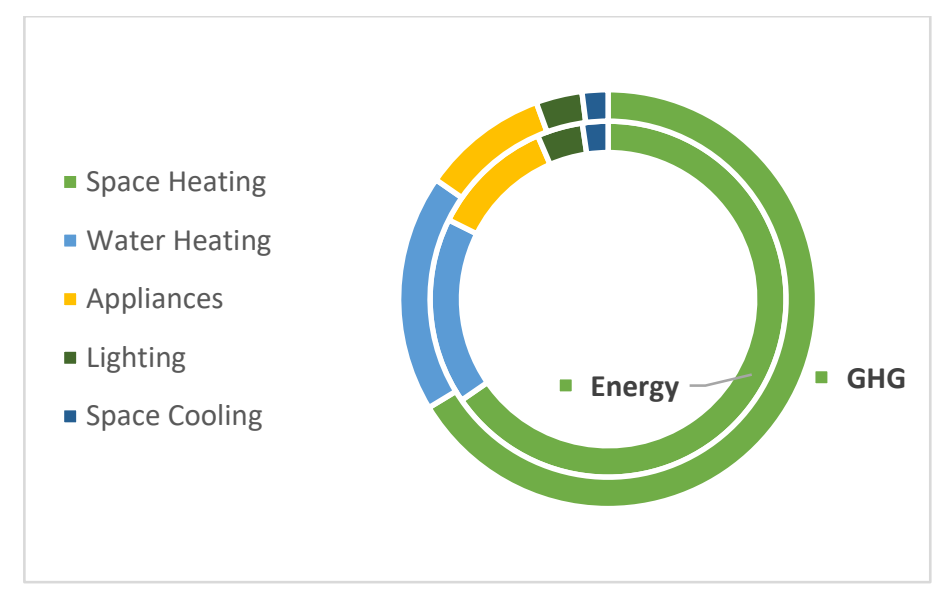

Figure 2-6 GHG emissions and energy use breakdown by end-use for single detached housing stock

It is important to recognize that these breakdowns represent the aggregate single-detached housing stock, and may vary substantially by location and building, especially if the electricity EF is low, if heating is supplied by electricity, or if the building has a high-performance thermal envelope. In the period from 1990 - 2013 substantial population growth, and reduced occupancy per household, more than compensated for efficiency improvements in building enclosure, equipment, appliance, and lighting during that period, resulting in a $6.5 \%$ increase in energy use by the residential sector. However, cleaner energy sources such as a transition from heating oil to 
natural gas and electricity, as well as reductions in the electricity EF, led to a $9 \%$ reduction in GHG emissions over the same period (NRCan, 2016). For Canada to achieve its GHG reductions targets, it is commonly acknowledged that emissions reductions from the residential sector will have to occur much more rapidly (ECCC, 2016).

\subsubsection{Heating Energy Use}

From Figure 2-6 it can be seen that space and water heating account for $65 \%$ and $17 \%$ of single-detached energy use respectively (note that these values refer to purchased energy consumption, as opposed to thermal energy demand, which cannot be known without knowing the average energy conversion efficiency of space and DHW heating systems). $82 \%$ of energy is consumed for the provision of heat, resulting in $85 \%$ of emissions, and is therefore a potential candidate for improved thermal efficiency and/or switching to cleaner energy sources. Table 2-1 indicates key metrics for the existing residential housing sector and single-detached subsector, including heating system input energy.

Table 2-1 Energy and GHG intensities of existing housing stock (NRCan, 2017)

\begin{tabular}{|c|c|c|}
\hline Intensity (annual) & All Residential & Single-Detached \\
\hline Total EUI $\left(\mathrm{kWh} / \mathrm{m}^{2}\right)$ & 212 & 228 \\
\hline Space Heating Input $\left(\mathrm{kWh} / \mathrm{m}^{2}\right)$ & 132 & 149 \\
\hline GHGI $\left(\mathrm{kg} \mathrm{CO} \mathrm{CO}_{2} / \mathrm{m}^{2}\right)$ & 32.3 & 34.8 \\
\hline
\end{tabular}

Heating energy for single-detached houses represents $73 \%$ of all residential heating energy, and although single-detached dwellings are slightly less efficient by floor area, performance is roughly similar to the parent sector. This is relevant because the following data on heating fuel use and heating system type are for the residential sector (detailed data is not available for singledetached specifically). Figure 2-7 shows the energy use breakdown by purchased energy type for space and DHW heating, indicating that natural gas accounts for half of space heating input energy, and roughly two thirds of DHW energy. 


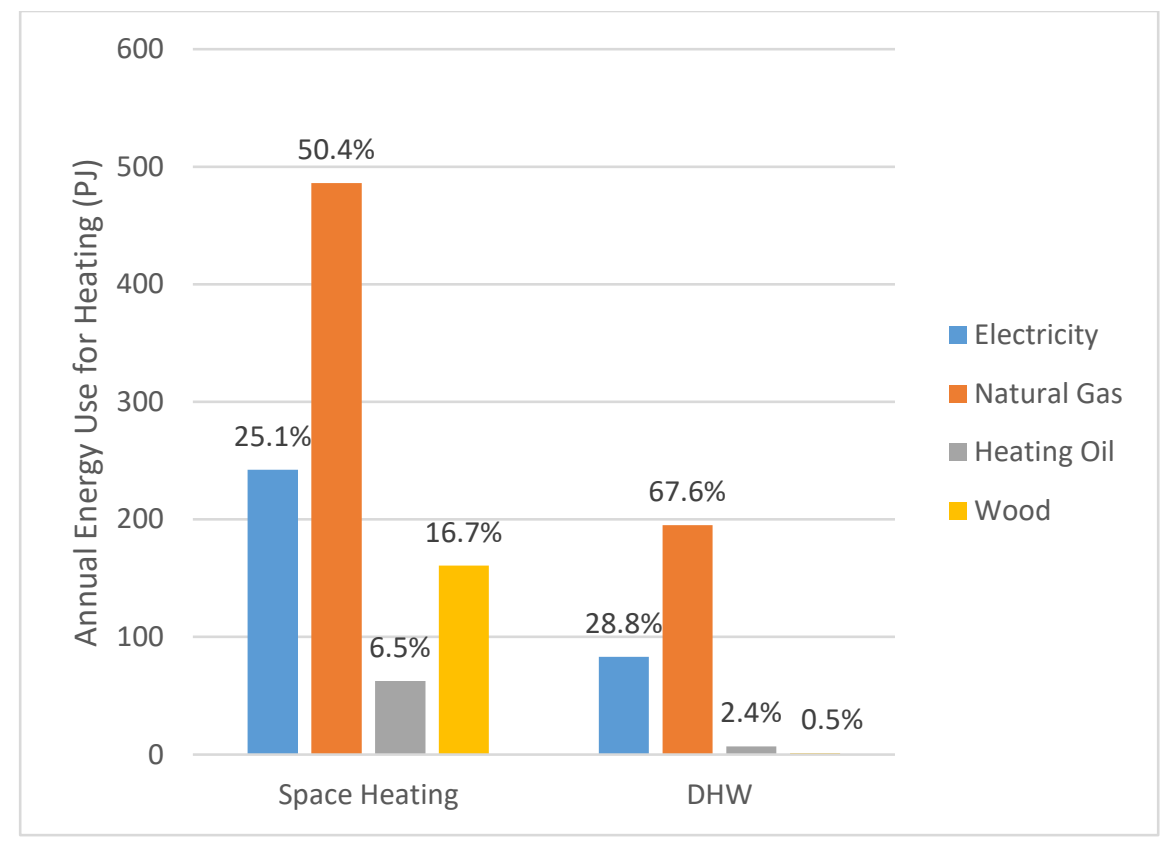

Figure 2-7 Purchased energy use breakdown for heating - existing residential stock

NRCan does not directly release thermal energy demand data, which differs more from heating system input energy the more the heating system energy conversion ratio (efficiency) deviates from 1:1. Electric heating efficiency is nearly 1:1 (although there can be substantial heat loss in older DHW tanks), and high efficiency natural gas furnaces and boilers can be greater than 90\% efficient. As heat pumps become adopted more widely, it will become increasingly important to clearly make this distinction, as the coefficient of performance (COP) can range from 2-5 for these technologies (i.e., a 200-500\% electrical energy to thermal energy conversion efficiency). In addition to heating system design and fuel use estimation, the SHDI metric is of interest as a proxy measure for the overall thermal performance of the building enclosure, including: envelope thermal resistance; window performance, orientation and area; air barrier system performance; and HRV thermal efficiency (it is also affected by building function and occupant density, in terms of internal heat gains).

\subsubsection{Heating System Type}

49.6\% of water heaters in the existing residential stock are electric, while $46.2 \%$ are natural gas. Figure 2-8 shows how the stock of space heating systems has changed since 1990. The clearest trend is the increase in efficiency of natural gas and heating oil furnaces/boilers. Natural gas is the most common heating type at $46.8 \%$, with electric at $29.1 \%$. Although heat pumps only account 
for $5 \%$ of stock (as of 2015), they represent the fastest growing share by system type, with a $210 \%$ increase in absolute quantity since 1990.

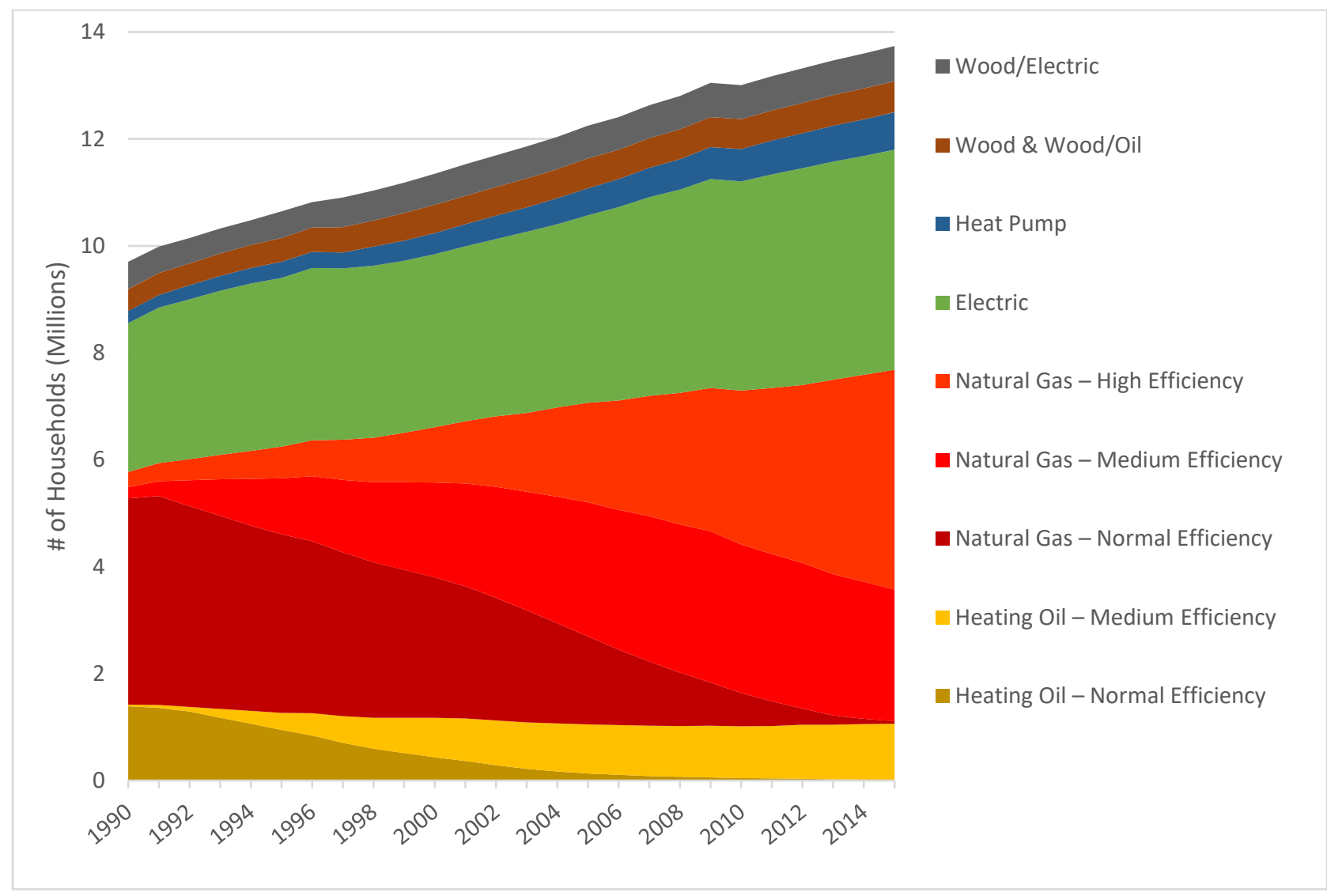

Figure 2-8 Residential space heating system stock by system type

\subsubsection{Electricity Emissions Factor (EF)}

Focusing on national average figures poses the risk of missing important regional variation, and this is especially true in the case of the provincial electricity generation mix and associated GHG emissions. The most recent, non-preliminary EFs are for 2015, from the 2018 ECCC NIR Part 3, Annex 13. These values are similar to 2016 preliminary values and are not expected to have deviated substantially in the interim.

Figure 2-9 shows the large variance in the electricity EF (i.e., carbon intensity) by province. Although there is electricity trading between provinces, as well as with the U.S., Canada's provincial grids are largely isolated systems (New Brunswick and P.E.I. are an exception). Of interest is that $80 \%$ of Canadians live in buildings connected to relatively "clean" electricity with an $\mathrm{EF}<50 \mathrm{~g} \mathrm{CO}_{2} \mathrm{e} / \mathrm{kWh}$, including the three most populous provinces. By comparison, a grid with 
primarily coal generation, such as that of Alberta, has an EF of nineteen times that value. This has important implications for the relative environmental value of electricity efficiency measures, as well as the electrification of heating in different regions.

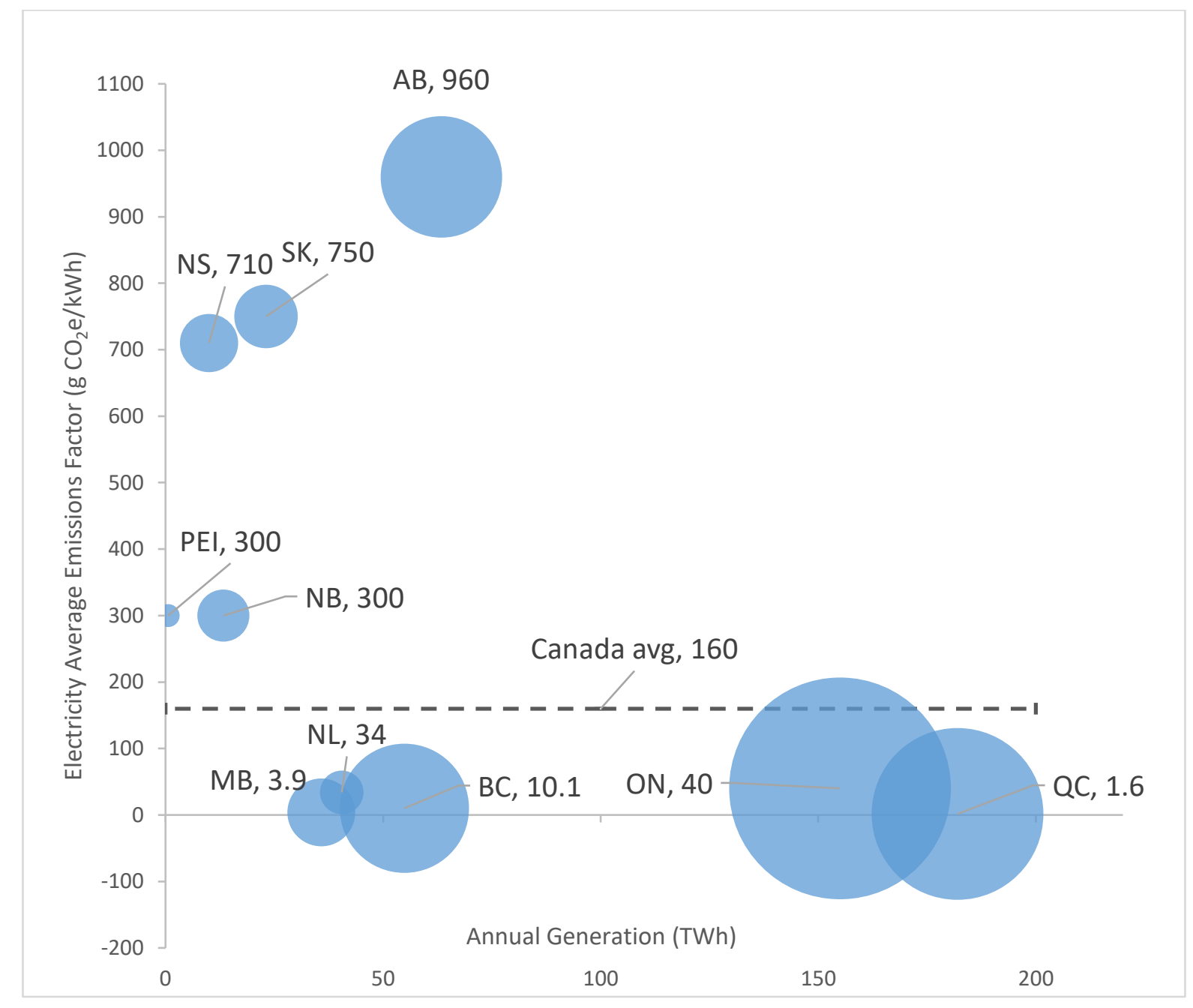

Figure 2-9 Electricity annual average emissions factors (EF) by province, 2015 [Bubble area indicates population. Electricity data from: (NIR, 2018)]

Note that EFs presented are annual average values for the given provincial grid, and that actual indirect emissions from a given building can vary depending on its specific temporal load profile (diurnal and seasonal). The hourly EF varies substantially in some provinces, such as Ontario where the baseload is provided primarily with non-emitting nuclear and hydro, and peak load is satisfied in large part with natural gas.

The most significant change to any province's generation mix in the last decade has been the coal phase-out in Ontario which resulted in a decrease in electricity EF of $86 \%$ between 2005 
and 2014. The Federal government's plans to phase-out coal generation in all provinces by 2030 will have the most profound impact on the EF of Alberta, Saskatchewan, and Nova Scotia.

In 2015, Cubi et al. conducted a building simulation-based study in which they compared the two indirect emissions accounting techniques - one using the hourly EF (which they denote as $\mathrm{CI}$ ) and one using the simpler, annual average EF-as well as a third, novel method of their devising (Cubi, Doluweera, \& Bergerson, 2015). They conducted the study using a TRNSYS model by comparing the relative GHG savings of 5 energy conservation measures (ECM), including the use of a heat pump, and the addition of photovoltaics (PV). They repeated the study 6 times for an office building and residential building using hourly GHG data for 2011 and 2013 in Alberta and Ontario. They identify the two existing indirect GHG accounting methods for buildings as:

Annual average EF:

$$
\text { Annual Indirect } G H G_{\text {current }}=\text { Annual Electricity Use } \times E F_{\text {avg }}
$$

Hourly EF:

$$
\text { Annual Indirect } G H G_{\text {hourly }}=\int_{0}^{y r} \text { Electricity } U s e_{t} \times E F_{t} d t
$$

Where:

$t=$ time step in hours, and

$E F_{t}=$ hourly emission factor (variables have been renamed to remain consistent with this document).

The hourly EF method is more accurate, as it represents the actual carbon intensity of electricity for that hour, calculated as:

$$
E F_{t}=\frac{\text { Total Grid } G H G_{t}}{\text { Total Energy Generation }_{t}}
$$

However, they identified that for some grids (such as Alberta in 2011) that generate baseload using coal, and meet peak load using relatively cleaner natural gas, the hourly EF is negatively correlated to total grid demand. This creates a perverse incentive for building designers and operators to consume more electricity during periods of high demand to reduce GHG emissions. Despite the EF being lower, total grid emissions are higher during high demand, as are electricity wholesale prices. The transmissions and distribution system and some generators are 
also much less energy efficient during peak demand. To deter the increase in total peak demand on the grid, Cubi et al. developed a third method for measuring indirect building emissions using:

$$
\text { Carbon Emissions Factor }{ }_{t}=C E F_{t}=\frac{\text { Total Grid } G H G_{t}}{\text { Total Grid } G H G_{\text {annual hourly average }}}
$$

Where:

$C E F_{t}=$ dimensionless factor calculated for every hour

The CEF is always positively correlated to total demand, regardless of the grid generation mix. Using this method, indirect building emissions are calculated as:

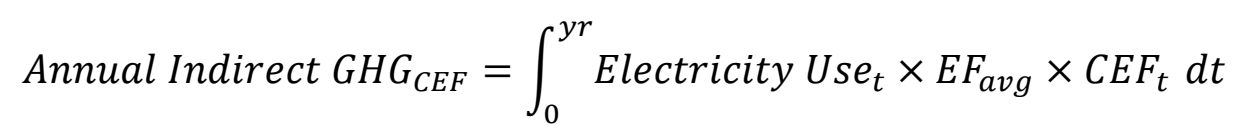

While this method may serve to prevent increased demand during peak times, it does not necessarily estimate GHG emissions accurately. If accurate emissions accounting is the sole purpose of the choice of method, then the hourly EF method is ideal (labelled the "CI" method in Cubi et al.). If combined with existing financial incentives, such as time-of-use pricing based on free market supply and demand, the hourly EF method will not necessarily encourage peak demand usage. The inaccuracy of the novel CEF method is especially problematic in the context of a carbon price, since it will both improperly charge for real emissions, as well as double-charge ratepayers during peak demand if combined with time-of-use pricing. Furthermore, although less accurate, the simpler average EF method does not result in the perverse peak demand usage incentive about which Cubi et al. are concerned.

Assessing both the hourly EF and the CEF methods, Cubi et al. find that "The GHG savings in the building variants that combine heat pumps with $\mathrm{PV}$ are dominated by the heat pump contribution in Ontario and by the PV contribution in Alberta." They also compare the GHG estimates using the two hourly methods to the existing industry convention, the average EF method. Results show that GHG emissions using the hourly EF method deviated no more than $12 \%$ from the average EF method, for 35 of the 36 building variants modeled across both electricity grids. As hourly EFs are not available for all provincial grids analyzed in this study, average EF is used. 


\subsection{Housing Energy and Emissions Standards}

Building energy standards typically regulate the design and construction quality of new buildings in one of two ways:

- Prescriptive Compliance

- Performance Compliance

The more traditional-style standard is the prescriptive compliance method which specifies minimum performance for individual components, such as insulation R-values, window U-values, mechanical equipment efficiencies, etc. They may or may not mandate the use of certain technologies, such as heat recovery ventilators (HRV). They can also contain flexibility in the form of "trade-off compliance" allowances, in which a non-compliant component is compensated for by a higher performance component elsewhere (such as in $N B C$ 9.36).

Energy standards can be developed by government agencies (such as the NRC or NRCan) or industry groups (such as ASHRAE or PHIUS). A standard is not mandatory until it is officially adopted by government and integrated into the building code, which is legally enforced. The energy standard forms a specific part of the code, but there can also be requirements elsewhere in the code that have important impacts on energy performance. For example, in Canada's NBC Part 9 Housing and Small Buildings, energy prescriptions are found in Section 9.36 - Energy Efficiency, but there are also construction specifications for the envelope air barrier system in Section 9.25 Heat Transfer, Air Leakage, and Condensation Control, which exist primarily to ensure envelope durability, and prevent mold growth due to moisture accumulation in the assembly. Standards also often cross-reference other more targeted standards, such as ASHRAE 62.2 or CSA F-326 for ventilation system design.

There are standards developed by multiple levels of government, some of which are code (legally binding), and some are not. In Canada, federal standards are developed as models for the provinces to adopt as code (NRC, 2018). This can be misleading as the NRC labels these model standards as codes: National Fire Code of Canada; National Plumbing Code of Canada; National Energy Code for Buildings (NECB). For low-rise residential buildings, these codes are covered by NBC Part 9, where 9.36 is the equivalent of the NECB. Provincial governments are free to adopt these standards, modify them, or develop their own standard (Table 2-2). There are also codes at the municipal level, such as the Toronto Green Standard, which has more stringent specifications 
in some respects, and overlaps the provincial code, the Ontario Building Code $(O B C)$. The TGS, however, does not apply to low-rise residential buildings with fewer than 5 units, therefore the only legally enforced building energy code for new single-detached houses in Toronto is the $O B C$ Supplementary Standard SB-12 Energy Efficiency for Housing (Toronto, 2018).

Table 2-2 National Building Code adoption by Province (NRC, 2018)

\begin{tabular}{|c|c|c|c|}
\hline & NBC 2010 & $\begin{array}{c}\text { NBC Revision } \\
\text { 2012 (9.36) }\end{array}$ & NBC 2015 \\
\hline Yukon* & & & $\checkmark$ \\
\hline NWT* $^{*}$ & & & $\checkmark$ \\
\hline Nunavut* & & & \\
\hline British Columbia** & $\checkmark$ & $\checkmark$ & \\
\hline Alberta** & $\checkmark$ & $\checkmark$ & \\
\hline Saskatchewan* & $\checkmark$ & & $\checkmark$ \\
\hline Manitoba* & $\checkmark$ & $\checkmark$ & \\
\hline Ontario*** & $\checkmark$ & & \\
\hline Quebec** & $\checkmark$ & & \\
\hline New Brunswick* & & & \\
\hline P.E.I.* & $\checkmark$ & & \\
\hline Nova Scotia* & & & \\
\hline Newfoundland* & $\checkmark$ & & \\
\hline
\end{tabular}

* Provinces and territories that adopt or adapt the national model codes

** Provinces that publish their own building codes that are "substantially the same as the national models with variations that are primarily additions"

*** Publishes its own building code "based on the national models, but with significant variations in content and scope"

The advent of building energy modelling and simulation software has resulted in an increase in the prevalence of performance compliance options. For this method a building design is modeled, and its energy performance is simulated in the proposed location, to "prove" that the building will meet a minimum level of performance. Standards often provide the option between prescriptive compliance and performance compliance. Additionally, performance compliance options sometimes include some specific prescriptions, such as minimum heating system efficiencies, or maximum air leakage rates, which are required to be tested and verified during construction (OBC SB-12, PHIUS+).

There are two different approaches to performance compliance: better than reference, and absolute performance targets. In the better than reference approach, a reference building design is prescribed by the standard, in a similar way as is done in the prescriptive compliance method. This reference building must be modeled (based on the proposed building geometry) to determine its 
performance (either SHDI, or EUI, or both). A proposed building must then meet or exceed the energy performance of this reference building but may do so with greater flexibility in the performance of specific components. Conversely, absolute performance targets do not prescribe a reference building, but rather set specific metrics (i.e., energy use ceilings), such as: SHDI, EUI (site or source), GHGI, or peak heating/cooling load intensities. See Table 2-3 for a summary of compliance options and performance metrics for a set of mandatory and voluntary housing energy standards. Component prescriptions and energy performance targets are climate-specific for all standards presented.

\subsubsection{Performance Metrics}

Building energy standards with performance-based metrics typically denominate energy use intensity by floor area. The average floor space for existing single-detached houses in 2015 was $159 \mathrm{~m}^{2}$ (1709 $\left.\mathrm{ft}^{2}\right)$, an increase of $15.8 \%$ since 1990 (Office of Energy Efficiency, 2017). Occupancy also plays an important role in energy use, including plug loads, large appliances, DHW usage, and the effect of internal heat gains on SHDI from these uses, as well as from the occupants themselves. O'brien et al. show that, while energy efficiency and the GHG intensity of energy sources for housing have decreased in the 1990-2013 period, increased floor area per person (due to the combined effects of larger houses and lower occupancy) has simultaneously increased by $28 \%$ to $56 \mathrm{~m}^{2} /$ person, offsetting much of the would-be GHG reductions (O'Brien, Gaetani, Carlucci, Hoes, \& Hensen, 2017). This review nonetheless is concerned mainly with the conventional energy and emissions intensities by floor area.

SHDI is the most common performance target in the housing energy standards reviewed. It is sometimes labelled "specific space heat demand" by PHIUS, and TEDI by the Toronto Green Standard (TGS Guidelines, 2018) (PHIUS+, 2015). The TEDI label is a misnomer, as it does not actually include thermal energy for space cooling or DHW. The term has been relabeled in this report for clarity, as well as consistency with the other floor area-denominated intensity metrics. It represents the amount of space heating required to be satisfied mechanically, after all internal and solar heat gains have been accounted for. Thus, by holding occupancy, appliances, lighting, control, and behavior fixed across designs, it is a useful way by which to quantify the thermal performance of the building enclosure (in heating-dominant climates). The metric accounts for heat loss by mass transfer of air through the envelope (infiltration/exfiltration), convective heat 
transfer between the envelope and indoor/outdoor air, conductive heat transfer through all envelope components, and radiative heat transfer between the envelope (especially windows), and interior/exterior objects. It also accounts for heat lost through mechanical ventilation, whether exhaust-only, HRV, or ERV.

Importantly, it is independent of heating system type and efficiency. As a quantification of the mechanical heating requirement, it also enables the simple calculation of operational heating cost and GHG emissions for different heating system efficiencies/types and purchased energy types for a specified enclosure design. In short, it is a simple and accurate way of isolating the energy performance of the passive building enclosure from that of the active conditioning system. The peak heating load (aka. design heating load/heat rate/thermal power) is another important value defined by the building enclosure, and is especially relevant for heating system capacity sizing, and peak electricity demand in the case of electric forms of heating. It is less relevant for energy, energy cost, and GHG accounting. Table 2-3 shows that $N B C 9.36$ relative metric and the $R$-2000 absolute metric is not SHDI, but space and DHW heating energy consumption, or input purchased energy.

$E U I$ is a measure of total annual purchased energy use intensity (aka. TEUI). Unless otherwise defined, it refers to site energy demand. It is sometimes defined on a source energy basis (U.S. DOE Net-Zero Energy Definition, PHIUS+), meaning the primary (offsite) energy used to generate the secondary (onsite) energy, for example, the amount of natural gas chemical energy required to generate a unit of electrical energy. The EUI metric is not useful unless accompanied by additional information. This fact is best illustrated through example:

Example 1:

Two buildings with identical enclosures, and identical natural gas heating, and DHW systems, have an EUI of 150 and $180 \mathrm{kWh} / \mathrm{m}^{2}$.

\section{Example 2:}

Two buildings have identical electricity demand and they have an EUI of 150 and 180 $\mathrm{kWh} / \mathrm{m}^{2}$.

Example 3:

A building's natural gas furnace is replaced by an air-source heat pump and the EUI falls from 200 to $140 \mathrm{kWh} / \mathrm{m}^{2}$. Nothing else has changed. 
Given that electricity and natural gas have different carbon intensities, as well as different costs per unit energy, it is necessary to know what portion of EUI is for gas and what portion is for electricity to determine the GHG reductions and total energy cost reduction. All the information provided is necessary to determine that the energy savings are entirely for electricity in example 1, and for gas in example 2. In example 3, despite knowing a great deal, it is not possible to calculate the GHG or energy cost savings, since the proportion of EUI for gas in the initial building is not known. This example illustrates that energy use is merely an intermediate metric of concern and does not always correlate to the primary metrics of interest for ratepayers, government, and society. The one instance in which EUI is a useful metric is when comparing all-electric buildings, in which it is a direct proxy for operational GHG emissions and energy cost.

Table 2-3 House energy standards compliance options and performance metrics

\begin{tabular}{|c|c|c|c|c|}
\hline Standard & Mandatory & $\begin{array}{c}\text { Prescriptive } \\
\text { Compliance }\end{array}$ & $\begin{array}{c}\text { Performance } \\
\text { Compliance }\end{array}$ & $\begin{array}{c}\text { Performance Metric(s) } \\
\text { (performance compliance option } \\
\text { only) }\end{array}$ \\
\hline NBC 9.36 (2015) & & $\checkmark$ & Reference & HVAC and DHW energy consumption \\
[9.36.5.2(2)]
\end{tabular}

* Value depends on space heating system type (fuel or electric only)

Sources: (PHIUS+, 2015) (R-2000, 2012) (OBC SB-12, 2016) (NBC 9.36, 2015)

GHGI is a more recently introduced metric by some standards and frameworks (Toronto, 2018) (CaGBC, 2016) (Architecture 2030, 2016). While the TGS v3 specifies GHGI, it still contains a loophole allowing for $O B C+15 \%$ energy performance, and as mentioned, is not at all applicable to single-detached houses. A building energy code that enforces a GHGI would be the first building code in Canada to directly address the different carbon intensities of different purchased energy sources, and by proxy the effect of heating system fuel switching and/or electrification on GHG emissions. GHGI is defined as (Toronto, 2018): 


$$
\begin{aligned}
& \text { GHGI }\left[\frac{k g \mathrm{CO}_{2 e q}}{\mathrm{~m}^{2} \mathrm{yr}}\right] \\
& =\frac{\sum\left(\text { Site Energy Use }\left[\frac{\mathrm{kWh}}{\mathrm{yr}}\right] \times \text { Emissions Factor }\left[\frac{\mathrm{kgCO} \mathrm{CO}_{2 e q}}{\mathrm{kWh}}\right]\right)}{\text { Modelled Floor Area }\left[\mathrm{m}^{2}\right]}
\end{aligned}
$$

\subsubsection{Net Zero Energy}

The National Institute of Building Sciences and the U.S. DOE, EERE report: A Common Definition for Zero Energy Buildings is a clear and concise definition complete with energy accounting examples for different types of site energy use (EERE, 2015). The report defines a NZE building as follows: "An energy-efficient building where, on a source energy basis, the actual annual delivered energy is less than or equal to the on-site renewable exported energy" (Figure 2-10). This definition does not address the issue of reliance on the grid for diurnal and seasonal deficits of onsite renewable power production, where such a building effectively uses the electric grid as a "battery" (Torcellini, Pless, Deru, \& Crawley, 2006).

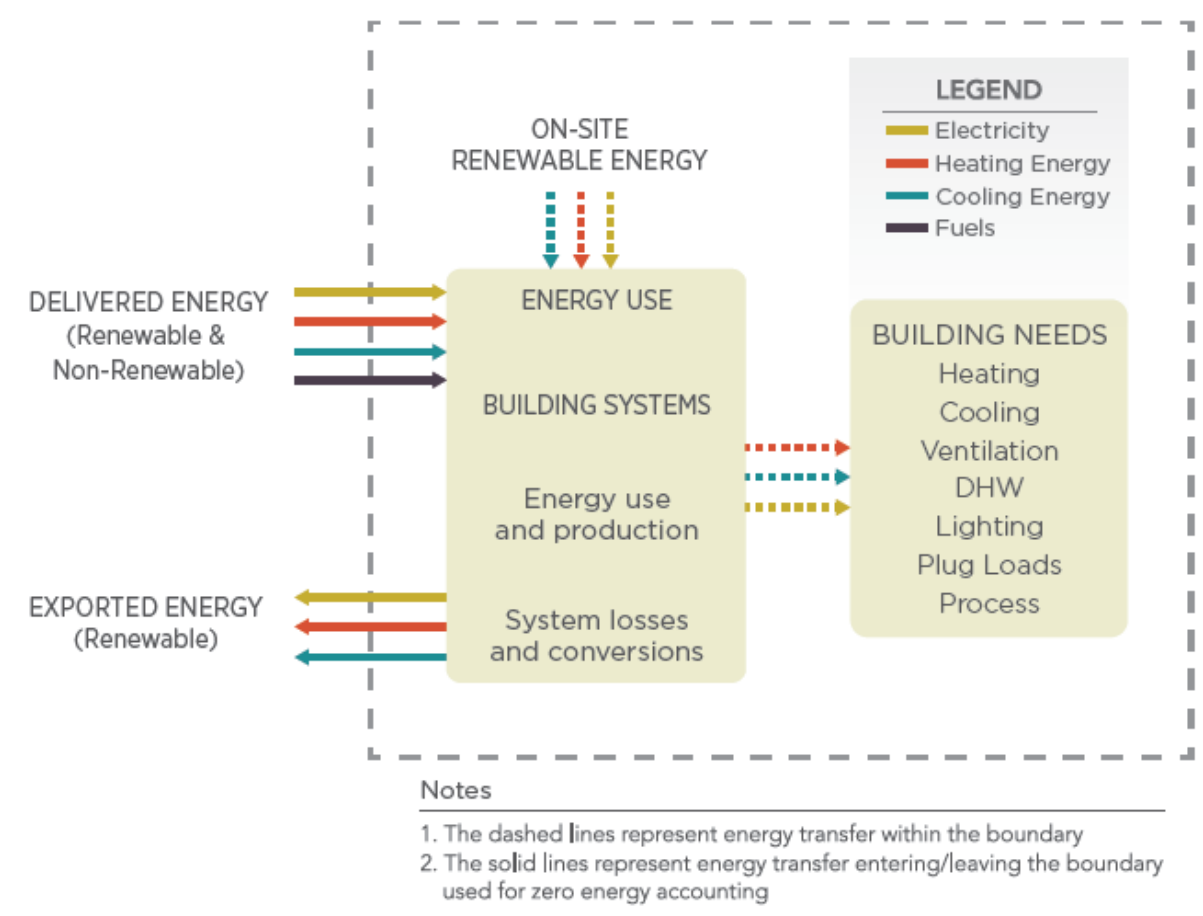

Figure 2-10 Site Boundary of Energy Transfer for Zero Energy Accounting (EERE, 2015)

The site-to-source ratio that differentiates the site energy (use and production) from the source energy, is a number that can have a significant impact on the annual energy accounting for 
the building (Wright, Klingenberg, \& Pettit, 2015). It varies by energy type, and in the case of electricity (site:source ratio of 3.15 for U.S. average) it is a function of several factors, the primary one being the efficiency of the natural gas and coal generators in the electric grid, but also the transmission and distribution losses within the grid. In the case of all-electric NZE buildings, the factor is irrelevant, since both electricity imports and exports are multiplied by the same factor. However, if a building consumes natural gas (site:source ratio of 1.09) and generates onsite renewable energy to offset both electricity and natural gas consumption on a source basis, there can be a substantial difference between the net source energy and the net site energy. Note that this scenario results in a building that must generate more electricity than it consumes annually. In the case of Ontario's net-metering policy, this annual surplus will not be rewarded financially.

Using the source energy versus site energy metric introduces an important concern: if the ratio for electricity differs by location, a given building design may have substantially different quantified performance for two different locations, even with identical climates. This is also true if using grid-specific EF when accounting on a GHG rather than energy basis. However, in the case of the source energy factor, the current norm by U.S. DOE and PHIUS is to use the same value of 3.15 for the U.S. national average, regardless of the actual value for the grid in question (even in Canada, where it is especially inaccurate for hydropower or nuclear-dominant grids). While this allows building performance to be fairly compared across any North American location, it introduces error, especially in buildings that consume natural gas. It also begs the question: why not simply use site energy?

The source energy metric (if using an accurate site:source factor) addresses the primary energy use of fossil fuels for electricity generation, which has an impact on GHG emissions, the cost of electricity, energy sovereignty, and resource scarcity. However, it is nevertheless an intermediate value of interest. GHG versus LCC optimization addresses the first two issues directly, if local grid EF is accounted for. Furthermore, with the recent abundance of unconventional fossil fuels in North America (oil sands, shale oil and gas), resource scarcity is not an immediate concern. Indeed, the macro-scale limiting factor for the combustion of fossil fuels is not resource availability, but rather atmospheric carbon dioxide concentrations, with the International Energy Agency warning that 2/3 of proven fossil fuel reserves must remain untapped to prevent to $2^{\circ} \mathrm{C}$ of global warming (Irish Times, 2013). 
A "zero energy ready home" is generally considered to be a candidate for NZE, but without the renewable generation capacity installed (PHIUS, 2015). Typically, much of the challenge in achieving NZE performance is the large necessary reduction in energy consumption of the building, such that all the building's electrical demand (including HVAC) annually can be met by means of a reasonably sized onsite renewable power generation system (EERE, 2016). However, this may not be the case if there is space for a very large rooftop PV array, which will not force thermally efficient enclosure design and could result in excessive peak electric demand.

\subsubsection{Passive House}

PH Institute

The Passive House standards employ passive design techniques which are by no means exclusive to these standards (Straube, 2009). The original PH standard developed by the Passive House Institute has as its premise that the most cost-effective means of reducing energy consumption is through passive design techniques, including: natural ventilation by means of operable windows; a highly insulated, airtight thermal envelope (including windows); thermal mass; passive solar heat gains from equator-facing windows combined with sufficient shading techniques; and thermal bridge-free construction (Stecher \& Klingenberg, 2008) (O'Brien, Kesik, \& Athienitis, 2014) (PHI, 2015). The theory is that the bulk of energy reduction can come from reducing the SHDI through passive design techniques, which are the cheapest to employ, beyond which efficiency gains must be sought in active thermal systems (HVAC, DHW, solar thermal) as well as electrical consumption (lighting, appliances, controls). This has been the conventional wisdom not only for Passive House design but for any ultra-low energy building design, the primary disagreements typically being a matter of degree (Straube, 2005). The $P H$ standard and PHIUS + are primarily standards for reducing consumption and increasing efficiency (primarily in thermal energy demand but also electrical/source energy) and are for this reason useful as an approach to designing a "zero-energy-ready house" (PHIUS, 2015). The $P H$ standard has 3 absolute performance (Table 2-4) as well as several stringent design prescriptions for minimum window and wall U-values, HRV efficiency (PHI, 2015).

In addition to the passive design strategies, a primary feature of the $P H$ standard is the emphasis on high efficiency HRVs, the combination of which is intended to eliminate the need for central heating or cooling systems. The corresponding reduction in capital costs associated with 
the HVAC system enables a greater expenditure on the envelope and gives rise to the claim of "tunneling through the cost barrier" (Wright, Klingenberg, \& Pettit, 2015). According to Wright et al., this effect "could not be observed" in North America, mainly due to the more extreme temperatures, such as in very hot climates of the southern U.S., and especially in colder parts of the continent (DOE zones 5-7). For example, Frankfurt, Germany, and Boston, Massachusetts have similar HDD requirements, yet Boston has a much higher peak heating demand. To achieve $P H$ SHDI requirements, a house in Boston would require huge investments in the thermal envelope yet would have the same number of HDD as Frankfurt by which to achieve a return on the investment. It is therefore often necessary and more cost-effective for North American houses to retain a central heating unit of some kind - that is, the optimal trade off point between active and passive measures can greatly vary by climate, and energy pricing. Straube points out that "The rules of thumb that guide the 'low cost' recommendations of the $P H$ standard are often not lowcost in America" (Straube, 2009).

\section{PHIUS+}

PHIUS has recognized these problems and has modified the standard for North America. In 2015, PHIUS+ 2015 was introduced, a climate-specific standard for different zones. Some of the changes introduced are as much a change in how performance is measured, in order to align with current US and ASHRAE methodologies (rather than European ones), as it is a change to the level of performance required.

The source energy requirement uses the U.S. average site:source factor (3.16) and is on a per occupant basis. There are different appliance and plug load assumptions than the $P H$ standard to better reflect occupant behavior and appliance efficiencies in North America. The space conditioning thermal energy and peak load limits are location specific, as well as denominated by "interior conditioned floor area" rather than the German convention of "treated floor area" (see Table 2-4 for comparison of both standards). The climate-specific targets were determined using LCC optimizations in BEopt according to the following strategy:

"Shift to mandatory, climate-specific thresholds on specific annual heating and cooling demands and peak heating and cooling loads. These are set at cost optimal "sweet spot" slightly beyond BEOpt's cost optimum for project's climate for increased resilience benefits. This ensures efficiency measures will have reasonable payback relative to operational energy 
savings. The peak load thresholds may be adjusted to ensure hourly comfort or the ability of the home to thermally coast through power outages" (Wright, Klingenberg, \& Pettit, 2015)."

Table 2-4 PH and PHIUS+Requirements (PHIUS+ thermal targets for Toronto, ON)

\begin{tabular}{|c|c|c|}
\hline & PH & PHIUS+ 2015 \\
\hline $\begin{array}{l}\text { Space Heating Demand } \\
\text { Intensity }\end{array}$ & $15 \mathrm{kWh} / \mathrm{m}^{2}-\mathrm{yr}(4.7 \mathrm{kBtu} / \mathrm{sf}-\mathrm{yr})$ & $6.4 \mathrm{kBtu} / \mathrm{ft}^{2}-\mathrm{yr}\left(20.2 \mathrm{kWh} / \mathrm{m}^{2}-\mathrm{yr}\right)$ \\
\hline $\begin{array}{l}\text { Space Cooling Demand } \\
\text { Intensity }\end{array}$ & NA & $1.8 \mathrm{kBtu} / \mathrm{ft}^{2}-\mathrm{yr}\left(5.7 \mathrm{kWh} / \mathrm{m}^{2}-\mathrm{yr}\right)$ \\
\hline Peak Heating Load & $10 \mathrm{~W} / \mathrm{m}^{2}$ (3.2 Btu/h-sf) & $4.6 \mathrm{Btu} / \mathrm{h}-\mathrm{sf}\left(14.5 \mathrm{~W} / \mathrm{m}^{2}\right)$ \\
\hline Peak Cooling Load & NA & 3.6 Btu/h-sf $\left(11.4 \mathrm{~W} / \mathrm{m}^{2}\right)$ \\
\hline $\begin{array}{l}\text { Total Primary (Source) } \\
\text { Energy Demand }\end{array}$ & $120 \mathrm{kWh} / \mathrm{m}^{2}-\mathrm{yr}$ & $6200 \mathrm{kWh} /$ person-yr \\
\hline Air leakage rate & $0.6 \mathrm{ACH} @ 50 \mathrm{~Pa}$ & $0.05 \mathrm{cfm} / \mathrm{ft}^{2}$ gross envelope area @ $50 \mathrm{~Pa}$ \\
\hline
\end{tabular}

\subsubsection{National Building Code}

As discussed at the beginning of Section 2.3, the National Building Code of Canada (2015) is a model standard that the provincial jurisdictions are free to ratify, modify, or replace with a custom standard that will be legally enforced. However, the NBC provides a standardized guide with which to create a baseline model for new houses. Section 9.36-Energy Efficiency of Part 9 - Housing and Small Buildings, constitutes a concise adaptation of the National Energy Code for Buildings (NECB) for small, low-rise buildings. Alternatively, designers are permitted to use the NECB 2015 for such buildings (NRC, 2017).

The prescription compliance option of $N B C 9.36$ provides climate zone-specific component prescriptions for the building enclosure (9.36.2 — wall, basement/floor, ceiling/roof RSI values, and window/door U-values; see Table 2-5), HVAC equipment (9.36.3-heating, ventilating, air-conditioning), and service water heating (DHW) equipment (9.36.4). It also references other Subsections of NBC Part 9 that relate to energy performance, including Section 9.32, which specifies ventilation system design (similar to ASHRAE 62.2 Ventilation and Acceptable Indoor Air Quality in Low-Rise Residential Buildings), and insulation (RSI 0.5) for outdoor air ducts (i.e., HRV intake and exhaust), and Section 9.25, which specifies construction methods to control airflow through the enclosure (based on CAN/ULC-S742 Air Barrier Assemblies - Specification standard). 
Table 2-5 NBC 2015 - Table 9.63.2.6.B. Effective Thermal Resistance of Above-ground Opaque Assemblies in Buildings with a Heat-Recovery Ventilator (NRC, 2015)

\begin{tabular}{|c|c|c|c|c|c|c|}
\hline \multirow{3}{*}{$\begin{array}{l}\text { Above-ground } \\
\text { Opaque Building } \\
\text { Assembly }\end{array}$} & \multicolumn{6}{|c|}{ Heating Degree-Days of Building Location, in Celsius Degree-Days } \\
\hline & $\begin{array}{l}\text { Zone } 4 \\
<3000\end{array}$ & $\begin{array}{c}\text { Zone } 53000 \\
\text { to } 3999\end{array}$ & $\begin{array}{l}\text { Zone } 64000 \\
\text { to } 4999\end{array}$ & $\begin{array}{c}\text { Zone } 7 A \\
5000 \text { to } 5999\end{array}$ & $\begin{array}{c}\text { Zone 7B } \\
6000 \text { to } 6999\end{array}$ & $\begin{array}{c}\text { Zone 8> } \\
6999\end{array}$ \\
\hline & \multicolumn{6}{|c|}{ Minimum Effective Thermal Resistance (RSI), $\left(\mathrm{m}^{2}-\mathrm{K}\right) / \mathrm{W}$} \\
\hline $\begin{array}{c}\text { Ceilings below } \\
\text { attics }\end{array}$ & 6.91 & 6.91 & 8.67 & 8.67 & 10.43 & 10.43 \\
\hline $\begin{array}{l}\text { Cathedral ceilings } \\
\text { and flat roofs }\end{array}$ & 4.67 & 4.67 & 4.67 & 5.02 & 5.02 & 5.02 \\
\hline Walls & 2.78 & 2.97 & 2.97 & 2.97 & 3.08 & 3.08 \\
\hline $\begin{array}{c}\text { Floors over } \\
\text { unheated spaces }\end{array}$ & 4.67 & 4.67 & 4.67 & 5.02 & 5.02 & 5.02 \\
\hline
\end{tabular}

Mechanical equipment minimum efficiencies are specified based on the system type (Table 9.36.3.10 in the standard), where many heating system types are acceptable, including: air/ground/water-source heat pumps (air-air, air-water, water-water), electric resistance (baseboard), electric/gas/oil/wood boilers and furnaces, and others.

$N B C 9.36$ is unique from the other standards reviewed here in that it provides separate thermal envelope component prescriptions depending on whether the building has an HRV/ERV (Subsection 9.36.2.3). Envelope component prescriptions do not differ relative to heating system type or fuel input type.

There is also a performance compliance option (Subsection 9.36.5) that allows the proposed building to be modelled relative to a reference model to control energy consumption for service water heating and space-conditioning (including ventilation). There is no distinction made between different types of purchased energy, however, it does require the HVAC and DHW system type and capacity (but not efficiency) to be the same for the reference house as for the proposed house. The rest of the prescriptions for the reference house are based on the prescriptive compliance option, and standardized modelling guidelines are provided for temperature set points, and lighting, DHW, appliance, and occupant internal heat gains. NBC 9.36 is not explicitly concerned with total energy use (EUI). The rationale is that the remaining electrical sources (appliances and lighting) have electrical efficiencies regulated on a per-appliance basis by other CSA standards. 


\subsubsection{Ontario Building Code}

The OBC Supplementary Standard SB-12 - Energy Efficiency for Housing (2017) is the only legally enforced energy standard for single-detached houses in Toronto. It is like NBC 9.36 in that it has a prescriptive compliance and a performance compliance (better than reference type) option. In addition to quantitative differences in component prescription values, it differs from $N B C 9.36$ qualitatively in that an HRV/ERV is mandatory, and a shower DWHR unit (efficiency $>42 \%$ ) is required on at least 1 of 2 showers, or 2 of $3+$ showers.

Most significantly, thermal envelope prescriptions are dependent on heating system and DHW type and efficiency and HRV efficiency (or vice versa). These prescriptions are provided as "compliance packages." For example, in Table 3.1.1.2.C of the standard (Zone 1 - Compliance Packages for Electric Space Heating), Package C2 and C3 both have electric resistance space heating, but C2 uses an HRV with a SRE 75\% and requires a ceiling insulated to R-59.9, whereas package C3 has an HRV with SRE of $81 \%$ and an R-49.23 ceiling. If an ASHP (minimum HSPF 7.1, package C4) is used, the HRV minimum SRE is only 55\%. There are also packages offering lower-performing windows, walls, and roof if, for example, the whole basement slab is insulated. There is a total of 16 prescriptive compliance packages for zone $1\left(<5000{ }^{\circ} \mathrm{C}\right.$-day of HDD). These packages have presumably been developed to balance initial construction cost with operational energy cost, or to reduce environmental harm, or peak electric demand, or some combination thereof, although the exact method by which they have been discovered is unknown.

The performance compliance option is like $N B C 9.36$ in that it requires that the proposed building "annual energy use" must not exceed that of a prescribed reference building. Since appliance and lighting loads must remain fixed for the reference and proposed buildings, it is effectively the energy consumed for HVAC and DHW, with the allowance for offsetting using onsite renewable energy generation. Although SHDI is not explicitly defined, there is effectively a restriction (relative to the reference) on this value, as described in 3.1.2.1-(6) (it is not clear if "overall thermal performance of the building envelope" includes heat recovered by the HRV):

"Where the overall thermal performance of the proposed building envelope is less than the envelope performance of the compliance package that is compared against it, the reduction in the performance level of the building envelope shall not be more than $25 \%$." 


\subsubsection{Natural Resources Canada’s R-2000 Standard}

The voluntary $R$-2000 Standard (2012) was developed by NRCan in 1982 to represent "best-in-class energy-efficient homes" (NRCan, 2018). The Standard was renewed in 2012 with energy efficiency requirements improved by $50 \%$ over the original standard to ensure it is the "leading edge of cost-effective housing technology" (NRCan, 2012). In addition to energy savings, the standard aims to provide improved comfort, health benefits, and environmental benefits including: reduced GHG, reduced water use, and recycled or low-impact building materials.

The standard contains several prescriptive requirements, such as: a maximum air leakage rate of $1.5 \mathrm{ACH} 50$, window type, and whole-house balanced ventilation with an HRV/ERV, carbon monoxide detectors, etc. However, in relation to energy performance, the standard is based on a climate-specific absolute performance target and is in this respect similar to PHIUS+. Uniquely, the annual energy performance target is only for heat sources: space heating and DHW. It can be useful to isolate these end uses, as they constitute the bulk of fuel use in houses (and in many cases GHG emissions), and are candidates for a. fuel conservation, or b. heating electrification. This method also avoids the obfuscatory effect caused by pooling fuels and electricity into a single value.

The annual energy target is determined as the sum of the space heating and DHW energy consumption, where each end-use target is determined using an equation. In the case of space heating, the target is determined based on the HDD for the location, and the interior heated volume of the use (rather than floor area), and for DHW it is based on the local water mains temperature. Internal gains, DHW draws ( $225 \mathrm{~L} /$ day at $\left.55{ }^{\circ} \mathrm{C}\right)$, temperature set points, and other modelling criteria are set by the standard. See the equation below for calculating the annual space heating energy consumption (not space heating thermal energy demand):

$$
Q_{s}=0.5 \times S \times\left(49 \times \frac{\mathrm{DD}}{6000}\right) \times\left(40+\frac{\mathrm{V}}{2.5}\right)
$$

Where:

$\mathrm{S}=4.5 \mathrm{MJ}$ for fuel-fired space heating systems, or

$\mathrm{S}=1.0 \mathrm{kWh}(3.6 \mathrm{MJ})$ for electric space heating systems

DD = Celsius heating degree-days for the locality

$\mathrm{V}=$ Interior heated volume, including basement $\left(\mathrm{m}^{3}\right)$ 
Somewhat similar to $O B C S B-12$, the energy target is also dependent on the heating/DHW system fuel type. Note that the equations have been adapted from the original version only by multiplying them by a factor of 0.5 . It is likely that the original fuel-specific $S$ factors were developed simply to address the lower efficiency of typical boilers and furnaces at the time. In this sense they are poorly suited to modern high-efficiency boilers, furnaces, and water heaters. However, the $S$ factors somewhat address the price differential between natural gas and electricity, by potentially driving better thermal envelopes in the case of electric resistance heating (but not in the case of electrically-driven heat pumps). The use of a heat pump could enable the substantial loosening of the enclosure performance down to the local code-compliance backstop. It can therefore be said that the $R-2000$ standard encourages high performance building enclosures, or the use of heat pumps, but not both together.

Table 2-6 illustrates how the thermal envelope required design/performance is affected based on mechanical system type and efficiency (if at all), as well as maximum air leakage requirements prescribed by each standard. For performance-based metric differences, see Table 2-3. Note that the fuel-specific energy target for $R-2000$ can affect either heating and DHW mechanical system efficiencies, or thermal envelope performance. While PHIUS+ performance targets are independent of mechanical system type and efficiencies, the "primary energy use" target can create a constraint on mechanical system efficiencies, which may encourage the use of one type over another (e.g., heat pump over gas furnace). The table holds true for both prescriptive and performance compliance options for $N B C 9.36$ and $O B C S B-12$.

Table 2-6 Qualitative Differences and Airtightness Prescriptions

\begin{tabular}{|c|c|c|c|}
\hline Standard & Envelope-mechanical dependence & Mandatory HRV & ACH50 \\
\hline NBC 9.36 (2015) & HRV versus no HRV & 3.2 \\
\hline OBC SB-12 (2017) & HVAC and DHW system type and efficiency & $\checkmark$ & 2.5 \\
\hline R-2000 (2012) & Heating and DHW fuel type & $\checkmark$ & 1.5 \\
\hline PHIUS+ (2015) & None & $\checkmark$ & $0.88^{*}$ \\
\hline
\end{tabular}

* The PHIUS+ air leakage requirement is $0.05 \mathrm{cfm} / \mathrm{ft}^{2}$ gross envelope area. The value shown here is specific to the single detached house modelled in this thesis.

\subsubsection{Net Zero Carbon}

Net Zero Carbon is calculated based on operational GHG emissions, both direct and indirect, of a building. However, the concept of net-zero emissions is not as straightforward as netzero energy, as the question of how to account for GHG credit from renewable energy is not clear. 
The Pembina Institute provides a helpful clarification of the relationship between NZE and NZC buildings in Figure 2-11. The "Zero Carbon" definition is for a building connected to an electric grid that never uses fossil fuel generation, which is an exceptional case. For this report NZC status corresponds specifically to all-electric NZC buildings (no on-site combustion of fossil fuels).

\section{Types of green buildings}

\section{How a highly energy efficient building can use and produce energy}

Limitations

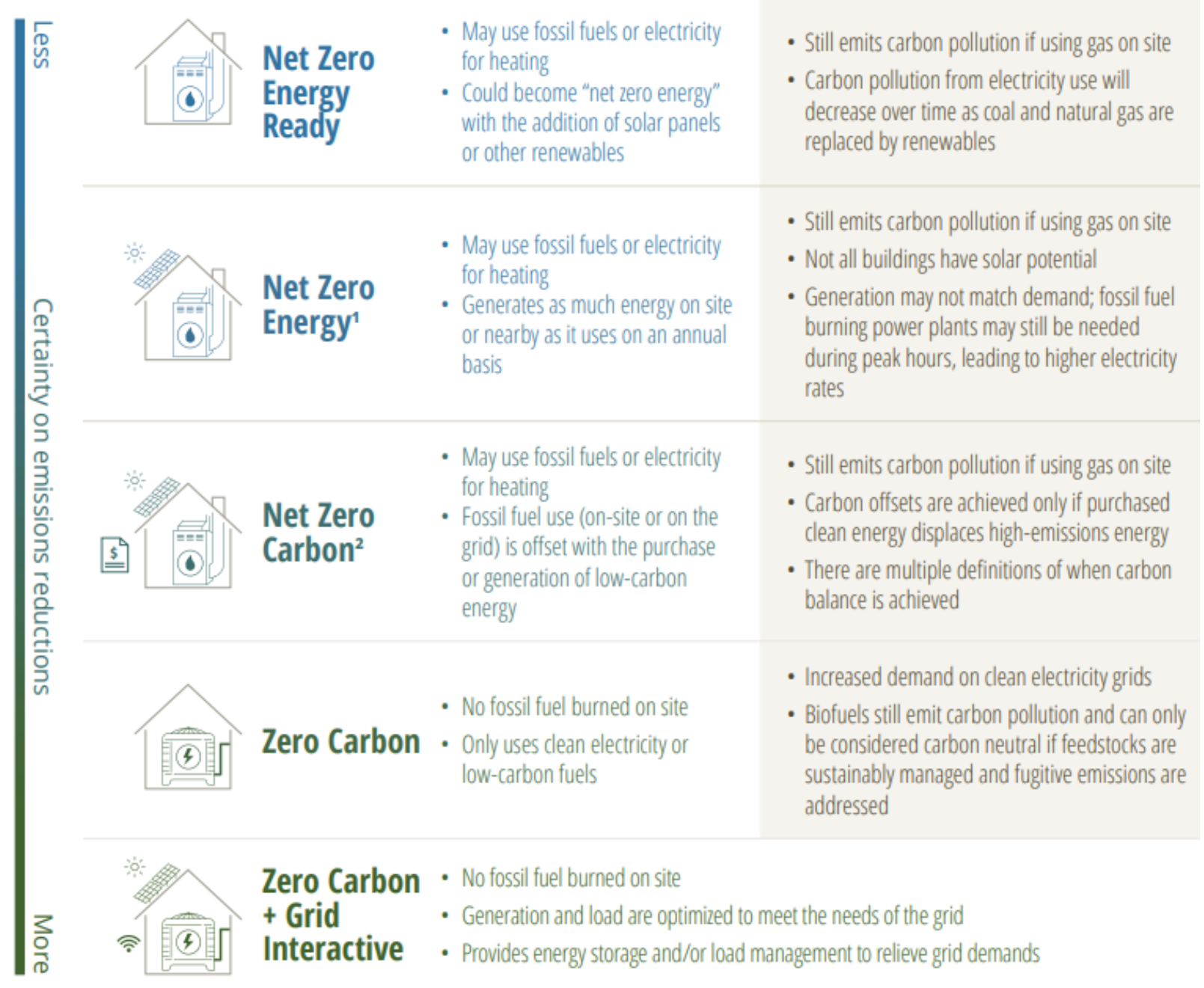

Figure 2-11 Summary of NZE and NZC building types (Pembina, 2018)

The TGS v3, which is in line with the City of Toronto/TAF Zero Emissions Buildings

Framework, provides a pathway for achieving NZE buildings by 2030. It also aims to reduce the 
GHGI of buildings by 2030 to zero, which is in effect a NZC building. The equation used by the $T G S v 3$ for calculating GHGI (in Subsection 2.3.1 of this report) is applied separately for each type of purchased energy used (e.g., electricity and natural gas). Emissions factors for each energy type are sourced from ECCC's NIR. The GHG offset by renewable energy generation (whether from onsite generation - exported or self-consumed - offsite generation, or credit procurement) is not calculated directly, but rather as an energy offset, as stated in Section 5.2.1 of the Energy Efficiency Report Submission and Modelling Guidelines, wherein: "renewable energy generated on-site may reduce the TEUI and subsequently the GHGI" (TGS Guidelines, 2018). Given the different EFs of different energy sources, this procedure would presumably be conducted separately for each source, although this is not clear from the document. Renewable electricity generation would then offset electricity use and would therefore be allocated an EF equivalent to the negative of the electricity annual average.

The GHG accounting procedure for renewable exports is not well defined in any of the reviewed documents. The CaGBC Zero Carbon Buildings Framework says only that, "A highly energy efficient building that produces on-site, or procures, carbon-free renewable energy in an amount sufficient to offset the annual carbon emissions associated with building operations" (CaGBC, 2016), whereas the Architecture 2030 Zero Net Carbon Building suggests "A zero net carbon balance is achieved when an equivalent unit of carbon-free renewable energy is produced (on or off-site) to offset each unit of fossil fuel energy used by the building" (Architecture 2030, 2016). Similarly, the City of Vancouver Zero Emissions Buildings Plan states: "When a building is required to achieve zero emissions if the electricity grid is not $100 \%$ renewable then the buildings will be obligated to install an onsite renewable energy system (or secure a share of Vancouverbased renewable power systems where on-site systems are not viable) that produces enough renewable energy to offset the small portion of grid power that comes from fossil fuel based generation" (Vancouver, 2016).

The Vancouver method would suggest that one would be required to know, not the EF of the grid, but the percentage of annual electricity generation derived from fossil sources for the whole grid. The main problem with this method is that it does not distinguish between different types of fossil fuel generation (i.e., it values renewable exports that offset coal generation identically as that which offsets natural gas generation, even though the two have significantly different emissions factors). 


\section{Marginal Emissions Factors}

One way to account for GHG offsets from renewable generation is to use a separate, marginal EF applied to generation. Marginal EFs represent the GHG intensity of generators "on the margin" required to follow the load on the grid as well as satisfy peak demand. It is a more accurate way of calculating "avoided emissions," such as from renewable generation. Conversations with modelers from $C a G B C$ confirmed that this is the current (unofficial) industry practice for NZC status and was used on the Stantec Evolv1 building in Waterloo, Ontario. It is derived from the World Resources Institute's GHG Protocol Scope 2 Guidance (WRI, 2015). Indirect GHG emissions (from electricity) are determined using the annual average EF for the specific provincial grid (from ECCC's NIR), whereas emissions offsets from PV are counted using the marginal EF for that grid. These factors are from Figure 9 of the Energy Star Portfolio Manager Greenhouse Gas Emissions Technical Reference (Figure 2 of that report provides a median natural gas EF for Canada of $52.5 \mathrm{~kg} \mathrm{CO} 2 \mathrm{e} / \mathrm{MBTU})$. See Figure 2-12 for average and marginal EF values for five Canadian cities.

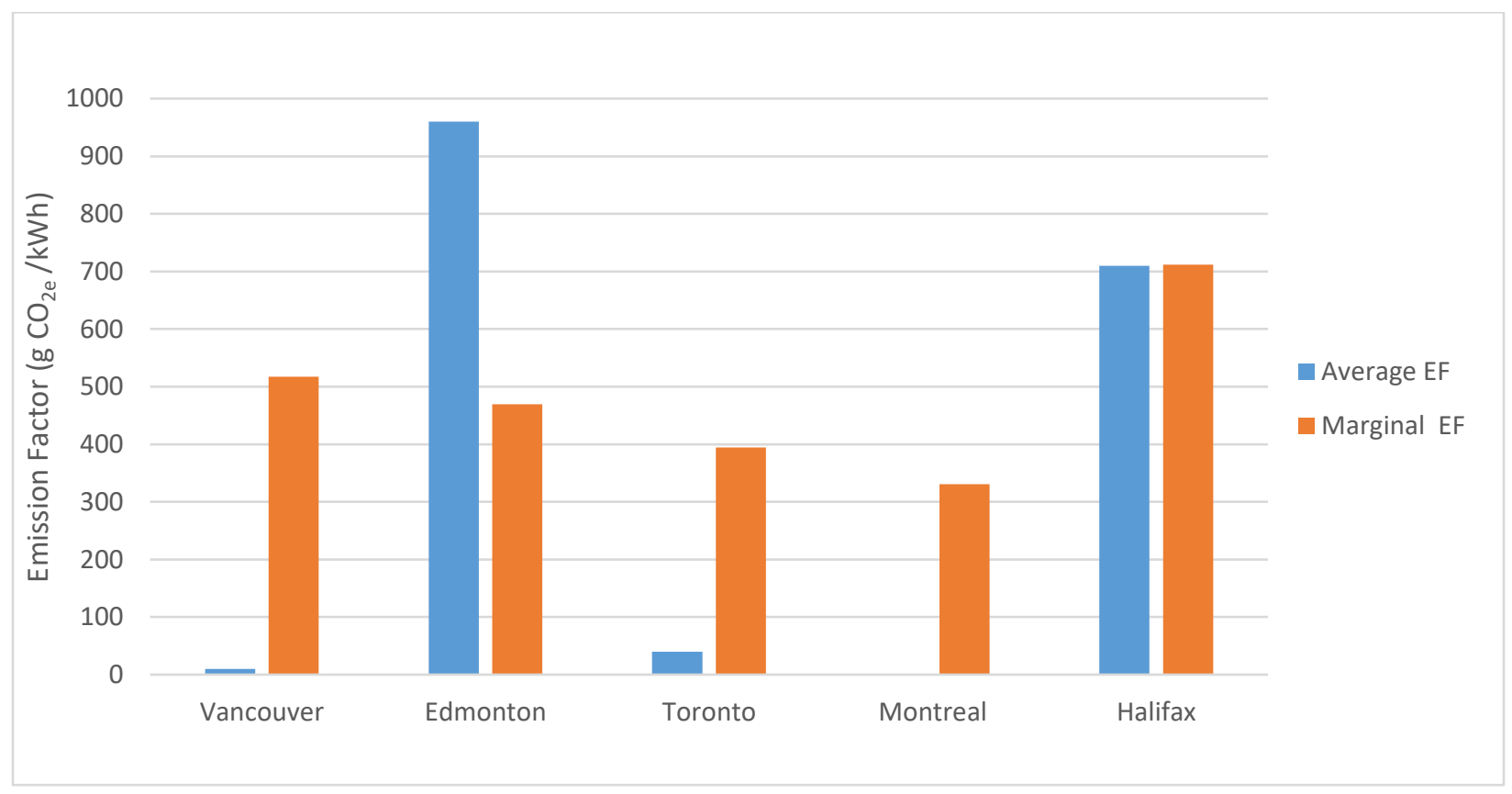

Figure 2-12 Provincial electric grid annual emission factors [marginal: (Energy Star, 2017), average: (NIR, 2018)]

Using this method, NZC status is determined using the following equation:

$$
\text { Indirect Emssions }=\text { Emissions Offsets }
$$




$$
\begin{gathered}
\text { Electricity }_{\text {gross }} \times E F_{\text {average }}=\text { Electricity }_{P V} \times E F_{\text {marginal }} \\
\frac{E F_{\text {average }}}{E F_{\text {marginal }}}=\frac{\text { Electricity }_{P V}}{\text { Electricity }_{\text {gross }}}
\end{gathered}
$$

Where:

Electricity $_{\text {gross }}=$ annual electricity consumption of building

Electricity $_{P V}=$ annual electricity generation required from PV to achieve NZC

Two advantages of this method are that:

1. It captures the difference in EF of different fossil fuel generators (unlike the Vancouver method), and

2. It incentivizes renewable generation more for grids with a high average EF than for grids with a low average EF (unlike the TGS method), which is intuitively correct. For example, the average EF: marginal EF ratio for the Nova Scotia grid, which is predominantly coalfired, is $99.7 \%$, whereas for Quebec, which is predominantly hydroelectric, it is $0.5 \%$ (i.e., a NZC building in Halifax must be NZE, whereas a NZC building in Quebec requires only negligible renewable generation).

The Atmospheric Fund's A clearer view on Ontario's emissions: Practice guidelines for electricity emissions factors provides a thorough analysis of the methodology used in calculating annual average and marginal EFs for Ontario using hourly average and marginal EFs. It notes that accurate annual average values depend on the specific building's electric load profile, while annual marginal values for calculating avoided emissions vary by specific electrical equipment consumption/generation profiles. It is calculated that the marginal EF for typical solar PV generation is $170.4 \mathrm{gCO}_{2 \mathrm{e}} / \mathrm{kWh}$, as opposed to the Energy Star value of $394.3 \mathrm{gCO}_{2 \mathrm{e}} / \mathrm{kWh}$. For achieving NZC status in Ontario, this represents the difference between offsetting $23 \%$ of annual site energy use with renewables, versus only $10 \%$, respectively. The hourly EF data that TAF analyzed for Ontario is not available in all provinces.

While the site NZE approach incentivizes efficiency and substantial renewable generation in all locations, the NZC approach accounts for the carbon intensity of the electricity grid. So long as the carbon accounting for electricity use is accurate, the NZC target will result in more economically optimal GHG reduction. As an example, consider a NZE and NZC building in 
Quebec, and assume both are all-electric. The average EF of the grid is so low that indirect emissions are negligible. Therefore, an electric building in Quebec is a NZC building. While this might be considered an "unfair" advantage for high performance/green building designers in Quebec relative to Alberta, it nonetheless achieves the true goal of environmentally responsible building design. Put another way, there is no GHG reduction benefit of adding solar PV to the building in an amount to meet the NZE target, since it will simply be offsetting clean hydroelectric power. Thus, in such a scenario, the value of solar PV should be assessed purely on an economic basis.

\subsection{Life-Cycle Cost Optimization}

By combining building energy simulation with cost data and an optimization algorithm, it is possible to investigate many design parameter options for many building parameters. As opposed to a parametric analysis, an optimization only simulates a subset of building design variants within the total solution set. This enables the investigation of more design options, while ensuring the optimization can be simulated within a reasonable time (i.e., reduce computational requirements). There are a variety of algorithms available for multi-objective building design optimization, but they share the commonality of efficiently identifying the Pareto front between two objective functions (e.g., LCC, site/source energy, GHG). Generally, this front can be said to be limited by the local economic reality (energy costs, construction materials and labour costs, inflation rate, discount rate, mortgage interest rate), and physical constraints (local climate, building physics, mechanical and electrical efficiencies, and purchased energy carbon intensities).

The general design optimization problem relating to NZE buildings is illustrated in Figure 2-13, where the life-cycle costs (LCC) versus percent energy savings optimization curve is represented by the "Total Cost" trend line. The so-called "sweet spot" referred to in ClimateSpecific Passive House Standard (Wright, Klingenberg, \& Pettit, 2015) for the development of PHIUS +2015 is the region between the total cost minimum, and the "optimal efficiency upgrades with zero extra cost" point in Figure 2-13 (Dembo \& Fung, Review and Economic Feasibility Study of the Currently Practiced New Housing Constructions in Ontario, 2012). This region represents the zone on the optimization curve wherein maximum efficiency can be achieved while ensuring either equal or lower total costs compared to the baseline house design. 


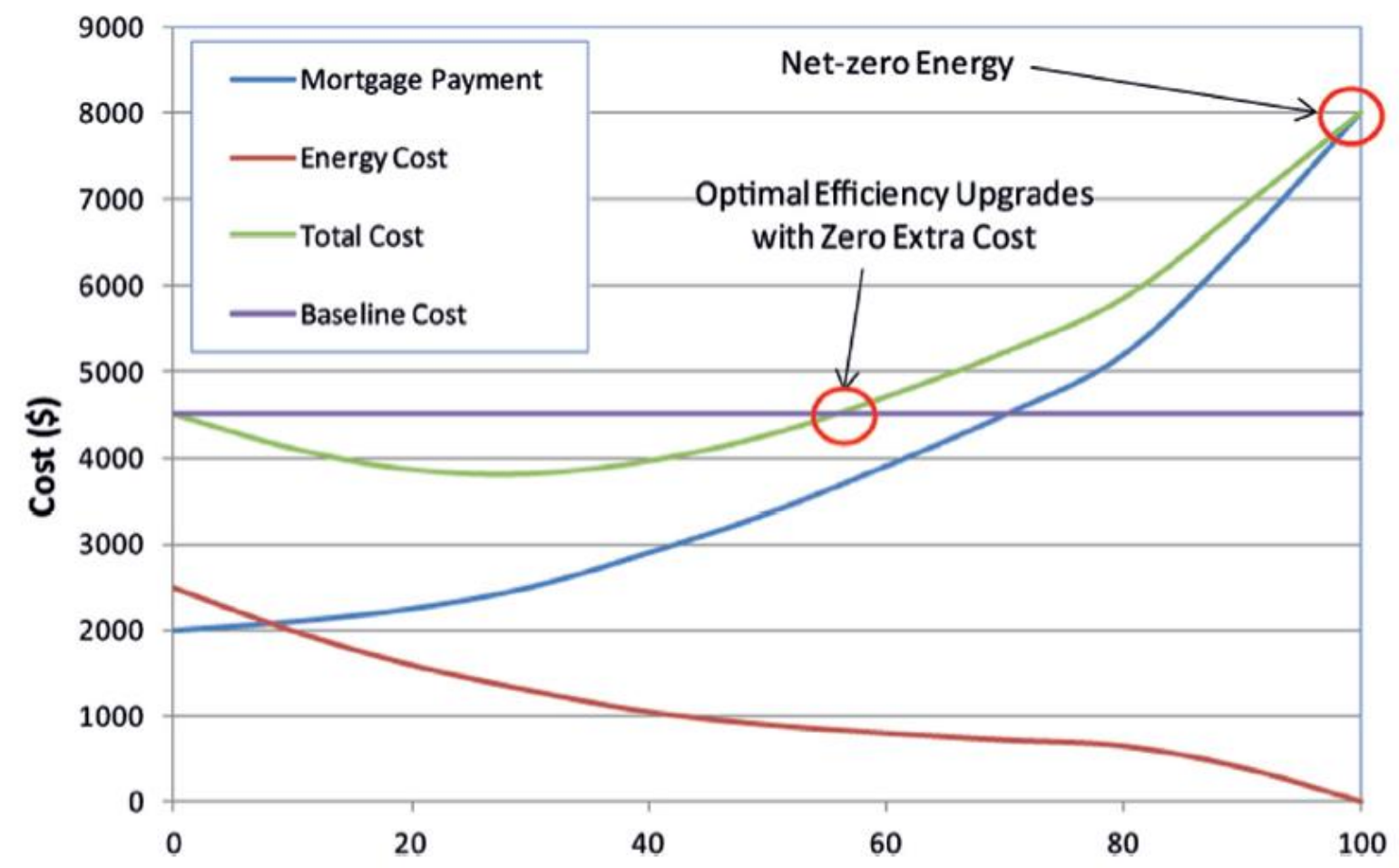

Figure 2-13 Conceptual optimization of NZE building (where $x$-axis is \% energy savings) (Dembo \& Fung, 2012)

In the case of a NZE target (100\% energy savings) on an annual basis, a multi-objective optimization problem becomes a single-objective optimization problem, in which the objective is to minimize LCC while satisfying the NZE definition (Bucking, Athienitis, \& Zmeureanu, 2014). The same is true if the goal is minimum LCC, where the only solution is the global minimum LCC output design, and the resultant energy (or GHG) savings is incidental. To find the Pareto/optimal front, cost is plotted against annual energy savings, where any given point on the plot represents a building design.

Building Energy Modelling software (i.e., EnergyPlus, TRNSYS, eQuest, HOT2000, WUFI Plus, etc.) is a powerful design tool for either individual building design or building energy standard design, however it is important to note that such software falls into two general categories: evaluative tools, and guidance tools. While evaluative tools are very common among energy modelers, they rely heavily on expertise and trial-and-error (O'Brien, Kesik, \& Athienitis, 2014) (O'Brien, Athienitis, \& Kesik, 2011).

A common guidance-focused tool for low-rise residential buildings is the U.S. DOE'S BEOpt program (NREL, 2016). NZE buildings have a point at which increased renewable energy 
generation becomes more economical than increased efficiency measures (the take-off point). As the cost of PV panels continues to decrease, or the cost of new efficiency technologies decreases, this optimal trade-off point will shift unpredictably (Dembo, Khaddad, \& Fung, 2013). It may therefore be counterproductive to prescribe specific efficiency details or specific energy generation quotas, but instead to simply require overall NZE or NZC performance.

BEopt, which is specialized for low-rise residential buildings, enables the user to create a building energy model and select several design parameter options for each of several design parameters. Each option, for example: "R-10 XPS" exterior insulation, includes performance data, material and labour cost data, and a material lifetime. This allows the creation of both an energy model and an economic model, to determine the energy performance and LCC of each building design variant simulated, i.e., every individual point on the optimization plot. EnergyPlus is the simulation engine used by BEopt, in which every design variant (determined by the BEopt algorithm based on the set of input parameter options selected by the user) is simulated over one year using 10 minute time-steps. Based on the design variant's input parameters and it's simulated performance, BEopt determines a new design variant to simulate, and the procedure repeats hundreds or thousands of times to create the optimization plot. The algorithm used by BEopt is "modified sequential search technique." This is a basic sequential search technique, that has been modified using three "speed techniques" allow BEopt to skip certain design variants unlikely to be near the Pareto front, thereby reducing the overall computation time. However, because this can increase the risk that the true Pareto front will not be identified, it has been further corrected with four "accuracy techniques" that provide back checks on additional design variants, without substantially increasing the number of variants simulated (Horowitz, Christensen, Brandemuehl, \& Krarti, 2008).

Figure 2-14 shows results from a study by Bucking et al. (2014) where the EcoTerra house in Montreal is assessed using BEOpt (Bucking, Athienitis, \& Zmeureanu, 2014). The optimization function selects energy models with a high probability of being nearer to the Pareto front. There are 25 variables available for adjustment within this optimization including PV generation, and it also accounts for time of use pricing and feed-in tariffs. 


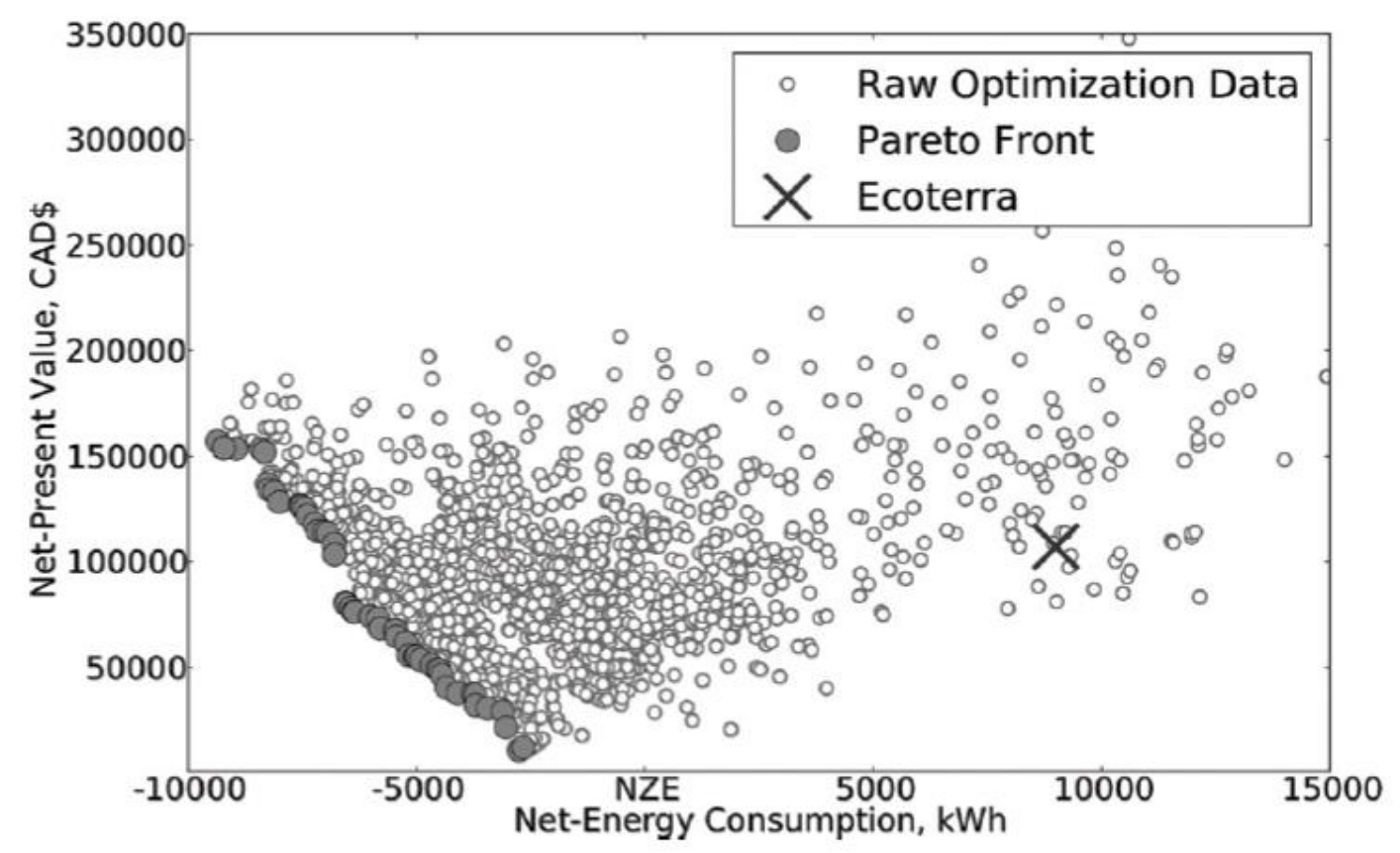

Figure 2-14 Multi-objective complete redesign of EcoTerra home (Bucking, Athienitis, \& Zmeureanu, 2014)

From Figure 2-14 for this house and the variables available, the Pareto front arises in the net-positive energy range. It can also be seen that if given complete freedom of design, the BEM + optimization software can be very effective in identifying optimal designs. Future work identified by Bucking et al. includes: to gain a better understanding of initial costs and construction costs, and to identify most appropriate incentives for reducing either initial or lifecycle costs to inform policy (Bucking, Athienitis, \& Zmeureanu, 2014).

A similar study to Bucking was conducted by Tokarik and Richman (2016) to determine the "Life cycle cost optimization of passive energy efficiency improvements in a Toronto house" (Tokarik \& Richman, 2016). While the relevance of this study is limited in that it assesses only improvements to an existing home and only passive conservation measures, it is nonetheless informative because it focuses attention on passive design and uses a similar optimization methodology to Bucking et al. (2014). Tokarik and Richman conclude that results "suggest that the current $\mathrm{PH}$ standard does not coincide with the economic minimum for the local economic and environmental climate," although it must be reiterated that retrofitting an existing home allows a limited application of the $P H$ methodology (Tokarik \& Richman, 2015).

Tokarik et al. made the assumption that "the Passive House standard should be set at the point of "the most energy efficient house design that is cost-competitive'," and commented that 
"The actual financial relationship between initial capital cost and long term savings for energy efficient homes is less obvious because of the variability in market construction rates, diminishing returns on building upgrades, mortgage rates, fuel price escalation, weather patterns, housing maintenance, and occupant behavior" (Tokarik \& Richman, 2016). Tokarik et al. determined LCC by summing all cash flows for each year of the financial project, converting each year's cost into present dollars according to the discount rate, and summing those costs. This generated the plot in Figure 2-15 based on various passive conservation measures considered. The equation considers: asset costs (i.e., mortgage), energy costs including generation, operation, maintenance, and replacement costs, and inflation.

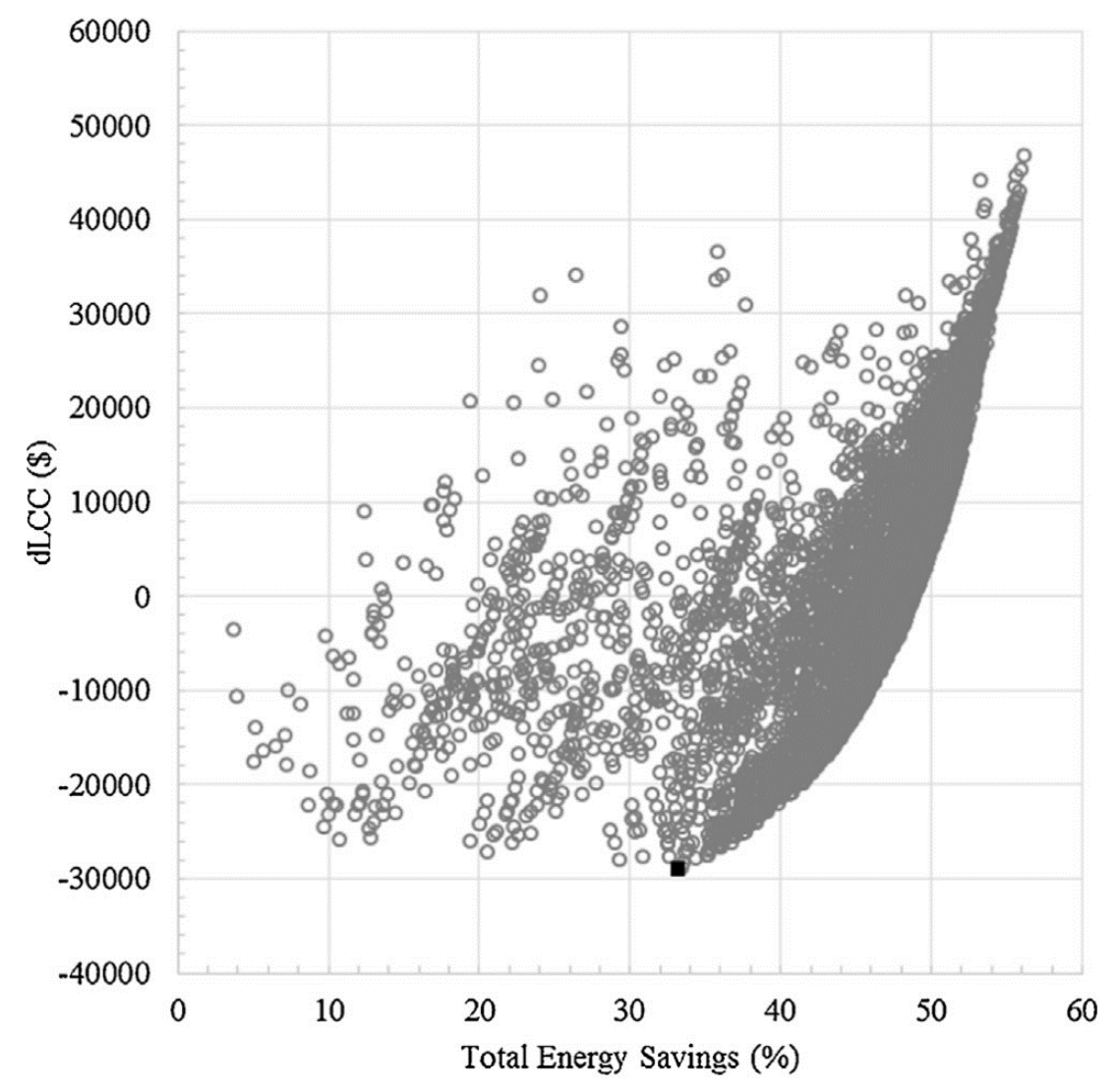

Figure 2-15 Optimization results of improvements showing energy savings versus change in life cycle costs and least cost improvement (Tokarik \& Richman, 2016)

Based on the Pareto curve identified using the measures considered, $P H$ was not achievable. From the least cost solution of 33\% energy savings over minimum building code requirements Tokarik et al. recommends a $P H$ standard of: $23.2 \mathrm{~W} / \mathrm{m}^{2}$ peak heating load, $22.5 \mathrm{~W} / \mathrm{m}^{2}$ peak cooling load, $42.4 \mathrm{kWh} / \mathrm{m}^{2}$-yr annual heating demand, and $3.6 \mathrm{kWh} / \mathrm{m}^{2}$-yr annual cooling 
demand for a Toronto climate. Note that these values are substantially higher than those specified by either $\mathrm{PH}$ standard (Table 2-4).

\section{Summary}

Though PHIUS+ and NREL have released a climate-specific standard there is still limited data on buildings that have followed it, and thus it is not yet validated. While it is founded upon multi-objective optimization (BEOpt), it introduces complexity as well as rigidity to the design process (even as it brings some flexibility as compared to the original $P H$ standard), rather than allow for ultimate flexibility.

PHIUS+ requires experimental data to be evaluated in Canadian climates. Using building energy modelling software combined with an optimization algorithm, it is possible to evaluate the relevance and usefulness of the standard. Common requests for future work include: a better understanding of occupant behavior during energy modelling; better data regarding initial costs and in particular constructions costs, such as understanding the incremental costs of increased airtightness of the envelope; further reduction in costs of NZE buildings by means of better integrating whole systems design and accelerating the NZE experience curve (Athienitis \& O'Brien, 2015) (Bucking, Athienitis, \& Zmeureanu, 2014) (Tokarik \& Richman, 2015).

Multi-objective whole building optimization studies reviewed evaluate building designs using a cost metric versus energy consumption. They do not explicitly evaluate GHG emissions, nor do they evaluate multiple heating system types or account for the carbon intensity of the electricity source. 


\section{Methodology}

The building design optimization objectives have been chosen based on the premise that energy demand (EUI and SHDI) is merely an intermediate concern associated with the 2 primary concerns of (see Figure 3-1):

1. Building LCC (accounting for initial and operational—i.e., energy cost), and

2. Building operational GHG emissions (both direct and indirect)

In addition to supporting evidence for this rationale provided in Chapter 2, it is worth considering the basic question: what is the purpose of building energy standards? The NECB 2015, on which $N B C 9.36$ is modeled, provides some insight where it states that, as an "objective based code," its purpose is to limit the risk that the design/construction of the building will have an "unacceptable effect on the environment," and to specifically limit the "excessive use of energy."

Insofar as the use of energy has negative effects on the environment, the GHG emissions from the combustion of fossil fuels, onsite and offsite, is of primary concern. However, different energy sources do not have equal carbon intensities, therefore energy use does not necessarily correlate to GHG. Additional concerns regarding the "excessive use of energy" could include energy costs, but again different energy sources can have very different energy costs, resulting yet again in poor correlation. Other issues might include energy independence and sovereignty, and peak electric demand implications for dispatchable generation, transmission, and distribution capacity. While peak electric capacity is not an explicit objective in this study, it is assessed during post-processing of results. 


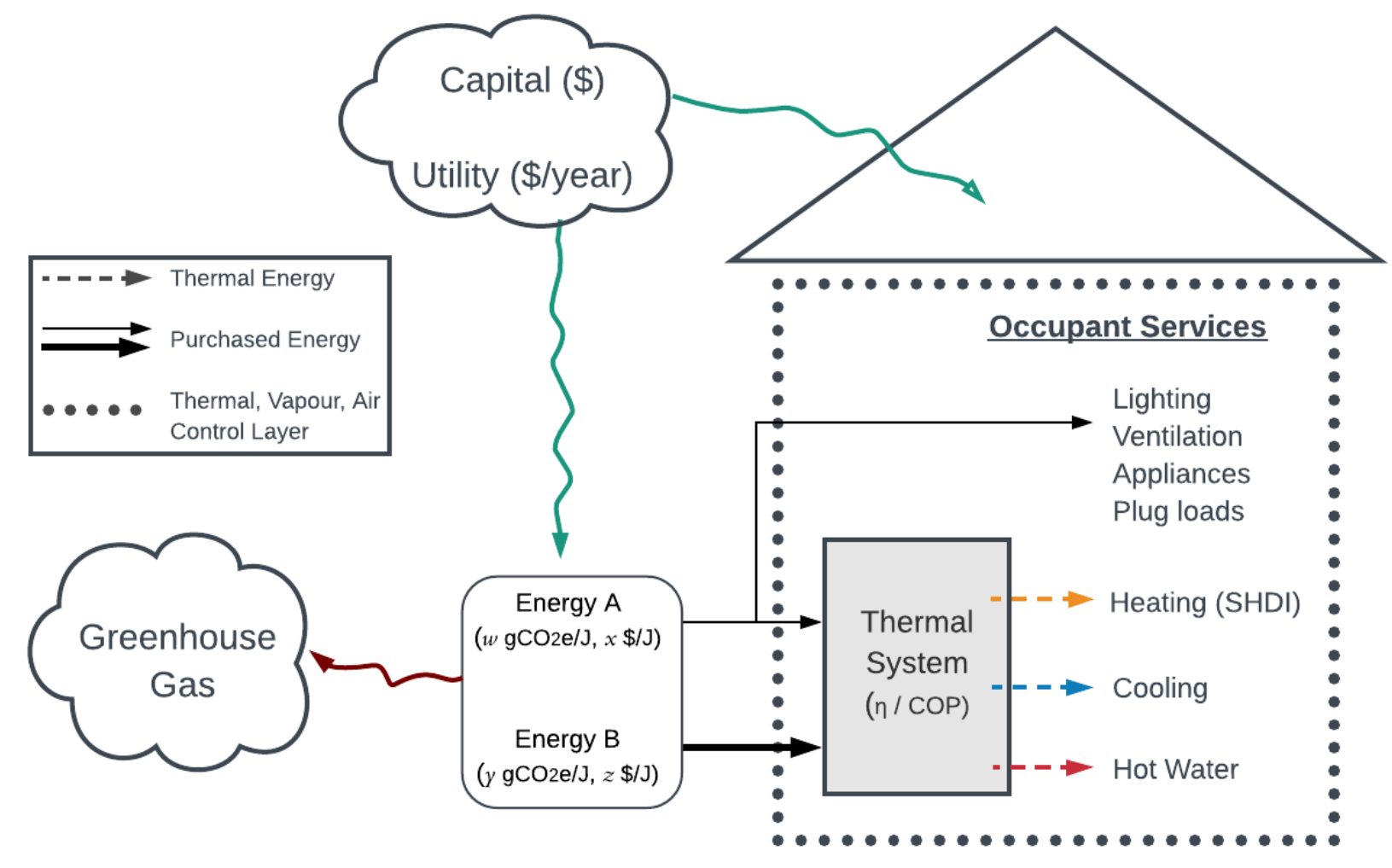

Figure 3-1 LCC vs GHG optimization rationale

Objectives identified in Section 1.1 are to be answered based on the whole-house optimized life-cycle least-cost design, separately for 5 locations across Canada. The resultant least LCC electric and NZC designs will be compared to an optimized gas-heated house design. In all locations the reference design is a gas-heated climate-specific minimum code-compliant design based on the $N B C$ 9.36. Location-specific factors affecting optimization results include:

- Climate

- Energy Prices

- Construction Costs

- Electricity EF

\subsection{Whole-Building Optimization}

Optimizations for an archetype single-detached house are performed using BEopt software by simulating a large set of building energy model variants. While the Pareto front is determined for LCC vs annual GHG, the desired resultant designs are the minimum cost, i.e., the global 
minimum. The NZC optimizations are an exception, wherein the least-LCC design to achieve a GHGI $=0$ is selected manually from the Pareto front.

\subsubsection{Thermal System-Specific Optimization}

Partly due to software limitations, and partly to allow the thorough investigation of the relationship between heating system type and optimal thermal envelope design (objectives 2.a, b), the archetype house model is optimized separately for each thermal system type. All models have a dedicated outdoor air ventilation system (DOAS), enabling the isolation of the thermal system as a set of interacting components, including: space heating (main and supplementary), space cooling, space conditioning delivery (ducting), and DHW production. The isolation of this system enables comparison with other systems on a capital, operational, and LCC basis, as well as its effect on optimal enclosure design. Equations 3-1, 3-2, and 3-3 illustrate the relationship between the thermal envelope, thermal system (heating), and purchased energy governing the annual heating cost (operational only).

Thermal Envelope:

$$
\text { Annual Heating Demand }\left(\frac{k W h_{Q}}{y}\right)=\operatorname{SHDI}\left(\frac{k W h_{Q}}{m^{2} \cdot y}\right) \times F F A\left(m^{2}\right)
$$

Mechanical Heating System:

$$
\text { Price of Heat }\left(\frac{\$}{k W h_{Q}}\right)=\text { Purchased Energy Price }\left(\frac{\$}{k W h_{\$}}\right) \div \eta\left(\frac{k W h_{Q}}{k W h_{\$}}\right)
$$

Passive-Active Relationship:

$$
\begin{aligned}
\text { Annual Heating Cost }\left(\frac{\$}{y}\right) & =\text { Annual Heating Demand }\left(\frac{k W h_{Q}}{y}\right) \\
& \times \text { Price of Heat }\left(\frac{\$}{k W h_{Q}}\right)
\end{aligned}
$$

Where:

$k W h_{\$}=$ purchased energy unit (electrical or chemical)

$k W h_{Q}=$ thermal energy unit

$\eta=$ system thermal efficiency (or COP in the case of heat pumps) 
Consider the example where there are two heating systems: system A and system B, with the same initial cost and replacement rates, but A has a lower operational price of heat than B. If two separate whole-building optimizations are conducted, one with heating system A, the other with heating system B, the resultant (least LCC) house design for system B will likely include a higher performing thermal envelope (i.e., reduced SHDI), thereby reducing the heating cost. In this example it is evident that the building with system $\mathrm{A}$ is preferable to that with system $\mathrm{B}$, however, if both capital and operational cost of heat for system A differ, the economically preferable system is not immediately obvious, nor is the effect that it will have on optimal envelope design. The problem is further complicated by capital and operational interactions between the heating system and other components of the thermal system.

Figure 3-2 illustrates the relevant interactions between the thermal system components. For the models containing a HPWH, DHW production interacts with space conditioning by generating an all-year space cooling effect, since the heat pump is using the ambient indoor air as the heat source.

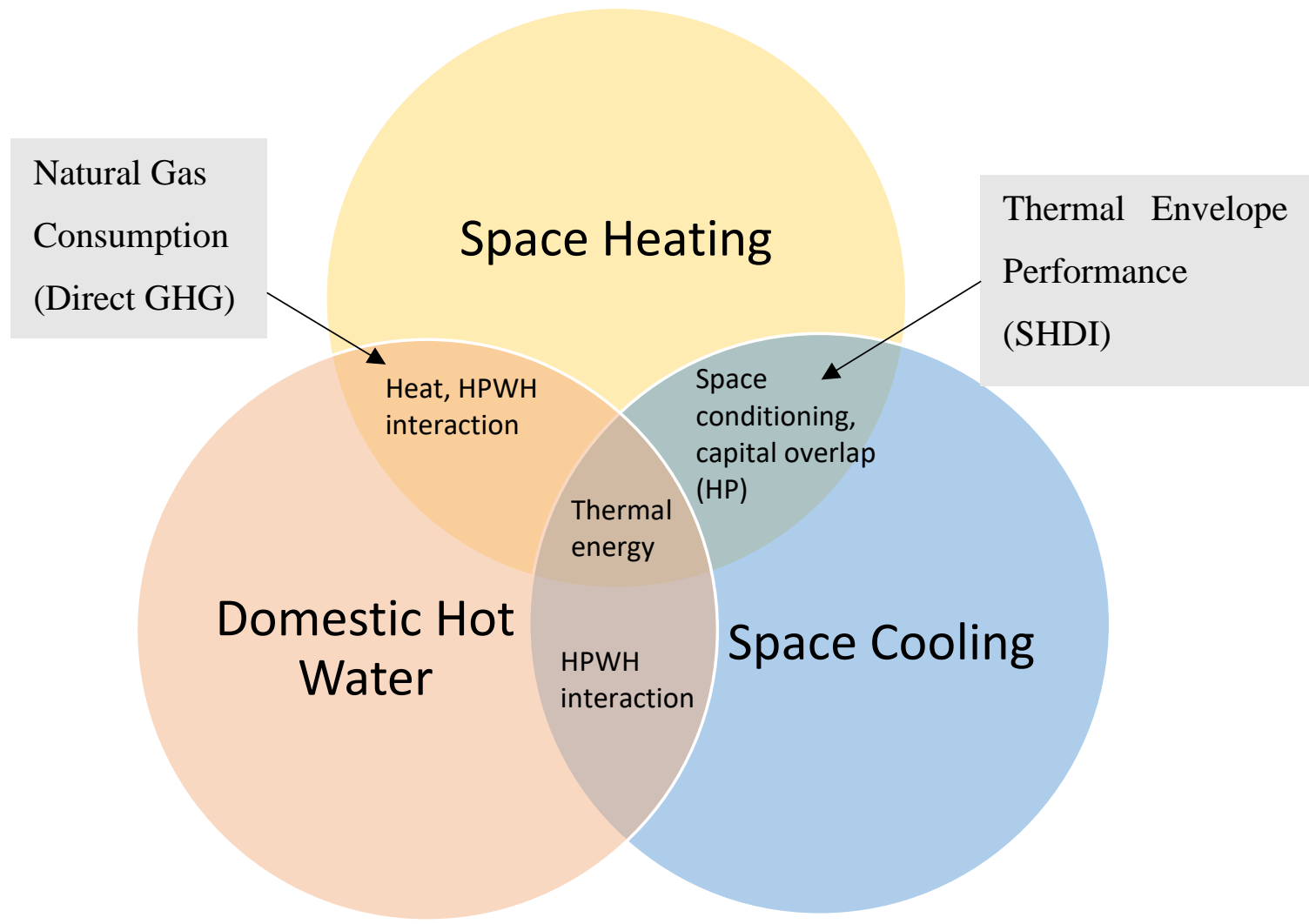

Figure 3-2 Active thermal system capital and operational interactions 
Six different thermal system configurations are investigated in separate optimizations (see Figure 3-3 for list by names - detail is presented in Chapter 4). Note that, operationally, different heating systems (space heating and DHW) can affect GHGI, EUI, and operational costs due to: input energy source and/or system efficiency (which can be energy source-dependent, e.g., only heat pumps, which use electricity, can have a COP>1). Additionally, some configurations can provide significant capital savings, for example if they: do not require ducting, or a single piece of equipment provides multiple services (all heat pumps in the study provide both space heating and cooling).

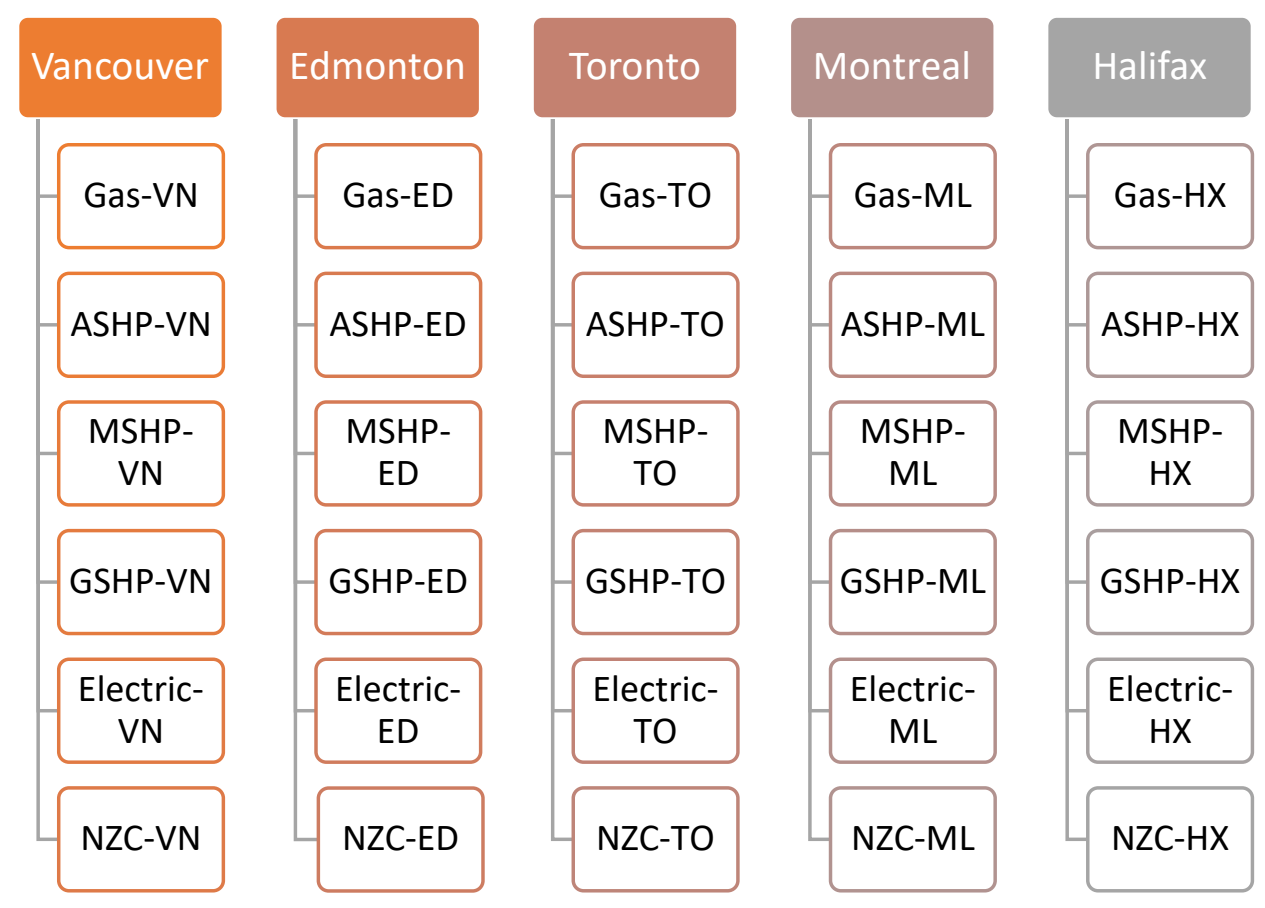

Figure 3-3 Optimization schedule by location and thermal system type (NZC is the overall least LCC allelectric design $+P V)$

In addition to the optimization study, it is in some instances necessary to conduct parametric and sensitivity analyses by isolating specific design parameters. This is useful in gaining a more detailed understanding of the performance of each thermal system, and its effect on the thermal envelope optimal design. Where such detailed manual analyses are useful, the Toronto models are used as the case study.

\subsubsection{Building Enclosure Thermal Performance}

Building enclosure component options (thermal resistance, air leakage, window type, WWR) are investigated to determine optimal whole-house designs separately for each thermal 
system type, and each location. The lower limit option for each component is defined by $N B C$ 9.36, whereas increments and upper limit options are selected based on available realistic options and engineering judgement (see Chapter 5). An effort has been made to ensure enough range and granularity of component options to determine the true Pareto front, while avoiding excessive computation time. Building enclosure option inputs are unchanged for each thermal system-type optimization.

\subsubsection{Electrification of Heating}

Only the "Gas" optimizations (and the Reference model) consume natural gas, with all other models being fully electric. Given the uncertainty associated with the GHG accounting of renewable energy generation offsets (see Subsections 2.2.3 and 2.3.7), this study prioritizes direct (onsite) GHG reduction, which can be calculated with a high degree of certainty, over indirect (offsite) GHG reduction. That is, renewable generation capacity for achieving NZC is added only to all-electric designs. Additional motivation for this approach is due to the very low electricity EF in several Canadian provinces. The relative merit of prioritizing full electrification is post-assessed by location, where electricity price and EF play an important role.

\subsubsection{Onsite Renewable Energy Generation}

All distributed (renewable) energy generation is from roof-mounted PV. Due to limitations with electricity input EF in BEopt (cannot input a separate marginal EF for PV generation), the NZC optimizations are performed as LCC versus site energy, and the optimal design is selected from the Pareto front based on the PV generation versus gross consumption ratio necessary to achieve NZC for the electric grid in question (see Subsection 2.3.7 for GHG accounting method for PV offset).

\subsection{Scope of Work}

The optimizations in this study contain fixed values over time for: electricity EF, inflation rate, mortgage interest rate, discount rate, and mechanical equipment efficiencies. Additionally, equipment replacement costs and energy prices are assumed to increase with inflation. Studies are limited to new construction in cold climates. 
Further limitations of this thesis are best defined by what it is not:

1. A GHG life-cycle assessment that accounts for the embodied energy or carbon of the building materials,

2. Universally applicable to all residential buildings, for example, existing houses or new multi-unit residential buildings,

3. A cost-benefit evaluation of individual energy conservation measures and their impact on building performance and economics,

4. An optimization of the operation of houses. Like building energy standards, the focus is on the installed components and hardware, not on control strategies. 


\section{Building Energy Model}

Any model input/output information not presented in this document can be found in the electronic BEopt project files available in the Appendix. The chapter establishes the "Reference" design model inputs as well as the specifications for each of the thermal systems modelled in the whole-building optimizations in Chapter 6. This chapter is focused on energy performance, with LCC and GHG results from the optimizations introduced in Chapter 6.

\subsection{Model House Description}

Due to the computational and time resource necessary to location-based and thermal system-based optimizations, only one single-detached, single-family house was modeled. The house model was designed to represent an archetypal new suburban house in Canada, and is based on the aspect ratio, footprint, and finished floor area of the $N R C$ CCHT twin test houses in Ottawa (NRC, 2013). The model includes realistic complex geometry, including an inset slab-on-grade garage. Roof geometry has been simplified and switched to gable style to enable a large southfacing roof suitable for rooftop PV, if necessary (see Figure 4-1 and Figure 4-2). Aside from geometry, and typology, all design aspects of the building have been tailored to comply with $N B C$ 9.36 for the reference model. While the number of bedrooms and bathrooms is specified, the exact floor plan is not possible to model in BEopt, though number of floors and house size are accounted for by EnergyPlus for such purposes as modelling and costing duct runs, DHW piping, ventilation, etc., according to the Building America House Simulation Protocol (BA Protocol, 2014). Occupancy is also determined using the BA Protocol (see

Table 4-1).

Due to the prevalence of basements in Canada, the house includes a foundation. It has been modelled with an unfinished basement, which is within the thermal envelope and air control layer, but which is not directly conditioned or ventilated. This approach was taken due to two software limitations: a) there is a bug that prevents the possibility of investigating basement wall insulation options for finished (conditioned) basements, and b) it is not possible to specify whole-slab insulation for basements (conditioned or unconditioned), resulting in a weak point in the thermal envelope whose negative effect can be somewhat mitigated by not conditioning the basement. Some thermal separation between the basement and conditioned first floor is modelled because of the wood sub-floor and finish (R-3.1), however, no insulation was added to the basement ceiling, 
as this would place the mechanical equipment (located in the basement) outside of the thermal envelope. Whole-slab insulation for basements is not required by either $N B C$ 9.36 or $O B C S B-12$. Note that, while likely to reduce total thermal energy demand, this approach may result in a higher SHDI, since the denominator (FFA) is much smaller for a building with an unfinished versus a finished basement.

The back of the house, which contains a higher glazing area than the front due to a sliding glass patio door, faces south. The author recognizes that this could be considered a nonconservative orientation that benefits from winter passive solar heating in a cold climate (and optimal rooftop PV generation) in a way that most houses cannot due to site limitations. This orientation was primarily chosen to investigate the cost feasibility of increased south glazing area for harvesting passive solar heat gain.

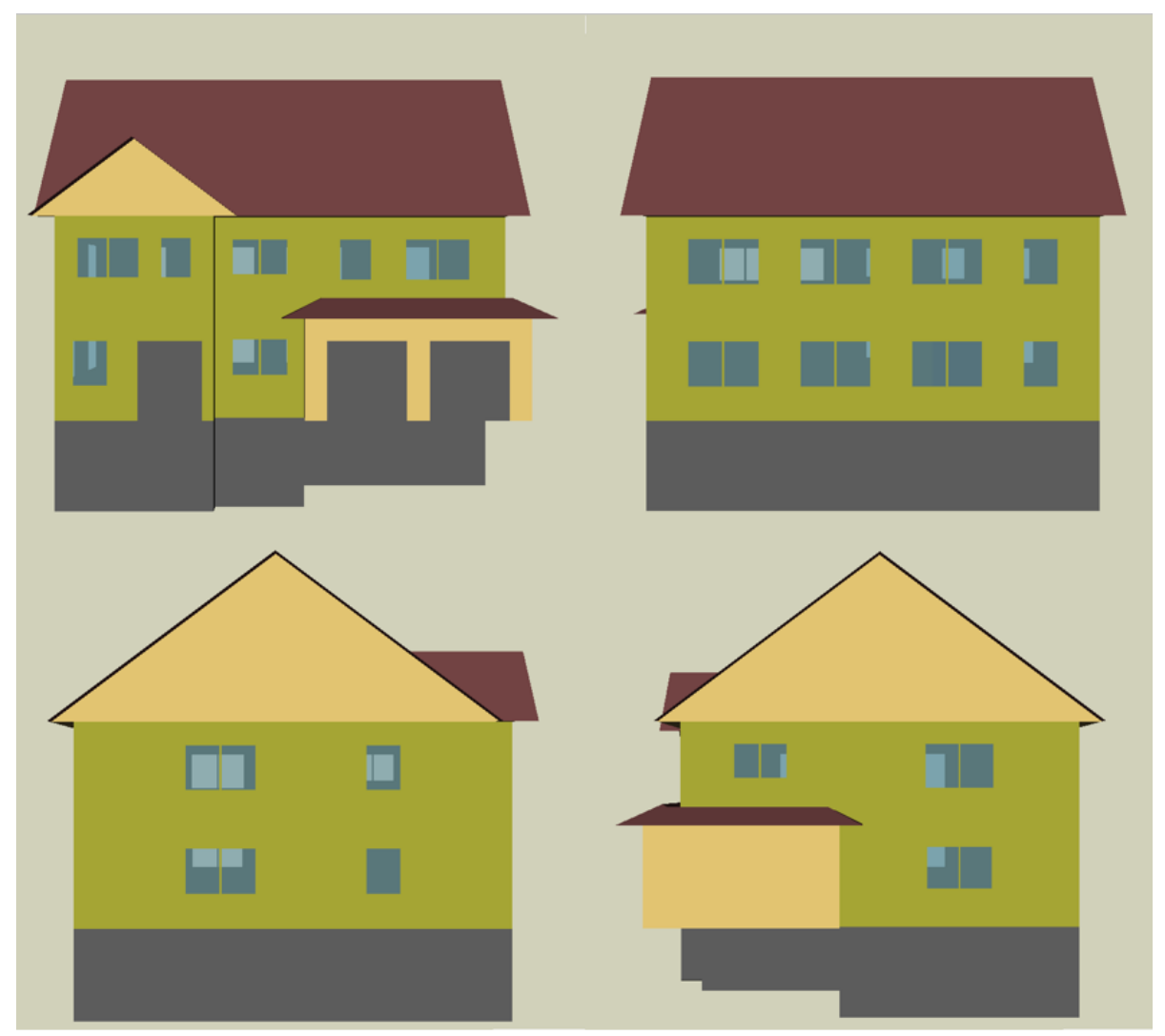

Figure 4-1 Model geometry - clockwise from top left: North, South, West, East (green = conditioned volume) 


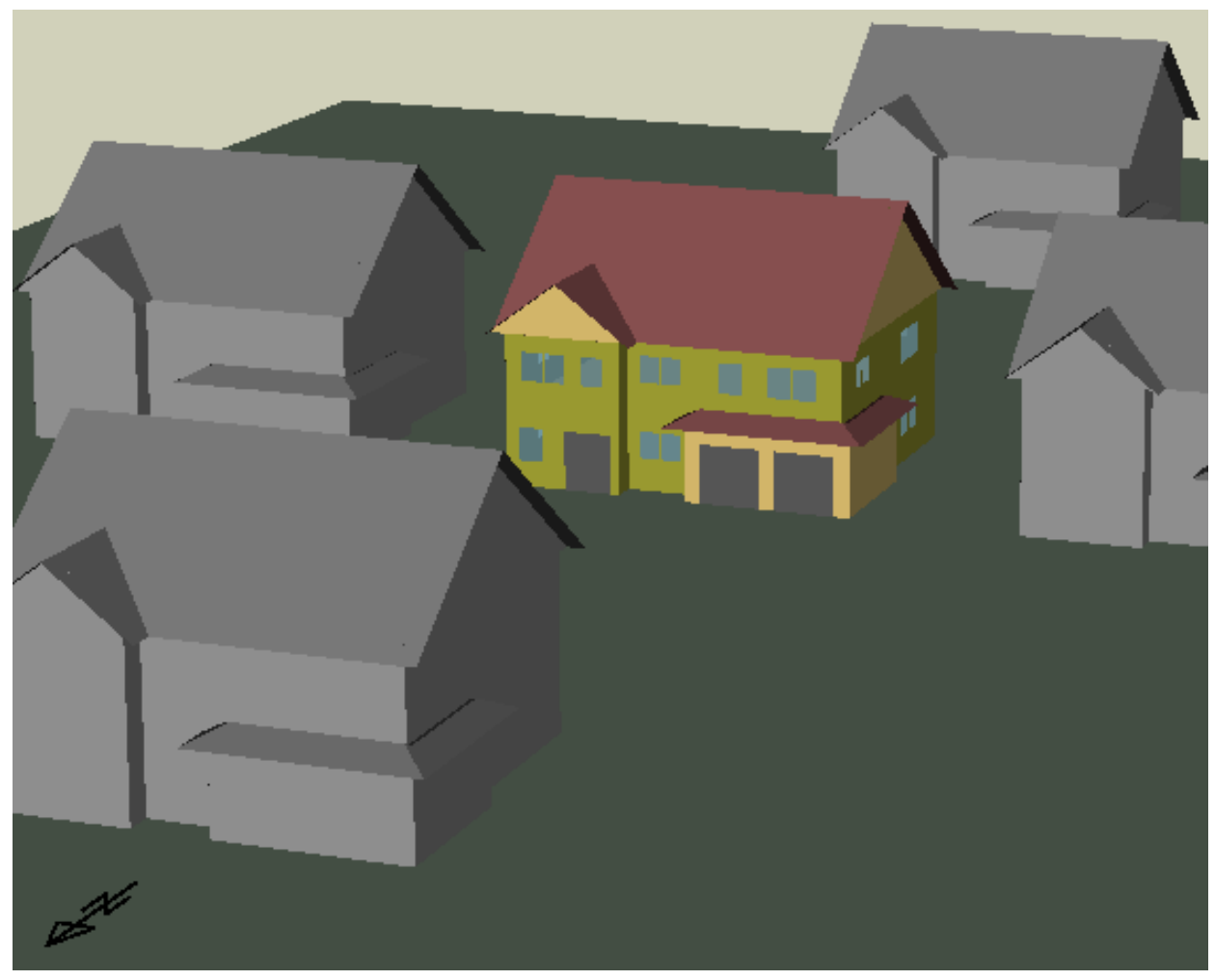

Figure 4-2 Orientation, shading, and wind sheltering

Table 4-1 House geometry and typology

\begin{tabular}{|c|c|}
\hline Footprint $\left(\mathrm{m}^{2}\right)$ & 142.1 \\
\hline FFA $\left(\mathrm{m}^{2}\right)$ & 244.5 \\
\hline Floors & 2 \\
\hline Floor Height $(\mathrm{m})$ & 2.74 \\
\hline Conditioned Volume $\left(\mathrm{m}^{3}\right)$ & 670.8 \\
\hline Gross Envelope Area $\left(\mathrm{m}^{2}\right)$ & 644.7 \\
\hline \# Bedrooms & 4 \\
\hline Occupancy & 3.23 \\
\hline \# bathrooms & 2.5 \\
\hline Attic & Unfinished \\
\hline Basement & Unfinished \\
\hline
\end{tabular}

\subsection{NBC 9.36 Reference Energy Model}

The "Reference" model for this study represents the least efficient code-compliant design based on NBC 9.36 prescriptive compliance. The reference building energy model varies by location (climate zone) in terms of envelope R-values (walls, roof, foundation/slab), and window 
U-values only (see Table 4-2). Climate zones are defined by Celsius HDD in increments of 1000, with zone 5 encompassing $3000-3999 \mathrm{HDD}^{\circ} \mathrm{C}$. HDD values for each location are from $\mathrm{NBC}$ 2015, Volume I, Table C-2 (NBC Volume I, 2015)All other location-specific differences are for weather files, energy prices, construction costs, and electricity EF, and are contained within the "site-input" screen in BEopt.

Table 4-2 NBC 9.36 R-Value requirements for house with HRV (table 9.36.2.6.B)

\begin{tabular}{|c|c|c|c|c|c|c|c|}
\hline \multirow[t]{2}{*}{ Location } & \multirow{2}{*}{$\begin{array}{c}\text { Climate } \\
\text { Zone }\end{array}$} & \multicolumn{5}{|c|}{ R-Value (ft $\left.{ }^{2}{ }^{\circ} \mathrm{F}-\mathrm{h} / \mathrm{Btu}\right)$} & \multirow{2}{*}{$\begin{array}{c}\text { U-value (US) } \\
\text { Window/Door }\end{array}$} \\
\hline & & Wall & $\begin{array}{l}\text { Ceiling } \\
\text { (attic) }\end{array}$ & $\begin{array}{l}\text { Interzonal } \\
\text { Floor }\end{array}$ & $\begin{array}{c}\text { Foundation } \\
\text { Wall }\end{array}$ & $\begin{array}{l}\text { Slab Below } \\
\text { Frost }\end{array}$ & \\
\hline VN & 4 & 15.78 & 39.23 & 26.52 & 11.30 & 0.00 & 0.32 \\
\hline ED & $7 A$ & 16.86 & 49.23 & 28.50 & 16.92 & 0.00 & 0.28 \\
\hline TO & 5 & 16.86 & 39.23 & 26.52 & 16.92 & 0.00 & 0.32 \\
\hline $\mathrm{ML}$ & 6 & 16.86 & 49.23 & 26.52 & 16.92 & 0.00 & 0.28 \\
\hline$H X$ & 6 & 16.86 & 49.23 & 26.52 & 16.92 & 0.00 & 0.28 \\
\hline
\end{tabular}

Note that the $N B C 9.36$ modeled reference house (whose annual energy consumption must not be exceeded by the proposed house) is in some respects more efficient than the minimum codecompliant design house based on the prescriptive compliance package. The "Reference" model for this study represents the least efficient code-compliant design based on 9.36 prescriptive compliance.

In some cases, the reference building inputs have been sourced from the BA Protocol "B10 Benchmark for New Construction" because these are the default assumptions in BEopt and because the BEopt model is not compatible with the NBC 9.36 modelling guidelines (as is the case with DHW). The BA Protocol is also a beneficial source as it is widely employed, and it allows a more granular understanding of control and schedules for specific appliances than is typically prescribed by building energy standards. Unless otherwise noted, DHW and electrical appliance usage and schedules are governed by the BA Protocol. The BA Protocol defines the "B10 Benchmark" as:

"A reference case representing a house built to the 2009 IECC, as well as the federal appliance standards in effect as of January 1, 2010, and lighting characteristics and miscellaneous electric loads (MELs) most common in 2010. The Benchmark is used as the point of reference for tracking progress toward multiyear energy savings goals established by BA." 


\subsubsection{Opaque Constructions}

Discrete components were selected as the minimum compliant available option, while ensuring relevance for the Canadian homebuilding industry. Additional component options are discussed in Chapter 5.

Wall construction is $2 \times 6$ " wood stud wall at 24 " on-center (o.c.), with cavity fiberglass batt insulation, exterior OSB sheathing, and opportunity for exterior foam insulation in the optimization. The stud wall R-effective includes the wood studs, interior and exterior air-films, $1 / 2$ ” gypsum board, $1 / 2$ " OSB sheathing, and light vinyl siding. The interzonal walls (connected to the garage) have the same construction without all exterior layers, resulting in slightly lower Reffective values. The unfinished attic is vented with blown fiberglass and the interzonal floor (garage ceiling) has the same nominal values, with R-effective values complying with the requirement for vaulted roof/interzonal floor in NBC 9.36.

As discussed, the basement slab is uninsulated, and the basement walls are fully insulated (8' depth), with exterior rigid foam (polyisocyanurate) insulation, as well as the $2 \times 10$ " first floor rim joists. See Table 4-3 for a summary of the reference model values (highlighted cells indicate values that deviate from the mode across locations).

Table 4-3 Reference model R-effective (R-nominal) values

\begin{tabular}{|c|c|c|c|c|c|c|}
\hline Location & Wall & $\begin{array}{c}\text { Interzonal } \\
\text { Wall }\end{array}$ & $\begin{array}{c}\text { Ceiling } \\
\text { (attic) }\end{array}$ & $\begin{array}{c}\text { Interzonal } \\
\text { Floor }\end{array}$ & $\begin{array}{c}\text { Foundation } \\
\text { Wall }\end{array}$ & $\begin{array}{c}\text { Slab Below } \\
\text { Frost }\end{array}$ \\
\hline VN & $16(19)$ & $16.8(21)$ & $39.6(38)$ & $28.7(38)$ & $13.3(12)$ & 0 \\
\hline ED & $17.7(21)$ & $16.8(21)$ & $50.6(49)$ & $28.7(38)$ & $19.3(18)$ & 0 \\
\hline TO & $17.7(21)$ & $16.8(21)$ & $39.6(38)$ & $28.7(38)$ & $19.3(18)$ & 0 \\
\hline ML & $17.7(21)$ & $16.8(21)$ & $50.6(49)$ & $28.7(38)$ & $19.3(18)$ & 0 \\
\hline HX & $17.7(21)$ & $16.8(21)$ & $50.6(49)$ & $28.7(38)$ & $19.3(18)$ & 0 \\
\hline
\end{tabular}

\subsubsection{Windows and Doors}

For windows and doors, NBC 9.36 only stipulates U-value, but SHGC, frame type, pane \#, gap-fill gas type also both affect performance and cost. There are two opaque doors with a U-value of 0.2 , and one sliding glass patio door of the same type as the windows in all models. Reference model windows are described in Table 4-4. 
Table 4-4 Reference model windows

\begin{tabular}{|c|c|c|c|c|c|c|}
\hline Location & U-value & Panes & SHGC & Frame & Gap & Coating \\
\hline VN, TO & 0.32 & 2 & 0.56 & insulated & air & low-e \\
\hline ED, ML, HX & 0.27 & 2 & 0.46 & insulated & argon & low-e \\
\hline
\end{tabular}

\section{Window - Wall Ratio}

The $N B C 9.36$ performance compliance method specifies that the reference model must have the same fenestration and door to wall ratio (FDWR) for each façade as the proposed building, but the reference must be: $17 \% \leq$ FDWR $\leq 22 \%$. To minimize window cost, the reference building has an FDWR of 17\%, which, after the two opaque doors are accounted for, results in a WWR (including patio door) of approximately $15 \%$ (see). This window area was distributed across the four orientations of the house using the following rationale: the minimum acceptable WWR on the side facades is $10 \%$, and the remaining window requirement is distributed between the front and back facades such that they have the same window area, but the back also includes the glass patio door. There is no overhang shading for any windows in the reference model, other than the roof eaves which are 2 ' on all sides.

Table 4-5 WWR distribution and FDWR verification

\begin{tabular}{|c|c|c|c|c|}
\hline Facade & Orientation & Wall Area $\mathbf{( m}^{\mathbf{2}} \mathbf{~}$ & Window Area $\left.\mathbf{( m}^{\mathbf{2}}\right)$ & WWR \\
\hline Front & North & 50.2 & 9.03 & $18 \%$ \\
\hline Back & South & 66.9 & 15.38 & $23 \%$ \\
\hline Left & East & 63.8 & 6.38 & $10 \%$ \\
\hline Right & West & 50.8 & 5.08 & $10 \%$ \\
\hline Total & & 231.6 & 35.87 & $15.5 \%$ \\
\hline & & & Door Area & Door: Wall \\
\hline Opaque doors & & & 3.72 & $1.6 \%$ \\
\hline FDWR & & & & $\mathbf{1 7 . 1 \%}$ \\
\hline
\end{tabular}

\subsubsection{Airflow and Ventilation}

\section{Enclosure Air Leakage}

$N B C 9.36$ allows the reference house air leakage (i.e., uncontrolled airflow) to be modelled as high as 3.2 ACH50 if air barrier prescriptions from 9.36 are not followed and the 
building is merely compliant with Section 9.25. The reference house in this study is assumed to have a complete are barrier system, which according to $\mathrm{NBC} 9.36$ is to be modelled as $2.5 \mathrm{ACH} 50$ (this is also the requirement for $O B C S B-12$ ).

\section{Ceiling Fans}

Ceiling fans can satisfy comfort conditions by increasing the rate of convective heat transfer between an occupant and the interior air, even at higher temperatures. However, savings in cooling energy use will only occur if the cooling set point temperature is raised during times when the fan is used. This study does not investigate energy savings from temperature set-backs and set-ups. However, ceiling fans are still modeled to capture the initial and operational cost of the equipment, and to investigate the economic feasibility of more efficient fans in the optimization. Ceiling fan energy use is modelled based on the U.S. average for new construction (B10 benchmark) from the BA Protocol using the equation:

$$
\text { Annual energy use }(k W h / y r)=7.3+0.0403 x F F A\left(f t^{2}\right)
$$

\section{Ventilative/Free Cooling}

Ventilative Cooling (aka. natural ventilation) is done, not primarily for the provision of fresh air (which is done continuously through mechanical ventilation), but for reducing space cooling energy use, when conditions are appropriate. According to BEopt/BA Protocol, this occurs when the building requires cooling, and outdoor air is below: the indoor air temperature, a humidity ratio of 0.0115 , and $70 \% \mathrm{RH}$. Implementing this measure of course requires very conscientious occupants, however, it can also be implemented to simulate the free cooling provided by an HRV economizer, which cannot be directly modeled in BEopt. It isn't a perfect solution, since air flow rate, which depends on wind speed, cannot be controlled (EnergyPlus uses the "Sherman-Grimsrud model" for natural ventilation).

The reference building is modelled with "enthalpy economizer control" according to the aforementioned criteria - that is, when the building is in free cooling mode (windows open), there is no mechanical cooling. It is available at all times of day, all year, assumes $1 / 3$ of window area

is operable, and are 100\% open during free cooling mode. Figure 4-3 (Toronto - Reference) illustrates the effect of this simulated economizer on annual cooling demand and cooling hours unmet relative to a) year-round natural ventilation with only $20 \%$ of operable windows open (i.e., 
$6.7 \%$ of glazing area) and, b) no natural ventilation. The economizer results in a $45 \%$ reduction in cooling hours unmet and a 37\% reduction in annual cooling demand over the always-sealed building (note that the main benefit of increasing the opened window area from $6.7 \%$ to $33 \%$ is not energy savings, but occupant comfort). This results in a substantial improvement over the minimum required by $N B C 9.36$, however, due to the uncertainty of costing economizer control for a residential HRV, all models in this study include an economizer for consistency.

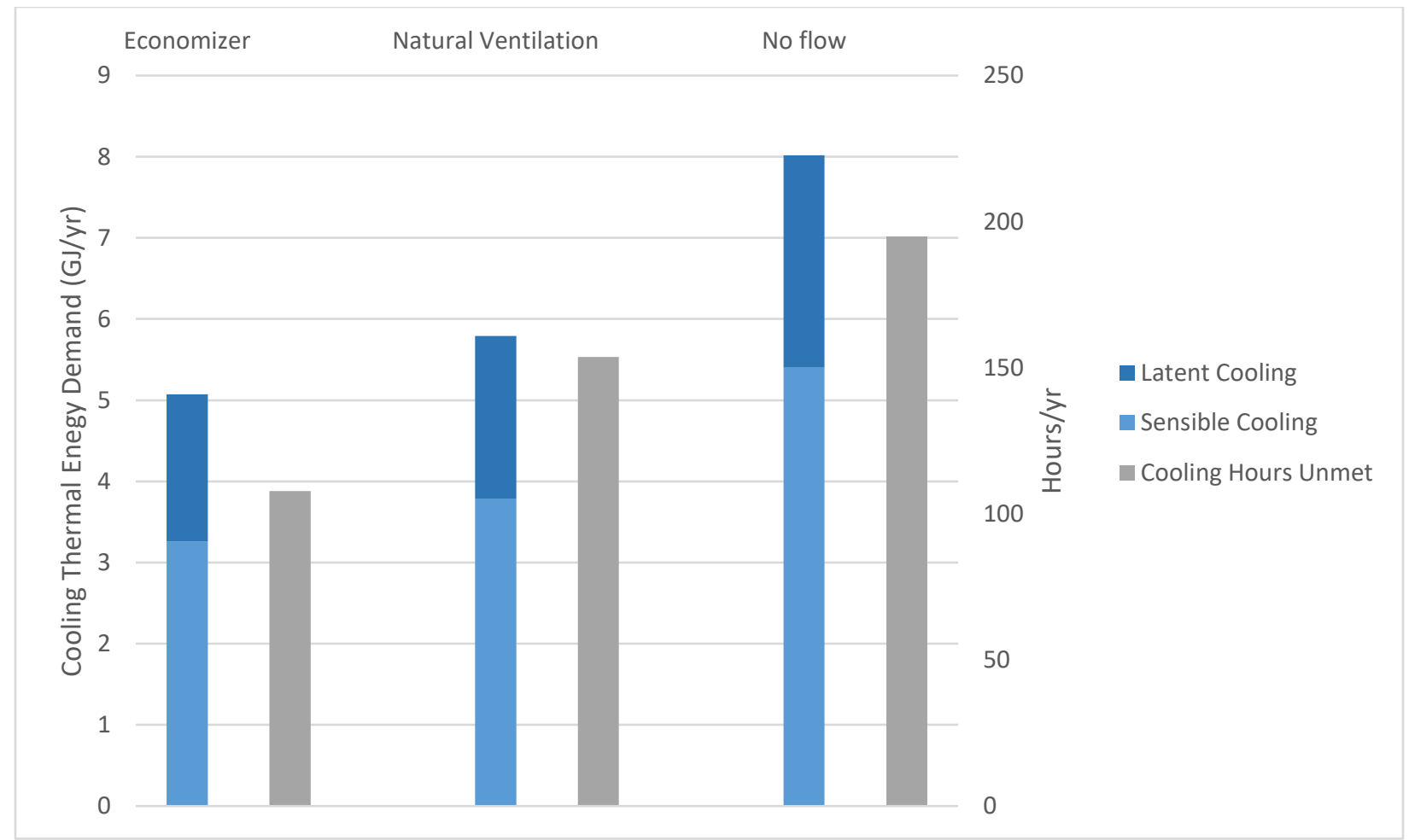

Figure 4-3 Effect of natural ventilation and "economizer" control on cooling demand and thermal comfort

Mechanical Ventilation

All models in the study include a whole-house dedicated outdoor air ventilation system (DOAS) with heat/energy recovery. NBC 9.36 requires an HRV only for the enclosure and window performance prescriptions from Table 4-2. Minimum SRE is $60 \%$ or $55 \%$ at $0^{\circ} \mathrm{C}$, depending on climate zone. However, due to a high uncertainty in the material cost premium associated specifically with increased SRE of the HRV, all models in this study include the only HRV/ERV equipment costed in the $N R E M D B$, which both have an SRE of $70 \%$. This decision was made to prevent the distortion of optimization results due to improperly costed equipment relative to the 
cost of other ventilators, as well as equipment/materials in other component categories (to maintain consistency of the costing sources). The author recognizes that this results in: a) a reference building exceeding minimum code-compliance, and b) a maximum available HRV/ERV thermal efficiency (for the optimizations) that is slightly lower than current affordable options for new construction. However, previous experience by the researcher with BEopt optimizations indicate that a higher efficiency HRV will only be selected in minimum LCC designs if the equipment cost premium (above the SRE 70\% model) is minimal.

All building model variants have the same control and air flow rates, as determined for the modeled house using standard ASHRAE 62.2 (2013) Ventilation and Acceptable Indoor Air Quality in Low-Rise Residential Buildings (ASHRAE, 2013). Models also include kitchen and bath exhaust fans, which do not perform heat recovery. Table 4-6 outlines the operational control of the ventilation system. The HRV provides approximately 0.3 air changes per hour for the conditioned volume of the house, representing $93 \%$ of total mechanical ventilation airflow. The equation governing the design flow rate of the HRV is:

$$
\text { Flow rate }(c f m)=0.03 \times F F A\left(f t^{2}\right)+(\# \text { bedrooms }+1) \times 7.5
$$

Table 4-6 Mechanical Ventilation Operational Control ( $V=$ air volume, HR=heat recovery)

\begin{tabular}{|c|c|c|c|c|c|c|c|}
\hline Component & $\begin{array}{c}\text { Flow } \\
\text { Rate } \\
\text { (cfm) }\end{array}$ & $\begin{array}{c}\text { Operation } \\
\text { (h/day) }\end{array}$ & $\begin{array}{c}\# \\
\text { Fans }\end{array}$ & $\begin{array}{c}\text { Electrical Efficiency } \\
\text { (W/cfm) }\end{array}$ & $\begin{array}{c}\text { Heat } \\
\text { Recovery }\end{array}$ & $\begin{array}{c}\text { Daily } \\
\text { Volume } \\
\text { (ft } \mathbf{3}^{\mathbf{}} \text { ) }\end{array}$ & $\begin{array}{c}\text { \% of Total } \\
\text { Daily } \\
\text { Volume }\end{array}$ \\
\hline HRV & 116 & 24 & 2 & 0.5 & Yes & 2795 & $93 \%$ \\
\hline Bath exhaust & 50 & 2.5 & 1 & 0.3 & No & 125 & $4 \%$ \\
\hline $\begin{array}{c}\text { Kitchen } \\
\text { exhaust }\end{array}$ & 100 & 1 & 1 & 0.3 & No & 100 & $3 \%$ \\
\hline
\end{tabular}

\subsubsection{Space Conditioning}

As discussed, the basement is within the building enclosure but not directly conditioned. There is assumed to be $0.1 \mathrm{ACHn}$ of exchange between the basement air and the conditioned zone to ensure sufficient heat supply for the models containing a HPWH, as well as simulate the ambient cooling effect.

All mechanical equipment (in the basement), heating and cooling delivery ducting, and DHW delivery piping is within the thermal envelope. The reference building includes a minimum 
compliant air conditioner (SEER 15), and natural gas furnace (80\% AFUE) with forced-air delivery by an AHU through uninsulated ducting with a 7.5\% air leakage rate. Heating and cooling temperature set points are $21.1{ }^{\circ} \mathrm{C}\left(70^{\circ} \mathrm{F}\right)$ and $25^{\circ} \mathrm{C}\left(77^{\circ} \mathrm{F}\right)$, respectively, and there are no setbacks. The equipment capacity is auto-sized by the software based on the building peak heating/cooling loads, according to the Air Conditioning Contractors of America (ACCA) Manual $J, 8^{\text {th }}$ Edition.

\subsubsection{Domestic Hot Water}

The reference model hot water tank has a 40-gallon $(151 \mathrm{~L})$ capacity, with a natural gas input of $40 \mathrm{kBTU} / \mathrm{h}(11.7 \mathrm{~kW})$ and an energy factor of 0.59 , which complies with $N B C$ 9.36. Distribution is in a trunk branch formation with cross-linked polyethylene (PEX) piping and no insulation.

The NBC 9.36 modelling requirement for DHW usage is $225 \mathrm{~L} /$ day of service hot water at $55^{\circ} \mathrm{C}\left(131^{\circ} \mathrm{F}\right)$, whereas $O B C S B-12 /$ EnerGuide is $178-199 \mathrm{~L} /$ day at the same temperature. However, as per the BA Protocol, BEopt models DHW usage by delivered hot water volume at the tap, after it has been mixed with cold water to achieve a temperature of $43.3^{\circ} \mathrm{C}\left(110^{\circ} \mathrm{F}\right)$, regardless of the hot water tank temperature set point. The volumetric conversion cannot be easily made, as BEopt calculates the necessary volume of service hot water dynamically based on fluctuating municipal service water temperatures by location and time of year (which is mixed with the service hot to achieve $43.3^{\circ} \mathrm{C}$ ). In any case, the resultant service hot water volume from this method is very similar to the $N B C 9.36$ requirement. BA Protocol delivered DHW use is determined using separate formulas (shown below) for sinks, showers, and baths (i.e., toilets) based on the number of bedrooms (which is a proxy for occupancy). Clothes washer and dishwasher DHW use is calculated separately for those appliances depending on appliance and usage frequency. A summary of the DHW use profile and control regime consistent for all models is illustrated in Table 4-7 and Figure 4-4 (includes standard dishwasher and clothes washer DHW use).

$$
\begin{aligned}
& \text { Sinks }(\mathrm{gal} / \mathrm{d})=12.5+4.16 x(\# \text { bed }) \\
& \text { Showers }(\mathrm{gal} / \mathrm{d})=14+4.67 x(\# \text { bed })
\end{aligned}
$$




$$
\operatorname{Bath}(\mathrm{gal} / \mathrm{d})=3.5+1.17 x(\# \text { bed })
$$

Table 4-7 DHW use and control

\begin{tabular}{|c|c|}
\hline End Use@43.3 ${ }^{\circ} \mathbf{C}$ & Use (L/day) \\
\hline Sinks & 110.3 \\
\hline Showers & 123.7 \\
\hline Bath & 31.0 \\
\hline Total & 265.0 \\
\hline \multicolumn{2}{|c|}{ Tank temperature set point ( $\left.^{\circ} \mathbf{C}\right)$} \\
\hline \multicolumn{2}{|c|}{51.7} \\
\hline
\end{tabular}

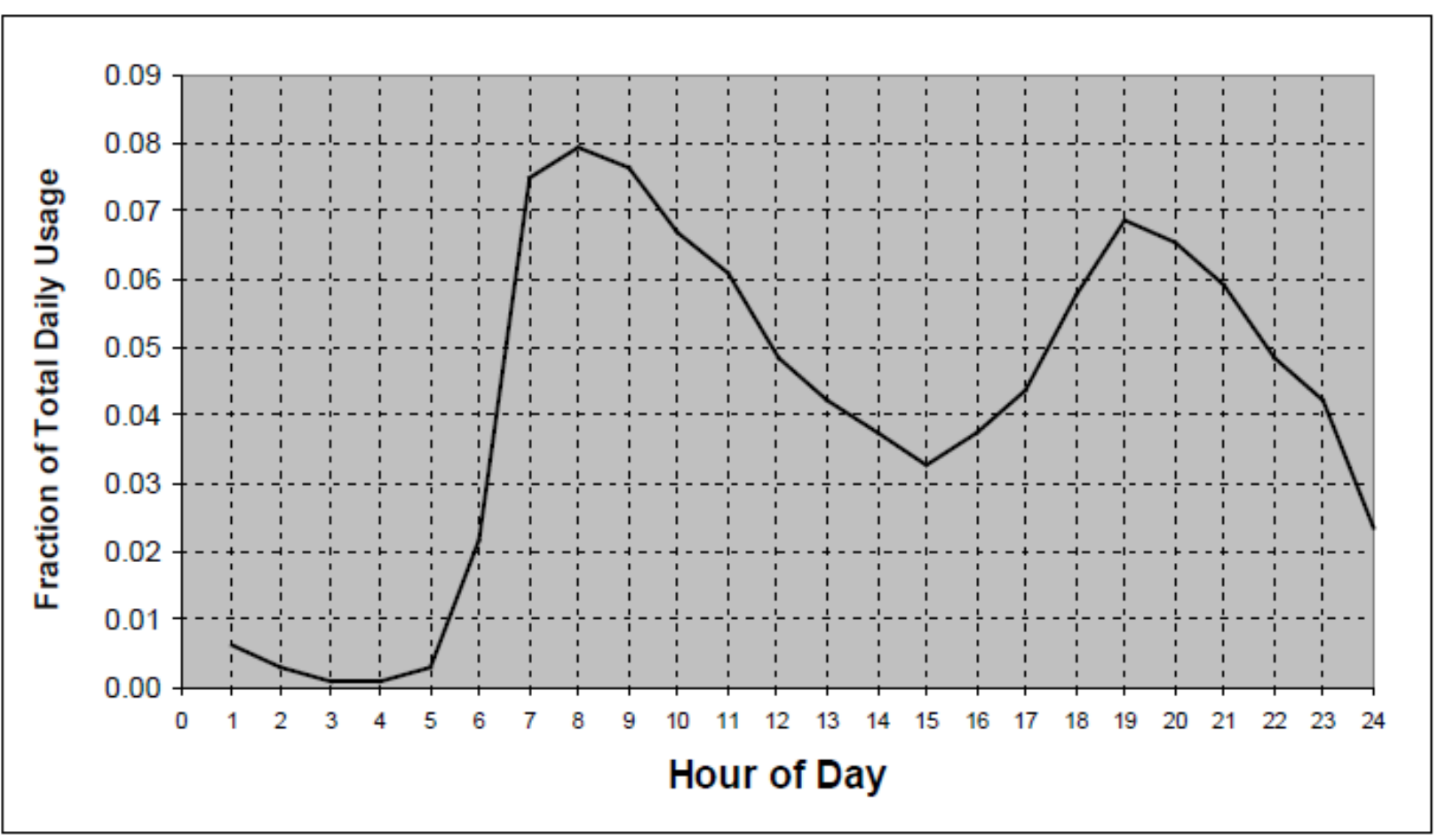

Figure 4-4 DHW use profile (BA Protocol, 2014)

\subsubsection{Lighting and Appliances}

Electricity use from lighting and large and small electrical appliances is fixed across all designs in the study. As NBC 9.36 is concerned only with energy use for space heating and DHW, electricity usage and schedules for appliances and lighting is not specified, however, internal heat gains from these sources is specified. As the BEopt optimizations encompass all energy use, 
including that from appliances, the usage and schedules from these sources - both for calculating electricity use and internal (sensible and latent) heat gain —is derived from the BA Protocol.

Miscellaneous electrical loads (MELs, or plug loads) are in addition to lighting and the five major appliances. This value is based on the B10 Benchmark and does not vary for all building variants in this study. MEL electricity use is determined using the equation:

$$
\text { Annual Use }\left(\frac{k W h}{y}\right)=1108.1+180.2 \times(\# \text { bed })+0.278 \times F F A\left(f t^{2}\right)
$$

Lighting equipment has been modified from the B10 Benchmark to be composed of 100\% LED interior and exterior lamps. This decision is justified by the fact that the B10 Benchmark is based on the 2010 U.S. national average for new construction, and LED lights have since become nearly ubiquitous in new construction as the most economical choice. Illumination levels and schedules have not been modified.

Of the five large appliances, only the dishwasher has been reset from the BA Protocol to an Energy Star compliant model. A summary of the lighting and appliances characteristics and energy use is summarized in (note that in addition to electricity use, the dishwasher and clothes washer also consume DHW).

Table 4-8 Lighting and appliance sources and consumption

\begin{tabular}{|c|c|c|c|}
\hline Component & Source & Description & $\begin{array}{c}\text { Annual Electricity } \\
\text { Consumption (kWh/y) }\end{array}$ \\
\hline MELs & B10 Benchmark & U.S. average & 2562 \\
\hline Refrigerator & B10 Benchmark & energy factor 17.6 & 434 \\
\hline Cooking Range & B10 Benchmark & electric standard & 584 \\
\hline Dishwasher & Energy Star & $318 \mathrm{kWh} / \mathrm{y}$ rated & 129.5 \\
\hline Clothes Washer & B10 Benchmark & $123 \mathrm{kWh} / \mathrm{y}$ rated & 40.7 \\
\hline Clothes Dryer & B10 Benchmark & Electric, energy factor 3.1 lb./kWh & 918.8 \\
\hline Appliance Total & & & $\mathbf{4 6 6 9}$ \\
\hline Lighting & Custom & $100 \%$ LED, $80 \mathrm{Im} / \mathrm{W}$ & $\mathbf{1 2 0 2}$ \\
\hline Total & & & $\mathbf{5 8 7 1}$ \\
\hline
\end{tabular}

\subsubsection{Internal Heat Gain and Mass}

Internal gains are calculated in EnergyPlus for both sensible and latent heat. Sources of internal gains include: occupants, lighting, appliances, and mechanical equipment waste heat. For 
the purpose of calculating internal gains from occupants, the BA Protocol uses Equation (5-6), resulting in an occupancy of 3.23 for a 4-bedroom house.

$$
\text { Occupancy }=\# \text { beds } \times 0.59+0.87
$$

In addition to the heat capacity of the materials in the building enclosure, the model accounts for the heat capacity (aka thermal mass) of a standard distribution of furniture. For the solar distribution calculation, there is assumed to be light furniture occupying $40 \%$ of the floor space. For the thermal mass calculation of all interior finishing and furniture, there is an average mass of $39 \mathrm{~kg} / \mathrm{m}^{2}\left(8 \mathrm{lb} . / \mathrm{ft}^{2}\right.$ ) for all conditioned floor area, or $9550 \mathrm{~kg}$ total. Assuming an average specific heat capacity similar to that of white pine $\left(1500 \mathrm{~J} / \mathrm{kg}-{ }^{\circ} \mathrm{C}\right)$, this results in an interior heat capacity of $14.3 \mathrm{MJ} /{ }^{\circ} \mathrm{C}$.

\subsubsection{Reference Model Summary}

Table 4-9 and Table 4-10 indicate the BEopt reference model input parameters, sources, and notes. Where input values for the thermal envelope and windows vary by location for the reference design, see Table 4-3 and Table 4-4. The "Reference" model refers only to the model with the thermal system specified in Table 4-9. For the thermal system-specific optimizations, the space conditioning and water heating parameters are specified in Section 4.3.

Table 4-9 Reference model input parameters (Toronto)

\begin{tabular}{|c|c|c|}
\hline Group & Category & Parameter \\
\hline \multirow{2}{*}{ Building } & Orientation & North (front of house) \\
\hline & Neighbors & Suburban \\
\hline \multirow{4}{*}{ Walls } & Wood Stud* & R-21 fiberglass batt, $2 \times 6,24$ in o.c., $1 / 2$ " OSB, air gap (R-effective: 17.7 ) \\
\hline & $\begin{array}{c}\text { Wall } \\
\text { Sheathing }\end{array}$ & None \\
\hline & Exterior Finish & Vinyl, light coloured \\
\hline & $\begin{array}{c}\text { Interzonal } \\
\text { Walls }\end{array}$ & R-21 fiberglass batt, $2 \times 6,24$ in o.c. (R-effective: 16.8 ) \\
\hline \multirow{3}{*}{ Ceilings/Roofs } & $\begin{array}{c}\text { Unfinished } \\
\text { Attic* }\end{array}$ & Ceiling R-38 fiberglass, vented (R-effective: 39.6 ) \\
\hline & Roof Material & Asphalt shingles, medium \\
\hline & $\begin{array}{l}\text { Radiant } \\
\text { Barrier }\end{array}$ & None \\
\hline \multirow{3}{*}{ Foundation/Floors } & $\begin{array}{l}\text { Unfinished } \\
\text { Basement* }\end{array}$ & Whole wall R-18 polyiso (R-effective: 19.3 ) \\
\hline & $\begin{array}{c}\text { Interzonal } \\
\text { Floor }\end{array}$ & R-38 fiberglass (R-effective: 28.7 ) \\
\hline & Carpet & $20 \%$ carpet \\
\hline
\end{tabular}




\begin{tabular}{|c|c|c|}
\hline \multirow{4}{*}{ Thermal Mass } & Floor Mass & Wood surface \\
\hline & $\begin{array}{l}\text { Exterior Wall } \\
\text { Mass }\end{array}$ & $1 / 2$ in. drywall \\
\hline & $\begin{array}{c}\text { Partition Wall } \\
\text { Mass } \\
\end{array}$ & $1 / 2$ in. drywall \\
\hline & Ceiling Mass & $1 / 2$ in. drywall \\
\hline \multirow{7}{*}{ Windows \& Doors } & Window Areas & Front: $18 \%$, back: $23 \%$, left: $10 \%$, right: $10 \%$ \\
\hline & Windows* & U-value 0.32 , Low-e, double, insulated, air, SHGC 0.56 \\
\hline & $\begin{array}{l}\text { Interior } \\
\text { Shading }\end{array}$ & Summer $=0.5$ unshaded, winter $=0.95$ unshaded \\
\hline & Door Area & $3.72 \mathrm{~m}^{2}\left(40 \mathrm{ft}^{2}\right)$ \\
\hline & Doors & Fiberglass, U-value 0.2 \\
\hline & Eaves & $0.61 \mathrm{~m}\left(2^{\prime}\right)$ \\
\hline & Overhangs & None \\
\hline \multirow{3}{*}{ Airflow } & Air Leakage & $2.5 \mathrm{ACH} 50$ \\
\hline & $\begin{array}{l}\text { Mechanical } \\
\text { Ventilation }\end{array}$ & HRV, SRE 70\% \\
\hline & $\begin{array}{c}\text { Natural } \\
\text { Ventilation }\end{array}$ & HRV economizer year-round, 24 hr, 7 days/wk. \\
\hline \multirow{4}{*}{ Space Conditioning } & $\begin{array}{l}\text { Central Air } \\
\text { Conditioner } \\
\end{array}$ & SEER 15 , single stage \\
\hline & Furnace & Gas, $80 \%$ AFUE \\
\hline & Ducts & 7.5\% air leakage, uninsulated \\
\hline & Ceiling Fan & Standard efficiency, $50 \%$ Coverage \\
\hline \multirow{2}{*}{$\begin{array}{l}\text { Space Conditioning } \\
\text { Schedules }\end{array}$} & $\begin{array}{l}\text { Cooling Set } \\
\text { Point }\end{array}$ & $25^{\circ} \mathrm{C}\left(77^{\circ} \mathrm{F}\right)$ \\
\hline & $\begin{array}{c}\text { Heating Set } \\
\text { Point }\end{array}$ & $21.1^{\circ} \mathrm{C}\left(70^{\circ} \mathrm{F}\right)$ \\
\hline \multirow{2}{*}{ Water Heating } & Water Heater & Gas Standard, Energy Factor 0.59 \\
\hline & Distribution & Uninsulated, trunk branch, PEX \\
\hline Lighting & Lighting & $100 \%$ LED \\
\hline \multirow{6}{*}{$\begin{array}{l}\text { Appliances \& } \\
\text { Fixtures }\end{array}$} & Refrigerator & Top freezer, Energy Factor $=17.6$ \\
\hline & Cooking Range & Electric \\
\hline & Dishwasher & 318 Rated kWh \\
\hline & $\begin{array}{l}\text { Clothes } \\
\text { Washer }\end{array}$ & EnergyStar \\
\hline & Clothes Dryer & Electric \\
\hline & $\begin{array}{l}\text { Hot Water } \\
\text { Fixtures }\end{array}$ & Standard \\
\hline Miscellaneous & Plug Loads & Standard \\
\hline
\end{tabular}

(grey=optimization options, green=value is reset for optimization)

*may vary by location (see Table 4-2) 
Table 4-10 Reference model parameter sources

\begin{tabular}{|c|c|c|}
\hline Design Parameter & $\begin{array}{c}\text { Reference Design } \\
\text { Source }\end{array}$ & Notes \\
\hline Geometry & Custom & Detached \\
\hline Basement & Custom & Unfinished \\
\hline Orientation & Custom & South facing \\
\hline Nearby obstructions & Custom & Suburban \\
\hline *Envelope thermal resistance & NBC 9.36 & \\
\hline Exterior finish & BA B10 & \\
\hline Roof material & BA B10 & \\
\hline Window/door area distribution & NBC 9.36 & \\
\hline *Windows & NBC 9.36 & \\
\hline Doors & BA B10 & \\
\hline Thermal mass & BA B10 & \\
\hline Airtightness & NBC 9.36 & \\
\hline HRV/ERV & Custom & SRE $70 \%$ \\
\hline Central AC & NBC 9.36 & All locations \\
\hline Furnace & NBC 9.36 & \\
\hline Ducts & Custom & Uninsulated, tight \\
\hline Ceiling fan & Custom & Standard efficiency \\
\hline Water heater & NBC 9.36 & \\
\hline DHW distribution & NBC 9.36 & no insulation \\
\hline DHW consumption (equipment) & BA B10 & \\
\hline Lighting & Custom/BA Protocol & $100 \%$ LED \\
\hline Large appliances & BA B10* & Washer - EnergyStar \\
\hline MEL & BA B10 & \\
\hline \multicolumn{3}{|c|}{ Control } \\
\hline Interior shading & Custom & High-latitude, cold climate \\
\hline Natural ventilation & Custom & HRV Economizer \\
\hline Mechanical ventilation & ASHRAE 62.2 & 2013 \\
\hline Conditioning setpoints & NBC 9.36 & \\
\hline DHW setpoint & BA Protocol & \\
\hline DHW consumption (behaviour) & BA B10 & \\
\hline Schedules & BA Protocol & \\
\hline
\end{tabular}

*Reference design varies by location (see Table 4-3 and Table 4-4) 


\subsection{Thermal System Models}

Each thermal system-specific energy model is labeled by the space heating method (see Figure 3-3). Each model contains a suite of space heating (main and supplementary) and cooling production and deliver, DHW production and delivery, and in the case of the NZC model, solar PV generation. Each model is intended to have a comparable level of service, including space cooling, and backup electric resistance for all air-source heat pumps (ASHP and MSHP) for reliability during very cold temperatures.

While it is possible that space cooling and/or backup electric heating is not necessary in some locations, it is maintained in all locations for consistency in comparison (In addition to local climate, microclimate can affect the importance of incorporating a cooling system, as outdoor air in urban locations can fail to cool during summer nights due to the urban heat island effect, increased outdoor mean radiant temperature, and reduced evaporative cooling from vegetation. Proximate wind obstructions can also reduce the efficacy of ventilative cooling if relying on natural ventilation, however this would not be factor if using HRV economizer control). It is also true that the models do not have exactly comparable levels of service, such as the "Electric" model window-AC cooling system having reduced thermal comfort due to poor delivery, or the ductless "MSHP" model being aesthetically undesirable because of the protruding wall-mounted indoor units.

There is one "gas-heated" model, and 5 "all-electric" models optimized in each location. The "Gas" model contains the same thermal system type as the "Reference" model, but with increased heating, cooling, and DHW thermal efficiency options, including condensing and tankless DHW production. The "NZC" model contains the thermal system from the least-LCC allelectric optimization result. Each all-electric system contains only one efficiency option for

heating, cooling, and DHW in the optimization, however, there are options to reduce delivery losses, improve heat recovery, and more (see Chapter 5). All space heating delivery is by means of air recirculation (either ducted or ductless), or radiant (for "Electric" model). No hydronic delivery options were investigated (this is not currently possible using BEopt).

In general, the DHW production system type is the same as the space heating system - that is, the "Gas" model has gas-heated, DHW, the heat pump models have a HPWH, and the "Electric" model has an electric hot water tank. The HPWH is a ductless tank with an integrated air-to-water HP that uses the indoor air as the heat source. It therefore results in some space cooling which is 
beneficial in the cooling season and detrimental in heating season. DHW is effectively generated in heat pump models by means of an indirect cascade heat pump. Previous personal optimization experience has indicated that in buildings not heated with electric resistance, the HPWH will always result in a substantially lower building LCC than using an electric water heater.

\subsubsection{Air-Source Heat Pump (ASHP)}

All heat pumps modeled are chosen based on the best available cold-climate models available. In this study, "ASHP" refers specifically to centrally ducted, air-to-air heat pumps. ASHP performance depends on several variables, including the electrical efficiency of the fans and compressor, the frequency and duration of the defrost cycle, the thermal efficiency of the refrigeration cycle at different outdoor air temperatures, and the "capacity retention fraction" at lower outdoor temperatures (which determines the amount of supplementary electric resistance heating required). When a heat pump is modelled in a specific building and climate, an annual average heating coefficient of performance (COP) and cooling COP are useful metrics for relating the building enclosure efficiency (SHDI) to the thermal system efficiency, and ultimately determining space heating/cooling annual cost (COP for an electrically-driven heat pump is the ratio of useful thermal energy output to electrical energy input). Outdoor temperature can have a substantial impact on the COP of an ASHP, which introduces a complexity in determining the annual efficiency that does not exist for natural gas furnaces and electric baseboard heating. Since the building heating load also increased at lower outdoor air temperatures, an ASHP the performs poorly at low temperatures can result in much greater annual heating costs in colder climates than warmer ones. Furthermore, there is no standard method for modelling heat pumps, or for characterizing their performance. For this reason, only pre-existing HP models in BEopt are used in this study, with some modifications.

The American Heating and Refrigeration Institute (AHRI) is the rating agency for heat pumps in North America, providing a summary performance metric for heating, called the Heating Season Performance Factor (HSPF) and cooling, the Seasonal Energy Efficiency Ratio (SEER). These values are calculated based on standardized tests and are meant to indicate the expected annual heating and cooling COP values for $A H R I$ "region IV," expressed in $\mathrm{kBTU} / \mathrm{kWh}_{\mathrm{e}}$. However, this metric does not include results from tests below $-8.3^{\circ} \mathrm{C}\left(17^{\circ} \mathrm{F}\right)$ outdoor dry bulb (ODB) temperature. It can therefore be misleading or uninformative in cold climate applications. 
To address this issue, the Northeast Energy Efficiency Partnership (NEEP) has created a cold-climate ASHP specification database. It contains additional performance data submitted by manufacturers and is not third-party tested or verified (NEEP, 2018). To qualify as a "cold climate" heat pump, NEEP has three primary criteria:

1. It must have a $\mathrm{COP} \geq 1.75$ at $-15 \mathrm{C}^{\circ}\left(5^{\circ} \mathrm{F}\right)$

2. The compressor must be variable capacity

3. It must have an $A H R I$ rated $\mathrm{HSPF} \geq 10$

The BEopt centrally ducted ASHP default models are based on a combination of AHRI and manufacturer performance data, which has been converted to the necessary input metrics for EnergyPlus. The NREL report "Improved Modeling of Residential Air Conditioners and Heat Pumps for Energy Calculations" describes the method and highlights the fact that not all manufacturer data is reliably accurate (NREL, 2013). The MSHP models are another type of airto-air heat pump. However, EnergyPlus requires a different set of input metrics than that for centrally ducted ASHPs. The method for determining these metrics is not as transparent as for ASHPs, however, BEopt states that they are at least partially determined based on manufacturer and AHRI performance data from the NEEP database. They may also have been verified through in-house laboratory testing by the U.S. DOE EERE, as has been done for the ductless MSHPs in the study, "Laboratory Test Report for Fujitsu 12RLS and Mitsubishi FE12NA Mini-Split Heat Pumps" (EERE, 2011).

Both types of air-to-air heat pumps (ASHP and MSHP) are modelled in this study, because while MSHPs could have lower initial costs as well as operational costs, due to the lack of ducting and energy losses through ducting and pressurization, only an ASHP results in the same interior aesthetic as a centrally-ducted natural gas furnace.

There are three types of air-source, air-to-air heat pumps systems available:

1. Centrally ducted ASHP via a conventional AHU and duct

2. Ductless MSHP, either single or multi-zone, where the indoor units can be wallmounted, floor-mounted, or in-ceiling.

3. Ducted MSHP, single or multi-zone, where the indoor units are concealed fan-coils that double as mini AHUs and can be ducted to multiple rooms in short duct runs (low static 
pressures). Multi-zone MSHPs can have a combination of ductless and ducted indoor units

The MSHP model in this study is ductless, multi-zone. For rating purposes, AHRI classifies air-source heat pumps somewhat differently, according to Table 4-11.

Table 4-11 AHRI small air-source heat pump classification

\begin{tabular}{|c|c|c|c|c|}
\hline AHRI Type* & HP type & Single/Multizone & $\begin{array}{c}\text { AHRI Rating } \\
\text { Standard }\end{array}$ & Ducted/Ductless \\
\hline HRCU-A-CB-O & Air-air & single & $\begin{array}{c}\text { ANSI/AHRI - } \\
210 / 240\end{array}$ & ductless \\
\hline HMSV-A-CB & Air-air & multi & ANSI/AHRI-1230 & either \\
\hline HRCU-A-CB** & Air-air & single & $\begin{array}{c}\text { ANSI/AHRI - } \\
210 / 240\end{array}$ & ducted \\
\hline
\end{tabular}

* these types include indoor fan power (indicated by the "B")

** can be centrally ducted, or single-zone ducted mini-split

The BEopt default ASHP model is based on a "generic" cold-climate centralized ASHP with a defrost cycle and integrated supplementary electric heating. Both the heat pump capacity and supplementary capacity are auto-sized for each building variant based on the peak heating load as determined using the standard ACCA Manual J method. The BEopt ASHP model was developed when EnergyPlus was incapable of modelling an ASHP below an ODB of $-20{ }^{\circ} \mathrm{C}\left(-4{ }^{\circ} \mathrm{F}\right)$. The minimum operating temperature has thus been modified to $-30{ }^{\circ} \mathrm{C}\left(-22^{\circ} \mathrm{F}\right)$ to reflect current bestin-class performance (Mitsubishi, 2017). Key metrics for the heat pump model are found Table 4-12 and performance details for each of the four compressor/fan speeds in Table 4-13. BEopt and EnergyPlus require heat pump model inputs in terms of "gross COP/EER" rather than "net COP/EER" (NREL, 2013). The latter includes energy consumed by the indoor fan whereas the former does not, because EnergyPlus models the fan power dynamically based on the individual building duct system, which governs the required volumetric flow rate and static pressure requirement. Since AHRI, NEEP, and manufacturers typically use net COP/EER (i.e., overall), this presents a major difficulty in developing valid heat pump models. 
Table 4-12 ASHP model inputs

\begin{tabular}{|c|c|}
\hline HSPF & 10 \\
\hline SEER & 22 \\
\hline Compressor speeds & 4 \\
\hline Heating cycling fraction & 0.24 \\
\hline Cooling cycling fraction & 0.25 \\
\hline Indoor supply fan power & $0.3 \mathrm{~W} / \mathrm{cfm}$ \\
\hline $\begin{array}{c}\text { Minimum operating } \\
\text { temperature }\end{array}$ & $-30^{\circ} \mathrm{C}\left(-22^{\circ} \mathrm{F}\right)$ \\
\hline
\end{tabular}

Table 4-13 ASHP model input values

\begin{tabular}{|c|c|c|c|c|c|}
\hline $\begin{array}{c}\text { Fan/Compressor } \\
\text { Speed }\end{array}$ & $\begin{array}{c}\text { Capacity } \\
\text { Ratio }\end{array}$ & $\begin{array}{c}\text { Cooling } \\
\text { Fan Speed } \\
\text { Ratio }\end{array}$ & $\begin{array}{c}\text { Heating } \\
\text { Fan Speed } \\
\text { Ratio }\end{array}$ & $\begin{array}{c}\text { EER } \\
\left(\mathbf{9 5} \mathbf{~}^{\circ} \mathbf{F} \text { ODB }\right)\end{array}$ & $\begin{array}{c}\text { COP } \\
\left(\mathbf{4 7} \mathbf{~}^{\circ} \mathbf{F} \text { ODB }\right)\end{array}$ \\
\hline 1 & 0.49 & 0.7 & 0.76 & 17.4 & 4.82 \\
\hline 2 & 0.67 & 0.9 & 0.92 & 16.8 & 4.56 \\
\hline 3 & 1 (nominal) & 1 & 1 & 14.3 & 3.89 \\
\hline 4 & 1.2 & 1.26 & 1.22 & 13 & 3.92 \\
\hline
\end{tabular}

\subsubsection{Mini-Split Heat Pump (MSHP)}

The MSHP, already discussed in Subsection 4.3.2, is a multi-zone, ductless model with four wall-mounted indoor units (IDUs). Like the ASHP, it also provides space cooling, but does not include integrated supplementary electric heating. Therefore, although it is not always necessary, the "MSHP" building models include supplementary electric baseboard heating. The EnergyPlus/BEopt heat pump model input parameters are very different for a MSHP than for an ASHP. The MSHP model is also a BEopt default model based on a single-zone ductless unit that can be found in the NEEP database under the AHRI Certificate No. 7002444. Since a single-zone (i.e., one wall-mounted IDU) cannot provide uniform space conditioning delivery to a fourbedroom, two-story house, the model has been modified to have four IDUs. This has been done by reducing the HSPF from 12 to 11 , which is the rated difference between the single and multizone models of the same product line from the same manufacturer, and by multiplying the indoor fan power by four. Both modifications result in a reduction in efficiency to the default BEopt model.

Unlike the ASHP, there is no minimum operating temperature for the MSHP, but rather a linear reduction in heating capacity (in addition to the reduction in COP) with reducing ODB, 
defined by a "heating capacity retention fraction." This value is a measure of the maximum heating capacity at a tested cold temperature $\left(-25^{\circ} \mathrm{C}\right.$ in this case) relative to the maximum heating capacity at the rated temperature of $8.33{ }^{\circ} \mathrm{C}$. This capacity allows the heat pump to be auto-sized for the given building enclosure and climate, based on the peak heating load and design heating temperature as determined by the Manual $J$ calculation. The heating capacity offset is the amount by which the nominal heating capacity at the rated temperature exceeds the nominal cooling capacity at the rated temperature. Heat pumps are labelled based on their nominal/rated cooling capacity. For example, for a $15 \mathrm{kBtu} / \mathrm{h}$ heat pump with a heating capacity offset of $2.3 \mathrm{kBtu} / \mathrm{h}$, and a maximum heating capacity fraction of 1.3 at the rated temperature, the maximum heating capacity at the rated temperature is: $(15+2.3) \times 1.3=22.5 \mathrm{kBtu} / \mathrm{h}$. See Table $4-14$ for a summary of the BEopt MSHP model inputs, and Figure 4-5 and Figure 4-6 for a characterization of the efficiency and capacity range versus outdoor temperature of the single-zone version of the heat pump using data from the NEEP database. Note that the large capacity range enabled by the variable speed fans and compressor allows better simultaneous load-matching between the building demand and heat pump output. This reduces the heating cycling rate, thereby increasing both comfort and efficiency.

Table 4-14 MSHP model inputs

\begin{tabular}{|c|c|}
\hline HSPF & 11 \\
\hline SEER & 18 \\
\hline Compressor speeds & Variable \\
\hline Heating cycling fraction & 0.4 \\
\hline Cooling cycling fraction & 0.25 \\
\hline Installed supply fan power & $\begin{array}{c}4 \text { fans } \times 0.07 \\
\mathrm{~W} / \mathrm{cfm}\end{array}$ \\
\hline Heating capacity offset & $2.3 \mathrm{kBtu} / \mathrm{h}$ \\
\hline
\end{tabular}




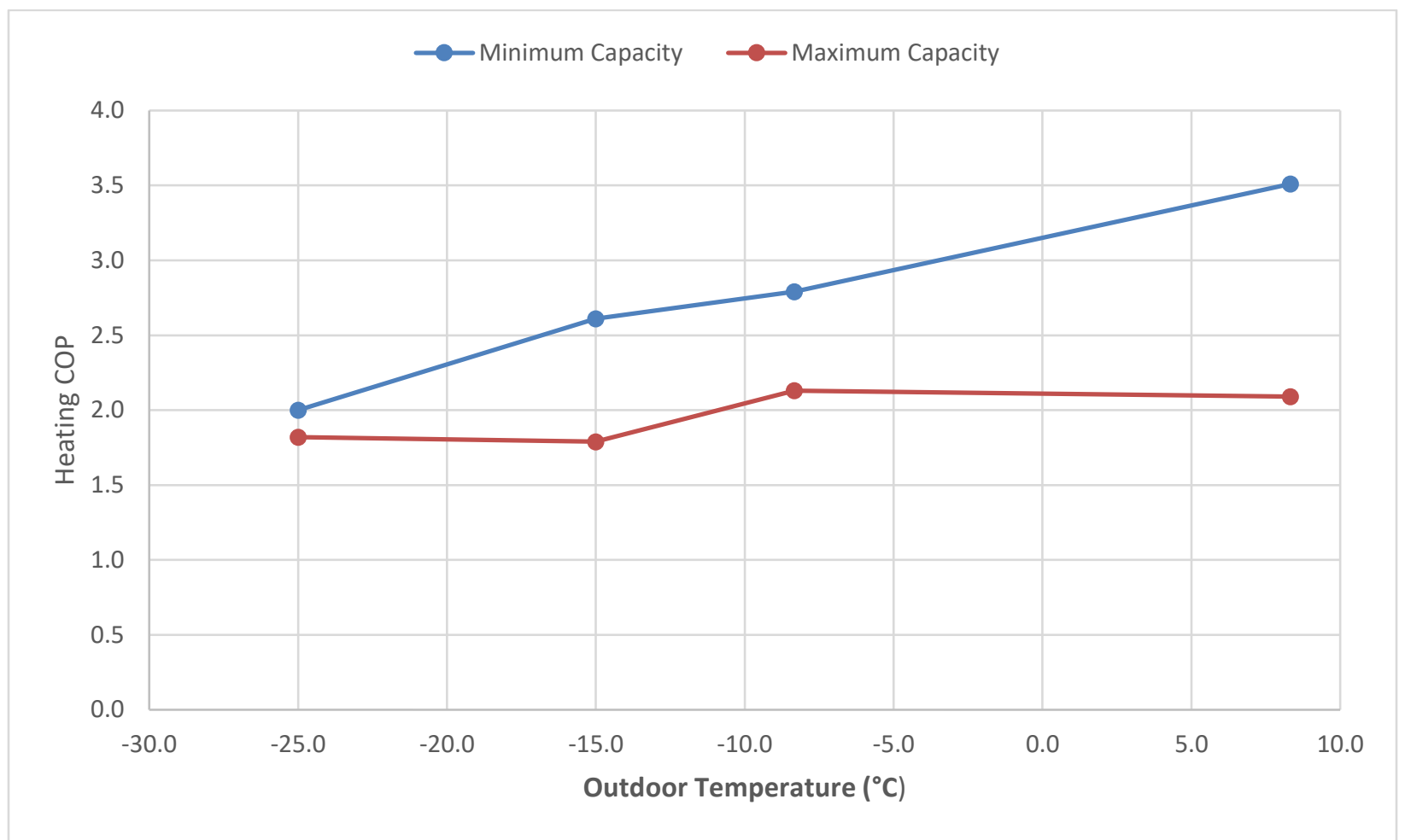

Figure 4-5 MSHP heating COP versus outdoor temperature

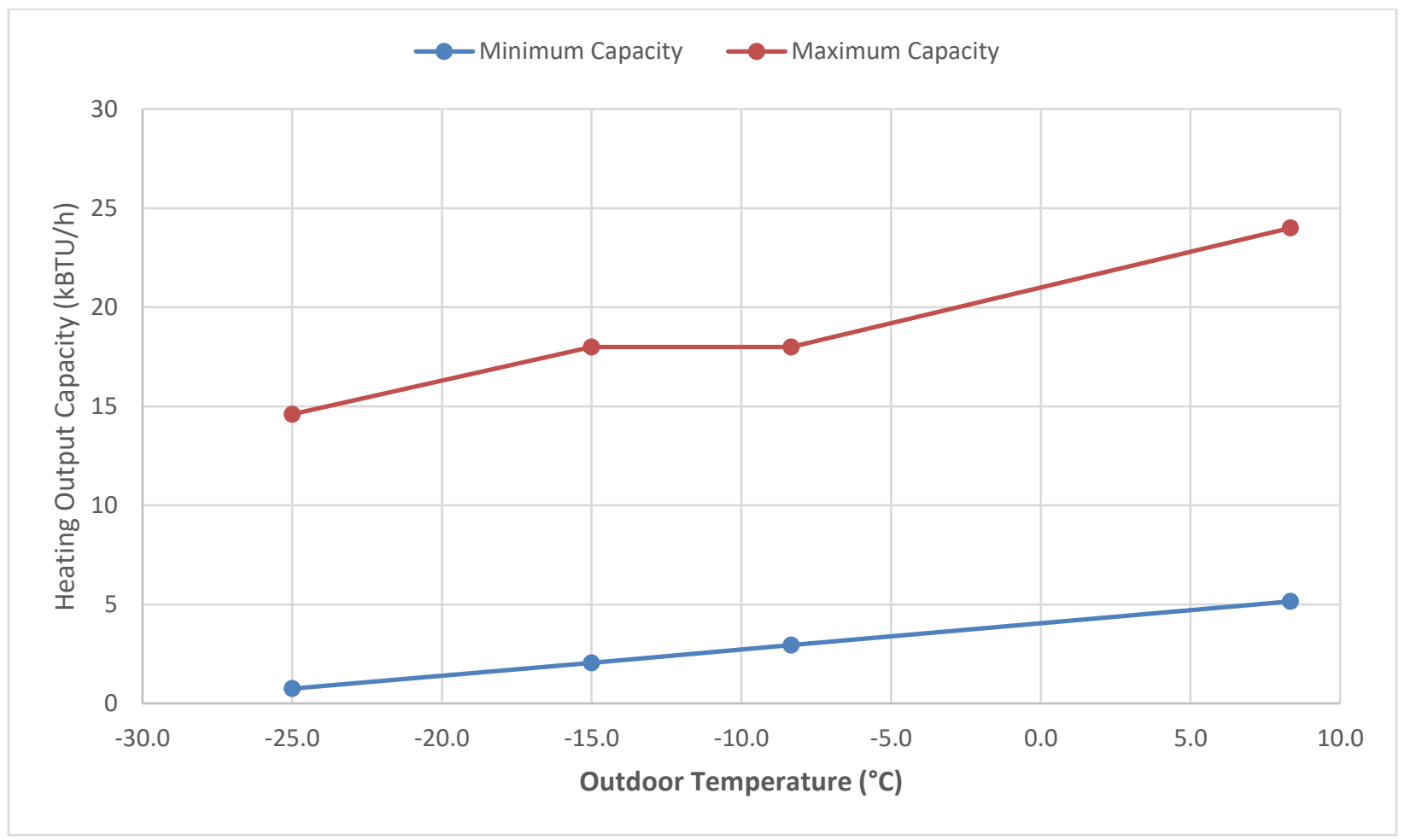

Figure 4-6 MSHP heating capacity versus outdoor temperature 


\subsubsection{Ground-Source Heat Pump (GSHP)}

The GSHP is the BEopt default EER 20.2, COP 4.2 rated model with a vertical heat exchange bore field, modelled in all locations with a mid-range conductivity soil. In terms of heating and cooling forced-air delivery and integrated supplementary electric heating, it is the same as the ASHP model. There is no option to produce DHW using a GSHP in BEopt, therefore a standalone HPWH is included, as with the other heat pump building models. Table 4-15 summarized the BEopt GSHP model inputs. The heating and cooling capacity, and borehole number, configuration, and depths are auto-sized separately for each modeled building variant.

\section{Table 4-15 BEopt GSHP model input parameters}

\begin{tabular}{|c|c|c|}
\hline Input Parameter & Value & Unit \\
\hline COP & 4.2 & \\
\hline EER & 20.2 & $\mathrm{ft} / \mathrm{ton}$ \\
\hline Bore field efficiency* & 421 & \\
\hline Heat exchanger (HX) type & vertical & BTU/ft-h-R \\
\hline Ground conductivity & 0.75 & BTU/ft-h-R \\
\hline Grout conductivity & 0.8 & $\mathrm{ft}$ \\
\hline Bore spacing & 20 & in \\
\hline Bore diameter & 5 & in \\
\hline Nominal pipe size & 0.75 & $\mathrm{ft}$ '2/h \\
\hline Ground diffusivity & 0.282 & \\
\hline HX fluid type & propylene-glycol & $\mathrm{F}$ \\
\hline Glycol fraction & 0.3 & $\mathrm{ft}$ of water \\
\hline Ground loop design delta-T & 10 & \\
\hline Pump head & 50 & $\mathrm{~W} / \mathrm{cfm}$ \\
\hline U-tube spacing type & $\mathrm{B}$ & \\
\hline Indoor supply fan power & 0.5 & \\
\hline
\end{tabular}

*Auto-calculated value based on input parameters

\subsubsection{Electric}

The primary advantage of electric baseboard space heating is the low initial cost. Part of the capital savings are due to the lack of space conditioning delivery system; therefore, a window $\mathrm{AC}$ unit is included in this model for cooling to preserve this effect. It is recognized that a single window AC unit, while sufficiently sized to meet the whole-building peak cooling load, would not provide the same comfort level as a centralized AC system. Furthermore, there would be little to no operational savings by using a HPWH for DHW, since the ultimate heat source is electric resistance through most of the year. Since an electric water heater is initially cheaper than a HPWH, this is used in the "Electric" house model. 


\subsubsection{Thermal Systems Summary}

As mentioned, the "Gas" optimization contains the same system type as the "Reference" model but with improved efficiency options (see Chapter 5 for details). All models undergo a whole-building optimization except the "Reference" model. Table 4-16 summarizes the thermal five thermal systems described in this section, as well as the Reference system.

Table 4-16 Thermal system model inputs summary

\begin{tabular}{|c|c|c|c|c|c|}
\hline $\begin{array}{l}\text { Model } \\
\text { Name }\end{array}$ & DHW & Cooling & Heating & $\begin{array}{l}\text { Backup } \\
\text { Heating }\end{array}$ & Delivery \\
\hline Reference & $\begin{array}{l}\text { natural gas, } 40 \text { gal. } \\
\text { Energy Factor } 0.59\end{array}$ & $\begin{array}{c}\text { central AC, SEER } \\
15 \\
\end{array}$ & $\begin{array}{c}\text { natural gas furnace, } \\
80 \% \text { AFUE }\end{array}$ & NA & ducted air \\
\hline Gas & $\begin{array}{l}\text { natural gas (tank/ } \\
\text { tankless options) }\end{array}$ & $\begin{array}{c}\text { central AC } \\
\text { (multiple options) }\end{array}$ & $\begin{array}{c}\text { natural gas furnace } \\
\text { (multiple options) }\end{array}$ & NA & ducted air \\
\hline ASHP & $\begin{array}{l}\text { HPWH 80-gal, Energy } \\
\text { Factor } 2.3\end{array}$ & $\begin{array}{c}\text { central ASHP, } \\
\text { SEER } 22 \\
\end{array}$ & $\begin{array}{c}\text { central ASHP, } 10 \\
\text { HSPF }\end{array}$ & $\begin{array}{c}\text { integrated } \\
\text { electric }\end{array}$ & ducted air \\
\hline MSHP & $\begin{array}{c}\text { HPWH 80-gal, Energy } \\
\text { Factor } 2.3 \\
\end{array}$ & $\begin{array}{c}\text { ductless MSHP, } \\
\text { SEER } 22\end{array}$ & $\begin{array}{c}\text { ductless MSHP, } 11 \\
\text { HSPF }\end{array}$ & $\begin{array}{c}\text { baseboard } \\
\text { electric }\end{array}$ & $\begin{array}{c}4 \text { Indoor } \\
\text { units }\end{array}$ \\
\hline GSHP & $\begin{array}{c}\text { HPWH 80-gal, Energy } \\
\text { Factor } 2.3 \\
\end{array}$ & $\begin{array}{c}\text { central GSHP, EER } \\
20.2 \\
\end{array}$ & $\begin{array}{c}\text { central GSHP, COP } \\
4.2\end{array}$ & $\begin{array}{c}\text { integrated } \\
\text { electric }\end{array}$ & ducted air \\
\hline Electric & $\begin{array}{l}\text { electric tank, } 50 \text { gal. } \\
\text { Energy Factor } 0.95\end{array}$ & $\begin{array}{c}\text { window } A C, \text { EER } \\
10.7\end{array}$ & electric baseboard & NA & NA \\
\hline
\end{tabular}

\subsection{Baseline Models Performance}

In addition to the "Reference" model for each location, each of the other four thermal system types have been modelled within the (non-optimized) reference building enclosure for the Toronto location to determine the energy efficiency of each space heating system and the total building EUI for each system type. This allows a baseline comparison with the whole-building optimizations for each system type in Chapter 6. Optimal thermal system component efficiencies for the "Gas" model are determined by the optimization results and so that model is not evaluated here.

\subsubsection{Thermal Envelope Performance (SHDI)}

The "thermal envelope performance" in this study is taking to be the overall building enclosure thermal performance, accounting for the thermal resistance, air leakage, and solar gain through the enclosure, as well as the heat recovered by the HRV/ERV. It also accounts for all internal heat gains from occupants, lighting, and appliances, all of which remain static across all models in this study. It is expressed as the SHDI value, and it varies by location due to climate as 
well as differences in the NBC 9.36 "Reference" enclosure design. Aside from slight variations in internal heat gain, and interactions with the HPWH, the SHDI value would not be substantially affected by different thermal system types. BEopt does not indicate space heating demand directly, but rather delivered heating energy (since heating systems with different delivery systems have varying amounts of heat loss through ducts, for consistency in this study SHDI is always determined by modelling the building in question with electric baseboard heating, which does not suffer delivery losses). "Reference" model SHDI and EUI values for all locations are illustrated in Figure 4-7 (recall that SHDI does not refer to the portion of the EUI used for heating energy input, but to the thermal energy output of the space heating system).

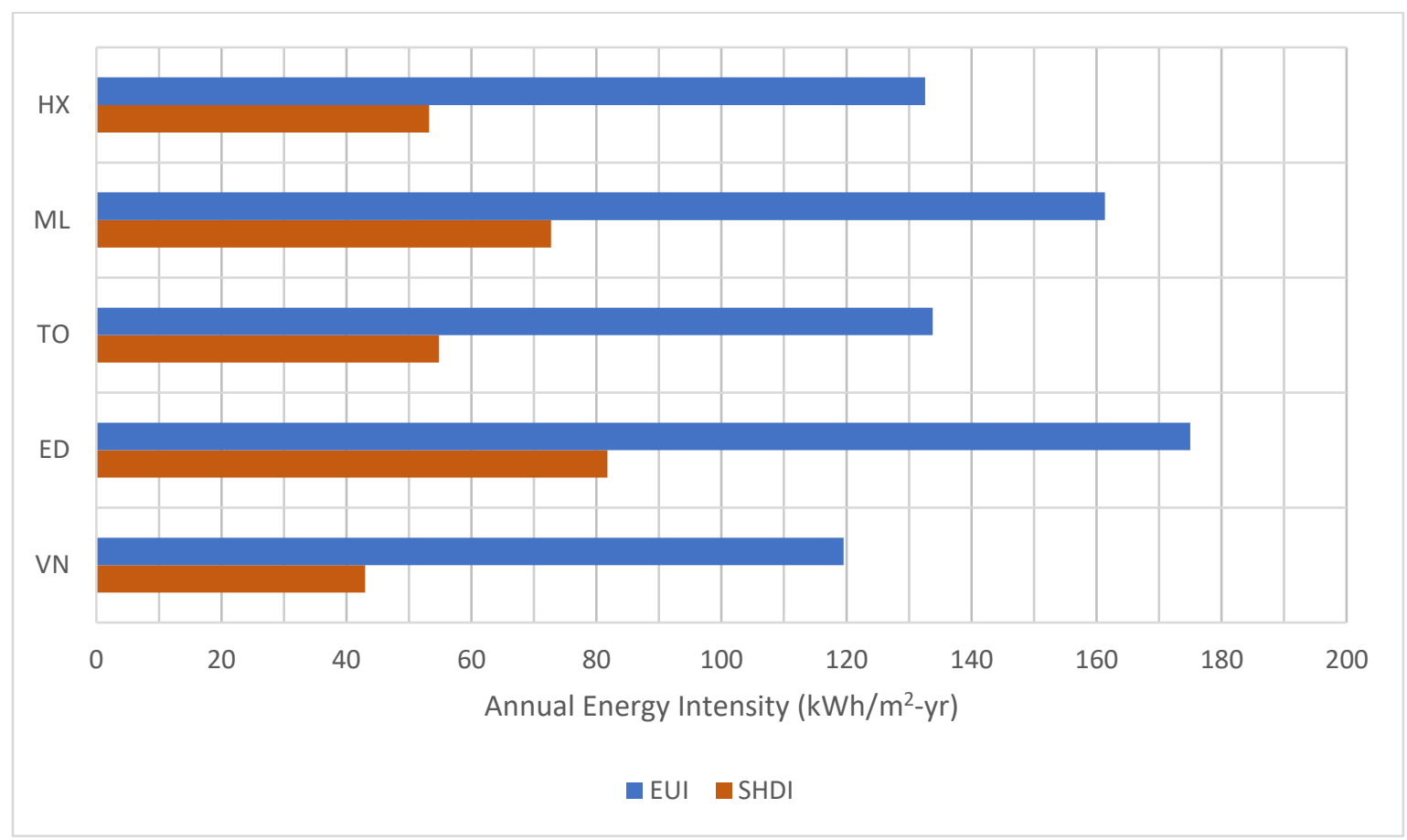

Figure 4-7 Reference model SHDI and EUI

\subsubsection{Purchased Energy Consumption (EUI)}

Figure 4-8 provides some insight into the energy end-use breakdown for the "Reference" model in Toronto, and how each of the all-electric thermal systems perform in the same building enclosure and location. The natural gas furnace and water heater in the "Reference" model are low-medium efficiency, and an improved system is optimized in the "Gas" design in Chapter 6. Furthermore, the fact that there are two types of purchased energy included in the chart renders it 
impossible to conclude anything about the operational cost or GHG emissions of the "Reference" building relative to the other buildings.

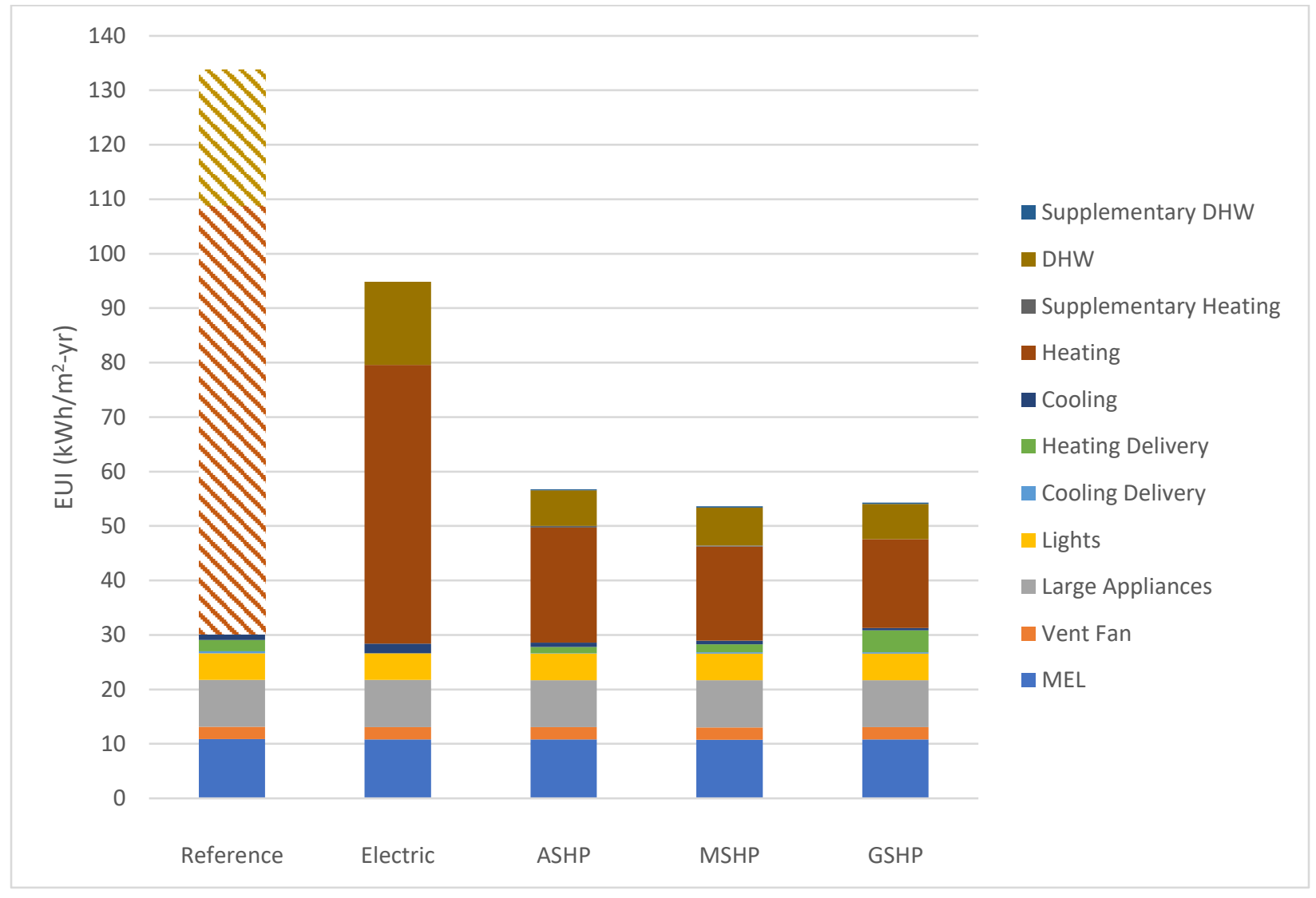

Figure 4-8 EUI Breakdown by end-use for thermal system-specific Toronto baseline models (hatching=natural gas, solid=electricity)

Table 4-17 summarizes the heating energy for each heat pump model and the resultant "Total simulated COP." This value includes duct losses and supplementary heat delivered in the numerator, and electricity used for the heat pump, delivery, and supplementary electric heating in the denominator. Note that although the MSHP has the lowest total heating COP, it has the lowest total purchased energy requirement (Figure 4-8). This is primarily due to the lack of heat lost through ducts. The MSHP is required to generate less heat annually to satisfy space heating demand (the "heating-main" value for the MSHP exceeds that for the other two heat pumps because EnergyPlus credits a portion of the duct losses as useful heat). Baseline model ducts have a $7.5 \%$ leakage rate and are uninsulated. Duct insulation is investigated in the optimizations. 
Table 4-17 Total simulated COP and heating delivery for Toronto baselines

\begin{tabular}{|c|c|c|c|}
\hline & ASHP & MSHP & GSHP \\
\hline Heating COP & 3.00 & 2.91 & 3.22 \\
\hline Cooling COP & 4.58 & 3.99 & 5.37 \\
\hline \multicolumn{4}{|c|}{ Delivered Heating (kWh/y) } \\
\hline Heating - main & 11,888 & 13,433 & 11,053 \\
\hline Heating - supplementary & 67 & 44 & \\
\hline Heating duct losses & 4,587 & & 4,930 \\
\hline
\end{tabular}




\section{Life-Cycle Cost Optimization}

This chapter discusses, justifies, and summarizes the optimization model input parameters. These parameters are separated into: location-specific factors, fixed financial metrics, and design input options. Each of the 30 optimization runs (see Figure 3-3) contains some variation in these input parameters.

\subsection{Location-Specific Factors}

The purpose of conducting the optimizations in five different Canadian cities is to evaluate by location the merit of energy conservation measures (passive and active), the electrification of heating, and onsite renewable generation on both LCC and GHG emissions. This section describes the factors affecting these values, due to: energy performance (climate and latitude), indirect emissions (electricity EF), construction cost (City Cost Index), and energy costs (purchased energy prices).

\subsubsection{Climate and Latitude}

All locations are Canadian Cities and are therefore heating-dominant, cold climates, with Vancouver being the warmest (and most temperate), and Edmonton the coldest. Aside from affecting the local climate, latitude is relevant in determining the solar PV generation potential, with Edmonton being the northernmost location, and Toronto the southernmost. Latitude also affects the seasonal fluctuation in electricity generation, which is not of concern to a customer with a grid-tied net metering contract, and therefore not directly relevant to this study, but can inform the aggregate value/burden of distributed solar generation to the electric utility.

Table 5-1 summarizes the climate and location data for each location in this study. Data is from NBC 2015, Volume I, Table C-2 (NBC Volume I, 2015). The house was modeled as suburban and locations outside of the city center were chosen where possible. The input CWEC (.epw) weather files for the simulation are not from $N B C 2015$, but correspond closely with the $N B C 2015$ locations. The design data from NBC 2015 is for illustration only. Actual design parameters are determined by EnergyPlus based in the .epw data according to ACCA Manual J, which employs a similar method.

The default weather files in BEopt/EnergyPlus for all Canadian locations use the original CWEC (Canadian Weather for Energy Calculations) files, which are outdated compared to the 
TMY3 files for U.S. locations. The white paper by RWDI, "Modelling Energy Futures" outlines the importance of using up-to-date weather files, given the measurable change in climate (Toronto specifically) over the past two decades. Their analysis and research indicate that, where the CWEC files (1958-1989) place Toronto in climate zone 6, data from 2000-2014 places it in climate zone 5 (RWDI, 2016). Furthermore, projected climate change indicates that it will be in climate zone 4 by the 2040s. The CWEC 2016 weather files for this study generate a typical meteorological year (TMY) using data from the 30 years prior to 2015. They are sourced from the website "climate.onebuilding.org" (Climate, 2018). These files have only been made publicly available recently, and EnergyPlus has not yet updated their default weather files for Canadian locations. It is not clear when/if they will be provided directly by the Government of Canada.

Table 5-1 Climate and location data

\begin{tabular}{|c|c|c|c|c|c|c|c|c|c|}
\hline \multirow{3}{*}{$\begin{array}{l}\text { Location } \\
\text { (NBC 2015) }\end{array}$} & \multirow{3}{*}{$\begin{array}{l}\text { Elevation } \\
\text { (m) }\end{array}$} & \multirow{3}{*}{$\begin{array}{l}\text { Latitude } \\
\text { (N) }\end{array}$} & \multicolumn{4}{|c|}{ Design Temperature } & \multirow{3}{*}{$\begin{array}{c}\text { Degree } \\
\text { days } \\
\text { below } \\
18^{\circ} \mathrm{C}\end{array}$} & \multirow{3}{*}{$\begin{array}{l}\text { NBC } \\
\text { Zone }\end{array}$} & \multirow{3}{*}{$\begin{array}{c}\text { CWEC } \\
2016 \\
\text { Climate } \\
\text { File }\end{array}$} \\
\hline & & & \multicolumn{2}{|c|}{ January } & \multicolumn{2}{|c|}{ July $2.5 \%$} & & & \\
\hline & & & $2.5 \%{ }^{\circ} \mathrm{C}$ & $1 \%{ }^{\circ} \mathrm{C}$ & Dry ${ }^{\circ} \mathrm{C}$ & $\begin{array}{l}\text { Wet } \\
{ }^{\circ} \mathrm{C}\end{array}$ & & & \\
\hline $\begin{array}{c}\text { Vancouver } \\
\text { (Granville \& } \\
41 \text { Ave) }\end{array}$ & 120 & $49^{\circ} 15^{\prime}$ & -6 & -8 & 28 & 20 & 2925 & 4 & Airport \\
\hline Edmonton & 645 & $53^{\circ} 32^{\prime}$ & -30 & -33 & 28 & 19 & 5120 & $7 A$ & City \\
\hline $\begin{array}{c}\text { Toronto } \\
\text { (North York) }\end{array}$ & 175 & $43^{\circ} 42^{\prime}$ & -20 & -22 & 31 & 24 & 3760 & 5 & City \\
\hline $\begin{array}{c}\text { Montreal } \\
\text { (St Laurent) }\end{array}$ & 45 & $45^{\circ} 30^{\prime}$ & -23 & -26 & 30 & 23 & 4270 & 6 & $\begin{array}{c}\text { Trudeau } \\
\text { airport }\end{array}$ \\
\hline Halifax & 55 & $44^{\circ} 38^{\prime}$ & -16 & -18 & 26 & 20 & 4000 & 6 & Dockyard \\
\hline
\end{tabular}

\subsubsection{Electricity Emissions Factor (EF)}

See Subsections 2.2.3 and 2.3.7 for a discussion of average and marginal annual EF, and Figure 2-12 for values for each of five electric grids (ECCC, 2018), (Energy Star, 2017). The carbon intensity of onsite natural gas combustion is constant for all locations at $179.1 \mathrm{~g} \mathrm{CO}_{2} \mathrm{e} / \mathrm{kWh}$ of input chemical energy, as per the same source as the marginal EFs (Energy Star, 2017).

\subsubsection{City Cost Index (CCI)}

The material and labour costs for all BEopt components are from NREL's NREMDB and represent the U.S. national average in USD. Costs for rapidly developing technologies, such as LED lighting and solar PV are updated frequently. To adjust these costs for each city, the RSMeans 
"City Cost Index" (CCI) has been applied. For Canadian cities, the CCI simultaneously adjusts for local construction costs and currency conversion from USD to CAD (RSMeans, 2015). By using the 2017 base CCI values for Canadian Cities, and fuel price inputs in CAD, all cost output from BEopt is in CAD (the 2017 average currency conversion was 0.77 CAD/USD). The CCI format used is the "MasterFormat" (MF2014). There is a separate CCI for materials and labour. The BEopt cost multiplier input corresponds to the CCI/100 (see equation (5-6). See Table 5-2 for a the CCI values used in the BEopt models.

$$
\begin{aligned}
& \text { Local Cost }(C A D) \\
& \qquad=\frac{\text { Local Canadian CCI }}{100} \times \text { US National Average Cost (USD) }
\end{aligned}
$$

\section{Table 5-2 RSMeans (2017) CCI (RSMeans, 2017)}

\begin{tabular}{|c|c|c|}
\hline City & Material & Labour/Inst. \\
\hline Vancouver & 115.6 & 93.9 \\
\hline Edmonton & 119.8 & 98.6 \\
\hline Toronto & 114.5 & 105.6 \\
\hline Montreal & 115.7 & 91.5 \\
\hline Halifax & 116.1 & 85 \\
\hline
\end{tabular}

\subsubsection{Purchased Energy Prices}

The only two types of purchased energy investigated in this study are electricity, which is necessary in all buildings, and natural gas. These constitute the second and first most common types of space heating input energy, respectively, for residential buildings in Canada (see Figure 2-8). The term "purchased energy," is necessary because electricity is not considered a fuel, and appropriate because it is precisely that energy with a cost that a homeowner seeks to minimize for reducing the building's operational cost. Such a statement may appear obvious, however it is useful to emphasize, since building enclosure designers and energy modelers sometimes prioritize reduction in the thermal energy demand (i.e., SHDI). This approach neglects the thermal conversion efficiency of the mechanical system, and the unit price of the input purchased energy, which can vary greatly by location. SHDI, therefore, may provide one with little-to-no useful information about the operational space heating cost of a building, if the heating system efficiency 
and type are not known. A potential reason for such an economically suboptimal design approach is an ongoing disconnect between the civil/architectural disciplines and the mechanical discipline. Every effort was made to provide current residential rates including all charges that ratepayers are subject to.

Electricity prices were derived from Hydro Quebec's annual report, "Comparison of Electricity Prices in Major North American Cities" (Hydro Quebec, 2017). This is the only known centralized repository of electricity rates across Canada (only selected cities) using a consistent comparison methodology and is also referenced by the Ontario Energy Board website. Variation in rate structures by province, utility, distribution company, and retailers render such a resource very valuable. These include all marginal and fixed charges based on a monthly usage of 1000 kWh. Rates have been disaggregated into monthly fixed and marginal (i.e., \$/kWh) rates according to sample bills and bill calculators from the relevant provincial government website. Furthermore, the aggregate rate from the Hydro Quebec report for Toronto has been discounted by $25 \%$ based on the "Ontario Fair Hydro Plan" which came into effect after the publication of the 2017 Hydro Quebec report. This was deemed acceptable based on the claim that "Ontario is lowering electricity bills by 25 per cent on average for all residential customers," and that the Quebec Hydro report rates are based on whole bills (including tax) for a typical residence consuming $1000 \mathrm{kWh} / \mathrm{month}$ (Ontario Energy Board, 2017).

There is no such central repository for natural gas prices across Canadian locations, and these rate structures can be similarly complex and discrepant. BEopt contains detailed, up to date rates for all electricity and natural gas utilities in the U.S. through the "OpenEI" database. The database does not contain rates for Canadian utilities, but such a project would be very valuable for NRCan to undertake. All electricity and natural gas prices include the relevant provincial and federal sales tax. For a natural gas price calculation details, see the "natural gas price.xls" file in the Appendix.

Natural gas prices were determined from sample bills and bill calculators from a combination of provincial government and natural gas retailer websites. In all cases, prices have been aggregated into marginal (\$/unit energy), and fixed (\$/month) prices, as inputs for BEopt. Separating marginal and fixed prices is important for calculating the benefit of full electrification due to the elimination of the fixed charge for natural gas service. For illustration only, Figure 5-1 provides a price comparison for the two purchased energy sources by location. Annual usage for 
electricity of $12 \mathrm{MWh}$ is the same as the value from the Hydro Quebec report, and considered the provincial average by the Ontario Energy Board. Natural gas usage of $80 \mathrm{GJ}$ is a typical value for a single detached Canadian home. For comparison, the TO-Reference model consumes 91 GJ. Consumption can vary substantially by location, thermal envelope performance, and furnace/water heater efficiency. Total energy price will vary depending on actual annual usage since the ratio of fixed charges to marginal charges will vary. BEopt calculates actual charges separately for fixed charge and marginal usage for each simulation.

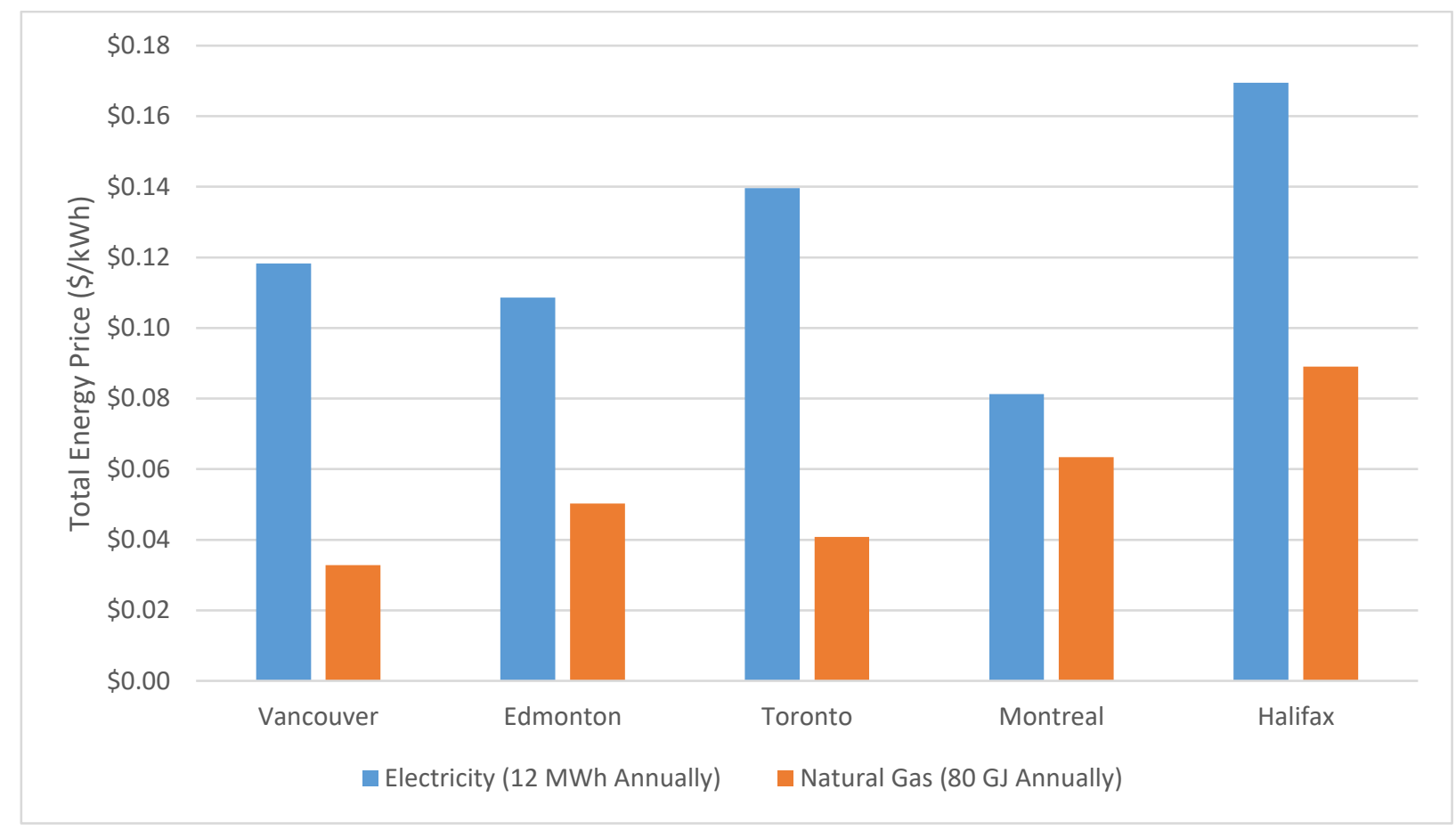

Figure 5-1 Electricity and natural gas price comparison (includes all marginal and fixed charges, expressed as a total price based on a set annual usage)

Figure 5-2 provides a detailed breakdown for natural gas prices. The "carbon" charge represents the carbon tax/levy resulting from the carbon tax or cap-and-trade program in the respective province. Electricity generators are currently exempt from the carbon tax/levy. The carbon charge has been omitted from the price in this study in an effort to evaluate subsidy-free optimal building designs. The "gas-marginal" charge is the actual cost of the fuel and is the portion of the cost that is subject to fluctuating natural gas prices. The "other-marginal" charge is for all other charges imposed on a per usage basis, including "rate riders", marginal components of transportation and delivery charges, etc. (exact bill structure varies by province). Note that for all locations most charges, whether marginal or fixed, are not for the fuel but for all other charges 
associated with administrating, operating, and maintaining the natural gas supply chain and distribution system. The high fixed charge for Edmonton is due to a "Retail Admin Fee" from the energy retailer, and the fixed component of a "Municipal Franchise Fee" from the City of Edmonton, in addition to the usual fixed charge from the gas utility.

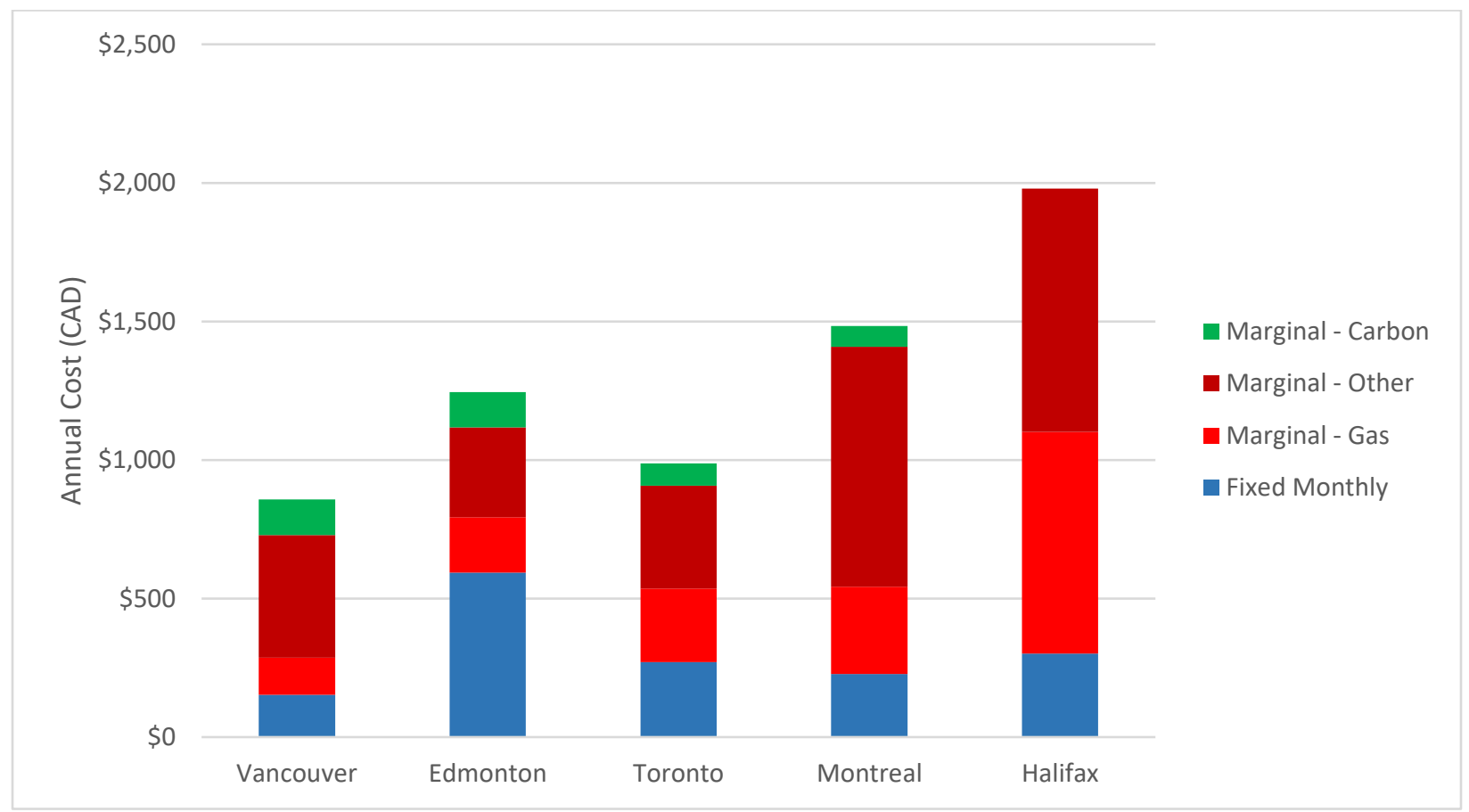

Figure 5-2 Annual cost of 80 GJ natural gas

The complexity and discrepancy in rate structures by energy type and location can easily result in flawed price comparisons. For evaluating the economic viability of the electrification of heating and complete building electrification, the primary metric of interest is the electricity/natural gas price ratio. In determining this value, it is essential to consider the effect of fixed charges. By eliminating a connection to the natural gas grid entirely, the savings in fixed charges provides a financial "boost" in favour of electric heating. This is because all buildings, whether heated by gas or electricity, nevertheless require electricity, therefore the electricity fixed charge does not figure in the question of whether to install a gas furnace or a heat pump. To 
understand the importance of this effect, Figure 5-3 illustrates the electricity/gas price ratio considering: 1) marginal prices only, 2) fixed and marginal charges ("Total") based on typical annual usage (using the same prices as Figure 5-1), and 3) the "Real" price ratio relevant for evaluating fuel switching, which includes fixed charges for gas but not electricity. Note that this effect can only be observed if there are no other gas appliances in the building, such as a gas cooktop.

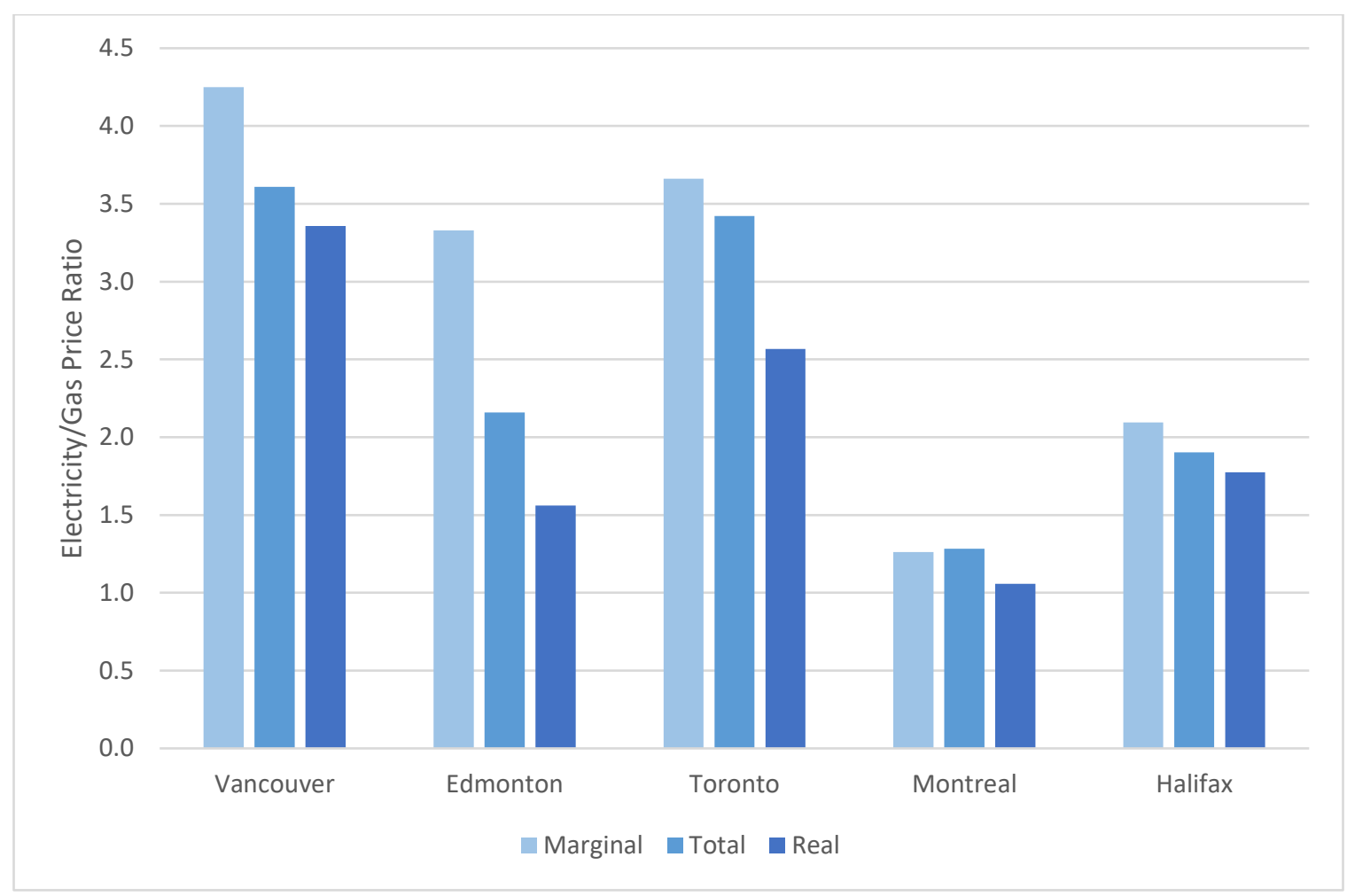

Figure 5-3 Electricity to gas price ratios (annual electricity use $=12 \mathrm{MWh}$, gas use=80 GJ)

Comparing the price ratio between the "Marginal" method and the "Real" method, the value for Toronto falls by $30 \%$, and for Edmonton as much as 53\%. The "Real" ratios will vary depending on annual gas usage, but not electricity usage. For example, if the building only requires $40 \mathrm{GJ}$ of natural gas annually, the total gas price will increase, and the electricity/gas price ratio will decrease. These ratios are useful in understanding the underlying functions affecting the viability of electrification in terms of operational cost only.

Table 5-3 and Table 5-4 summarizes the purchased energy input prices for the BEopt models and the sources from which they were retrieved or derived. All electricity prices are from the Hydro Quebec report, with only the fixed charges derived from the source listed. All values represent costs for the year 2017. 
Table 5-3 Electricity prices and sources

\begin{tabular}{|c|c|c|c|c|}
\hline Location & \multicolumn{2}{|c|}{ Electricity } & Sources & Utility \\
\hline & $\begin{array}{c}\text { Marginal } \\
\text { (CAD/kWh) }\end{array}$ & $\begin{array}{c}\text { Fixed } \\
\text { (CAD/month) }\end{array}$ & (BC Hydro, 2018) & BC Hydro \\
\hline Vancouver & $\$ 0.1101$ & $\$ 8.26$ & $\begin{array}{c}\text { EPCOR } \\
\text { 2018) }\end{array}$ & $\begin{array}{c}\text { (Utilities Consumer Advocate, } \\
\text { regulated rate }\end{array}$ \\
\hline Edmonton & $\$ 0.0785$ & $\$ 30.10$ & (Ontario Energy Board, 2018) & Toronto Hydro \\
\hline Toronto & $\$ 0.1048$ & $\$ 34.89$ & (Hydro Quebec, 2018) & Hydro Quebec \\
\hline Montreal & $\$ 0.0670$ & $\$ 14.25$ & (Nova Scotia Power, 2017) & $\begin{array}{c}\text { Nova Scotia } \\
\text { Power }\end{array}$ \\
\hline Halifax & $\$ 0.1582$ & $\$ 11.37$ & & \\
\hline
\end{tabular}

Table 5-4 Natural gas prices and sources

\begin{tabular}{|c|c|c|c|c|}
\hline Location & & Gas & Sources & Utility \\
\hline & $\begin{array}{l}\text { Marginal } \\
\text { (CAD/GJ) }\end{array}$ & $\begin{array}{c}\text { Fixed } \\
\text { (CAD/month) }\end{array}$ & & \\
\hline Vancouver & $\$ 7.19$ & $\$ 12.75$ & (Fortis BC, 2018) & Fortis BC \\
\hline Edmonton & $\$ 6.55$ & $\$ 49.50$ & $\begin{array}{l}\text { (Utilities Consumer Advocate, } \\
\text { 2018) }\end{array}$ & $\begin{array}{l}\text { Direct Energy } \\
\text { regulated rate }\end{array}$ \\
\hline Toronto & $\$ 7.95$ & $\$ 22.60$ & $\begin{array}{c}\text { (OEB 2, 2018) (Ontario Energy } \\
\text { Board, 2018) }\end{array}$ & Enbridge \\
\hline Montreal & $\$ 14.76$ & $\$ 18.98$ & (Gaz Metro, 2017) & Gaz Metro \\
\hline Halifax & $\$ 20.97$ & $\$ 25.15$ & $\begin{array}{c}\text { (Heritage Gas, 2017) (Heritage } \\
\text { Gas 2, 2017) }\end{array}$ & Heritage Gas \\
\hline
\end{tabular}

\subsection{Financial Model}

Information in this section is true for all models and all locations.

\subsubsection{Capital Costs}

Due to the large number of component options explored, comprehensive input cost data is not represented here. However, a breakdown in initial cost for the optimization output designs is provided in Chapter 6. For detailed input cost data please see the BEopt files in the Appendix.

The initial cost of the building is only for "energy related" components and equipment. Since almost every aspect of the building affects performance-including the thermal mass of gypsum wall board, roof finish material, overall wall assembly with structural wood studs, large appliances, etc. - this value excludes only a few items: concrete foundation, interior finishing, and miscellaneous electrical appliances. 
Apart from the shower DWHR unit, all material and labour cost data is derived from the NREMDB. In some cases, additional parameter options have been added, such as thicker exterior insulation sheathing options. Material and labour costs for these options have been appropriately linearly extrapolated from existing cost data. In the case of the cost of the air barrier, costs are determined using the default equation in BEopt, resulting in the inverse natural logarithmic function illustrated in Figure 5-4. Equation (5-2) defines this function. It has been extracted from BEopt and is derived from empirical data based on the U.S. national average.

Air Sealing Cost $(\$)=(0.65 \times F F A)-(0.205 \times \ln (A C H 50) \times F F A)$

Where:

FFA = building finished floor area in $\left(\mathrm{ft}^{2}\right)$

ACH50 = building airtightness in are changes per hour at 50 Pascal depressurization

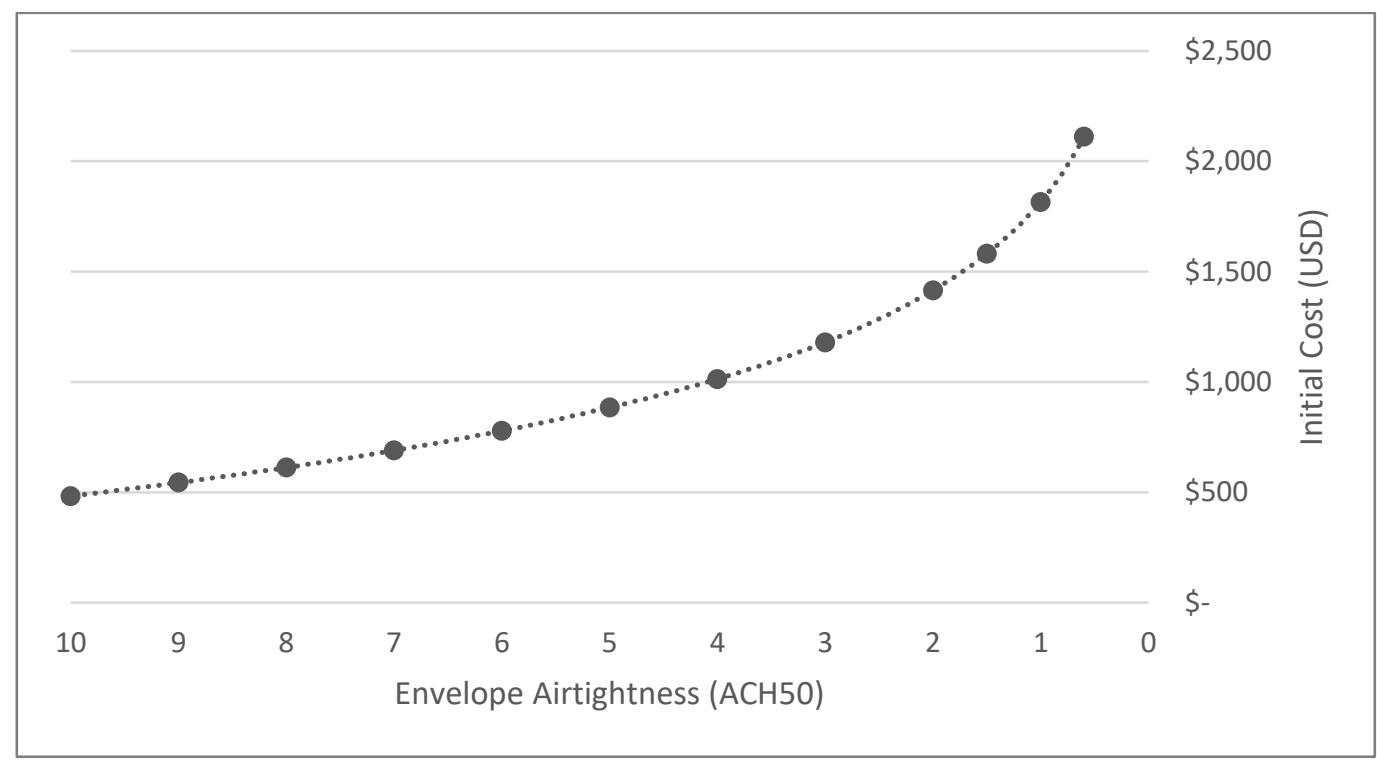

Figure 5-4 Cost of air sealing for single-detached home (U.S. national average)

Space conditioning systems have a fixed cost and a capacity cost that correlates to the design peak heating load of the building. Table 5-5 lists these costs for each thermal system (excludes DHW cost) and Figure 5-5 illustrates how each system scales with increasing capacity. 
Table 5-5 Space conditioning system input capital costs

\begin{tabular}{|c|c|c|c|c|c|c|c|c|}
\hline \multirow{3}{*}{$\begin{array}{l}\text { Design } \\
\text { Name }\end{array}$} & \multirow{3}{*}{$\begin{array}{c}\text { Space Conditioning } \\
\text { System }\end{array}$} & \multicolumn{7}{|c|}{ Price Metrics (CAD) } \\
\hline & & \multicolumn{2}{|c|}{ Heating Main } & \multirow{2}{*}{$\begin{array}{c}\text { Supplementary } \\
\text { Electric }\end{array}$} & \multicolumn{2}{|c|}{ Cooling (AC) } & \multicolumn{2}{|c|}{ Delivery (Ducting) } \\
\hline & & $\begin{array}{l}\text { Capacity } \\
\text { [output] } \\
\text { (\$/kBtuh) }\end{array}$ & $\begin{array}{c}\text { fixed } \\
\text { (\$/unit) }\end{array}$ & & $\begin{array}{l}\text { Capacity } \\
\text { (\$/kBtuh) }\end{array}$ & $\begin{array}{c}\text { fixed } \\
\text { (\$/unit) }\end{array}$ & Area $\left(\$ / \mathrm{ft}^{2}\right)$ & Total (\$/unit) \\
\hline Reference & $\begin{array}{c}\text { Gas } 80 \% \text { AFUE + AC } \\
\text { SEER } 15\end{array}$ & $\$ 3.09$ & $\$ 2,157$ & & $\$ 48.09$ & $\$ 2,698.83$ & $\$ 5.56$ & $\$ 5,266.99$ \\
\hline Gas & $\begin{array}{c}\text { Gas } 92.5 \% \text { AFUE + AC } \\
\text { SEER } 16\end{array}$ & $\$ 4.78$ & $\$ 2,630.60$ & & $\$ 48.09$ & $\$ 2,840.81$ & $\$ 7.04$ & $\$ 6,669.00$ \\
\hline ASHP & $\begin{array}{c}\text { ASHP } 10 \text { HSPF, SEER } \\
22\end{array}$ & $\$ 48.09$ & $\$ 4,395.00$ & & & & $\$ 7.04$ & $\$ 6,669.00$ \\
\hline MSHP & $\begin{array}{l}\text { MSHP } 11 \text { HSPF + } \\
\text { baseboard }\end{array}$ & $\$ 92.75$ & $\$ 1,856.62$ & $\$ 41.78$ & & & & \\
\hline GSHP & $\begin{array}{c}\text { GSHP 4.2 COP, EER } \\
20.2\end{array}$ & $\$ 564.25$ & $\$ 1,833.36$ & & & & $\$ 7.04$ & $\$ 6,669.00$ \\
\hline Electric & $\begin{array}{c}\text { Baseboard Electric + } \\
\text { window } A C\end{array}$ & $\$ 41.78$ & & & $\$ 50.95$ & $\$ 38.02$ & & \\
\hline
\end{tabular}




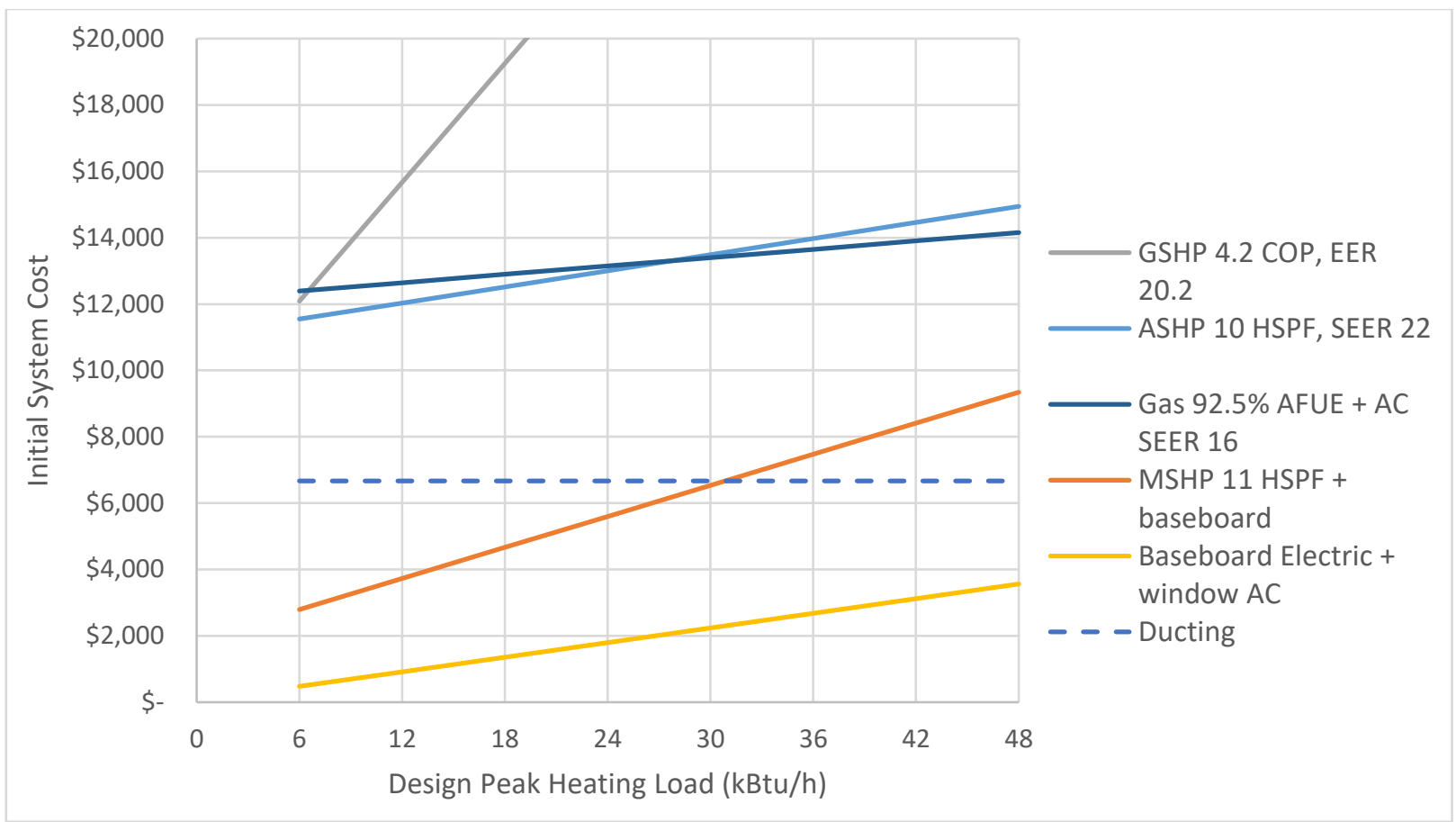

Figure 5-5 Space conditioning system initial cost (heating main, supplementary electric, cooling, and delivery)

\subsubsection{Mortgage}

While $79 \%$ of Canadians opt for a high-ratio mortgage ( $<20 \%$ down payment, maximum 25-year amortization), a conventional mortgage has been selected because it enables a longer amortization period (30 years vs. 25), and it does not require $C M H C$ mortgage default insurance (Ratehub.ca, n.d.). The software input limitations render it impossible to accurately capture the cost of default insurance for all designs in an optimization. A conventional mortgage requires a down payment of $20 \%$ (Canada, 2017). This also simplifies the financial analysis, since the financial project period is also 30 years.

The inflation rate and mortgage interest rate (5-year fixed-rate mortgage) are based on the Canadian average in the 2013-2017 period (CMHC, 2018), (Inflation.eu, 2018). The monthly mortgage payments are determined using equation (5-3). This method results in fixed monthly payments that include both the interest and principal charges over the 30-year amortization period. 


$$
\text { Monthly Payment }=P\left[\frac{m(1+m)^{n}}{(1+m)^{n}-1}\right]
$$

Where:

$P=$ Principal amount on loan after down payment

$n=$ Number of mortgage payments (i.e., $12 \times 30=360$ )

$m=$ Monthly interest rate (i.e., $0.039 / 12=0.00325$ )

\subsubsection{Economic Parameters}

The real discount rate is a function of the inflation rate and the nominal discount rate, which has been set equal to the mortgage interest rate, as per the report from the U.S. DOE EERE Building Technologies Program "Methodology for Evaluating Cost-Effectiveness of Residential Energy Code Changes" (EERE, 2012). Justification for this method is as follows:

"The purpose of the discount rate is to reflect the time value of money. Because DOE's economic perspective is that of a homeowner, that time value is determined primarily by the owner's best alternative investment at similar risk to the energy features being considered-in this case a typical homeowner who holds a home throughout a 30-year mortgage term. DOE sets the discount rate equal to the mortgage interest rate in nominal terms. Because mortgage prepayment is an investment available to consumers who purchase homes using financing, the mortgage interest rate is a reasonable estimate of a consumer's alternative investment rate."

The real discount rate is thus calculated as:

$$
R_{\text {real }}=\left[\frac{\left(1+R_{\text {nominal }}\right)}{(1+i)}\right]-1
$$

Where:

$$
\begin{aligned}
& R_{\text {real }}=\text { real discount rate } \\
& R_{\text {nominal }}=\text { nominal discount rate } \\
& i=\text { inflation rate }
\end{aligned}
$$

A summary of the mortgage and financial project inputs the BEopt model is presented in Table 5-6. Real fuel escalation rates have been kept at zero - that is, electricity and natural gas prices rise with inflation. 
Table 5-6 Mortgage and financial project inputs

\begin{tabular}{|c|c|c|c|}
\hline \multicolumn{2}{|c|}{ Economics } & \multicolumn{2}{c|}{ Mortgage } \\
\hline Project Analysis Period (yr.) & 30 & Down Payment & $20 \%$ \\
\hline Inflation Rate & $1.54 \%$ & Mortgage Interest Rate & $3.90 \%$ \\
\hline Discount Rate (Real) & $2.33 \%$ & Mortgage Period (yr.) & 30 \\
\hline Discount Rate (Nominal) & $3.90 \%$ & & \\
\hline
\end{tabular}

\subsubsection{Cash Flows and LCC}

Cash flows for the financial project include: mortgage down payment in year zero, annual mortgage payments, annual utility charges (purchased energy use), annual PV generation payments (if applicable), equipment replacement costs, and the building residual value credit in year thirty. The residual value of all building components is calculated based on linear asset value depreciation over time. This is determined based on the material input data for each component, which includes both cost and lifetime.

All cash flows except mortgage payments (principle and interest) are inflated according to the year they occur. Annual energy use is based on the annual simulation and does not change over the project life. Inflated future costs are calculated using equation (5-5).

$$
\text { Cost }_{\text {year }=k}=\text { Cost }_{\text {initial }}(1+i)^{k}
$$

Where:

$i=$ inflation rate

Cost $_{\text {initial }}=$ Cost of component/payment in year $\mathrm{k}=0$

$k=$ the year the costs occur

To understand LCC for a given model it helps to visualize an annual cash flow diagram. Output from BEopt for the optimal TO-MSHP model results in the cash flow shown in Figure 5-6. Only replacement events for HVAC and DHW equipment are labelled. Other events include ceiling fans and major appliances, and do not change for all models in this study. 


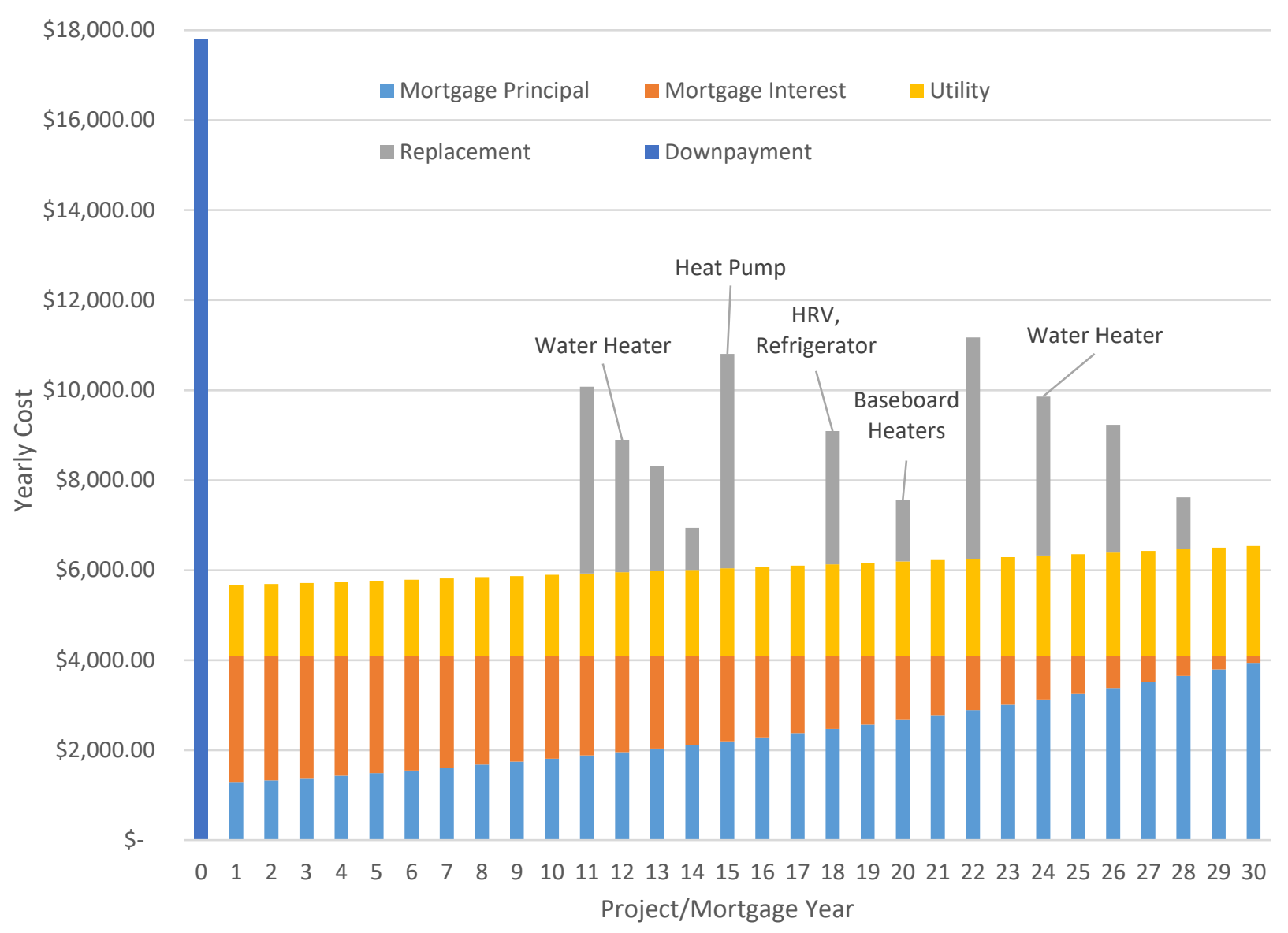

Figure 5-6 Toronto MSHP design cash flows (chart excludes residual value: $\$ 79,938$ in year 30, i.e., a negative cost)

All cash flows for a given year are then summed to obtain a net total cost (TC) for each project year. These future costs are then converted into present costs using the nominal discount rate and summed to obtain the LCC equation (5-6).

$$
L C C=\sum_{k=0}^{N}\left(T C_{\text {year }=k}\left(1+d_{n}\right)^{-k}\right)
$$

$$
\begin{aligned}
& T C_{\text {year }=k}=\text { total costs in year }=\mathrm{k} \\
& d_{n}=\text { the nominal discount rate }
\end{aligned}
$$

\subsection{Design Input Options}

This section refers to design input categories for which there is more than one parameter option selected for the optimization run. For fixed design parameters, see Table 4-9 (Table 4-3 and 
Table 4-4 for location-specific reference values), and for fixed thermal system-specific parameters, see Table 4-16. Note that of the fixed parameters, two have been reset from the Reference model, but are not optimization options. This has been done for the categories of "interzonal wall," and "interzonal floor." These are the envelope components separating the building living space from the garage, and they constitute a small portion of the total enclosure area. To reduce computational intensiveness, these components were not separately optimized. However, to ensure that they did not "pull down" the resultant optimal R-value of the rest of the enclosure, the interzonal floor and walls were reset to an effective R-value of 36.6 and 38.6 respectively (see Table 4-3 for Reference values).

The "Gas" thermal system model was the only one for which multiple heating, cooling, and DHW system efficiency options were explored (see Table 5-7). The water heater options that use a storage tank have a 40-gallon tank. However, multiple DHW and space conditioning delivery system efficiencies were explored for all applicable models (e.g., ductwork insulation for centralized conditioning systems; and hot water piping insulation, and shower DWHR for all models).

\section{Table 5-7 Optimization design input options - "Gas" model only}

\begin{tabular}{|c|c|c|c|c|c|}
\hline Group & Category & $\mathbf{1}$ & $\mathbf{2}$ & $\mathbf{3}$ & $\mathbf{4}$ \\
\hline $\begin{array}{c}\text { Space } \\
\text { Conditioning }\end{array}$ & $\begin{array}{c}\text { Central Air } \\
\text { Conditioner }\end{array}$ & SEER 15 & SEER 16 (2 stage) & SEER 18 & SEER 24.5 \\
\cline { 2 - 6 } & Gas Furnace & $80 \%$ AFUE & $92.5 \%$ AFUE & $95 \%$ AFUE & $98 \%$ AFUE \\
\hline $\begin{array}{c}\text { Water } \\
\text { Heating }\end{array}$ & $\begin{array}{c}\text { Gas Water } \\
\text { Heater }\end{array}$ & $\begin{array}{c}\text { Energy } \\
\text { Factor: } 0.59\end{array}$ & $\begin{array}{c}\text { condensing, Energy } \\
\text { Factor: } 0.82\end{array}$ & $\begin{array}{c}\text { tankless, Energy } \\
\text { Factor: } 0.82\end{array}$ & $\begin{array}{c}\text { tankless condensing, } \\
\text { Energy Factor: } 0.96\end{array}$ \\
\hline
\end{tabular}

To create an option for a DWHR unit in BEopt, a custom option for the "hot water fixtures" category was created that has a shower DHW use reduced by 53\% (the efficiency of the unit), resulting in a total DHW use reduction of 25\%. The standard 3" diameter, 60" long unit selected has a cost of $\$ 622+\$ 80$ (material and labour in USD), and a lifetime of 40 years.

Since the Reference model varies for some parameters by location (wall, ceiling, and foundation R-values, and window U-value), the lower limit of the options range varies for these categories, though intermediate options and the upper limit do not. Only design options were explored that do not comply with $N B C 9.36$ for the location in question (i.e., all options explored meet or exceed the Reference model parameter for that category, by location). The only exception to this rule is the possibility to downgrade from a U-0.27 window to a U-0.29 window for 
Edmonton, Montreal, and Halifax. Table 5-8 is a complete list of design input options used for all models. 
Table 5-8 Optimization design input options for all models

\begin{tabular}{|c|c|c|c|c|c|c|c|c|c|c|c|}
\hline Group & & Category & 1 & 2 & 3 & 4 & 5 & 6 & 7 & 8 & 9 \\
\hline Walls & 1 & $\begin{array}{c}\text { Wall } \\
\text { Sheathing }\end{array}$ & none & R-5 XPS & R-10 XPS & R-15 XPS & R-20 XPS & R-25 XPS & R-30 XPS & R-35 XPS & $\begin{array}{l}\text { R-40 } \\
\text { XPS }\end{array}$ \\
\hline \multirow{2}{*}{ Ceilings/Roofs } & 2 & $\begin{array}{l}\text { Unfinished } \\
\text { Attic }\end{array}$ & $\begin{array}{c}R-38 \\
(39.6)\end{array}$ & R-49 (50.6) & R-60 (61.6) & R-70 (71.6) & & & & & \\
\hline & 3 & $\begin{array}{l}\text { Radiant } \\
\text { Barrier }\end{array}$ & none & $\begin{array}{l}\text { double-sided } \\
\text { foil }\end{array}$ & & & & & & & \\
\hline $\begin{array}{l}\text { Foundation/ } \\
\text { Floors }\end{array}$ & 4 & $\begin{array}{l}\text { Unfinished } \\
\text { Basement }\end{array}$ & $\begin{array}{c}\mathrm{R}-12 \\
\text { polyiso } \\
(13.3)\end{array}$ & $\begin{array}{c}\text { R-18 polyiso } \\
\text { (19.3) }\end{array}$ & (22.6) & (28.1) & (33.4) & (38.6) & & & \\
\hline \multirow{3}{*}{$\begin{array}{l}\text { Windows \& } \\
\text { Doors }\end{array}$} & 5 & $\begin{array}{l}\text { Window } \\
\text { Areas }\end{array}$ & $\begin{array}{l}\text { back: } \\
23 \%\end{array}$ & back: 33\% & back: $43 \%$ & & & & & & \\
\hline & 6 & Windows & $\begin{array}{c}\text { U-value } \\
0.32 \\
\end{array}$ & U-value 0.3 & U-value 0.29 & $\begin{array}{c}\text { U-value } \\
0.27\end{array}$ & $\begin{array}{c}\text { U-value } \\
0.3 \\
\text { (triple) }\end{array}$ & $\begin{array}{c}\text { U-value } \\
0.29 \\
\text { (triple) }\end{array}$ & $\begin{array}{c}\text { U-value } \\
0.21 \\
\text { (triple) }\end{array}$ & $\begin{array}{c}\text { U-value } \\
0.18 \\
\text { (triple) }\end{array}$ & \\
\hline & 7 & Overhangs & none & $\begin{array}{c}\text { back windows: } \\
2^{\prime}\end{array}$ & $\begin{array}{c}\text { back windows: } \\
3^{\prime}\end{array}$ & & & & & & \\
\hline \multirow{2}{*}{ Airflow } & 8 & Air Leakage & $\begin{array}{c}2.5 \\
\mathrm{ACH} 50 \\
\end{array}$ & $2 \mathrm{ACH} 50$ & $1 \mathrm{ACH} 50$ & $0.6 \mathrm{ACH} 50$ & & & & & \\
\hline & 9 & $\begin{array}{l}\text { Mechanical } \\
\text { Ventilation }\end{array}$ & $\begin{array}{c}\text { HRV, } \\
\text { SRE: } 70 \%\end{array}$ & $\begin{array}{c}\text { ERV, SRE: } 70 \% \text {, } \\
\text { TRE: } 0.48 \%\end{array}$ & & & & & & & \\
\hline \multirow{2}{*}{$\begin{array}{c}\text { Space } \\
\text { Conditioning }\end{array}$} & 10 & $\begin{array}{c}\text { Duct } \\
\text { insulation }\end{array}$ & none & R-4 & $\mathrm{R}-8$ & & & & & & \\
\hline & 11 & $\begin{array}{c}\text { Ceiling Fans } \\
\text { (4 fans) }\end{array}$ & $45 \mathrm{~W} / \mathrm{fan}$ & $20 \mathrm{~W} / \mathrm{fan}$ & & & & & & & \\
\hline \multirow{2}{*}{ Hot Water } & 12 & $\begin{array}{c}\text { Pipe } \\
\text { insulation }\end{array}$ & none & $\mathrm{R}-2$ & $R-5$ & & & & & & \\
\hline & 13 & $\begin{array}{l}\text { Shower } \\
\text { DWHR }\end{array}$ & none & $53 \%$ efficiency & & & & & & & \\
\hline
\end{tabular}

Blue=VN \& TO only, Green=VN only, Yellow=category not available for "Electric" \& "MSHP" models

Bracketed values indicate assembly R-effective (US units) 


\section{Optimization Results and Discussion}

This Chapter presents the results of the LCC versus GHG whole-building optimizations for the five locations and six thermal/photovoltaic system-specific models. Resultant optimal designs of interest for the Toronto location are compared and their initial and operational costs, energy use, and GHG emissions are deconstructed. Finally, the primary and secondary objectives introduced in Section 1.1 are addressed. Additional details of the optimization inputs, resultant optimal designs, and energy/cost/emissions performance can be found in the electronic appendix.

\section{1 “Gas" Model Optimization}

This section provides an example of the optimization results for the "Gas" model. It represents a whole-building optimization using the same thermal system type as the Reference model which, as previously mentioned, is the new construction norm in Canada. It therefore can be considered the global minimum LCC gas-heated house design and can thus be used as a secondary reference or benchmark design against which to compare the true economic feasibility of all-electric and NZC design alternatives.

In all locations the optimal, or least LCC Gas design, results in reduced GHG emissions and a reduced energy-related building LCC over the Reference for that location. In Toronto it is a $33 \%$ reduction in emissions and 3\% reduction in LCC. Figure 6-1 illustrates results for the Toronto (Gas-TO) optimization, including sensitivity frontiers for the exterior wall insulation category options. Each point on the plot represents the performance and cost of a unique building design variant. The reference model is indicated on the right with a dashed grey line, and the least LCC resultant design is at the bottom with the dashed blue line. Note that while increased insulation can

result in improved energy/emissions performance, but the capital costs do not outweigh the energy cost savings (remember initial and energy costs are captured in the LCC metric). The resultant least LCC Gas design for each location is summarized in Table 6-1. Only design options are listed. For fixed input design parameters, see Chapters 4 and 5. 


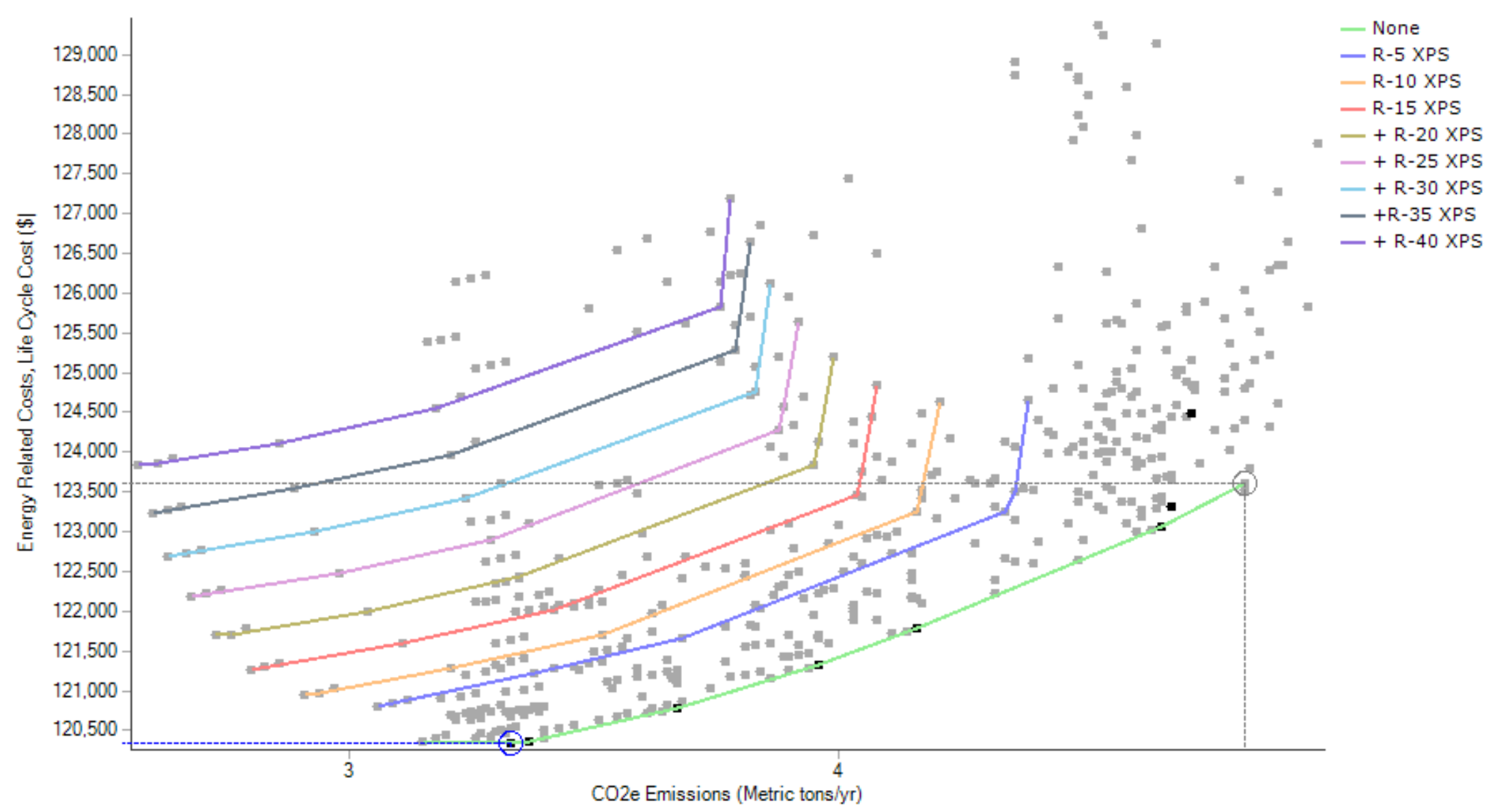

Figure 6-1 Gas-TO optimization plot with exterior wall insulation sensitivity frontiers 
Table 6-1 Resultant least LCC Gas designs by location

\begin{tabular}{|c|c|c|c|c|c|c|c|}
\hline Group & Category & Ref-TO & Gas-VN & Gas-ED & Gas-TO & Gas-ML & Gas-HX \\
\hline Walls & Wall Sheathing & none & none & none & none & $\mathrm{R}-15 \mathrm{XPS}$ & $\mathrm{R}-20 \mathrm{XPS}$ \\
\hline \multirow{2}{*}{$\begin{array}{l}\text { Ceilings/ } \\
\text { Roofs }\end{array}$} & Unfinished Attic & R-38 (39.6) & R-38 (39.6) & R-49 (50.6) & R-38 (39.6) & R-60 (61.6) & R-60 (61.6) \\
\hline & Radiant Barrier & none & none & none & none & none & none \\
\hline $\begin{array}{c}\text { Foundation/ } \\
\text { Floors }\end{array}$ & $\begin{array}{l}\text { Unfinished } \\
\text { Basement }\end{array}$ & $\begin{array}{c}\text { R-18 polyiso } \\
(19.3) \\
\end{array}$ & $\begin{array}{c}\text { R-12 polyiso } \\
(13.3) \\
\end{array}$ & $\begin{array}{c}\text { R-18 polyiso } \\
(19.3) \\
\end{array}$ & $\begin{array}{c}\text { R-18 polyiso } \\
(19.3) \\
\end{array}$ & $\begin{array}{c}\text { R-18 polyiso } \\
(19.3) \\
\end{array}$ & R-18 polyiso (19.3) \\
\hline \multirow{3}{*}{$\begin{array}{l}\text { Windows \& } \\
\text { Doors }\end{array}$} & Window Areas & back: $23 \%$ & back: $23 \%$ & back: $23 \%$ & back: $23 \%$ & back: $23 \%$ & back: $23 \%$ \\
\hline & Windows & U-value 0.32 & U-value 0.32 & U-value 0.27 & U-value 0.32 & U-value 0.27 & U-value 0.27 \\
\hline & Overhangs & none & none & none & none & none & none \\
\hline \multirow[b]{2}{*}{ Airflow } & Air Leakage & $2.5 \mathrm{ACH} 50$ & $2.5 \mathrm{ACH} 50$ & $0.6 \mathrm{ACH} 50$ & $1 \mathrm{ACH} 50$ & $0.6 \mathrm{ACH} 50$ & $0.6 \mathrm{ACH} 50$ \\
\hline & $\begin{array}{l}\text { Mechanical } \\
\text { Ventilation }\end{array}$ & HRV, SRE: $70 \%$ & HRV, SRE: $70 \%$ & HRV, SRE: $70 \%$ & $\begin{array}{c}\text { ERV, SRE: } 70 \% \text {, } \\
\text { TRE: } 0.48 \% \\
\end{array}$ & $\begin{array}{c}\text { ERV, SRE: } 70 \% \text {, } \\
\text { TRE: } 0.48 \% \\
\end{array}$ & HRV, SRE: $70 \%$ \\
\hline \multirow{2}{*}{$\begin{array}{c}\text { Space } \\
\text { Conditioning }\end{array}$} & Duct insulation & none & $\mathrm{R}-8$ & $\mathrm{R}-8$ & $\mathrm{R}-8$ & $\mathrm{R}-8$ & $\mathrm{R}-8$ \\
\hline & $\begin{array}{l}\text { Ceiling Fans (4 } \\
\text { fans) }\end{array}$ & $45 \mathrm{~W} / \mathrm{fan}$ & $45 \mathrm{~W} / \mathrm{fan}$ & $45 \mathrm{~W} / \mathrm{fan}$ & $45 \mathrm{~W} / \mathrm{fan}$ & $45 \mathrm{~W} / \mathrm{fan}$ & $45 \mathrm{~W} / \mathrm{fan}$ \\
\hline \multirow{2}{*}{ Hot Water } & Pipe insulation & none & $\mathrm{R}-2$ & $\mathrm{R}-2$ & $\mathrm{R}-5$ & $\mathrm{R}-5$ & $\mathrm{R}-5$ \\
\hline & Shower DWHR & none & none & none & none & DWHR & DWHR \\
\hline \multicolumn{8}{|c|}{ "Gas" model-specific options } \\
\hline \multirow{2}{*}{$\begin{array}{c}\text { Space } \\
\text { Conditioning }\end{array}$} & $\begin{array}{l}\text { Central Air } \\
\text { Conditioner }\end{array}$ & SEER 15 & SEER 15 & SEER 16 ( 2 stage) & $\begin{array}{c}\text { SEER } 16 \text { (2 } \\
\text { stage) }\end{array}$ & $\begin{array}{l}\text { SEER } 16 \text { (2 } \\
\text { stage) }\end{array}$ & SEER 15 \\
\hline & Furnace & $80 \%$ AFUE & 92.5\% AFUE & 92.5\% AFUE & $92.5 \%$ AFUE & $92.5 \%$ AFUE & $92.5 \%$ AFUE \\
\hline $\begin{array}{l}\text { Water } \\
\text { Heating }\end{array}$ & Water Heater & $\begin{array}{c}\text { Energy Factor: } \\
0.59\end{array}$ & $\begin{array}{c}\text { tankless, Energy } \\
\text { Factor: } 0.82\end{array}$ & $\begin{array}{c}\text { tankless, Energy } \\
\text { Factor: } 0.82\end{array}$ & $\begin{array}{c}\text { tankless, Energy } \\
\text { Factor: } 0.82\end{array}$ & $\begin{array}{c}\text { tankless, Energy } \\
\text { Factor: } 0.82\end{array}$ & $\begin{array}{c}\text { tankless } \\
\text { condensing, } \\
\text { Energy Factor: } \\
0.96\end{array}$ \\
\hline
\end{tabular}

Grey=upgrade from reference, green=downgrade for reference

Bracketed values indicate assembly R-effective (US units) 
In general, mechanical system upgrades were more economically desirable than thermal envelope upgrades. An exception is that for all locations except Vancouver, there was a substantial increase in air sealing. To better understand the impact of design improvements on energy performance, the Gas-TO model has been deconstructed and compared to the Reference-TO model on the basis of purchased energy consumption. Figure 6-2 illustrates improvements in performance by cumulative changes in the design, progressing from the Reference on the left to the optimal design on the right. The space conditioning system and DHW steps include added insulation to the ducts and DHW pipes. Note that the "Enclosure \& ERV" step includes increased thermal resistance of the enclosure and reduced energy loss due to the upgrade from an HRV to ERV. However, the only insulation improvements for this location were the garage interzonal wall and floor resets (see Section 5.3), which were not selected by the optimization.

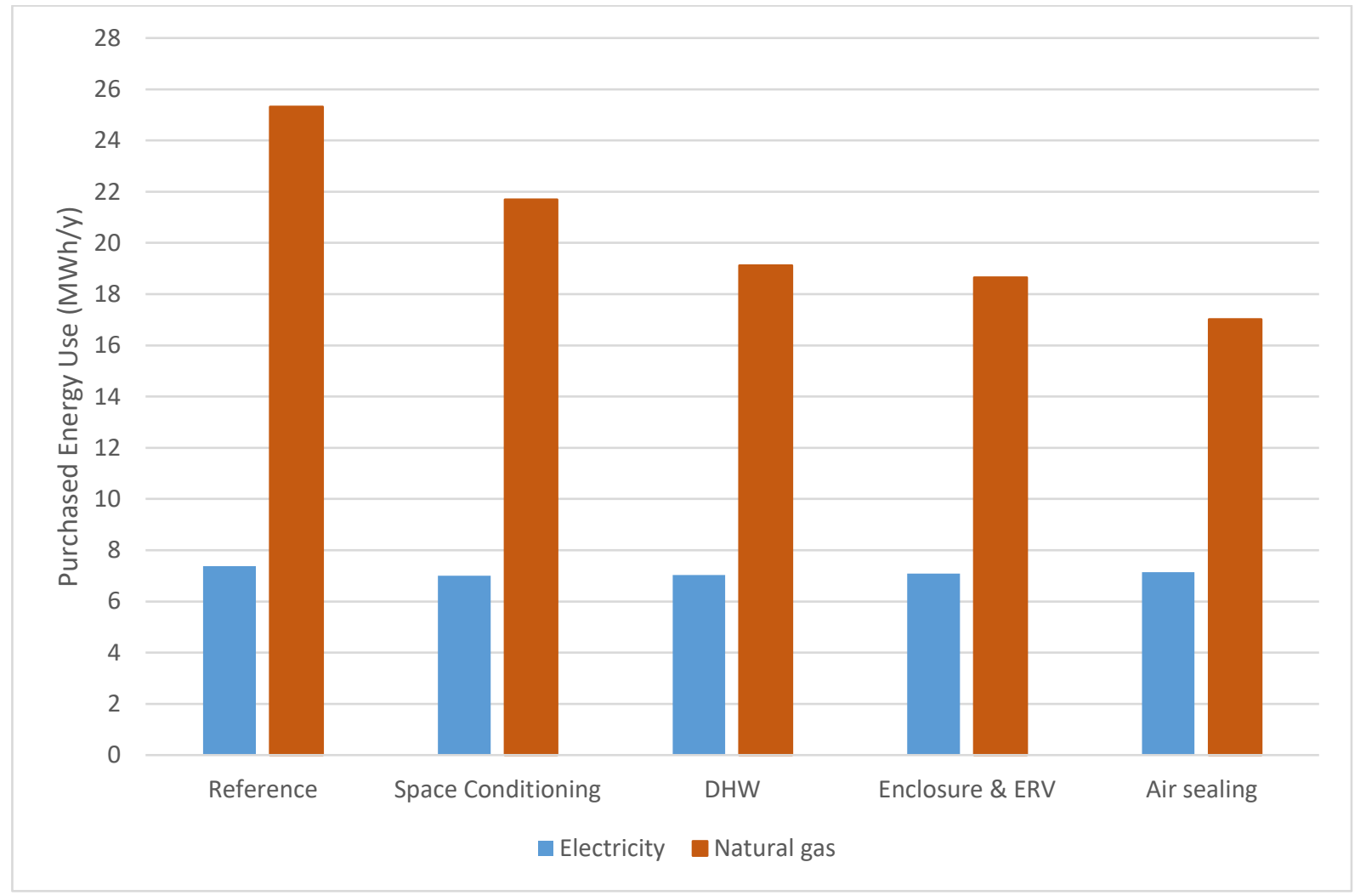

Figure 6-2 Gas-TO design breakdown by cumulative improvement 


\subsection{LCC versus GHG Optimization Results}

\subsubsection{Results Summary}

The following plots (Figure 6-3 through Figure 6-7) show the Reference design, plus the least-LCC design from each optimization. For comparison, all y-axis minor gridlines are by $\$ 1000$ $\mathrm{CAD}$ increments, and $\mathrm{x}$-axis minor gridlines are 0.5 tonnes $\mathrm{CO}_{2} \mathrm{e} / \mathrm{yr}$.

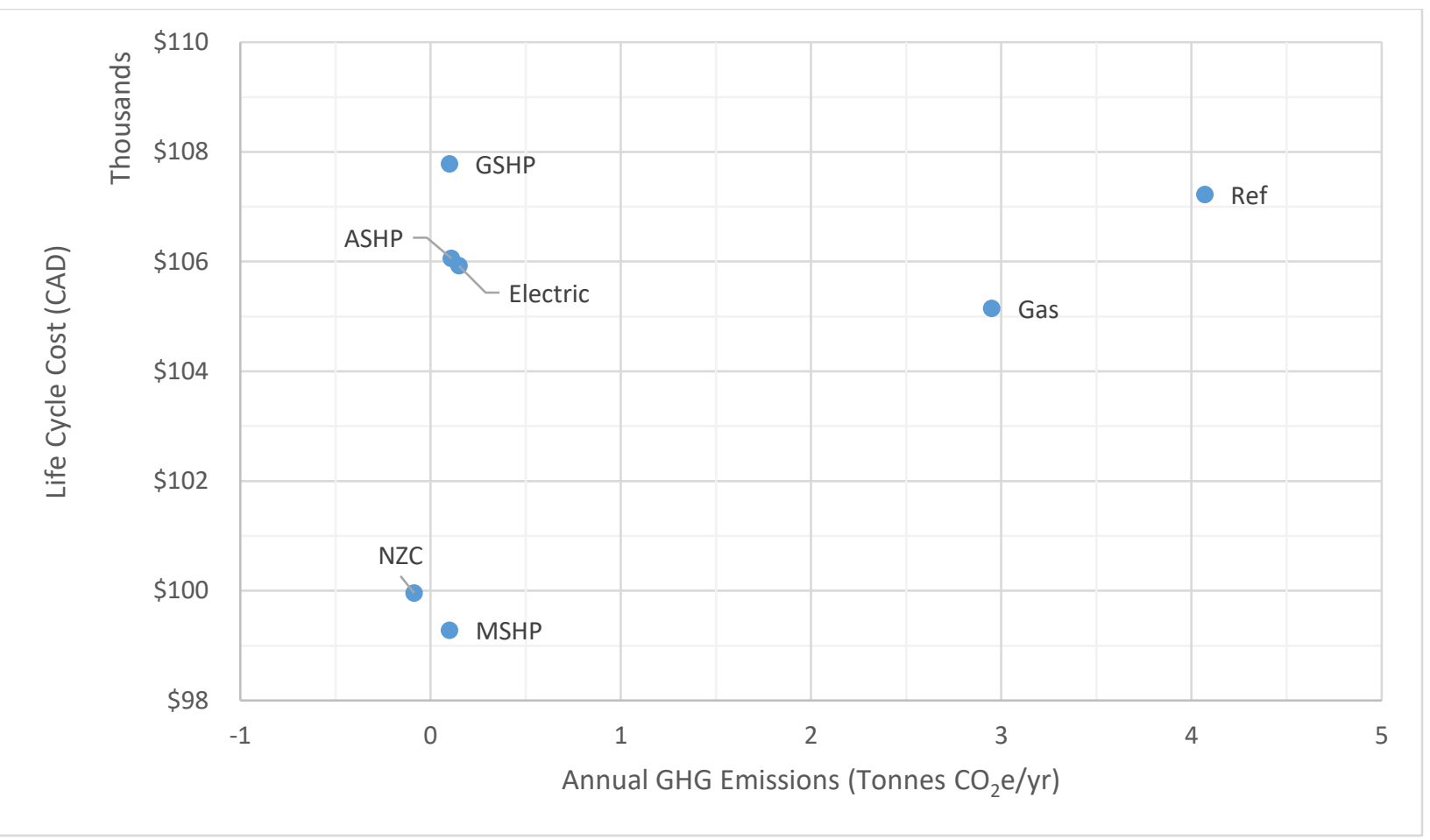

Figure 6-3 Vancouver optimal designs 


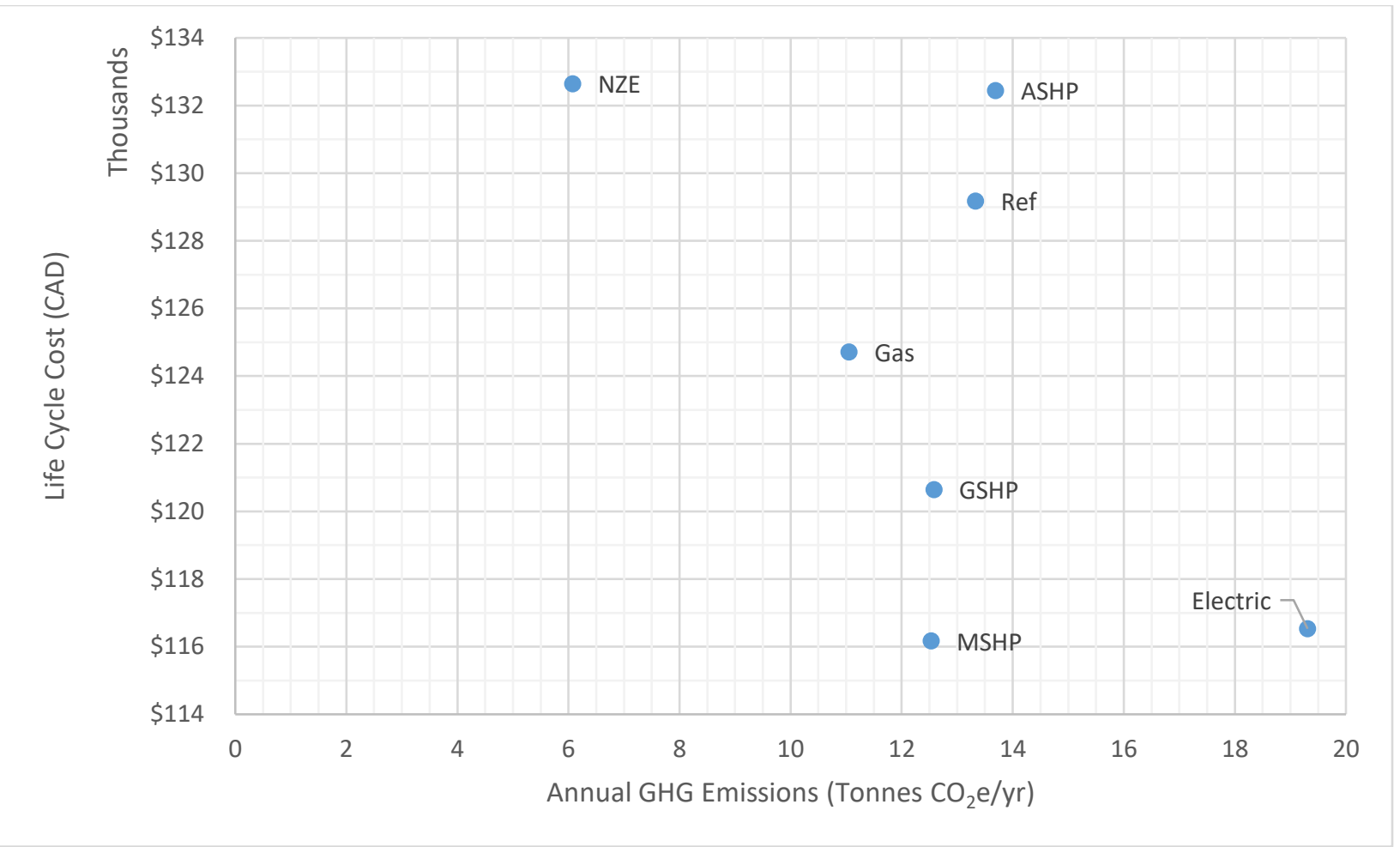

Figure 6-4 Edmonton optimal designs

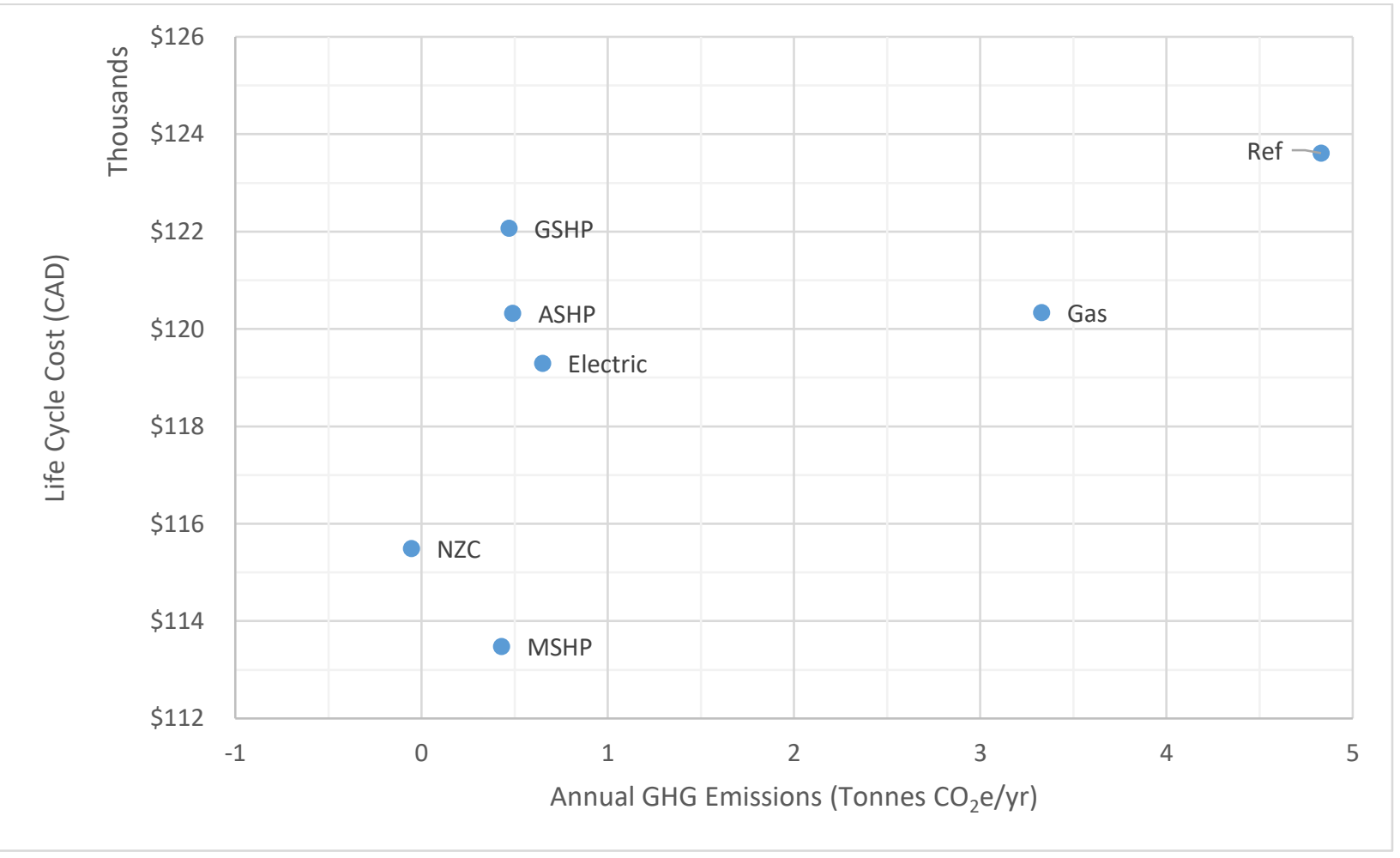

Figure 6-5 Toronto optimal designs 


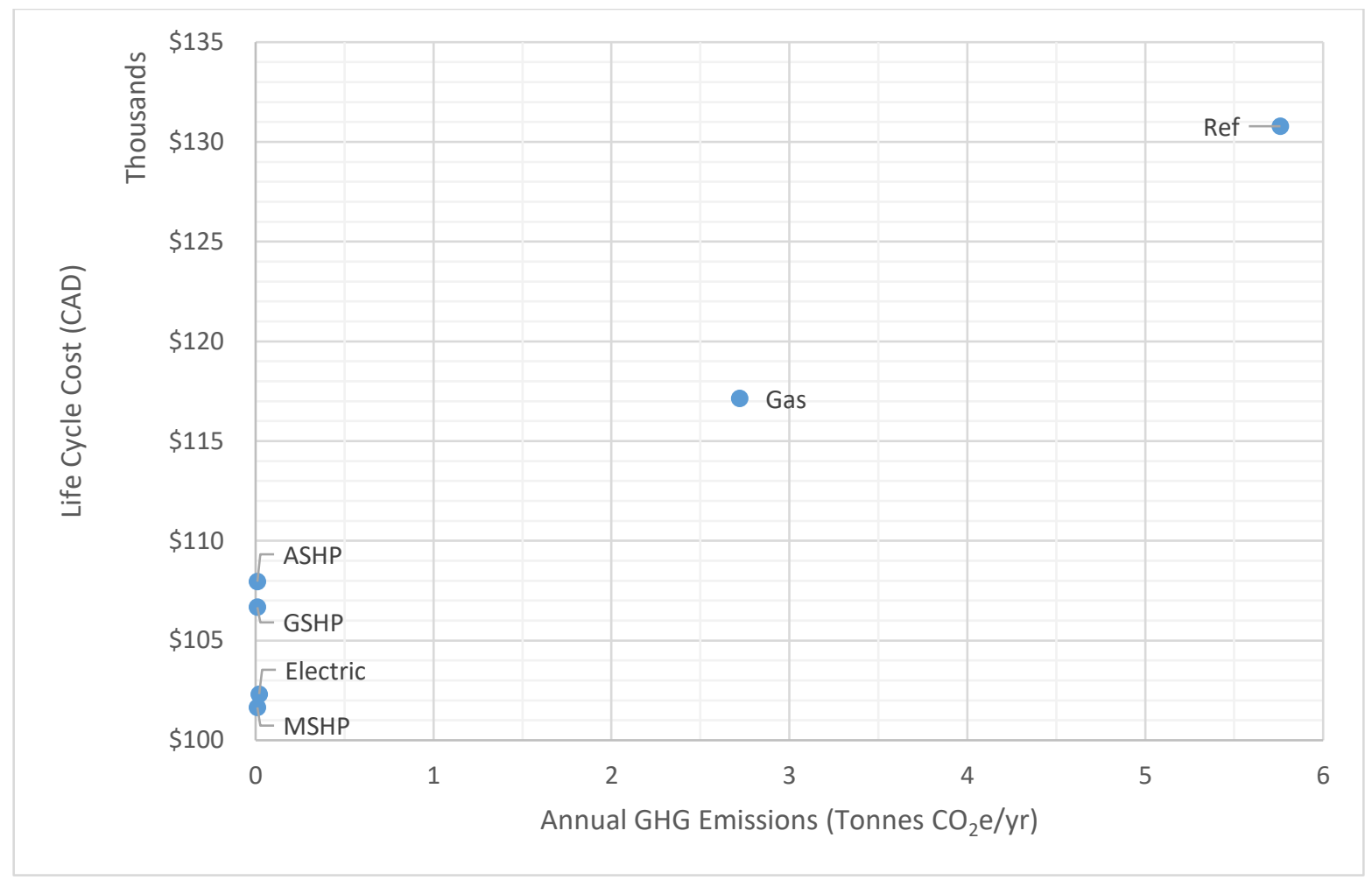

Figure 6-6 Montreal optimal designs

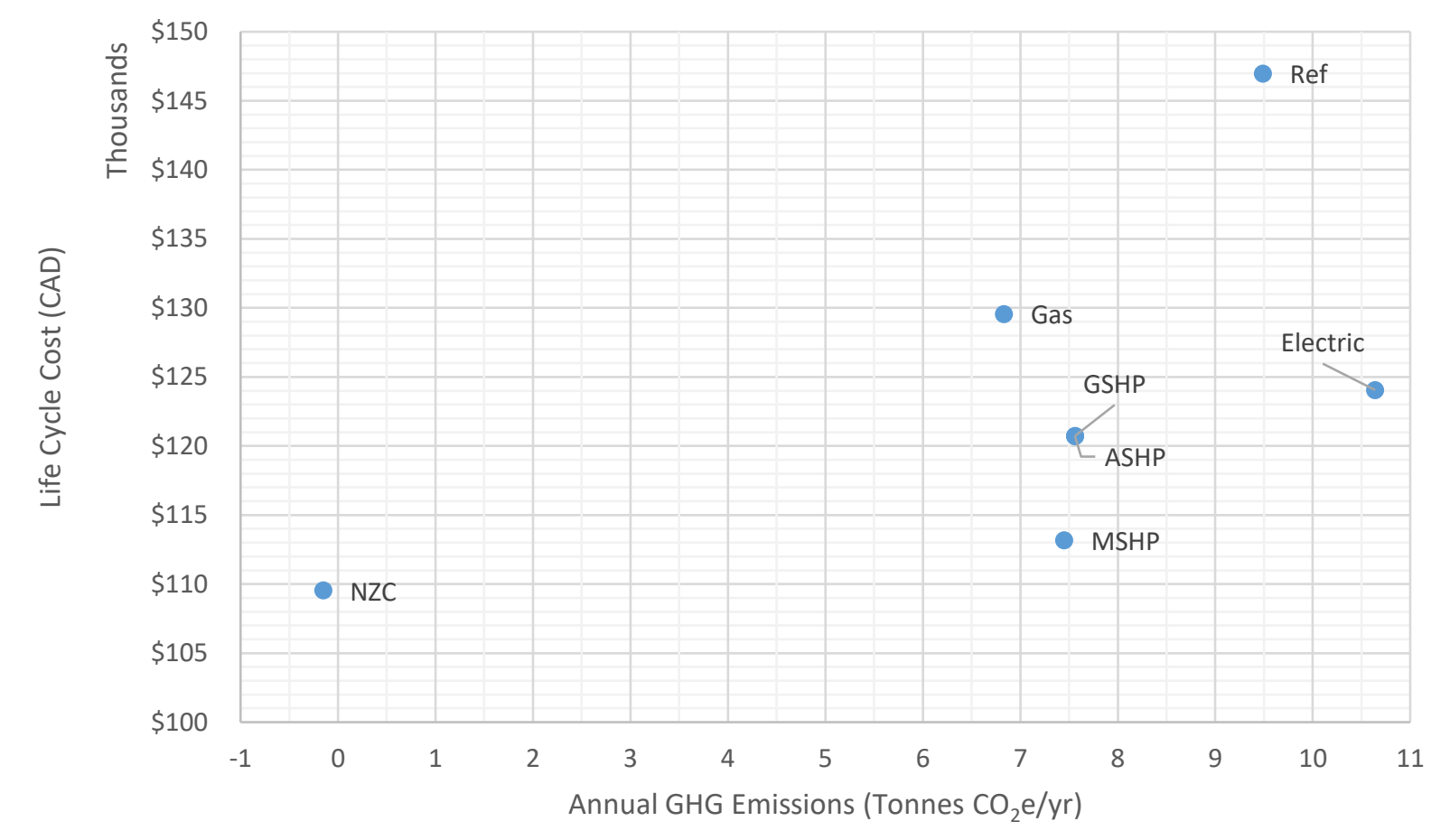

Figure 6-7 Halifax optimal designs 
The following are initial observations on the charts above:

- Several of the all-electric models have a lower LCC than the Gas model in all locations, with MSHP being the overall least-cost design in every location except Halifax. This is due to some combination of efficiency (low utility bills), and initial system cost (savings from the lack of ductwork, and dual-purpose heating/cooling).

- The high EF of the Alberta and Nova Scotia electric grids results in Gas being the lowest emitting design without PV. However, even the Gas models in these locations have higher GHG emissions than for other locations because the buildings must still use high-emitting electricity for non-heating end uses.

- In locations with a high electricity EF, PV has a more substantial impact on emissions reductions than (economical) thermal envelope improvements and thermal system efficiency improvements combined.

- PV is most affordable Halifax (and is economical only here, according to the LCC metric), because PV exports are priced higher due to the high cost of electricity (using the net-metering energy credit system).

- In locations with low EF electricity, electrification of heating appears to be the most advantageous economical measure in reducing emissions. However, it is not immediately clear from the charts how much of the emissions reductions are due to electrification, and how much is due to energy conservation measures, as there are many hidden parameters.

\subsubsection{Net Zero Carbon Models}

This subsection explains in more detail how the NZC/NZE optimizations were conducted that yielded the results shown in Figure 6-3 through Figure 6-7.

Since it is not possible to specify in BEopt a different EF for imported vs. exported electricity, the optimizations were conducted using site energy savings as the $\mathrm{x}$-axis metric. The method described in Section 2.3.7 has been used to determine the amount of renewable generation required as a proportion of total energy consumption to achieve NZC status. Recall that the NZC model applies PV to the resultant lowest cost all-electric optimization model, which for every location was the MSHP model. However, rather than simply add PV to the resultant design, the 
model is re-optimized with all the original options, but with PV options included. In this way it is a true whole-building optimization like the other models.

The following is a discussion and rationale of how NZC and/or NZE status is achieved for each location (percentage indicates amount of PV energy generation relative to total annual energy use). See Figure 6-8 for an example using the Edmonton case for a least LCC NZE design.

Vancouver (2\%) - A single 325-Watt module would be sufficient to render the optimized MSHP design a NZC, therefore the PV System size of this model was reset to 325 Watts and rerun to determine the new global minimum.

Edmonton (204.5\%) - Being the only location where the average EF exceeds the marginal EF, it would require a net-positive energy building to achieve NZC status. However, since netmetering programs do not reward annual generation in excess of annual usage, this design was optimized to be site-NZE rather than NZC. A preliminary optimization iteration was conducted to determine the appropriate cost-optimal range of PV system size. The resultant design uses 12.6 MWh of electricity, requiring $10 \mathrm{~kW}$ of PV.

Toronto $(10.1 \%)$ - PV system size options in the range of $1-2.5 \mathrm{~kW}$ were investigated, and the global minimum (with $1 \mathrm{~kW}$ ) resulted in enough generation for NZC status.

Montreal $(0.5 \%)$ - Quebec's average EF is so low that the EF ratio is considered negligible and MSHP model does not require PV. This makes sense logically too-if Quebec's electricity is very clean, there is little to no GHG benefit to onsite renewables. All-electric models have annual emissions of only $10 \mathrm{~kg} \mathrm{CO} 2 / y r$. The NZC design for this location is thus considered identical to the MSHP design.

Halifax (99.7\%) - The EF ratio being nearly 1:1, this design is optimized to be NZE in the same way as the Edmonton model, except that here it also qualifies as NZC. The resultant design uses 10.5 MWh of electricity, requiring $9 \mathrm{~kW}$ of PV. 


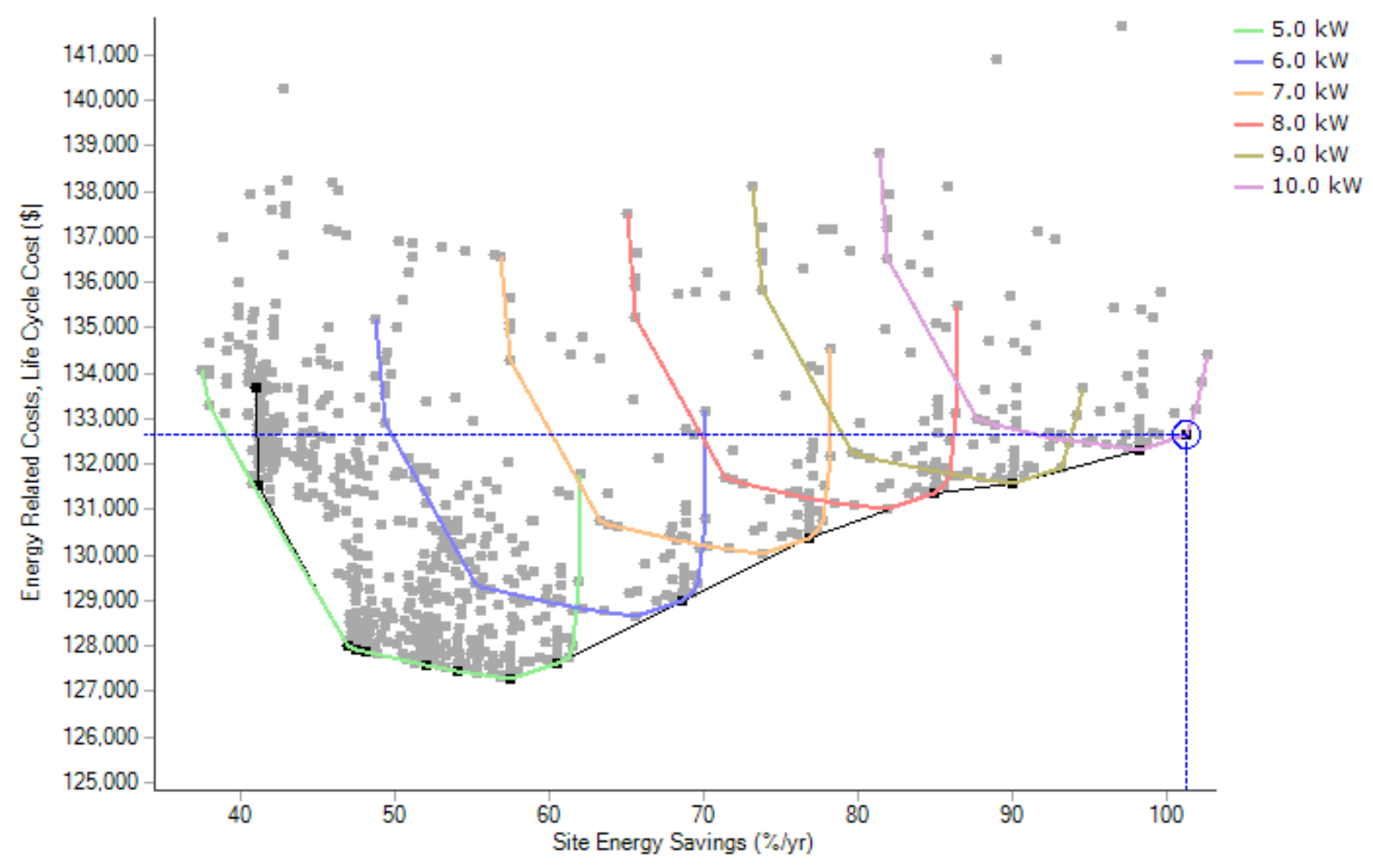

Figure 6-8 Edmonton NZE optimization results and selected design

While it is an interesting exercise to conduct a whole-building optimization including only the required quantity of PV to achieve NZC, in reality the question of rooftop PV economic feasibility can be answered in isolation. If it is profitable, the rational decision would be to install the maximum amount allowed, which would be the lesser of what can fit on the roof and what will attain NZE levels of generation (since this is the maximum rewarded by the utility). In such a case it would still be beneficial to conduct a whole-building LCC vs. site energy optimization to determine the optimal overall design. Depending on the profitability of PV, this can yield a less efficient building design that enables more PV. Though this could benefit the homebuyer, it would result in the electrically-heated building having a higher peak winter electricity demand (when PV is not generating), and therefore negatively impact the utility (and ultimately all ratepayers).

\subsection{Initial Cost and Design}

The initial cost of each of the optimal designs for Toronto displayed in Figure 6-5 are broken down by building component category and illustrated in Figure 6-9. In each case, $20 \%$ of the total cost is paid as the down payment, with the remaining $80 \%$ constituting the mortgage 
principal which is paid over the 30-year mortgage period (refer to cash flow diagram in Figure 5-6 for example).

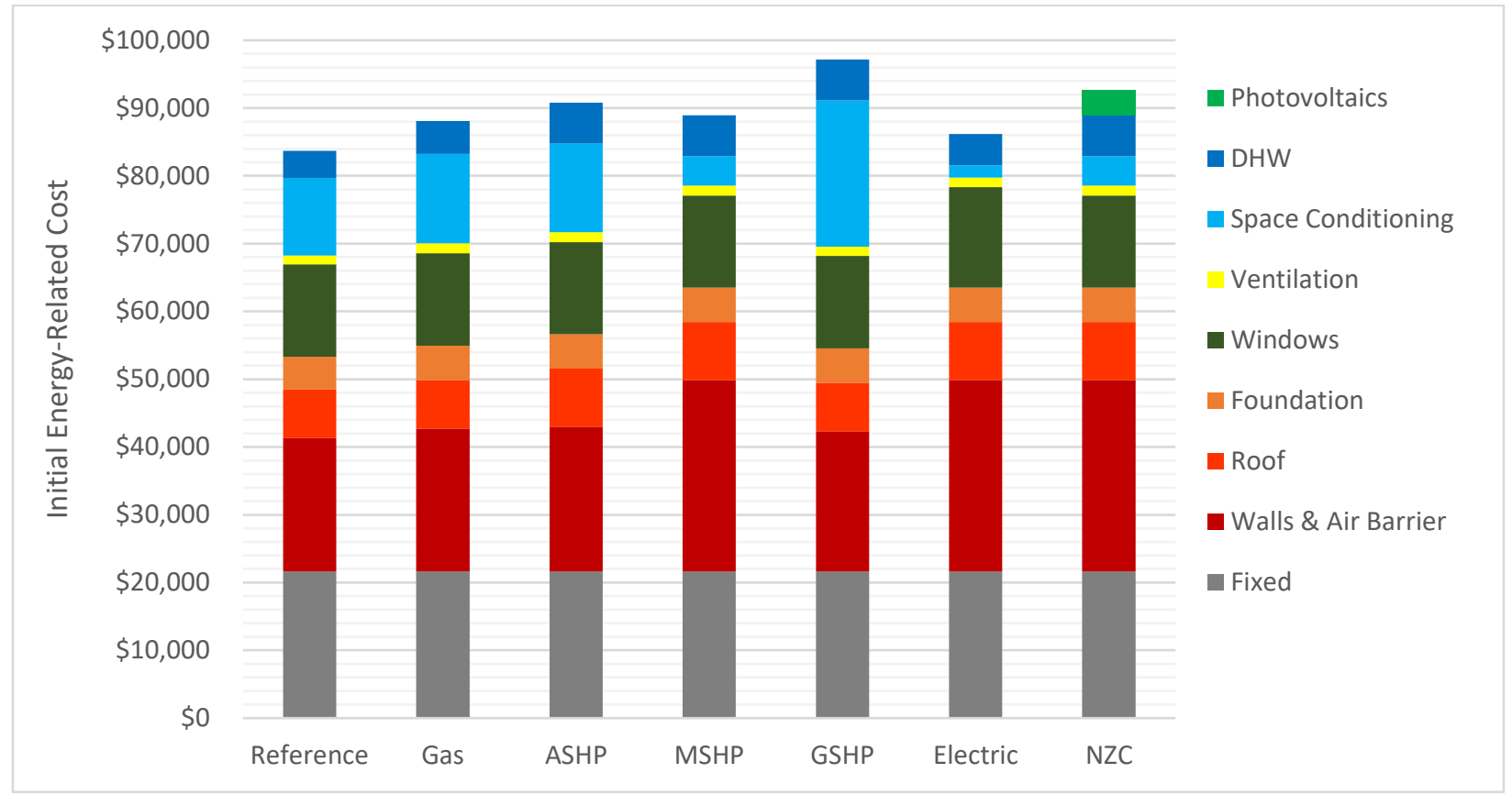

Figure 6-9 Initial cost optimal designs - Toronto ("fixed" includes lighting, appliances, ceiling fans, doors, eaves, \& thermal mass)

Note that the building components with the greatest cost variation are the walls, air barrier and the space conditioning system. Also note that, while the Reference design has the lowest initial cost, it has the highest LCC in charts above (Figure 6-3 to Figure 6-7). The MSHP design is 1.0\% costlier initially than the optimal Gas design, whereas the Electric design is $2.2 \%$ cheaper.

Resultant optimal designs for each of the Toronto models are listed in Table 6-2. The Reference and Gas model designs from Table 6-1 are repeated here for comparison. Fixed parameters for all Toronto models are in Table 4-9, and fixed parameters by thermal system type are in Table 4-16. 
Table 6-2 Resultant least LCC designs for all thermal system types - Toronto

\begin{tabular}{|c|c|c|c|c|c|c|c|}
\hline Group & Category & Ref-TO & Gas-TO & ASHP-TO & MSHP-TO & GSHP-TO & Electric-TO \\
\hline Walls & Wall Sheathing & none & none & none & $\mathrm{R}-20 \mathrm{XPS}$ & none & R-20 XPS \\
\hline \multirow{2}{*}{ Ceilings/ Roofs } & Unfinished Attic & $\mathrm{R}-38$ (39.6) & $\mathrm{R}-38$ (39.6) & R-60 (61.6) & $\mathrm{R}-60(61.6)$ & $\mathrm{R}-38$ (39.6) & $\mathrm{R}-60(61.6)$ \\
\hline & Radiant Barrier & none & none & none & none & none & none \\
\hline $\begin{array}{c}\text { Foundation/ } \\
\text { Floors }\end{array}$ & $\begin{array}{l}\text { Unfinished } \\
\text { Basement }\end{array}$ & $\begin{array}{c}\text { R-18 polyiso } \\
(19.3) \\
\end{array}$ & R-18 polyiso (19.3) & $\begin{array}{c}\text { R-18 polyiso } \\
(19.3) \\
\end{array}$ & $\begin{array}{c}\text { R-18 polyiso } \\
(19.3) \\
\end{array}$ & $\begin{array}{c}\text { R-18 polyiso } \\
(19.3) \\
\end{array}$ & $\begin{array}{c}\text { R-18 polyiso } \\
(19.3) \\
\end{array}$ \\
\hline \multirow{3}{*}{$\begin{array}{l}\text { Windows \& } \\
\text { Doors }\end{array}$} & Window Areas & back: $23 \%$ & back: $23 \%$ & back: $23 \%$ & back: $23 \%$ & back: $23 \%$ & back: $23 \%$ \\
\hline & Windows & U-value 0.32 & U-value 0.32 & U-value 0.32 & U-value 0.32 & U-value 0.32 & U-value 0.29 \\
\hline & Overhangs & none & none & none & none & none & none \\
\hline \multirow[b]{2}{*}{ Airflow } & Air Leakage & $2.5 \mathrm{ACH} 50$ & $1 \mathrm{ACH} 50$ & $0.6 \mathrm{ACH} 50$ & $0.6 \mathrm{ACH} 50$ & $2 \mathrm{ACH} 50$ & $0.6 \mathrm{ACH} 50$ \\
\hline & $\begin{array}{l}\text { Mechanical } \\
\text { Ventilation }\end{array}$ & HRV, SRE: $70 \%$ & $\begin{array}{c}\text { ERV, SRE: } 70 \% \text {, TRE: } \\
48 \% \\
\end{array}$ & HRV, SRE: $70 \%$ & HRV, SRE: $70 \%$ & HRV, SRE: $70 \%$ & HRV, SRE: $70 \%$ \\
\hline \multirow{2}{*}{$\begin{array}{c}\text { Space } \\
\text { Conditioning }\end{array}$} & Duct insulation & none & $\mathrm{R}-8$ & $\mathrm{R}-8$ & NA & $\mathrm{R}-8$ & NA \\
\hline & Ceiling Fans (4 fans) & $45 \mathrm{~W} / \mathrm{fan}$ & $45 \mathrm{~W} / \mathrm{fan}$ & $45 \mathrm{~W} / \mathrm{fan}$ & $45 \mathrm{~W} / \mathrm{fan}$ & $45 \mathrm{~W} / \mathrm{fan}$ & $45 \mathrm{~W} /$ fan \\
\hline \multirow{2}{*}{ Hot Water } & Pipe insulation & none & $\mathrm{R}-5$ & $\mathrm{R}-5$ & $\mathrm{R}-5$ & $\mathrm{R}-5$ & $\mathrm{R}-5$ \\
\hline & Shower DWHR & none & none & DWHR & DWHR & DWHR & DWHR \\
\hline
\end{tabular}

Grey=upgrade from reference

Bracketed values indicate assembly R-effective (US units) 
No optimization in any location selected upgrades to the: radiant barrier, back window area, overhangs, ceiling fans, or basement insulation. All Toronto models have an upgrade in the enclosure airtightness, which is substantial in every case except the GSHP. This was the only thermal envelope improvement that was consistently selected for models across all locations. All models in Toronto have an upgrade in DHW piping insulation, and those with ducts have insulation upgrades (in other locations the upgrades also occur, but not always to the same option). Some, but not all models have a DWHR upgrade. The Electric optimization yielded the most substantial thermal envelope upgrades and is the only one for which the window performance was increased. This is consistent with the fact that electric baseboard heating is the most expensive heating system operationally.

Note that in some cases the results are not perfectly rational. For example, why is the Gas model the only one with an ERV upgrade, but does not have significant enclosure upgrades? These occurrences are most likely an artifact of the discretized optimization method. The least LCC design from the optimization typically has several other design points clustered very close to it. These designs have slightly different parameters, resulting in nearly identical performance and cost. It is more useful to think of the optimization as approximating the ideal solution and ruling out very suboptimal choices. It is also important to realize that results rely as much on material/equipment and labour cost inputs as they do on the performance of those components.

NZC design is identical to the MSHP design, but with $1 \mathrm{~kW}$ of PV added. This was not the case for Edmonton and Halifax, where higher quantities of PV influenced both cost and emissions results more substantially, thereby causing a slight effect on the building designs.

\subsection{Operational Energy, Cost, and Emissions}

\subsubsection{Purchased Energy Use}

Energy use by end-use for each of the Toronto designs is shown in Figure 6-10 and utility costs by fuel type for the same designs can be seen in Figure 6-11. The comparisons in Figure 6-10 are analogous to EUI, since the building geometry is unchanged for all designs. Figure 6-12 provides a breakdown of GHG emissions by fuel type for the same designs. 


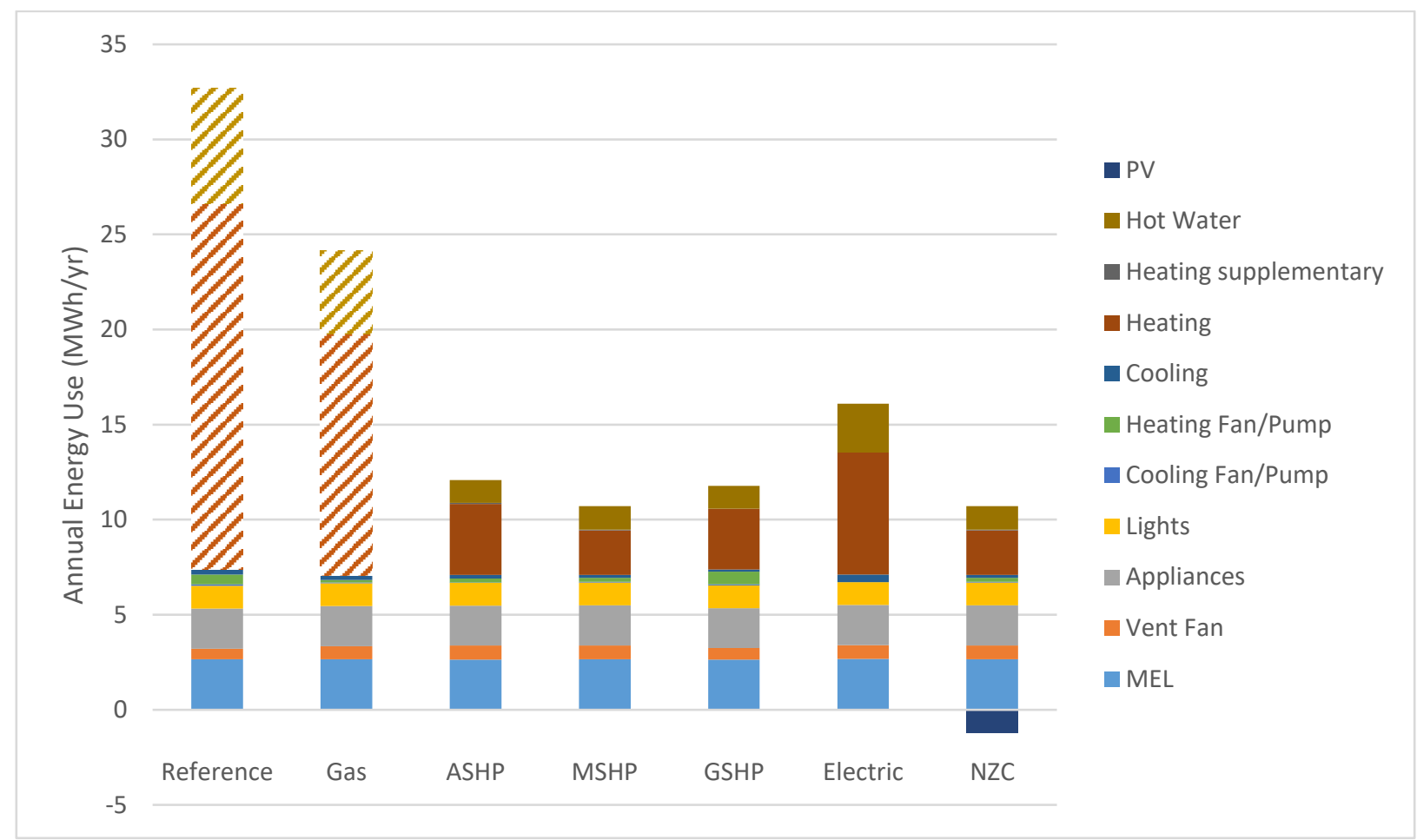

Figure 6-10: Annual energy use by end-use - Toronto (hatched=natural gas, solid=electricity)

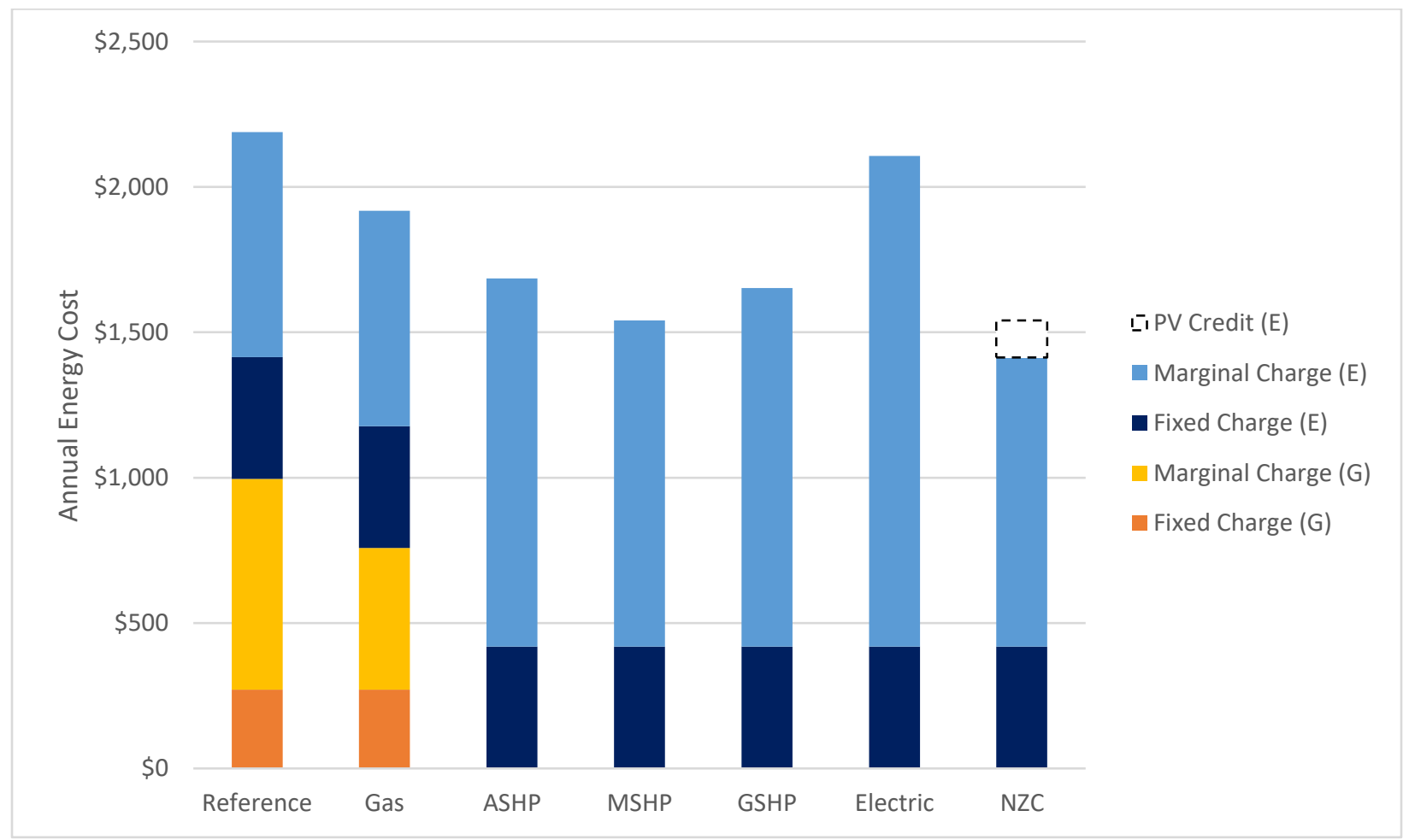

Figure 6-11 Annual energy costs of optimal models - Toronto (E=electricity, G=natural gas) 


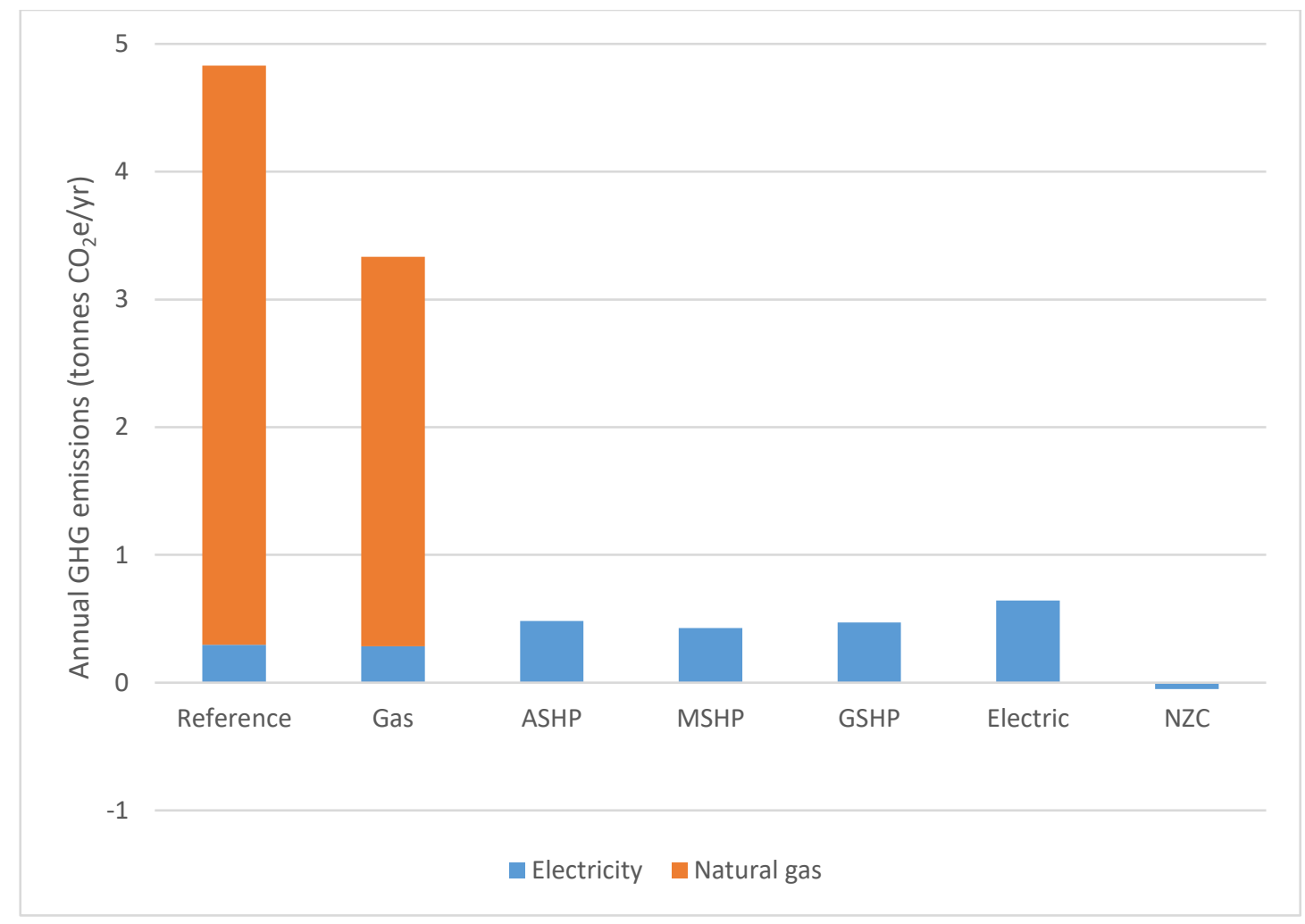

Figure 6-12 Annual GHG emissions by fuel type - Toronto

The models that use heat pumps to provide space heating and DHW unsurprisingly have the lowest energy consumption. However, somewhat surprisingly, they also have a lower operational cost than the Gas design. The Electric design consumes less energy, but the energy cost is higher. Taken together, these three charts illustrate how total energy use does not necessarily provide any useful information regarding either energy cost, or energy-related emissions, especially when comparing buildings with different heating system types. For the gas-heated designs, the natural gas proportion of total cost is much less than it is for total energy, but it accounts for almost all the GHG emissions. Furthermore, these interrelationships can vary greatly by location, as the electricity/gas price ratio changes, as well as the electricity EF.

\subsubsection{Enclosure Thermal Performance}

Since the resultant designs from the thermal system-specific whole-building optimizations do not have identical thermal envelope performance, it is useful to quantify the space heating demand for each. This is also relevant for building energy standard evaluation and design, since SHDI is sometimes a target metric. 
The SHDI metric is intended here as a means of characterizing the thermal performance of the building enclosure, including heat recovered by the HRV/ERV. In addition to representing the enclosure performance, it indicates how much heat is required to be provided by any given mechanical space heating system. However, for models containing a HPWH, the space heating and space cooling demands are "distorted" by the cooling effect it provides. To understand the magnitude of this effect, the optimal MSHP design has been run separately, with and without the HPWH. When the building includes a HPWH, the space heat demand, or SHDI, for the building increases by $3.3 \mathrm{kWh} / \mathrm{m}^{2}$, or $12 \%$. Additionally, the space cooling demand intensity decreases by $0.7 \mathrm{kWh} / \mathrm{m}^{2}$, or $15 \%$ For the ASHP and GSHP models, the SHDI increases by 3.5 and $3.6 \mathrm{kWh} / \mathrm{m}^{2}$, respectively, when the HPWH is included. To achieve a fair comparison of enclosure thermal performance, SHDI values illustrated in Figure 6-13 have been determined without the distorting effect of the HPWH. To understand how much heat is delivered by the heating system for the heat pump models, add approximately 3.5 to the value shown below for those models.

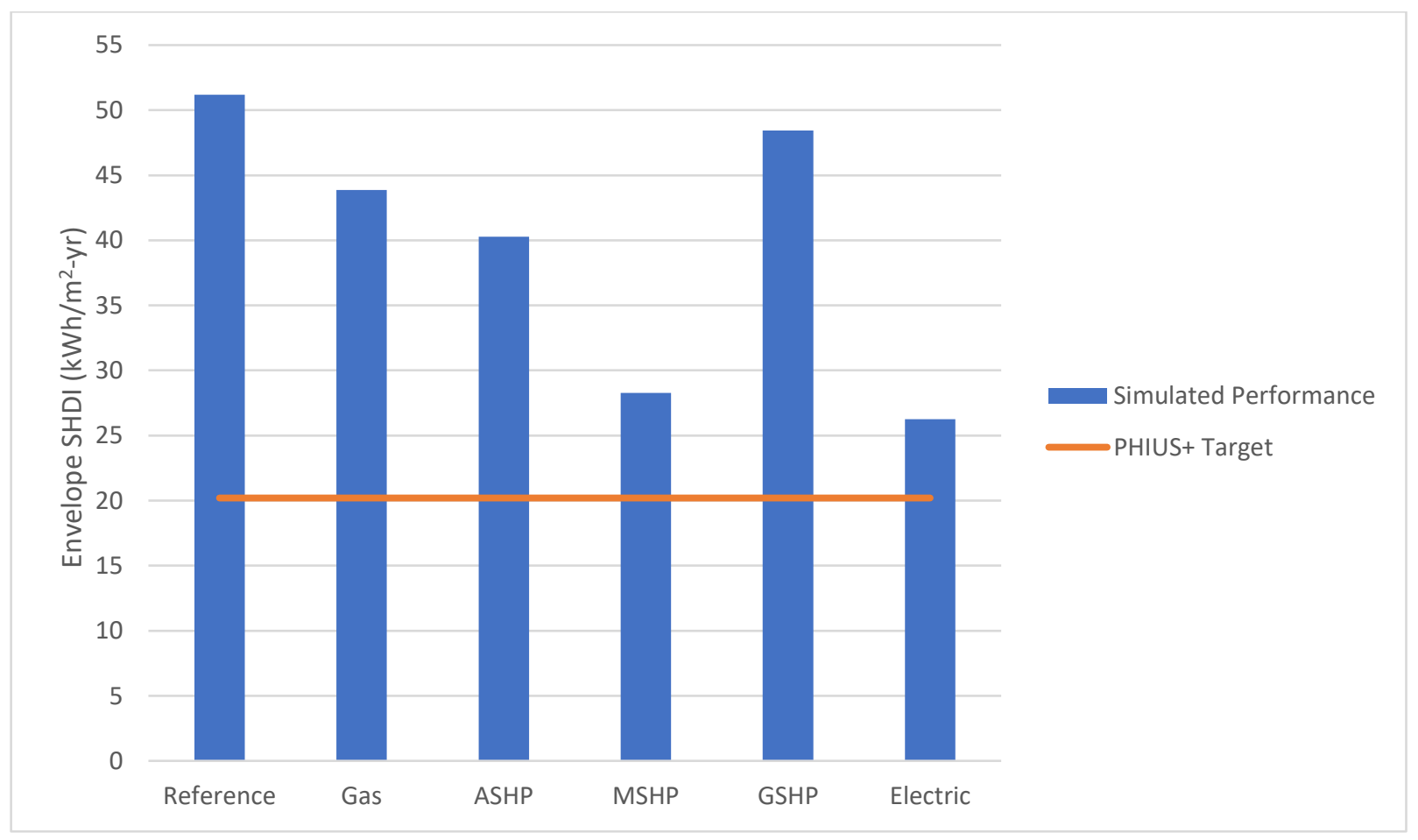

Figure 6-13 SHDI of optimal Toronto design enclosures

Whether thermal system type has a substantial impact on optimal thermal envelope design is inconclusive based on these data alone. There are many factors including both the capital and operational price of heat. Ideally, one would attempt to correlate an enclosure's SHDI and the life- 
cycle price of heat $(\$ / J)$. However, since the capital investment in the heating source is interlinked with the equipment for cooling and DHW, and in different ways for different thermal system types, it is difficult to isolate.

However, at least for the electric heating sources, there appears to be an inverse correlation with the operational price of heat. From the simulated heating COP values in Table 4-17, we can see that the price of heat from the GHSP is lowest, followed by the ASHP, followed by the MSHP, and finally electric baseboard. It is therefore logical that as a heat source becomes more expensive, it is optimal to invest more in a higher performing thermal envelope to reduce the SHDI.

This is a fact that is not recognized by $N B C$ 9.36, or either of the Passive House standards, and only very crudely by $O B C S B-12$.

Furthermore, when multiple heating system types are considered, as is the case here, a lower SHDI guarantees neither reduced GHG emissions (compare with Figure 6-12), nor a lower LCC building, as can be seen by the lack of correlation with LCC in Figure 6-5.

\subsubsection{Mechanical Heating}

Simulated hourly heat delivered by the MSHP to the building for the MSHP-TO optimal design is illustrated in Figure 6-14. The maximum capacity limit of the heat pump, which falls with outdoor temperature, can be seen at the top left of the scatter. Beyond this point, supplementary electric baseboard heating is provided to meet the hourly load. However, supplementary heating only accounts for $0.7 \%$ of annual delivered heat. 


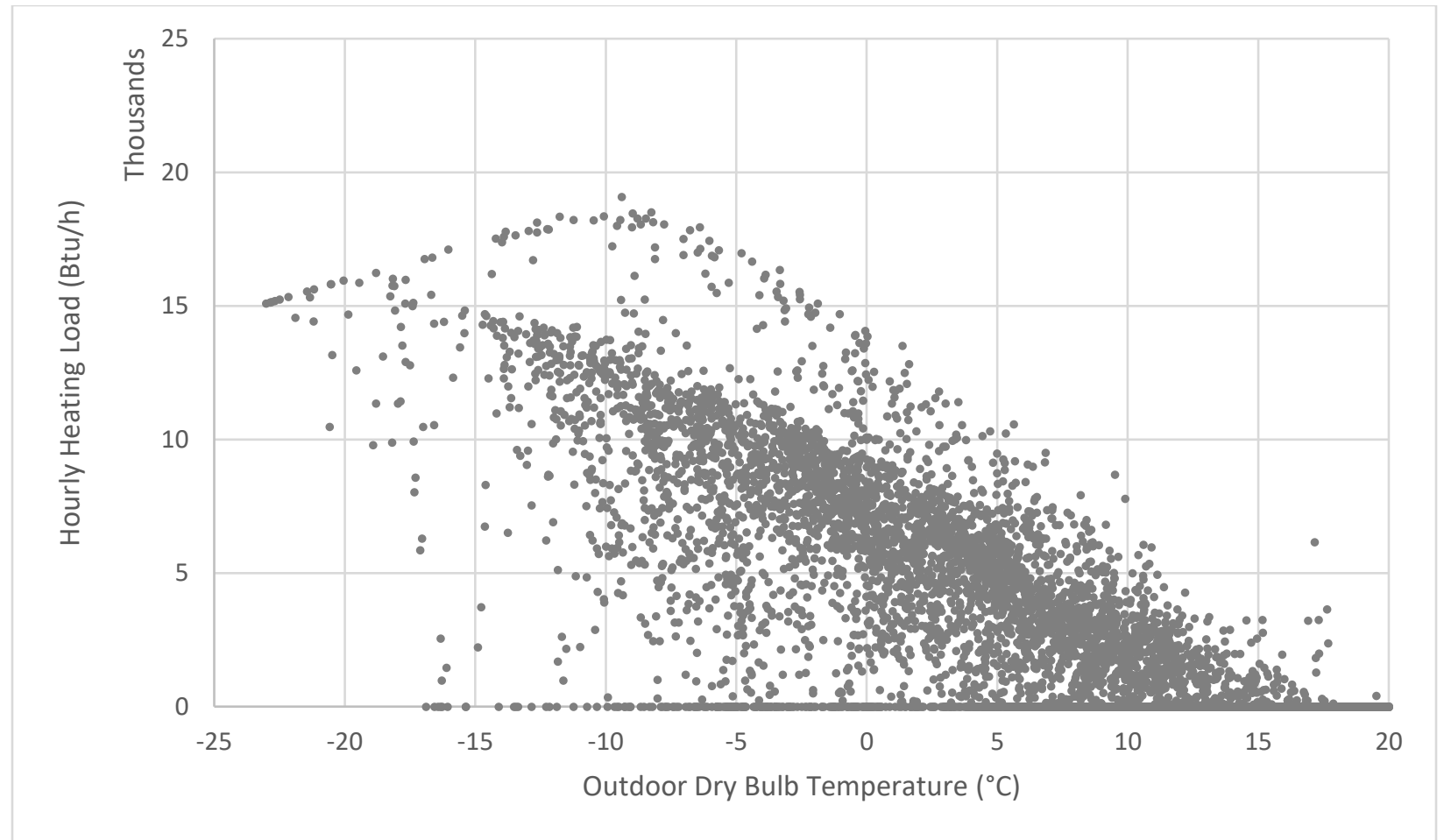

Figure 6-14 Hourly heating delivered by the MSHP - Toronto

If large numbers of buildings begin switching to electric sources of heating, it will be important to mitigate peak electric demand on the grid. Part of the way this can be done is through higher performance enclosures to minimize the peak heating load. The largest spikes in demand are due to the electric supplementary heating, which for the MSHP-TO design can result in a whole building electric demand of up to $7 \mathrm{~kW}$. However, as is illustrated in Figure 6-15, in this case the building electric demand rarely exceeds $4 \mathrm{~kW}$, and the heat pump never exceeds $2.3 \mathrm{~kW}$. On the other hand, heating with a heat pump can serve to reduce peak electric demand if the alternative is baseboard electric heating (see Figure 6-16). 


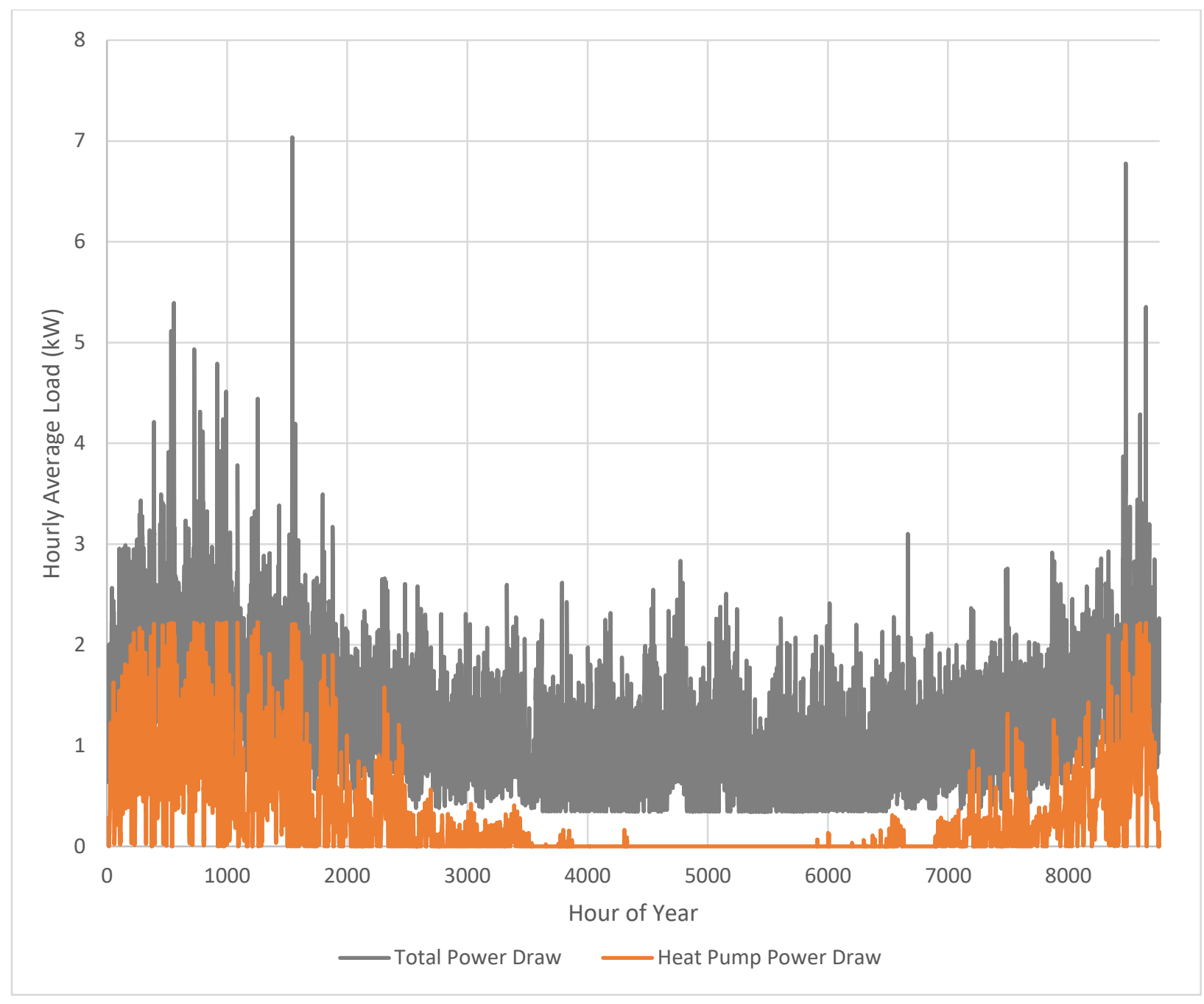

Figure 6-15 Electric load profile of heat pump and whole building for MSHP-TO design 


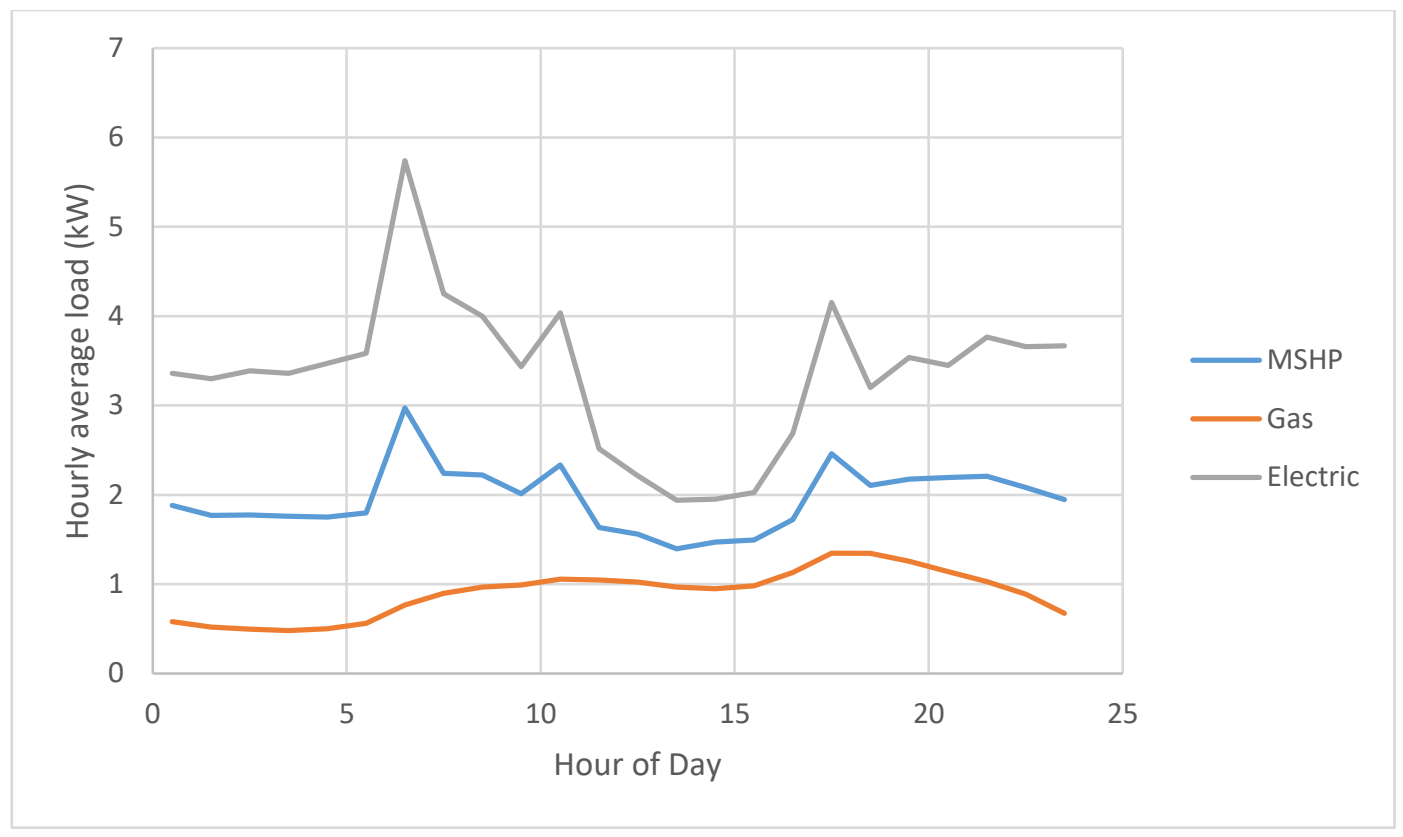

Figure 6-16 January day electric load profile - Toronto

\subsubsection{EUI versus GHGI Relationship}

It is already clear that EUI does not necessarily correlate to energy cost or LCC, when considering multiple thermal system types. Figure 6-17 plots site energy use against GHG emissions (analogous to EUI versus GHGI in this case) for all building variants simulated by the Gas-TO and MSHP-TO optimizations. In each case, there is very good positive correlation. In the case of the Gas model, this is likely due to a combination of the fact that the vast majority of emissions are from natural gas consumption, and because for the Gas models, electricity consumption varies little for all design variants. In the case of the MSHP, it theoretically should be perfect correlation, since there is only one purchased energy type, with a fixed carbon intensity. Imperfect correlation here is simply caused by rounding errors, which are due to BEopt's insufficiently small GHG accounting increments for very low emitting buildings. However, when building designs across thermal system types are compared, the correlation is less clear. To illustrate this, the procedure was repeated for Edmonton, but this time considering all points as a single data series (Figure 6-18). 


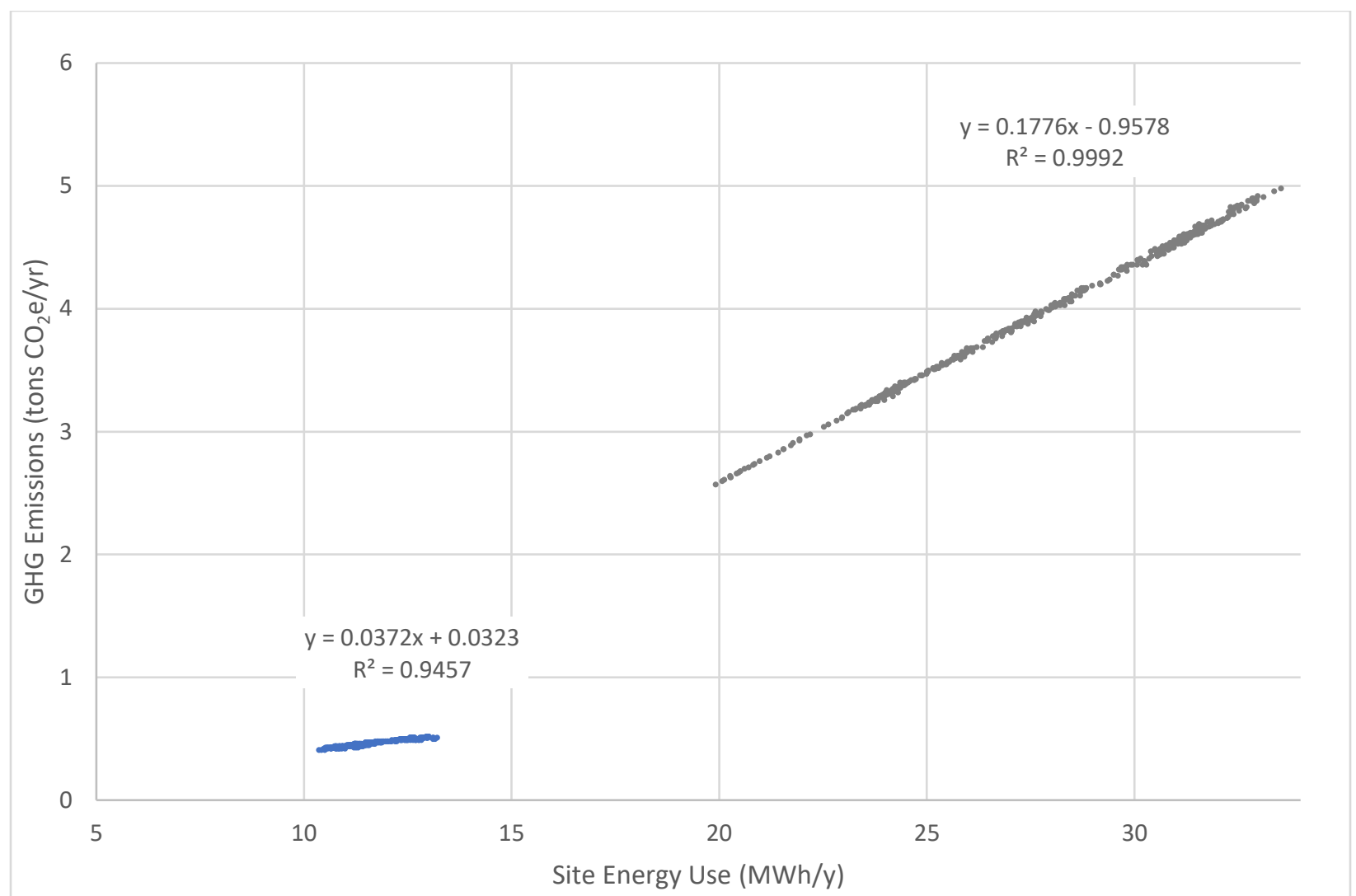

Figure 6-17 Energy use versus GHG emissions - Toronto (blue=MSHP design variants, grey=Gas design variants) 


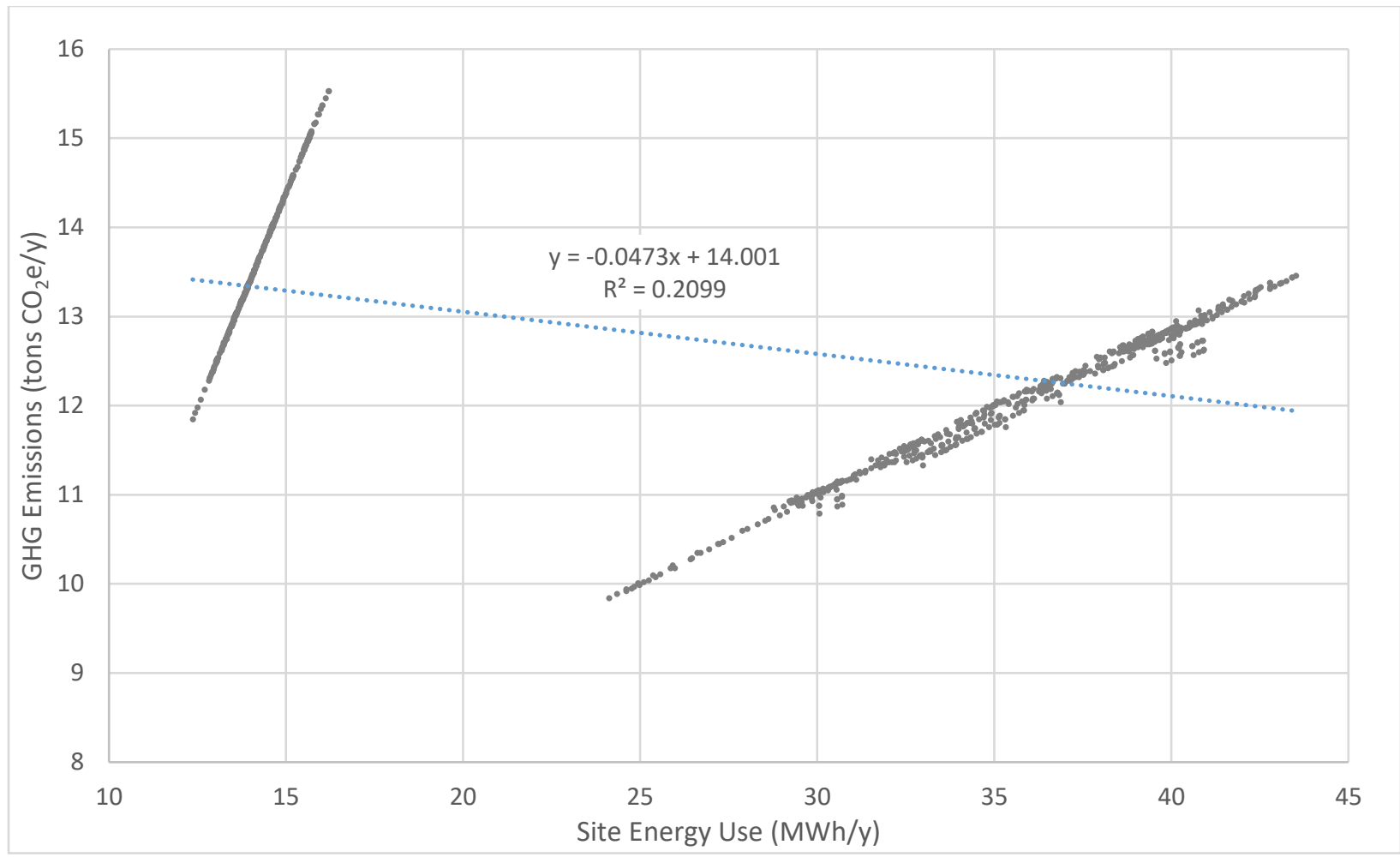

Figure 6-18 Energy use versus GHG emissions - Edmonton

In Figure 6-18 the left cluster is the MSHP variants and the right is the Gas variants. Here again there is good correlation within a thermal system type, but very poor correlation across system types. In this location for these two system types, there is actually a slightly negative correlation between EUI and GHGI. 


\section{Conclusions and Recommendations}

Whole-building multi-objective design optimizations were conducted to find the operational GHG emissions versus LCC pareto fronts for five thermal system types plus a NZC model in five Canadian cities. The "optimal" resultant design from each optimization was chosen as the least LCC in all cases but the NZC designs, which were selected from the pareto front at the NZC performance level.

Of the five thermal system types investigated, one included a centrally ducted natural gas furnace to determine the GHG level and LCC for the optimal design of this type, which remains the new construction norm for single detached houses in Canada. Against this optimal Gas design, and a Reference gas-heated design compliant with $N B C$ 9.36, were compared the four all-electric thermal system options: central ASHP, ductless MSHP, central GSHP, and electric baseboard. The all-electric strategy was borne of the recognition that most Canadians live in a jurisdiction with a very low carbon-intensity electricity supply.

Of the all-electric thermal systems, the optimized designs containing the MSHP are not only the cheapest in every location but are cheaper than the optimal Gas design as well. In Halifax and Montreal, the optimal design of every all-electric type is cheaper than the optimal Gas design. In Toronto, the ASHP and Electric models are also cheaper than Gas, and in Edmonton, the GSHP and Electric models are cheaper. In every location except Edmonton, the NZC design is lower cost than the Gas design, and in Halifax, it is the overall global minimum.

Every all-electric design in Vancouver, Ontario, and Montreal is substantially loweremitting than the Gas design, whereas in Montreal and Edmonton, the Gas model was the leastemitting thermal system option. In these locations, emissions reductions best achieved through a combination of passive and active energy conservation, and rooftop PV addition. However, as the electricity grids in these locations reduces due to the phase out of coal by 2030, electrification of heating will become advantageous here as well for GHG reduction. These findings indicate that it may be advantageous to both consumers and environmentally for building energy standards to mandate, not simply minimum heating system efficiency by system type (as they currently do), but to mandate heating system type. It is not without precedent, but more rigorous economic analysis is needed, as well as thorough analysis into the impact that broad electrification of heating will have on the electricity grid due to changes in aggregate building load profiles and increased winter peak demand. 
A deconstruction in LCC, GHG by fuel type, and energy use by end use and fuel type in the Toronto location enabled a more thorough understanding of the final optimization results. While the MSHP design does not have either the lowest initial cost (Gas and Electric are lower) or energy cost (NZC is lower) it has the lowest LCC. Furthermore, the Electric design has the highest energy cost, but a lower LCC than Gas, and much lower emissions.

These findings highlight, firstly, the importance of evaluating design variants, not on energy use, but on the metrics of most concern to the homebuyer, and to society: cost (initial and operational), and GHG emissions. When comparing heating system types, initial cost is as important as the input purchased energy price and the system's thermal efficiency. Furthermore, the overlapping capital expenditures on equipment that provide multiple services, such as heat pumps with heating and cooling, renders it necessary to compare whole thermal system configurations, rather than simply space heating, to provide an accurate comparison. Finally, the price ratio of electricity to natural gas affects the economic feasibility of heating electrification, but accounting for the monthly fixed cost savings of eliminating a natural gas bill effectively reduces this ratio.

There is likely a correlation between heating system type and the optimal building enclosure thermal efficiency, most simply expressed as the SHDI in cold climates. That is, a heating system providing a lower price of heat, such as a GHSP, will not drive deep energy efficiency in the thermal envelope design, but a high price of heat such as electric baseboard will. Price of heat and SHDI are therefore inversely correlated. The National Building Code and Passive House standards do not address this issue. Optimal SHDI is also likely partly related to the initial cost of the heating system, and a "life-cycle price" of heat based on the system cost, efficiency, and input energy price would provide a clearer picture of the correlation, or lack thereof, between these metrics. The task is complicated by the different capital cost overlaps with other building services that vary by thermal system type, but further research on this question could be informative.

Finally, total building EUI and SHDI are the two most common performance metrics for performance-based building energy standards. By controlling the use of purchased energy, and minimizing the heating demand of the building, it is expected that costs and emissions will also be reduced. The purpose of building energy standards, therefore, is not primarily to reduce energy 
consumption (regardless of type), but as a means of both consumer and environmental protection. Energy performance is an intermediate goal.

This study shows that, while EUI is perfectly correlated to energy cost when only one purchased energy type is used (e.g., all-electric), there is reduced correlation for buildings with two purchased energy types and associated prices, as well as when comparing these buildings to other building types, such as all-electric. In the case of GHGI, EUI is tightly correlated for buildings either with one or two types of purchased energy (such the all-electric MSHP model, and the gas-heated Gas model). However, when comparing emissions from buildings across these thermal system types, there is no longer correlation. Building energy standards reviewed for this study either do not address this issue or do so poorly. Comparing Toronto optimal design SHDI values to the GHGI values for those designs suggests that there is poor correlating with those metrics as well, when considering multiple thermal system types, even prior to considering multiple electricity carbon intensities. However, this comparison was not investigated as thoroughly as the EUI - GHGI relationship, and it is not conclusive.

Recommendations for further actions and research include:

- Design building energy standards to optimize for the metrics of concern: cost and greenhouse gas emissions, rather than energy use, which does not correlate to either.

- Design building energy standards to evaluate the whole building as an integrated machine (i.e., where heating system initial cost, efficiency, and cost of heat influence the optimal enclosure design and vice versa).

- When comparing the costs of different heating system types, compare whole thermal systems to accurately capture the overlapping capital and operational costs, especially accounting for: the cost of the space cooling system, and the fixed monthly cost savings of detaching from the natural gas grid.

- Conduct more specialized optimizations/analysis to determine the interaction between heating system type (initial cost, efficiency, cost of heat), and the optimal thermal enclosure for that system. 
- Conduct sensitivity analyses to determine the influence of the economic variables, including: mortgage interest rate, discount rate, inflation rate, and fuel escalation rates.

- For each thermal system type, determine a) the required carbon price to achieve cost parity with the optimal gas-heated design (if necessary), and b) the required electricity EF to achieve GHG parity with the optimal gas-heated design (if necessary). 


\section{Appendix}

The 29 BEopt models that formed the basis of this study contain all the input data, output design specifications, performance data, and cost data. The amount of information that can be extracted from the models is too excessive to provide hard copies. Therefore, the main text is intended to provide enough information for comprehensive understanding. A summary of the GHG and LCC values for each of the 29 optimized designs and the 5 Reference designs are presented below. For the Toronto optimized designs, energy use by end-use is also tabulated below. For energy use breakdowns of models for other locations, data can be extracted from the BEopt files. A digital-only appendix is provided containing the BEopt models and a selection of output data. Additional information can be made available upon request to the author. 
Table 0-1 Optimal designs GHG \& LCC by system type

\begin{tabular}{|c|c|c|c|c|}
\hline \multicolumn{5}{|c|}{ By Thermal System Type } \\
\hline & Point & CO2e Emissions (tonnes/yr) & & Energy Related Life Cycle Cost (\$) \\
\hline 1 & Ref-VN & 4.07 & $\$$ & $107,219.20$ \\
\hline 2 & Ref-ED & 13.33 & $\$$ & $129,180.30$ \\
\hline 3 & Ref-TO & 4.83 & $\$$ & $123,611.60$ \\
\hline 4 & Ref-ML & 5.76 & $\$$ & $130,785.80$ \\
\hline 5 & Ref-HX & 9.49 & $\$$ & $146,968.09$ \\
\hline 6 & Gas-VN & 2.95 & $\$$ & $105,146.80$ \\
\hline 7 & Gas-ED & 11.05 & $\$$ & $124,712.50$ \\
\hline 8 & Gas-TO & 3.33 & $\$$ & $120,341.10$ \\
\hline 9 & Gas-ML & 2.72 & $\$$ & $117,133.00$ \\
\hline 10 & Gas-HX & 6.83 & $\$$ & $129,560.40$ \\
\hline 11 & ASHP-VN & 0.11 & $\$$ & $106,059.10$ \\
\hline 12 & ASHP-ED & 13.69 & $\$$ & $132,438.91$ \\
\hline 13 & ASHP-TO & 0.49 & $\$$ & $120,324.40$ \\
\hline 14 & ASHP-ML & 0.01 & $\$$ & $107,950.10$ \\
\hline 15 & ASHP-HX & 7.70 & $\$$ & $121,358.40$ \\
\hline 16 & MSHP-VN & 0.10 & $\$$ & $99,280.18$ \\
\hline 17 & MSHP-ED & 12.53 & $\$$ & $116,167.60$ \\
\hline 18 & MSHP-TO & 0.43 & $\$$ & $113,481.00$ \\
\hline 19 & MSHP-ML & 0.01 & $\$$ & $101,649.00$ \\
\hline 20 & MSHP-HX & 7.45 & $\$$ & $113,177.70$ \\
\hline 21 & GSHP-VN & 0.10 & $\$$ & $107,776.10$ \\
\hline 22 & GSHP-ED & 12.58 & $\$$ & $120,638.30$ \\
\hline 23 & GSHP-TO & 0.47 & $\$$ & $122,072.30$ \\
\hline 24 & GSHP-ML & 0.01 & $\$$ & $106,671.00$ \\
\hline 25 & GSHP-HX & 7.56 & $\$$ & $120,724.70$ \\
\hline 26 & Electric-VN & 0.15 & $\$$ & $105,919.90$ \\
\hline 27 & Electric-ED & 19.31 & $\$$ & $116,529.30$ \\
\hline 28 & Electric-TO & 0.65 & $\$$ & $119,297.80$ \\
\hline 29 & Electric-ML & 0.02 & $\$$ & $102,313.00$ \\
\hline 30 & Electric-HX & 10.64 & $\$$ & $124,055.50$ \\
\hline 31 & NZC-VN & -0.09 & $\$$ & $99,956.07$ \\
\hline 32 & NZE-ED & 6.08 & $\$$ & $132,640.80$ \\
\hline 33 & NZC-TO & -0.05 & $\$$ & $115,492.00$ \\
\hline 34 & NZC-ML & -- & -- & \\
\hline 35 & NZC-HX & -0.15 & $\$$ & $109,535.20$ \\
\hline
\end{tabular}


Table 0-2 Optimal designs GHG and LCC by location

\begin{tabular}{|c|c|c|c|c|c|c|}
\hline Location & Type & $\begin{array}{c}\text { BO2e } \\
\text { Emissions } \\
\text { (tons/yr) }\end{array}$ & Loc & ted Life Cycle Cost (\$) & $\begin{array}{c}\text { Savings ove } \\
\text { GHG savings }\end{array}$ & $\begin{array}{l}\text { Reference } \\
\text { LCC savings }\end{array}$ \\
\hline & Ref & 4.07 & $\$$ & $107,219.20$ & $0 \%$ & $0 \%$ \\
\hline & Gas & 2.95 & $\$$ & $105,146.80$ & $28 \%$ & $2 \%$ \\
\hline & ASHP & 0.11 & $\$$ & $106,059.10$ & $97 \%$ & $1 \%$ \\
\hline VN & MSHP & 0.10 & $\$$ & $99,280.18$ & $98 \%$ & $7 \%$ \\
\hline & GSHP & 0.10 & $\$$ & $107,776.10$ & $98 \%$ & $-1 \%$ \\
\hline & Electric & 0.15 & $\$$ & $105,919.90$ & $96 \%$ & $1 \%$ \\
\hline & NZC & -0.09 & $\$$ & $99,956.07$ & $102 \%$ & $7 \%$ \\
\hline & Ref & 13.33 & $\$$ & $129,180.30$ & $0 \%$ & $0 \%$ \\
\hline & Gas & 11.05 & $\$$ & $124,712.50$ & $17 \%$ & $3 \%$ \\
\hline & ASHP & 13.69 & $\$$ & $132,438.91$ & $-3 \%$ & $-3 \%$ \\
\hline ED & MSHP & 12.53 & $\$$ & $116,167.60$ & $6 \%$ & $10 \%$ \\
\hline & GSHP & 12.58 & $\$$ & $120,638.30$ & $6 \%$ & $7 \%$ \\
\hline & Electric & 19.31 & $\$$ & $116,529.30$ & $-45 \%$ & $10 \%$ \\
\hline & NZE & 6.08 & $\$$ & $132,640.80$ & $54 \%$ & $-3 \%$ \\
\hline & Ref & 4.83 & $\$$ & $123,611.60$ & $0 \%$ & $0 \%$ \\
\hline & Gas & 3.33 & $\$$ & $120,341.10$ & $31 \%$ & $3 \%$ \\
\hline & ASHP & 0.49 & $\$$ & $120,324.40$ & $90 \%$ & $3 \%$ \\
\hline TO & MSHP & 0.43 & $\$$ & $113,481.00$ & $91 \%$ & $8 \%$ \\
\hline & GSHP & 0.47 & $\$$ & $122,072.30$ & $90 \%$ & $1 \%$ \\
\hline & Electric & 0.65 & $\$$ & $119,297.80$ & $87 \%$ & $3 \%$ \\
\hline & NZC & -0.05 & $\$$ & $115,492.00$ & $101 \%$ & $6 \%$ \\
\hline & Ref & 5.76 & $\$$ & $130,785.80$ & $0 \%$ & $0 \%$ \\
\hline & Gas & 2.72 & $\$$ & $117,133.00$ & $23 \%$ & $10 \%$ \\
\hline & ASHP & 0.01 & $\$$ & $107,950.10$ & $43 \%$ & $17 \%$ \\
\hline $\mathrm{ML}$ & MSHP & 0.01 & $\$$ & $101,649.00$ & $43 \%$ & $22 \%$ \\
\hline & GSHP & 0.01 & $\$$ & $106,671.00$ & $43 \%$ & $18 \%$ \\
\hline & Electric & 0.02 & $\$$ & $102,313.00$ & $43 \%$ & $22 \%$ \\
\hline & Ref & 9.49 & $\$$ & $146,968.09$ & $0 \%$ & $0 \%$ \\
\hline & Gas & 6.83 & $\$$ & $129,560.40$ & $28 \%$ & $12 \%$ \\
\hline & ASHP & 7.56 & $\$$ & $120,724.70$ & $20 \%$ & $18 \%$ \\
\hline$H X$ & MSHP & 7.45 & $\$$ & $113,177.70$ & $21 \%$ & $23 \%$ \\
\hline & GSHP & 7.56 & $\$$ & $120,724.70$ & $20 \%$ & $18 \%$ \\
\hline & Electric & 10.64 & $\$$ & $124,055.50$ & $-12 \%$ & $16 \%$ \\
\hline & NZC & -0.15 & $\$$ & $109,535.20$ & $102 \%$ & $25 \%$ \\
\hline
\end{tabular}


Table 0-3 Toronto optimal designs energy use by end-use

\begin{tabular}{|c|c|c|c|c|c|c|c|}
\hline \multicolumn{8}{|c|}{ Energy Use by End-Use (MWh) } \\
\hline & Reference & Gas & ASHP & MSHP & GSHP & Electric & NZC \\
\hline MEL & 2.655 & 2.653 & 2.644 & 2.652 & 2.641 & 2.670 & 2.652 \\
\hline Vent Fan & 0.554 & 0.695 & 0.733 & 0.733 & 0.601 & 0.733 & 0.733 \\
\hline Appliances & 2.107 & 2.107 & 2.107 & 2.107 & 2.107 & 2.107 & 2.107 \\
\hline Lights & 1.202 & 1.202 & 1.202 & 1.202 & 1.202 & 1.202 & 1.202 \\
\hline Cooling Fan/Pump & 0.088 & 0.041 & 0.015 & 0.047 & 0.053 & & 0.047 \\
\hline Heating Fan/Pump & 0.507 & 0.141 & 0.202 & 0.199 & 0.659 & & 0.199 \\
\hline Cooling & 0.267 & 0.232 & 0.191 & 0.161 & 0.111 & 0.407 & 0.161 \\
\hline Heating & 19.239 & 12.691 & 3.725 & 2.330 & 3.200 & 6.407 & 2.330 \\
\hline Heating supplementary & & & 0.067 & 0.053 & & & 0.053 \\
\hline Hot Water & 6.082 & 4.391 & 1.193 & 1.222 & 1.196 & 2.579 & 1.222 \\
\hline PV & & & & & & & -1.225 \\
\hline Total & 32.710 & 24.151 & 12.078 & 10.706 & 11.770 & 16.105 & 10.706 \\
\hline
\end{tabular}




\section{References}

Architecture 2030, New Buildings Institute, Rocky Mountain Institute. (2016, 07 11). Zero Net Carbon (ZNC): A Definition. Retrieved from Architecture 2030: http://www.architecture2030.org/downloads/znc_building_definition.pdf

ASHRAE. (2013). entilation and Acceptable Indoor Air Quality in Low-Rise Residential Buildings. American Society of Heating, Refrigeration, and Air-Conditioning Engineers.

Athienitis, A. K., \& O'Brien, W. (2015). Modeling, design, and optimization of net-zero energy buildings. Wilhelm Ernst \& Sohn.

BC Hydro. (2018). Residential Rates. Retrieved from BC Hydro Power Smart: https://app.bchydro.com/accounts-billing/rates-energy-use/electricity-rates/residentialrates.html

Bucking, S., Athienitis, A., \& Zmeureanu, R. (2014). Multi-Objective Optimal Design of a Near Net Zero Energy Solar House. ASHRAE Transactions 120, no. 1, 224.

Bucking, S., Zmeureanu, R., \& Athienitis, A. (2013). An Information Driven Hybrid Evolutionary Algorithm for Optimal Design of a Net Zero Energy House. Solar Energy, 129(39), 96.

Canada. (2017, 11 22). How much you need for a downpayment. Retrieved from Government of Canada: https://www.canada.ca/en/financial-consumer-agency/services/mortgages/downpayment.html

Climate.OneBuilding. (2018, 07 10). Canada. Retrieved from Climate.OneBuilding: http://climate.onebuilding.org/WMO_Region_4_North_and_Central_America/CAN_Can ada/index.html

CMHC. (2018). Housing Information Monthly. Publications and Reports. Canada Mortgage and Housing Corporation. Retrieved from https://www03.cmhcschl.gc.ca/catalog/productDetail.cfm?lang=en\&cat=57\&itm=1\&sid=aZeq6394x2F73dtp WYAFr7MMZCQT1YUx6dtQLk3d0jbrPKWmVO25EpaSvrlRpPNQ\&fr=15248676965 90

CMHC. (2018, 01). New Housing Construction Activity - Canada. Retrieved from HOUSING MARKET INFORMATION PORTAL: https://www03.cmhcschl.gc.ca/hmiportal/en/\#Profile/1/1/Canada

Council, Canada Green Building. (2016). Zero Carbon Building Framework. CaGBC. 
Cubi, E., Doluweera, G., \& Bergerson, J. (2015). Incorporation of Electricity GHG Emissions Intensity Variability into Building Environmental Assessment. Applied Energy, 159, 6269. doi:10.1016/j.apenergy.2015.08.091

Dembo, A., \& Fung, A. S. (2012). Review and Economic Feasibility Study of the Currently Practiced New Housing Constructions in Ontario. ASHRAE Transactions, 118(2).

Dembo, A., Khaddad, F., \& Fung, A. (2013). Least-Cost Upgrade Solutions to Achieve Improved Energy Efficiency Standards For Residential New Housing in Canada. ASHRAE Transactions, 119(1), 1.

ECCC. (2016). Canada's mid-century long-term low-greenhouse gas development strategy. Gatineau, Quebec: Environment and Climate Change Canada. Retrieved from http://publications.gc.ca/pub?id=9.825953\&sl=0

ECCC. (2018). National Inventory Report 1990-2016: Greenhouse Gas Sources and Sinks in Canada, Part 3. Environment and Climate Change Canada.

EERE. (2011). Laboratory Test Report for Fujitsu 12RLS and Mitsubishi. Office of Energy Efficiency and Renewable Energy, Building Technologies Program. U.S. Department of Energy.

EERE. (2012). Methodology for Evaluating Cost-Effectiveness of Residential Energy Code Changes. Office of Energy Efficiency and Renewable Energy, Building Technologies Program. U.S. Department of Energy. Retrieved from https://www.energycodes.gov/sites/default/files/documents/residential_methodology.pdf

EERE. (2015). A Commmon Definition for Zero Energy Buildings. U.S. Department of Energy, Office of Energy Efficiency \& Renewable Energy.

EERE. (2016). Zero Energy Ready Home. (DOE) Retrieved 04 2016, from Office of Energy Efficiency \& Renewable Energy: http://energy.gov/eere/buildings/zero-energy-readyhome

Energy Star. (2017). Portfolia Manager Greenhouse Gas Emissions Technical Reference. Energy Star.

Fortis BC. (2018). Sample bill for Mainland, Vancouver Island and Whistler customers. Retrieved from Fortisbc.com: https://www.fortisbc.com/NaturalGas/Homes/Rates/Mainland/Pages/Sample-bill-forMainland-customers.aspx 
Gaz Metro. (2017, 10 1). Conditions and Service Tariffs. Retrieved from regie-energie.gc.ca: http://www.regieenergie.qc.ca/en/consommateur/Tarifs_CondServ/GM_TarifsOct2017.pdf

Gordian. (2015). City Cost Indexes - How to Use the City Cost Indexes. Retrieved from RSMeansonline.com: https://www.rsmeansonline.com/References/HowToUsePages/How-to-Use-CCI2014.pdf

Gordian. (2017). MasterFormat City Cost Index - Year 2017 Base. Retrieved from RSMeansonline.com: $\quad$ https://www.rsmeansonline.com/References/CCI/1Unit\%20Cost\%20(MasterFormat\%202010)/3-Year\%202017\%20Base.PDF

Heritage Gas. (2017). Historical Rates. Retrieved from Heritagegas.com: http://www.heritagegas.com/natural-gas/historical-rates/

Heritage Gas. (2017). Rates. Retrieved from Heritagegas.com: https://www.heritagegas.com/rates/ Horowitz, S., Christensen, C., Brandemuehl, M., \& Krarti, M. (2008). Enhanced Sequential Search Methodology for Identifying Cost-Optimal Building Pathways. Simbuild. Berkeley: National Renewable Energy Laboratory.

Hydro Quebec. (2017). Comparison of Electricity Prices in Major North American Cities 2017. Hydro Quebec.

Hydro Quebec. (2018). 2018 Electricity Rates. Retrieved from Hydroquebec.com: http://www.hydroquebec.com/data/documents-donnees/pdf/electricity-rates.pdf

Inflation.eu. (2018). Historic inflation Canada - CPI inflation. Retrieved from Inflation.eu Worldwide Inflation Data: https://www.inflation.eu/inflation-rates/canada/historicinflation/cpi-inflation-canada.aspx

Irish Times. (2013, June 12). Two-thirds of energy sector will have to be left undeveloped, Bonn conference told. The Irish Times. Dubblin. Retrieved from https://www.irishtimes.com/news/world/europe/two-thirds-of-energy-sector-will-have-tobe-left-undeveloped-bonn-conference-told-1.1425009

Ministry of Municipal Affairs. (2016). MMA Supplementary Standard SB-12 Energy Efficiency for Housing. Government of Ontario.

Ministry of Municipal Affairs. (2016). Supplementary Standard SB-10 Energy Efficiency Requirements. Building and Development Branch. Government of Ontario. 
Mitsubishi. (2017). Zuba-Central. Retrieved from Mitsubishi Electric Canada: http://www.mitsubishielectric.ca/en/hvac/professionals/zuba-family/Zuba-Central

NEEP. (2018). Cold Climate Air Source Heat Pump. Retrieved from Northeast Energy Efficiency Partnerships: $\quad$ https://neep.org/initiatives/high-efficiency-products/emergingtechnologies/ashp/cold-climate-air-source-heat-pump

Nova Scotia Power. (2017). How to Read Your Bill. Retrieved from Nspower.ca: https://www.nspower.ca/en/home/myaccount/billing-and-payments/how-to-read-yourbill/default.aspx

NRC. (2013). Twin Houses. Retrieved from Canadian Centre for Housing Technology: http://www.ccht-cctr.gc.ca/eng/facilities/twin_houses.html

NRC. (2015). National Building Code of Canada, Volume I. Canadian Commission on Building and Fire Codes. National Research Council.

NRC. (2015). National Building Code of Canada, Volume II, Part 9. Canadian Commission on Building and Fire Codes. National Research Council.

NRC. (2017). 2015 editions of Codes Canada publications: Significant technical changes. Retrieved from National Research Council Canada: https://www.nrccnrc.gc.ca/eng/solutions/advisory/codes_centre/technical_changes_2015.html

NRC. (2018, 06 11). Model code adoption across Canada. Retrieved from National Research Council Canada: https://www.nrccnrc.gc.ca/eng/solutions/advisory/codes_centre/code_adoption.html

NRCan. (2012). 2012 R-2000 Standard. Natural Resources Canada.

NRCan. (2016). Energy Efficiency Trends in Canada 1990-2013. Office of Energy Efficiency. Natural Resources Canada.

NRCan. (2017). Handbook Tables. Retrieved from Natural Resources Canada: http://oee.nrcan.gc.ca/corporate/statistics/neud/dpa/menus/trends/handbook/handbook_re S_00.cfm

NRCan. (2018). R-2000: environmentally friendly homes. Retrieved from Natural Resources Canada: https://www.nrcan.gc.ca/energy/efficiency/homes/20575

NREL. (2013). Improved Modeling of Residential Air Conditioners and Heat Pumps for Energy Calculations. U.S. Department of Energy. Colorado: National Renewable Energy Laboratory. 
NREL. (2014). 2014 Building America House Simulation Protocols. U.S. Department of Energy, Office of Energy Efficiency \& Renewable Energy. National Renewable Energy Laboratory.

NREL. (2016). BEOpt. Retrieved 02 2016, from National Renewable Energy Laboratory: https://beopt.nrel.gov/home

O'Brien, W., Athienitis, A., \& Kesik, T. (2011). Parametric Analysis to support the integrated design and performance modeling of net-zero energy houses. ASHRAE Transactions 117, no.1, pp. 1-12.

O'Brien, W., Gaetani, I., Carlucci, S., Hoes, P.-J., \& Hensen, J. (2017). On occupant-centric building performance metrics. Building and Environment, 122. doi:10.1016/j.buildenv.2017.06.028

O'Brien, W., Kesik, T., \& Athienitis, A. (2014). Solar Design Days: A Tool for Passive Solar House Design. ASHRAE Transactions, 120(1), 101.

Office of Energy Efficiency. (2017). Residential Housing Stock and Floor Space. Retrieved from Natural Resources Canada: http://oee.nrcan.gc.ca/corporate/statistics/neud/dpa/showTable.cfm?type=HB\&sector=res \&juris $=00 \&$ rn $=11 \&$ page $=5$

Ontario Energy Board. (2017, June 15). Ontario Fair Hydro Act, 2017. Retrieved from Ontario Energy Board: https://www.oeb.ca/newsroom/2017/fair-hydro-act-2017

Ontario Energy Board. (2018). Bill Calculator. Retrieved from Ontario Energy Board: https://www.oeb.ca/consumer-protection/energy-contracts/bill-calculator

Ontario Energy Board. (2018). Historical Natural Gas Rates. Retrieved from oeb.ca: https://www.oeb.ca/rates-and-your-bill/natural-gas-rates/historical-natural-gas-rates

Pembina. (2018, April 18). Types of green buildings. Retrieved from Pembina Institute: http://www.pembina.org/pub/green-buildings-infographic

PHI. (2015). Passive House Requirements. (Passive House Institute) Retrieved 04 2016, from http://passiv.de/en/02_informations/02_passive-house-requirements/02_passive-houserequirements.htm.

PHIUS. (2015). PHIUS+ Project Certification. Retrieved 04 2016, from http://www.phius.org/phius-certification-for-buildings-and-products/phius-2015-projectcertification/phius-overview 
PHIUS+. (2015). PHIUS+ 2015: Passive Building Standard -- North America. Retrieved from Passive House Institute U.S.: http://www.phius.org/phius-2015-new-passive-buildingstandard-summary

Ratehub.ca. (n.d.). Amortization. Retrieved 02 2018, from Ratehub.ca: https://www.ratehub.ca/amortization

RWDI. (2016). Modelling Weather Futures, \#1602202. White Paper, Toronto, ON. Retrieved from http://rwdi.com/assets/factsheets/Modelling-weather-futures.pdf

Statistics Canada. (2017, May 3). Cencus in Brief, Dwellings in Canada. Retrieved from Statistics Canada: $\quad$ http://www12.statcan.gc.ca/census-recensement/2016/as-sa/98-200x/2016005/98-200-x2016005-eng.cfm

Statistics Canada. (2017, 05 09). Dwellings in Canada. Retrieved from Statistics Canada: http://www12.statcan.gc.ca/census-recensement/2016/as-sa/98-200-x/2016005/98-200x2016005-eng.cfm

Statistics Canada. (2017, 05 03). Infographic: Dwellings in Canada, 2016 Census of Population. Retrieved from Statistics Canada: https://www150.statcan.gc.ca/n1/pub/11-627-m/11-627m2017017-eng.htm

Stecher, D., \& Klingenberg, K. (2008). Design and Performance of the Smith House, A Passive House. ASHRAE Transactions, 114, 209.

Straube, J. (2005). Building Science for Building Enclosures. Building Science Press.

Straube, J. (2009, 10 05). BSI-026: PassivHaus Becomes Active-- Further Commentary on PassivHaus. (Building Science Corporation) Retrieved 01 2016, from http://buildingscience.com/documents/insights/bsi-026-passivhaus-becomes-activefurther-commentary-on-passivhaus

Tokarik, M. S., \& Richman, R. C. (2015). A MULTI-OBJECTIVE OPTIMIZATION ANALYSIS OF PASSIVE ENERGY. Toronto, ON: Ryerson University.

Tokarik, M. S., \& Richman, R. C. (2016). Life cycle cost optimization of passive energy efficiency improvements in a Toronto house. Energy and Buildings, 118, 160-169.

Torcellini, P., Pless, S., Deru, M., \& Crawley, D. (2006). Zero Energy Buildings: A Critical Look at the Definition. Pacific Grove, California: National Renewable Energy Laboratory.

Toronto. (2017). Zero Emissions Buildings Framework. The City of Toronto. 
Toronto. (2018). Energy Efficiency Report Submission \& Modelling Guidelines. Toronto: City of Toronto.

Toronto. (2018, 05). Toronto Green Standard Version 3. Retrieved from City of Toronto: https://www.toronto.ca/city-government/planning-development/official-planguidelines/toronto-green-standard/toronto-green-standard-version-3/

Utilities Consumer Advocate. (2018). Compare Your Energy Choices. Retrieved from Utilities Consumer Advocate: https://ucahelps.alberta.ca/cost-comparison-tool.aspx

Vancouver. (2016). Zero Emissions Building Plan. City of Vancouver.

WRI. (2015). GHG Protocal Scope 2 Guidance. Corporate Standard, World Resources Institute. Retrieved from https://ghgprotocol.org/scope_2_guidance

Wright, G., Klingenberg, K., \& Pettit, B. (2015). Climate-Specific Passive Building Standard, Building America Report - 1405. US Department of Energy, Energy Efficiency \& Renewable Energy. 